\title{
IntechOpen
}

\section{Mass Production Processes}

Edited by Anil Akdogan and Ali Serdar Vanli

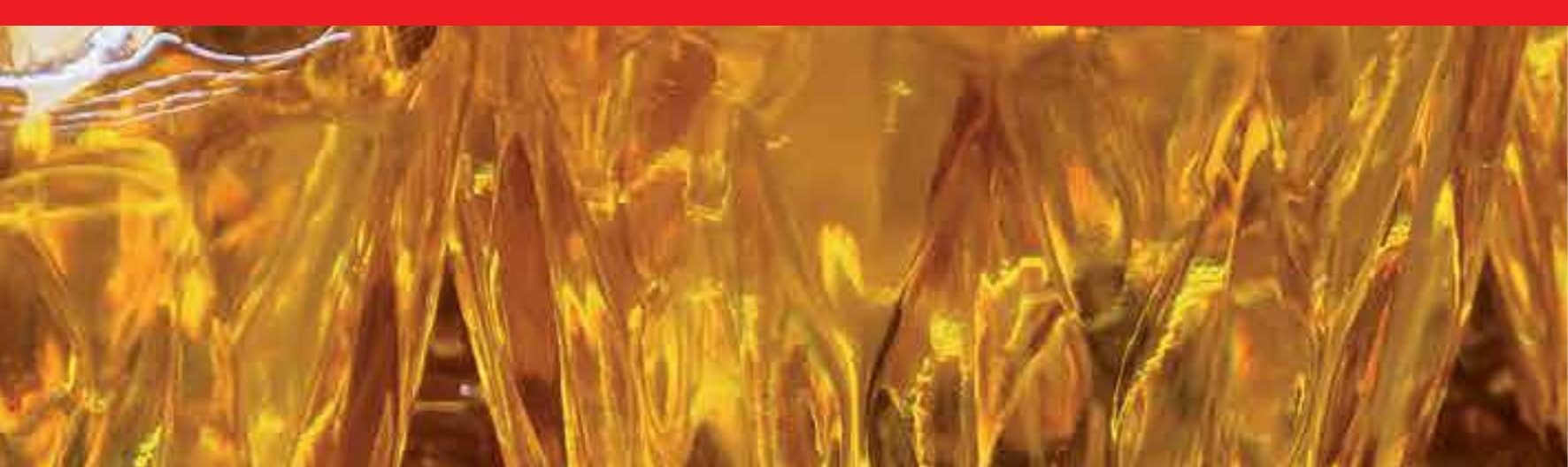



Mass Production Processes

Edited by Anil Akdogan

and Ali Serdar Vanli 

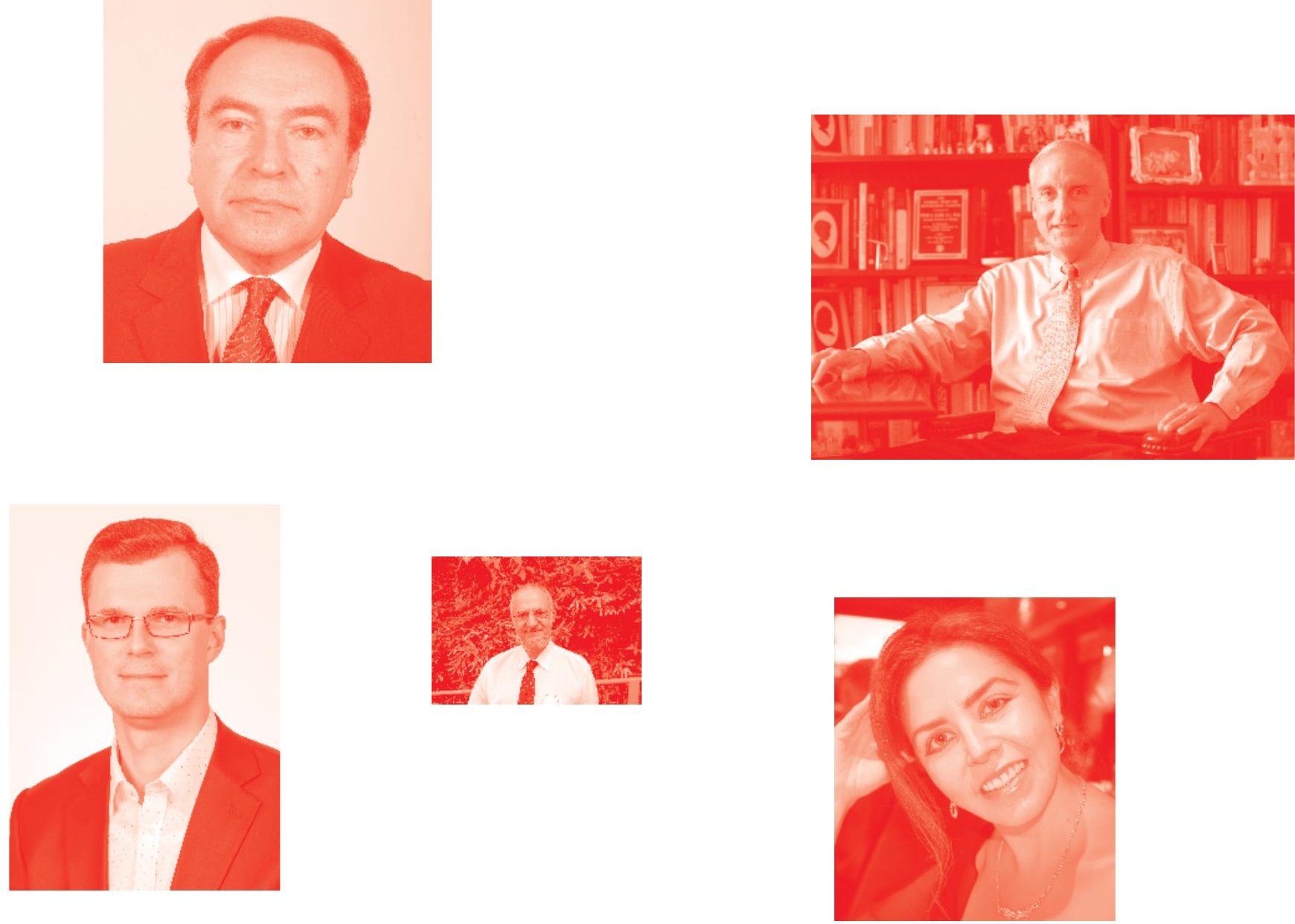

Supporting open minds since 2005
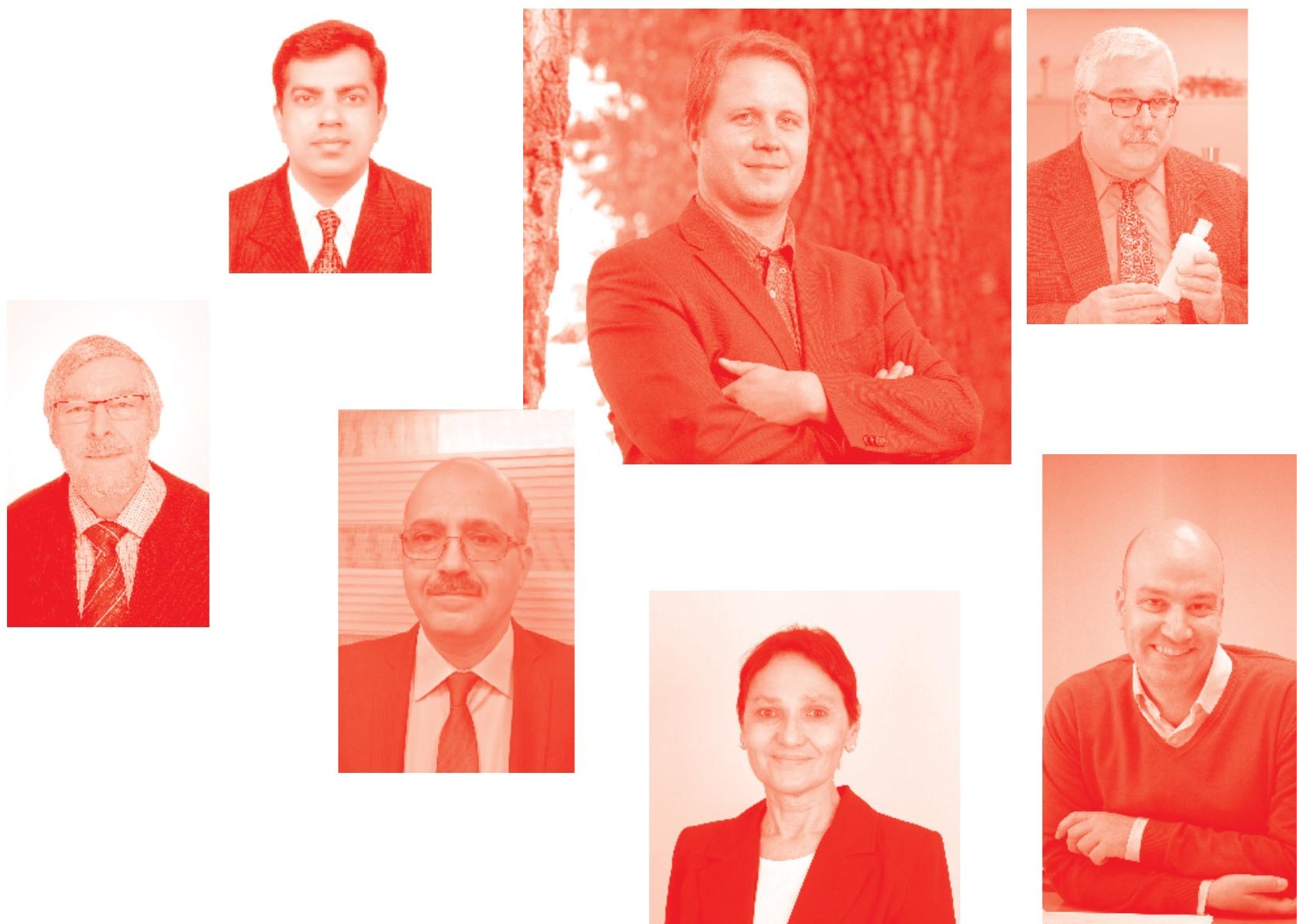
Mass Production Processes

http : //dx. doi. org/10.5772/intechopen. 83280

Edited by Anil Akdogan and Ali Serdar Vanli

\section{Contributors}

Ramesh Rudrapati, Ilesanmi Afolabi Daniyan, Moses Oyesola, Khumbulani Mpofu, Samuel Nwankwo, Richard Wysk, Katie Basinger, Ola Harrisson, Caroline Webster, Carter Keough, Jonathan David Morales M``ondez, Ramon Silva, Chike Oduoza, Pedro Palominos, Luis Valdivia, Hana Trollman, Frank Trollman, Teresa Taurino, Agostino Villa, Nguyen Duc-Toan, Long Hoang, Srecko Manasijevic, Gerhard Huber, Mile Djuredjicic, Azrul Azwan Abdul Rahman, Anil Akdogan

( ) The Editor(s) and the Author(s) 2020

The rights of the editor(s) and the author(s) have been asserted in accordance with the Copyright, Designs and Patents Act 1988. All rights to the book as a whole are reserved by INTECHOPEN LIMITED. The book as a whole (compilation) cannot be reproduced, distributed or used for commercial or non-commercial purposes without INTECHOPEN LIMITED's written permission. Enquiries concerning the use of the book should be directed to INTECHOPEN LIMITED rights and permissions department (permissions@intechopen.com).

Violations are liable to prosecution under the governing Copyright Law .

\section{(cc) BY}

Individual chapters of this publication are distributed under the terms of the Creative Commons Attribution 3.๑ Unported License which permits commercial use, distribution and reproduction of the individual chapters, provided the original author(s) and source publication are appropriately acknowledged. If so indicated, certain images may not be included under the Creative Commons license. In such cases users will need to obtain permission from the license holder to reproduce the material. More details and guidelines concerning content reuse and adaptation can be found at http : //www . intechopen . com/copyright-policy . html .

\section{Notice}

Statements and opinions expressed in the chapters are these of the individual contributors and not necessarily those of the editors or publisher. No responsibility is accepted for the accuracy of information contained in the published chapters. The publisher assumes no responsibility for any damage or injury to persons or property arising out of the use of any materials, instructions, methods or ideas contained in the book.

First published in London, United Kingdom, 2020 by IntechOpen IntechOpen is the global imprint of INTECHOPEN LIMITED, registered in England and Wales, registration number: 11086078 , 7th floor, 10 Lower Thames Street, London,

EC3R 6AF, United Kingdom

Printed in Croatia

British Library Cataloguing-in-Publication Data

A catalogue record for this book is available from the British Library

Additional hard and PDF copies can be obtained from orders@intechopen.com

Mass Production Processes

Edited by Anil Akdogan and Ali Serdar Vanli

p. cm.

Print ISBN 978-1-83880-215-8

Online ISBN 978-1-83880-216-5

eBook (PDF) ISBN 978-1-78985-983-6 


\section{We are IntechOpen, \\ the world's leading publisher of Open Access books}

Built by scientists, for scientists

\section{$4,700+$}

Open access books available

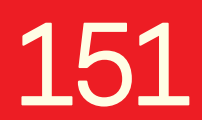

Countries delivered to
$120,000+$

International authors and editors

Our authors are among the

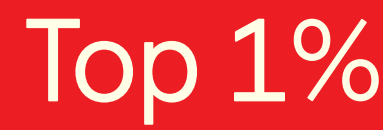

most cited scientists

Contributors from top 500 universities
$135 \mathrm{M}+$

Downloads

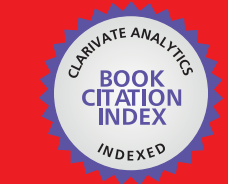

WEB OF SCIENCE ${ }^{\mathrm{MM}}$

Selection of our books indexed in the Book Citation Index in Web of Science ${ }^{\mathrm{TM}}$ Core Collection (BKCI)

\section{Interested in publishing with us? \\ Contact book.department@intechopen.com}

Numbers displayed above are based on latest data collected.

For more information visit www.intechopen.com 



\section{Meet the editor}

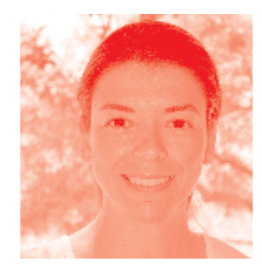

Assoc. Prof. Anil Akdogan was born in Antalya, Turkey in 1976. Prof. Akdogan earned her Bachelor of Science degree in Mechanical Engineering in 1996 and her PhD degree in Mechanical Engineering in 2005 from Yildiz Technical University, Mechanical Engineering Department, Istanbul, Turkey. She has over 20 years' experience in teaching at the Mechanical Engineering Faculty at Yildiz Technical University. She has been instructing courses in "Measurement Techniques and Evaluation", "Quality in Industry", "Manufacturing Technologies", and "Measurement Techniques and Quality Management" for many years. She has published many manuscripts in international journals and presented proceedings at different international conferences about manufacturing technologies and industrial metrology.

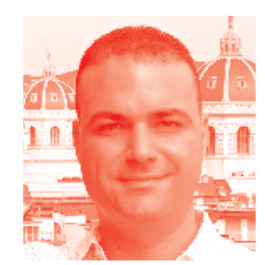

Dr Ali Serdar Vanli was born in Istanbul, Turkey in 1982. Dr Vanli earned his Bachelor of Science degree in Mechanical Engineering in 2007. He received his PhD degree in Mechanical Engineering from Yildiz Technical University, Mechanical Engineering Department, Istanbul, Turkey in 2013. He has almost 15 years' experience in teaching at the Mechanical Engineering Faculty at Yildiz Technical University. He has been working as a research assistant and additionally instructing "Casting" and "Die Casting" courses in the Mechanical Engineering Department. He has published many manuscripts in international journals and presented proceedings at different international conferences about manufacturing technologies. He has consulted many exporting mass production companies in Turkey for many years. 



\section{Contents}

Preface

Section 1

Alloys in Manufacturing

Chapter 1

Introductory Chapter: Mass Production and Industry 4.0

by Anil Akdogan and Ali Serdar Vanli

Chapter 2

Recent Advances in Joining of Aluminum Alloys by Using Friction Stir Welding

by Ramesh Rudrapati

Chapter 3

Quantification of Feeding Regions of Hypoeutectic Al-(5, 7, 9)

$\mathrm{Si}-(0-4) \mathrm{Cu}$ (wt.\%) Alloys Using Cooling Curve Analysis

by Gerhard Huber, Mile B. Djurdjevic and Srećko Manasijević

\section{Section 2}

Advanced Production Systems

Chapter 4

A Methodology to Design and Balance Multiple Cell

Manufacturing Systems

by Luis Valdivia and Pedro Palominos

Chapter 5

A Sustainability Assessment of Smart Innovations for Mass Production, Mass Customisation and Direct Digital Manufacturing by Hana Trollman and Frank Trollman

Chapter 6

The Use of Lean Manufacturing Tools to Improve the Production of Automobile Parts

by Jonathan-David Morales-Méndez and Ramón Silva-Rodríguez 
Chapter 8

Advanced Manufacturing Using Linked Processes:

Hybrid Manufacturing

by Katie Basinger, Caroline Webster, Carter Keough, Richard Wysk

and Ola Harrysson

Chapter 9

Quality Control Perspectives during Mass Production with a Focus on the Chemical Industry

by Chike F. Oduoza

Section 3

Industry 4.0 Applications

Chapter 10

Application of the Fourth Industrial Revolution for High Volume

Production in the Rail Car Industry

by Daniyan Ilesanmi, Oyesola Moses, Mpofu Khumbulani

and Nwankwo Samuel

Chapter 11

Revolution of Production System for the Industry 4.0

by Azrul Azwan Abdul Rahman

Chapter 12

Innovate Manufacturing SMEs in the Context of Industry 4.0:

A Formal Approach

by Teresa Taurino and Agostino Villa 


\section{Preface}

In competitive market conditions, manufacturing enterprises should produce high quality products using productive manufacturing processes. Mass production requires standardized processes for manufacturing of interchangeable parts in large quantities at comparable prices. While this sounds good, it is hard to do as it requires many components to be considered in great detail. The use of modern methods and techniques of mass production provides improvements in the manufacturing costs and product quality. Manufacturers are trying to survive and/or to take a share in hard global market conditions by using these methods and techniques. With the associated advanced technologies of Industry 4.0 such as cyber physical systems and internet of things, mass production has been revolutionised but it will always have issues such as quality control of the production process.

Thanks to all the manufacturers working for better quality products.

Anil Akdogan and Ali Serdar Vanli

Yildiz Technical University, Department of Mechanical Engineering, Istanbul, Turkey 

Section 1

Alloys in Manufacturing 



\title{
Introductory Chapter: Mass Production and Industry 4.0
}

\author{
Anil Akdogan and Ali Serdar Vanli
}

\section{Introduction}

When it comes to the history of mass production enterprises, the revolutionary developments in mass production come to mind from the past to the present. To be able to better adapt to today's industrial revolution, of course it is necessary to understand the past industrial revolutions. On the basis of industrial revolutions, each of which is more or less rooted in a technological and cultural basis, there was always an effort to achieve better and faster solutions. Of course, economic concerns have always been taken into consideration. Industry 4.0 is a target of the research policy of the German government. Today, in the focus of integrated mass production, systems benefit from the advantages of this novel industrial revolution.

Since it is a great way to meet the large-scale demand of most products, mass production is used in many industries which are big and/or small. For instance, automobiles, computers, and cellular phones are the typical examples of mass production products. A high demand rate for a product is the main specification of mass production. The manufacturing area is typically dedicated to the production of a single type product and/or its variations.

Typical or conventional manufacturing methods can be adapted as mass production lines which are machining, casting, joining, and forming or plastic deformation. Each of them has its principles, manufacturing parameters, application areas, methods, and technologies to be considered in detail. It is always hard to set manufacturing systems to produce large quantities of standardized parts. Controlling these mass production lines needs deep knowledge and hard experience and the required related tools as well. The use of modern methods and techniques to produce large quantity products within productive manufacturing processes provides improvements in manufacturing costs and product quality. In order to serve these purposes, many works aim to reflect advanced manufacturing systems of different alloys in production with related components and automation technologies. Additionally, there are many works that focus on mass production processes designed according to Industry 4.0 considering different kinds of advanced quality and improvement research in mass production systems for high productive and sustainable manufacturing $[1,2]$. This chapter gives general information about the components of a conventional mass production system and an Industrial 4.0-adapted mass production system with their individual advantages.

\section{Components of a conventional mass production system}

Conventional mass production processes may be also called as continuous production that involves the fabrication of a known part in a specific production way and shape, in a consistent manner. In the mass production area, there are typical 
manufacturing processes dedicated to the production of a single type product and/ or its variations. However, there are lots of benefits of mass production including decreased labor, decreased time in manufacturing, increased output, and lower cost per unit [3]. Besides, there are many components of a conventional production system which need to be considered in detail. The machining lathe, the processing tool, the processed material, the process parameters, and others directly affect the quality of the product. One of the main disadvantages of the conventional manufacturing systems is being not very flexible systems. It is usually difficult to adapt the production line to a different kind of process. Conventional manufacturing systems require close inspection to control the process parameters which are in a close relationship with the quality of the product. With the help of related quality control methods, the required quality works can be reached in conventional mass production systems.

\section{Components of an industry 4.0 -adapted mass production system}

Today, some Industry 4.0-adapted factories are called as "smart." A “smart factory" has a highly flexible production system, which is capable of producing single individual parts with high precision and better quality in an economically efficient way. Additionally, a component-driven logistic system is required to achieve this task besides high flexible production systems and processes. In order to meet the requirements of the hard manufacturing task, digitalization of the systems and sub-systems is also essential. Calling a factory as smart requires at least following the supporting systems of the last industrial revolution [4].

A "cyber-physical system" is a physical object or a process that is connected and interacting with a digital representation of that object or process. This is one of the key tools supporting the development of smart factories. The definition of cyberphysical system includes a permanent digital interaction of the object from the physical world and the virtual representation. A permanent flow of data and information between both is the core of the cyber-physical system definition. One of the most important steps toward a functional cyber-physical system and a challenge today is to digitize and network non-digital machines and processes.

"The Internet of Things" is a system that supplies an ability to transfer data over a network. Cyber-physical system is enables every device and even every sensor and actor in a production or logistic system to communicate with each other over a common digital network. According to the vision of a smart factory, it is not only internally digitally connected but also with the external supply chain for the product to be produced. In a networked supply chain, smart factories have a network system of hundreds or thousands of cyber-physical systems. They are connected to a common exchanging data and information Ethernet network.

"Component-driven production" has been formulated to control the process chain of a product inside of the production. To achieve this, components need to carry their construction plans and other information for manufacturing. In this way the components are taking individual paths toward the production plant without complex planning. Of course, to plan the production future of a component requires knowing the past of that part in detail.

"Big Data analytics" is an inevitable tool of an Industry 4.0. It was always hard to analyze the data than to collect it. Additionally we are talking about diverse and larger data than being in the past. A smart factory must have advantages of some analytical techniques against to process that kind of large and diverse data. The data can be supplied from different sources and sizes and be a structured, semistructured, or unstructured type. With those data-driven solutions, the processed 
high-quality data can be used at each step of the system even in the complex systems.

"Flexible manufacturing systems": As being discussed at the second section, one of the main disadvantages of the conventional manufacturing systems is being not very flexible systems. This disadvantage of the conventional manufacturing systems could be eliminated by the flexible manufacturing systems of Industry 4.0. One of the most important tasks of Industry 4.0 is to realize a highly flexible production system. The system is usually capable to produce with small lot sizes. The smart factory has to deal with smaller lot sizes and an increasing number of changeover processes during the day-to-day work. Therefore, equipment and labor requirements are prepared in order to cope with the flexibility requirements of the process not only for the present times but also for the possible needs in the future [5].

\title{
4. Conclusions
}

In competitive market conditions of manufacturing, the enterprises should produce high-quality products within productive manufacturing processes. Mass production requires standardized processes for manufacturing of interchangeable parts in large quantities at comparable prices. In fact, it is a hard work which requires many components to be considered in great detail. The use of modern methods and techniques of mass production provides decreases in the manufacturing costs and improvements in product quality. Manufacturers are trying to survive and/or to take share in hard global market conditions by using such these advantages. With the associated advanced technologies of Industry 4.0 such as cyber-physical systems and Internet of Things, mass production has been revolutionized, but it looks like it will always have issues like quality control of the production process.

\section{Author details}

\author{
Anil Akdogan* and Ali Serdar Vanli \\ Mechanical Engineering Department, Yildiz Technical University, İstanbul, Turkey \\ *Address all correspondence to: nomak@yildiz.edu.tr
}

\section{IntechOpen}

(C) 2020 The Author(s). Licensee IntechOpen. This chapter is distributed under the terms of the Creative Commons Attribution License (http://creativecommons.org/licenses/ by/3.0), which permits unrestricted use, distribution, and reproduction in any medium, provided the original work is properly cited. (c) BY 


\section{References}

[1] Vanli AS, Akdogan A. Manufacturing automation for magnesium die casting. In: Proceedings of the 12th International Conference on Measurement and Quality Control - Cyber Physical Issue; 2019. Vol. 26, pp. 122-130. DOI: 10.1007/978-3-030-18177-2_13

[2] Majstorovic VD, Durakbasa MN, Takaya Y, Stojadinovic S. Advanced manufacturing metrology in context of industry 4.0 model. In: Proceedings of the 12th International Conference on Measurement and Quality Control Cyber Physical Issue, 2019. Vol. 26, pp. 1-11. DOI: 10.1007/978-3030-18177-2_13

[3] Mital A, Desai A, Subramanian A, Mital A. Chapter: The significance of manufacturing. In: Product Development (Second Edition) a Structured Approach to Consumer Product Development, Design, and Manufacture. Holland: Elsevier; 2014. pp. 3-19

[4] Vanli AS, Akdogan A, Kerber K, Ozbek S, Durakbasa MN. Smart die casting foundry according to industrial revolution 4.0. Acta Technica Napocensis, Series: Applied Mathematics, Mechanics, and Engineering. 2018;61(IV):787-792

[5] Vanli AS, Akdogan A, Durakbasa MN. Tools of industry 4.0 on die casting production systems. In: Durakbasa N, Gençyılmaz M, editors. Proceedings of the International Symposium for Production Research 2019, ISPR 2019. Lecture Notes in Mechanical Engineering. Switzerland: Springer; 2019. pp. 328-334 


\title{
Recent Advances in Joining of Aluminum Alloys by Using Friction Stir Welding
}

\author{
Ramesh Rudrapati
}

\begin{abstract}
Aluminum and its alloys have gained much interest in advanced industrial applications due to its excellent mechanical properties. Welding is one of prominent fabrication technique which has to be performed to make assembling of different parts to create one complete product. Welding of aluminum alloys (al) using traditional welding methods is difficult task due to un-weldability of aluminum alloys, more defects in weldment, presence of aluminum oxide film, etc. Friction stir welding (FSW) is a novel welding technique which was developed specially to join the aluminum alloys without melting of materials to be joined. Achieving the good qualities of welded joint with enhanced efficiency of the FSW process needs, proper understanding of principles of FSW. In the present chapter, various aspects of FSW of aluminum alloys related to effects of process welding parameters and temperature distribution during welding on mechanical and metallurgical properties of weldment has been presented. Extending applications of FSW in joining of dissimilar aluminum alloys and welding of al alloys with other materials has also been discussed. Concluding remarks are drawn from the study. From the study, it is stated that FSW is suitable for mass production welding method for joining of similar/dissimilar aluminum alloy materials in large quantity of similar products.
\end{abstract}

Keywords: friction stir welding, aluminum alloys, mechanical properties, metallurgical properties, dissimilar welding

\section{Introduction}

Aluminum materials are being used for variety of purposes like industrial, household, construction, etc., because of its advantages compared with other materials. It is easily available third most abundant material in the earth crust. Pure aluminum materials cannot be used directly for industrial applications due to its poor mechanical and metallurgical properties. With addition of some additives like copper, manganese, magnesium, zinc, silicon, etc., to aluminum materials; aluminum alloys can be produced which possess extraordinary mechanical and metallurgical properties comparison with the pure form of aluminum. Different aluminum alloys which are developed and widely used for various industrial applications are given in Table 1. As per the statistics of consumption of materials in industries; steel is occupying first position due to their mechanical properties like hardness, strength, stiffness, etc., In the recent times, the usage of aluminum alloys is growing in many industrial applications instead of steel and steel-based alloys, due to 


\begin{tabular}{ll}
\hline Alloy series & Major alloying element \\
\hline $1 \mathrm{xxx}$ & Pure aluminum \\
\hline $2 \mathrm{xx}$ & Copper $(1.9-6.8 \%)$ \\
\hline $3 \mathrm{xxx}$ & Manganese $(0.3-1.5 \%)$ \\
\hline $4 \mathrm{xxx}$ & Silicon $(3.6-13.5 \%)$ \\
\hline $5 \mathrm{xxx}$ & Magnesium $(0.5-5.5 \%)$ \\
\hline $6 \mathrm{xxx}$ & Magnesium and silicon $(\mathrm{Mg} 0.4-1.5 \%$. Si $0.2-1.7 \%)$ \\
\hline $7 \mathrm{xxx}$ & Zinc (1-8.2\%) \\
\hline $8 \mathrm{xxx}$ & Others \\
\hline
\end{tabular}

Table 1.

Various aluminum alloys and its major alloying elements [10].

its excellent properties such as corrosion resistance [1], light in weight as having one third density of steel, machinability, thermal and electrical conductivity, easy manufacturing methods, low cost of manufacturing, etc. The applications of aluminum alloys are found in variety of applications ranging from basic to complex such as in the making of aircraft bodies [2], construction [3], structural applications [4], transportation, packing, aerospace [5, 6], automobile [4], automotive, railway, personal computers, cutlery, aeronautical and shipbuilding industries [7], naval and marine [8]. All the mentioned applications need to join, two or more parts to create one complete structure or device. Welding is one of the most widely used fabrication technique for joining similar/dissimilar parts permanently. Tungsten inert gas (TIG) and metal inert gas (MIG) welding are generally used joining methods for different materials. But, in case of welding of aluminum alloys by TIG and MIG welding processes, produces welding defects on welded joint like porosity, lack of fusion, incomplete penetration and create many cracks such as hot crack, stress corrosion [9]. Defects in the welded joints weaken the quality characteristics. Welding of aluminum alloys by TIG and MIG welding techniques are not recommended and not economical as well.

Friction stir welding (FSW) is an innovative welding methodology developed to join especially aluminum alloys [4] and other light-weight materials, economically [11] without any severe distortions which expected to influence mechanical and metallurgical behavior of welded sample $[6,12]$. The weldability of various aluminum alloys by fusion welding methods like TIG and MIG welding, and FSW are shown in Figure 1.

In FSW, the job that is being welded does not melt and recast [12]. Cavaliere et al. [13] had stated that FSW is novel fabrication approach which capable to replace other joining techniques like fastener, riveted and arc welding for production of large-scale applications. FSW has various advantages over other traditional welding techniques including the following:

i. The welding procedure is relatively easy, as, it does not require consumables or filler materials for welding

ii. It does not require shielding gas, no arc formation and no fumes generated, as it is environment friendly

iii. Joint edge preparation is not at all required and Oxide removal/pre-heating prior to welding is not needed, thus, welding time minimized little bit 


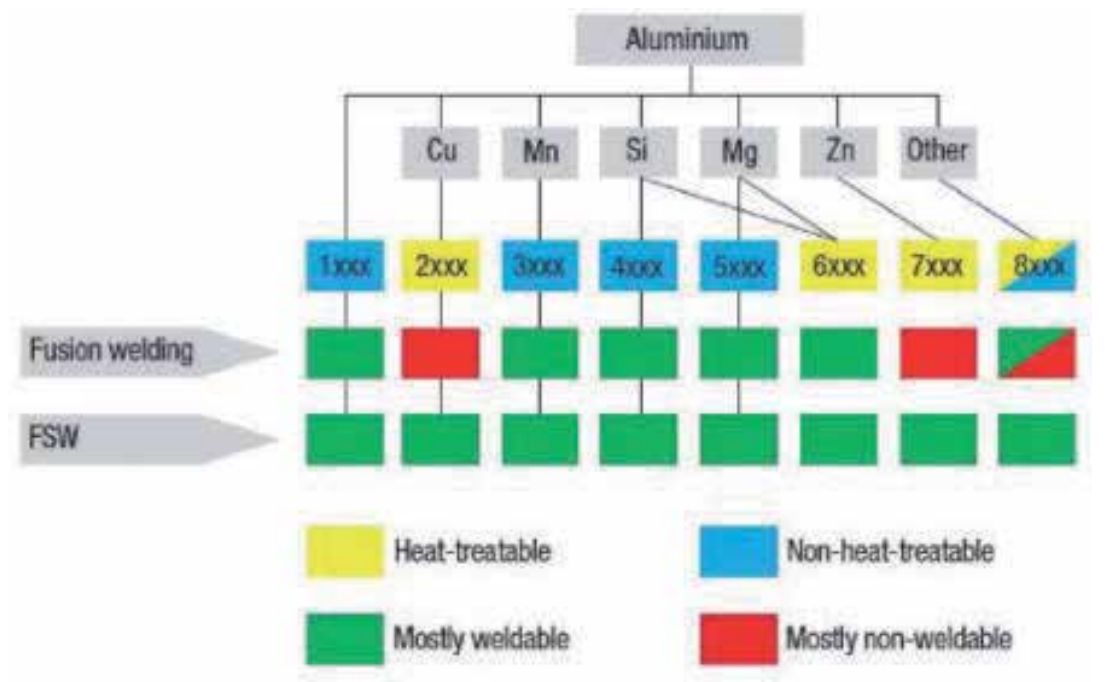

Figure 1.

Weldability of different aluminum alloys [10].

iv. FSW can be automated and performed in all directions, as it is conducted based on machine tool technology

v. Parent material chemistry is free from segregation of alloying elements.

vi. Process is solid phase with process temperature regimes much lower than in fusion techniques, thus avoiding welding defects like porosity, cracking, etc.

FSW is an efficient and effective process to produce high quality welds consistently, but its performance is depending on the optimum selection of process input parameters, welding machine parameters and work material properties. Improper selection of parametric combination(s) may deteriorate the output quality parameters like mechanical properties of welded joint. Systematic analysis is required to understand the FSW process to obtain best weld qualities of weldment. The important welding input parameters which may influence the joint quality in FSW are tool's rotational speed, welding speed, welding pressure, feed rate, pin temperature, temperature distribution, downwards forging force on the tool shoulder, rotating tool torque, forces generates from the weld in welding direction and perpendicular to weld seam, etc. FSW is a relatively newly developed method, much more studies need to conduct on different aspects to utilize it economically and effectively. FSW is attracting an increasing amount of research interest [14-16].

\section{Working principle of FSW}

Friction stir welding (FSW) is a solid-state welding process created and patented by The Welding Institute (TWI) in 1991 [17]. It is a relatively novel joining technology, which has caught the interest of many industrial sectors, including automotive, aeronautic and transportation due to its many advantages and clear industrial potential. The process adds new possibilities within component design and allows more economical and environmentally efficient use of materials $[18,19]$. FSW can produce low-cost and high-quality joints of heat-treatable aluminum alloys without 


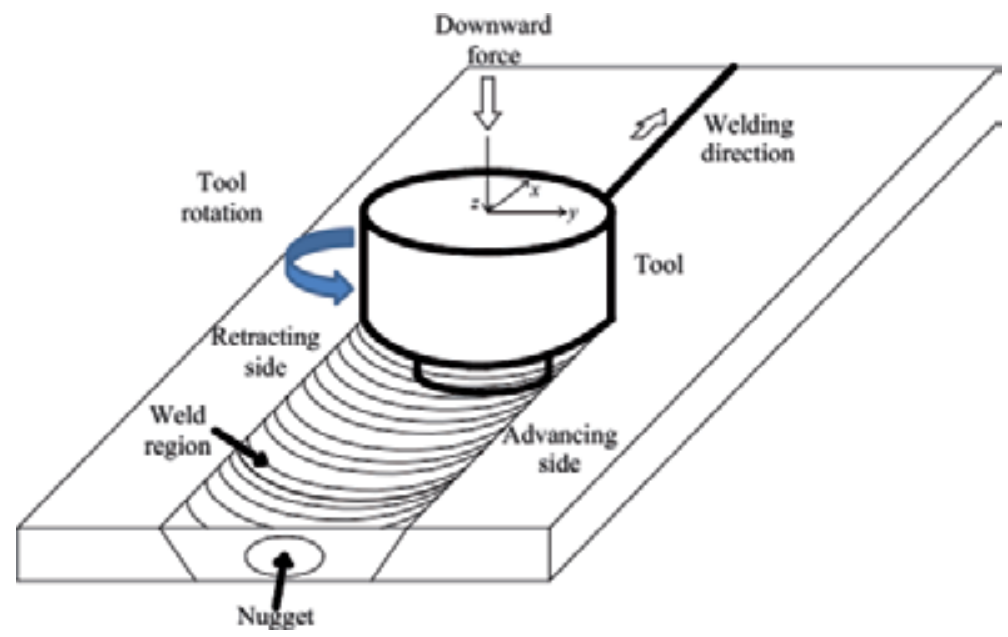

Figure 2.

Schematic diagram of the friction stir welding process [22].
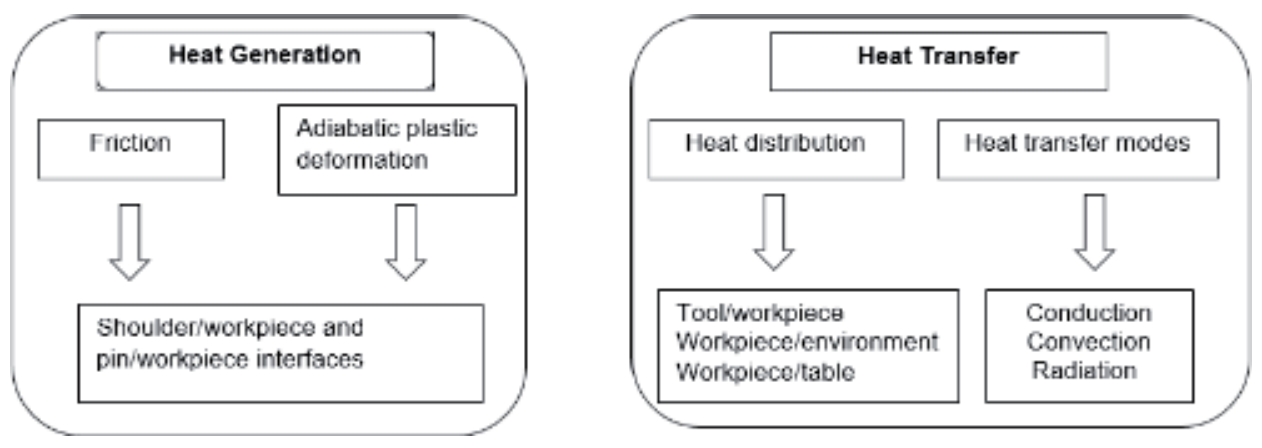

Figure 3.

The schematic diagram showing heat energy generation and distribution during FSW process [25].

use of consumable filler materials, no special preparation of the welding sample is required and can eliminate welding defects, little waste or pollution is generated during the welding process $[20,21]$. Friction stir welding offers distinguish advantages like ease of handling by precise external process control and can create homogeneous welds with high levels of repeatability [21]. The working principle of FSW is shown in Figure 2.

In FSW, cylindrical rotating tool consisting of a concentric threaded pin and tool shoulder are used for welding the parts. A non-consumable rotating tool along with specially designed pin and shoulder is attached at the faying edges of the plates to be joined and traversed along the welded joint. The clamps are used to fix the two sheets on the bed and force is applied vertically to fix the tool on the collect of vertical milling machine. The friction between the welding tool i.e. rotating tool and workpiece is generated due to rotation of rotation tool on the plated to be welded which leads to plastic deformation of work piece. The plates get soften at the around the pin due to generation localized heat from the friction and the combination of tool rotation and translation leads the movement of the soften material from front of the pin to back of the pin. The welded joint is formed by deforming the material at temperatures below the melting point of parent material. If the direction of tool rotation and translation of the welding tool in same direction, then it is called advancing side whereas both the motions in opposite direction then it is 
called retreating side. In FSW process, geometry of the tool is very important which highly depends on deciding the quality levels of joint obtained.

During the FSW process, the temperature distribution is a function of the heat generated by the friction between the workpiece and tip and shoulder of the tool [4]. The heat generation is depending on the physical properties of the workpiece and the tool [23]. And the generated heat equal distribution is crucial for the quality of the weldment and heat distribution is depends on the thermal conductivities of the tools and workpieces, thermal capacities, the relative speed, and the intersection area [24]. The heat distribution is clearly shown in Figure 3.

\section{Literature review}

As mentioned earlier that fusion based welding of aluminum alloys is difficult because of limited weldability. Some aluminum alloys can be resistance welded but the surface preparation is problematic, and time consuming and surface oxide is being a major problem during welding [26] On the other hand, FSW can be used join most of the aluminum alloys without any surface oxide problems and no special cleaning is required prior to welding. Some of the research publications which reported to literature based on friction stir welding of aluminum alloys are discussed as follows:

Rhodes et al. [26] had been made an experimental analysis to study the significance of welding process on weld nugget (WN), heat affected zone (HAZ) and microstructural changes of FSWed 7075 aluminum alloy material. They stated from the study that friction stir welding process was useful to join unweldable aluminum alloys without introducing a cast microstructure and it was not influencing much on WN, HAZ and microstructure of welded joint compared to fusion welding techniques. Jata et al. [27] were investigated the effects of FSW method on microstructure and mechanical properties of friction stir welded aluminum alloy 7050- T7451. Researchers observed from analysis that FSW process transforms the initial millimeter sized pancake-shaped grains in the parent work-material to fine 1 to 5 micrometer dynamically recrystallized grains and it also redissolves the strengthening precipitates in the weld-nugget area. The fatigue strength of welded specimen depends on the bonding between the intergranular mechanism. Frigaard et al. [4] had been studied the microstructure evolution and its effects on hardness distribution of FSWed samples of AA6082-T6 and AA7108-T79 aluminum alloys with the use of numerical three-dimensional heat flow model. They observed that thermal effects were main reasons behind the strength losses of welded samples during FSW of age hardening aluminum alloys. This was because of high level welding speeds which introduces plastic deformation resulting initiation of the dissolution of hardening precipitates. The grain structure within the plastically deformed region was analyzed by electron backscattered diffraction (EBSD) technique in the scanning electron microscope (SEM) and stated that dynamic recovery is significant softening procedure for FSW of age hardening aluminum alloys. Lee et al. [28] had made an investigation-based on experiments study to enhance welding process performance of FSW of A356 Al alloy. Liu et al. [20] had made an experimental investigation to study, analyze the effects of process welding parameters on tensile properties of friction stir welded 2017-T351 aluminum alloy and optimum welding parameters to attain better quality response of weldment. They observed from analysis that tensile properties and fracture locations of the welded joints are significantly affected by the friction stir process parameters. Peel et al. [21] had made a research analysis on welded samples of aluminum AA5083 in friction stir welds process. They studied the influences of varied process conditions 
on microstructural, mechanical property and residual stress. They observed from the work that there is uncertainty of weld quality characteristics with varying welding speeds. Researchers mentioned in their research that thermal input is most significantly affecting welding responses than the mechanical deformation created by the tool.

Fersini and Pirondi [29] had been conducted a research work to study and analyze the fatigue behavior of friction stir welded aluminum alloy Al2024- T3 materials. Shen et al. [30] had been studied the mechanical properties and failure mechanisms of aluminum alloy AA 6061-T4 sheets in friction stir spot welding. Kah et al. [31] had been investigated the weld defects in aluminum alloys welded by friction stir welding and fusion welding. Researchers found that defects in aluminum alloy welds are less as compared to the fusion welds. Effertz et al. [32] had been analyzed and optimized the process welding parameters in friction spot welding of 7050-T76 aluminum alloy. They stated that process parameters in friction spot welding were highly influential for quality responses of weldment. Guo et al. [33] had been studied the fatigue performance of aluminum friction stir welded joints. Kaushik and Singhal [34] had made an experimental investigation to analyze the influences of FSW process on microstructure and mechanical properties of cast composite matrix AA6063 reinforced with $7 \mathrm{wt} \% \mathrm{SiC}$ particles. They mentioned from the study that FSW had impacts on the growth, dissolution and reprecipitation of the hardening precipitates during welding. Mechanical properties like ultimate tensile strength, percentage elongation, hardness, of friction stir welded joint improved due to microstructural changes taken place during FSW process. Behrouz et al. [35] had investigated the effect of vibration on microstructure and thermal properties of Al5083 welded specimen made by friction stir spot welding (FSSW). They conducted experiments at rotation speed of $1500 \mathrm{rpm}$ and different dwelling times. They observed from their study that vibration during FSSW leads to decrease of grain size weld region thereby improved mechanical properties. Kunitaka et al. [36] had been developed the corner adstir fillet stationary shoulder FSW (SSFSW) process for welding of the reinforced fillet joints. The welding of reinforced fillet welded is difficult with conventional FSW due to complexity and unpractical joint preparation. Researchers were observed better mechanical properties in reinforced fillet welded joints as like conventional FS welds. Silva et al. [37] had been studied the temperature distribution around a FSW tool on bead-on-plate welds in $20 \mathrm{~mm}$ thickness aluminum alloy, AA6082-T6. Shen [38] had been evaluated the weld performance in terms of microstructure, interfacial bonding, hardness, static and fatigue strength of 7075-T6 Al alloy welded joint in refill friction stir spot welding using a modified tool based on the experimental analysis.

Dissimilar welding is an important research area for many industrial applications. Joining two different materials to create cost effective product is difficult task due different materials properties and varying melting points [21]. Welding of aluminum alloys with other materials has huge industrial requirement. Friction stir welding (FSW) is extended to join various un-weldable aluminum alloys within other aluminum alloys and also with other materials like steel, manganese, etc. Some of the dissimilar welding of aluminum alloys with other materials are discussed as follows:

Cavaliere et al. [13] had been analyzed the mechanical and metallurgical properties of dissimilar friction stir welded aluminum alloys 2024 and 7075 respectively. After welding experiments, the microstructure of weldment had been investigated by optical microscopy and observed that grain structure and precipitates distribution differences initiated during welding process. Mechanical behavior of welded samples had been tested by performing tensile and fatigue tests. From the research analysis, they mentioned that proper understanding 
and correct selection of process variables are very crucial for optimal conduction of FSW process to obtain desired welding performance. Yutaka et al. [39] were discussed the influences of varied rotation speeds on microstructure and hardness of friction stir welded aluminum (Al) alloys 6063-T5 and T4. Researchers analyzed the relationships between the microstructure and mechanical properties of welded specimens. They observed that grain size of the stir zone increased exponentially with increasing of temperature. The hardness values in welded condition in weld center in weld of Aluminum alloy 6063-T5 and distributed homogeneously in the weld of Aluminum alloy 6063-T4. The effects of rotation speeds on hardness of weldment were insignificant except softened region of aluminum alloy 6063-T5. Song et al. [40] had been analyzed the mechanical properties of friction stir lap welded dissimilar AA2024-AA7075 aluminum alloy materials. They were also studied the defects in the welded joints and found good quality welds without major defects. Shen et al. [41] were made an experimental research to determine the influences of welding input parameters on interfacial bonding in dissimilar steel/aluminum friction stir welds. Investigators stated that control parameters were most significant for quality of the welded joint of dissimilar aluminum alloy and steel materials in friction stir welding. Ding et al. [42] had also been studied the quality levels of dissimilar aluminum alloy and AISI coated steel in friction stir welding process. They found better weld qualities and stated that FSW was better welding method for joining of aluminum alloys to steel materials. Tianhao et al. [43] had been applied friction stir scribe (FSS) technique to join the dissimilar aluminum alloy and mild steel materials. The difference between the FSW and FSS are reduced heat is supplied in FSS during dissimilar welding because of varying melting points of materials to be joined. They studied the fracture modes of welded joints under tensile shear loading. They observed from the study that fracture mode and quality of joint was highly depends on welding process parameters and tool scribe height.

Raju et al. [44] had been investigated the significances of friction stir parameters on responses: microstructure and corrosion of friction stir welded AA6061-T6 and AISI30 4 materials. They analyzed the effect of process variables on microstructures, intermetallic compounds and their phases, and thereby on corrosion of the aluminum-steel welded joint and stated that quality of welded joint depends on the correct selection of process parameters in FSW of dissimilar materials. Gopkalo [45] had analyzed the microstructure in heat affected zone (HAZ) of dissimilar friction stir welded age hardened Al-Mg-Zn and Al-Mg-Si alloys. Li et al. [46] had been studied the influences of friction parameters namely welding speed and rotational speed on microstructure and tensile strength in FSW of dissimilar AZ91 magnesium $(\mathrm{Mg})$ alloy and A383 aluminum (AL) alloy materials. They stated from the study that optimum selection of process parameters was necessary to obtain defect free welded joint of AZ91 Mg alloy and A383 al alloy in friction stir welding. Jedrasiak and Shercliff [47] had been developed a finite element model to predict the spatial and temporal variation of heat generation and temperature in friction stir spot welding of aluminum and magnesium alloys. Guo et al. [33] had conducted research analysis to study the dependency of fatigue performance in friction stir welding of dissimilar 6061-T651 and 5083-H321 aluminum alloys. They observed from the investigation that kissing bond defect had significant effect on fatigue life and toe-flash defect had small or less effect on fatigue performance of dissimilar 6061-T651 and 5083-H321 aluminum alloys friction stir welds. Pratik et al. [48] studied the effects of cylindrical tool pin profile on macrostructure, microstructure, and tensile property of welded sample of dissimilar aluminum alloys AA6061 and AA7075 when other process parameters: tool traverse feed kept at $31.5 \mathrm{~mm} / \mathrm{s}$, tool rotational speed kept at $765 \mathrm{rpm}$, and tool tilt angle of $2^{\circ}$ forward position. They 
stated that cylindrical tool pin profile was beneficial for obtaining defect free stir zone and better tensile properties on weldment.

From the extensive review of friction stir welding of aluminum alloys, it is stated that friction stir welding is best alternative to join almost all types of aluminum alloys. The uses of FSW can also be extended to weld dissimilar aluminum alloys and with other materials also. FSW can be used as mass production technology or fabrication process, as it does not have melting phase, no special preparation of welding joint, minimum problems related to welding metal re-solidification, uses non-consumable tool, etc. Performing FSW process to create aluminum sheets in economical manner is important area of work and it is highly depends on the proper understanding of principles of FSW, relations between the process parametric conditions and response characteristics, properties of work-piece material and welding tool, shape and geometry of welding tool, etc. More research investigations related to various aspects of FSW of similar aluminum (AL) alloys and dissimilar AL alloys and or with other materials will create a sound knowledge bank; from which industrial persons can be benefitted to conduct FSW process with enhanced efficiency. Present chapter is one step forward for making the FSW of similar and dissimilar aluminum alloys in an economical and predictive manner.

\section{Conclusions}

The followings are the conclusions drawn from the present study of advancements of FSW of aluminum alloys:

1. Aluminum alloys are useful alternative materials of steel, and those are used make products in many advanced industrial applications

2. Aluminum alloys are treated as un-weldable materials

3. Welding of aluminum alloys with fusion welding (tungsten inert gas, and metal inert gas) and resistance welding techniques are difficult and not economical methods

4. Friction stir welding (FSW) is solid state welding which used non-consumable rotating tool to weld aluminum alloys by using frictional energy

5. FSW does not need to weld joint preparation, melting of material to be joined and recast

6. Welding defects can be eliminated with FSW process

7. Fundamental understanding of FSW is required to conduct it efficiently and effectively

8. Selection correct process welding parameters, temperature distribution during welding, are important parameters which expected to influence the weld quality and welding performance.

9. FSW can be used weld similar and dissimilar aluminum alloys

10. FSW can also be used to join aluminum alloys with high strength steels and other light-weight materials 
11. Advancements of various types of FSW process like friction stir scribe (FSS) technique, stationary shoulder FSW (SSFSW) process, friction stir spot welding (FSSW) to weld similar and dissimilar aluminum alloys are discussed

12. From the present study, it is mentioned that FSW is highly suitable for mass production process to produce large quantity parts with high production rate

\section{Acknowledgements}

The author acknowledges to Dr. Asish Bandyopadhyay, Professor, Mechanical Engineering Department, Jadavpur University, India, for encouraging me to write this chapter.

\section{Conflict of interest}

The author declaring no conflict of interest.

\section{Author details}

Ramesh Rudrapati

Department of Mechanical Engineering, Institute of Technology, Hawassa

University, Hawassa, Ethiopia

*Address all correspondence to: rameshrudrapati@gmail.com

\section{IntechOpen}

(C) 2019 The Author(s). Licensee IntechOpen. This chapter is distributed under the terms of the Creative Commons Attribution License (http://creativecommons.org/licenses/ by/3.0), which permits unrestricted use, distribution, and reproduction in any medium, provided the original work is properly cited. (cc) BY 


\section{References}

[1] Schneider R, Heine B, Grant RJ. Mechanical behaviour of commercial aluminium wrought alloys at low temperatures. In: Light Metal Alloys Applications. Croatia. UK: InTech Open; 2014. pp. 61-76

[2] Rajkumar V, Venkatesh K, Arivazhagan N. Friction stir welding of aluminium alloys. In: Aluminium Alloys - Recent Trends in Processing, Characterization, Mechanical Behavior and Applications. UK: Intech open; 2017. pp. $81-97$

[3] Mazzolani FM. Structural applications of aluminium in civil engineering. Structural Engineering International. 2006;16(4):280-285

[4] Frigaard Ø, Grong Ø, Midling OT. A process model for friction stir welding of age hardening aluminum alloys.

Metallurgical and Materials

Transactions A. 2001;32A:1189-1200

[5] Subodh KD, Kaufman JG. Aluminum alloys for bridges and bridge decks. In: Aluminium Alloys for Transportation, Packing, Aerospace and Other Applications. The Minerals, Metals \& Materials Series. Switzerland AG: Springer; 2007. pp. 61-67

[6] John R, Jata KV, Sadananda K. Residual stress effects on near threshold fatigue crack growth in friction stir welded aerospace alloys. International Journal of Fatigue. 2003;25:939-948

[7] Sheikhi S, Bolfarini C. Preliminary study on the microstructure and mechanical properties of dissimilar friction stir welds in aircraft aluminium alloys 2024-T351 and 6061-T4. Journal of Materials Processing Technology. 2007;6:132-142

[8] Yuri H, John EC, Kester DC, Paul EK. Friction-stir welding and processing. Journal of Metals. 2015;67(5):996-997

[9] Debroy T, Bhadeshia HKDH. Friction stir welding of dissimilar alloys- a perspective. Science and Technology Welding Joining. 2010;15:266-270

[10] Pratik HS, Vishvesh JB. Friction stir welding of aluminium alloys: An overview of experimental findings - process, variables, development and applications. Proceedings of the Institution of Mechanical Engineers, Part L. 2019;233(6):1191-1226

[11] Rajakumar S, Muralidharan C, Balasubramanian $\mathrm{V}$. Influence of friction stir welding process and tool parameters on strength properties of AA7075-T6 aluminium alloy joints. Materials and Design. 2011;32(2):535-549

[12] Jata KV, Sankaran KK, Ruschau JJ. Friction-stir welding effects on microstructure and fatigue of aluminum alloy 7050-T7451. Metallurgical and Materials Transactions A. 2000;31A:2181-2192

[13] Cavaliere P, Nobile R, Panella FW, Squillace A. Mechanical and microstructural behaviour of 20247075 aluminium alloy sheets joined by friction stir welding. International Journal of Machine Tools and Manufacture. 2006;46:588-594

[14] Hakan A, Mumin T, Kurtulus Y, Ali B. Mechanical properties of friction stir welded 3003 aluminum alloy in different welding conditions. International Journal of Mechanical and Production Engineering. 2017;5(12):92-96

[15] Balasubramanian V. Relationship between base metal properties and friction stir welding process parameters. Materials Science and Engineering A. 2008;480:397-403 
[16] Barcellona A, Buffa G, Fratini L, Palmeri D. On microstructural phenomena occurring in friction stir welding of aluminium alloys. Journal of Materials Processing Technology. 2006;177:340-343

[17] Thomas WM, Nicholas ED, Needham JC, Murch GM, Temple-SP, Dawes CJ. Friction stir butt welding. International Patent Application No. PCT/GB92/02203; 1991

[18] Dawes CJ, Thomas WM. Friction stir process welds aluminum alloys. Welding Journal. 1996;75(3):41-45

[19] Jata KV, Semiatin SL. Continuous dynamic recrystallization during friction stir welding of high strength aluminum alloys. Scripta Materialia. 2000;43:743-749

[20] Liu HJ, Fujii H, Maeda M, Nogi K. Tensile properties and fracture locations of friction-stir-welded joints of 2017-T351 aluminum alloy. Journal of Materials Processing Technology. 2003;142:692-696

[21] Peel M, Steuwer A, Preuss M, Withers PJ. Microstructure, mechanical properties and residual stresses as a function of welding speed in aluminium AA5083 friction stir welds. Acta Materialia. 2003;51:4791-4801

[22] Ramona G, Jorge FS. Friction stir welding development of aluminium alloys for structural connections. Proceedings of the Romanian Academy Series A. 2013;14:64-71

[23] Verma S, Meenu, Misra JP. Study on temperature distribution during friction stir welding of 6082 aluminum alloy. Materials Today: Proceedings. 2017;4(2):1350-1356

[24] Ahmet Ç, Hatice A, Mustafa U. Analysis and joining of $\mathrm{Al}-\mathrm{Cu}$ plates using friction-stir welding technique.
European Mechanical Science. 2018;2(1):1-8

[25] Durdanovic MB, Mijajlovic MM, Milcic DS, Stamenkovic DS. Heat generation during friction stir welding process. Tribology in Industry. 2009;31:8-14

[26] Rhodes CG, Mahoney MW, Bingel WH, Spurling RA, Bampton CC. Effects of friction stir welding on microstructure of 7075 aluminum. Scripta Materialia. 1997;36:69-15

[27] Jata KV, Sankaran KK, Ruschau J. Friction stir welding effects on microstructure and fatigue of aluminium alloy 7050- T7451. Metallurgical and Materials Transactions. 2000;31A:2181-2192

[28] Lee WB, Yeon YM, Jung SB. The improvement of mechanical properties of friction-stir-welded A356 Al alloy. Materials Science and Engineering A. 2003;355:154-159

[29] Fersini D, Pirondi A. Fatigue behaviour of Al2024- T3 friction stir welded lap joints. Engineering Fracture Mechanics. 2007;74(4):468-480

[30] Shen Z, Yang X, Zhang Z, Cui L, Yin Y. Mechanical properties and failure mechanisms of friction stir spot welds of AA 6061-T4 sheets. Materials and Design. 2013;49:181-191

[31] Kah P, Rajan R, Martikainen J, Suoranta R. Investigation of weld defects in friction stir welding and fusion welding of aluminium alloys. International Journal of Mechanical and Materials Engineering. 2015;10:26

[32] Effertz P, Quintino L, Infante V. The optimization of process parameters for friction spot welded 7050-T76 aluminium alloy using a Taguchi orthogonal array. International Journal of Advanced Manufacturing Technology. 2017;91(9-12):3683-3695 
[33] Guo S, Shah L, Ranjan R, Walbridge S, Gerlich A. Effect of quality control parameter variations on the fatigue performance of aluminum friction stir welded joints. International Journal of Fatigue. 2019;118:150-161

[34] Kaushik N, Singhal S. Experimental investigations on microstructural and mechanical behavior of friction stir welded Aluminum matrix composite. International Journal of Engineering. 2019;32:162-170

[35] Behrouz B, Mahmoud A, Mohammad G. Effects of vibration on microstructure and thermal properties of friction stir spot welded (FSSW) aluminum alloy (Al5083). International Journal of Precision Engineering and Manufacturing. 2019;20:1219-1227

[36] Kunitaka M, Hiroshi S, Koji N, Shoko K, Yutaka SS, Hiroyuki K. Material flow and microstructure evolution in corner friction stir welding of $5083 \mathrm{Al}$ alloy using adstir technique. In: Friction Stir Welding and Processing X. The Minerals, Metals \& Materials Series. Switzerland AG: Springer; 2019. pp. 181-188

[37] Silva MA, Backer JD, Martin J, Bolmsjö G. In-situ temperature measurement in friction stir welding of thick section aluminium alloys. Journal of Manufacturing Processes. 2019;39:12-17

[38] Shen Z, Ding Y, Chen J, Fu L, Liu XC, Chen H, et al. Microstructure, static and fatigue properties of refill friction stir spot welded 7075-T6 aluminium alloy using a modified tool. Science and Technology Welding Joining. 2019;24(7):587-600

[39] Yutaka SS, Mitsunori U, Hiroyuki K. Parameters controlling microstructure and hardness during friction-stir welding of precipitation-hardenable aluminum alloy 6063. Metallurgical and Materials Transactions A. 2002;33A:625-634

[40] Song Y, Yang X, Cui L, Hou X, Yan X. Defect features and mechanical properties of friction stir lap welded dissimilar AA2024-AA7075 aluminum alloy sheets. Materials and Design. 2014;55:9-18

[41] Shen Z, Chen Y, Haghshenas M, Gerlich AP. Role of welding parameters on interfacial bonding in dissimilar steel/aluminum friction stir welds. Engineering Science and Technology, an International Journal. 2015;18(2):270-277

[42] Ding Y, Shen Z, Gerlich A. Refill friction stir spot welding of dissimilar aluminum alloy and AISI coated steel. Journal of Manufacturing Processes. 2017;30:353-360

[43] Tianhao W, Harpreet S, Rajiv SM, Yuri H, Piyush U, Blair C. Effect of hook characteristics on the fracture behaviour of dissimilar friction stir welded aluminium alloy and mild steel sheets. Science and Technology Welding Joining. 2019;24:178-184

[44] Raju PM, Sharath A, Arnab S, Omkar M, Surjya KP, Jyotsna DM. Interfacial microstructural and corrosion characterizations of friction stir welded AA6061-T6 and AISI304 materials. Metals and Materials International. 2019;25(3):752-767

[45] Gopkalo O, Liu X, Long F, Booth M, Gerlich AP, Diak BJ. Non-isothermal thermal cycle process model for predicting post-weld hardness in friction stir welding of dissimilar age hardenable aluminum alloys. Materials Science and Engineering A. 2019;754:205-215

[46] Li P, You G, Wen H, Guo W, Tong X, Li S. Friction stir welding between the high-pressure die casting of AZ91 
magnesium alloy and A383 aluminum

alloy. Journal of Materials Processing

Technology. 2019;264:55-63

[47] Jedrasiak P, Shercliff HR. Small

strain finite element modelling of

friction stir spot welding of $\mathrm{Al}$ and $\mathrm{Mg}$

alloys. Journal of Materials Processing

Technology. 2019;263:207-222

[48] Pratik SG, Vivek VP, Jay JV,

Nishit DC, Rishab B. Effect friction stir

welding of aluminum alloys AA6061/

AA7075: Temperature measurement,

microstructure, and mechanical

properties innovations in infrastructure.

Advance In Intelligent System and

Computing. 2019;757:591-598 



\title{
Quantification of Feeding Regions of Hypoeutectic Al- $(5,7,9)$ $\mathrm{Si}-(0-4) \mathrm{Cu}$ (wt.\%) Alloys Using Cooling Curve Analysis
}

\author{
Gerhard Huber, Mile B. Djurdjevic and Srećko Manasijević
}

\begin{abstract}
This chapter presents the potential of the cooling curve analysis to characterize the solidification path of the cast hypoeutectic series of $\mathrm{Al}-\mathrm{Si}-\mathrm{Cu}$ alloys and to quantify their feeding regions. The aim of this work is to examine how variations in the chemical composition of $\mathrm{Si}(5,7$ and $9 \mathrm{wt} . \%)$ and $\mathrm{Cu}$ (from 0 to $4 \mathrm{wt} . \%$ ) might affect the characteristic solidification temperatures, their corresponding fraction solid, and feeding regions of investigated alloys. These parameters collected from the cooling curve analysis can be used for better understanding of the solidification paths of Al-Si-Cu alloys and could easily be incorporated into existing simulation software packages to improve their accuracy.
\end{abstract}

Keywords: aluminum alloys, thermal analysis, cooling curves, fraction solid, feeding

\section{Introduction}

Al-Si-Cu casting alloys show a great promise for several fields of engineering applications. Over the past few years, these alloys have been widely used in the automotive industry due to their suitable properties such as their lightness, strength, recyclability, corrosion, resistance, durability, ductility, formability and conductivity. Their good metallurgical properties, such as castability and fluidity, further enhance the applicability of these alloys for the production of intricate castings such as, e.g., the engine parts and cylinder heads. The chemical compositions of these alloys have a significant impact on all of the aforementioned properties. The alloying elements are usually added with the intent to improve the specific properties of casting parts. The main alloying elements: $\mathrm{Si}$ and $\mathrm{Cu}$ are primarily responsible for defining the microstructure and mechanical properties of aluminum alloys [1-7]. The castability and fluidity of these alloys have improved through $\mathrm{Si}$ addition. Additionally, the presence of Si leads to the reduction of shrinkage porosity, giving those alloys superior mechanical and physical properties.

Copper, as a second major alloying element, has been added to considerably increase strength and hardness of $\mathrm{Al}-\mathrm{Si}-\mathrm{Cu}$ alloys in as cast and heat-treated conditions. In addition, $\mathrm{Cu}$ reduces the corrosion resistance of aluminum alloys, and in certain alloys increases stress corrosion susceptibility. This element is generally 
responsible for reducing the casting characteristics, especially the feeding ability of Al-Si-Cu alloys [8-10].

Any cast aluminum alloy during the transition from liquid to solid condition characterizes reduction in its volume. That reduction is usually in the range between 4 and 8 wt.\% (higher Si content corresponds to lower reduction in the volume and vice versa). In order to eliminate the potential formation of shrinkage porosity by maintaining a path for fluid flow from the higher heat mass and the pressure of the riser to the isolated liquid pool, cast parts need to be additionally fad with a new volume of the liquid melt. According to Campbell [11], during directional solidification, it can be recognized five feeding mechanisms. They are, as Figure 1 illustrates liquid feeding, mass feeding, interdendritic feeding, burst feeding, and solid feeding [11].

The liquidus $\left(T_{\text {liq }}\right)$, dendrite coherency temperature $\left(T_{\mathrm{DCT}}\right)$, rigidity $\left(T_{\text {Rigidity }}\right)$ and solidus temperature $\left(T_{\text {sol }}\right)$ are important characteristic solidification temperatures of any aluminum alloys, which could be successfully used to delineate transition between various types of feeding mechanisms. All of these characteristic solidification temperatures, as Figure 2 illustrates, can be easily determined using the thermal analysis (TA) technique [12]. The TA has been used for many years in aluminum casting plants as a quality control tool [3, 4, 13-28]. There are many reasons why this more than hundreds of years old technique has commercially

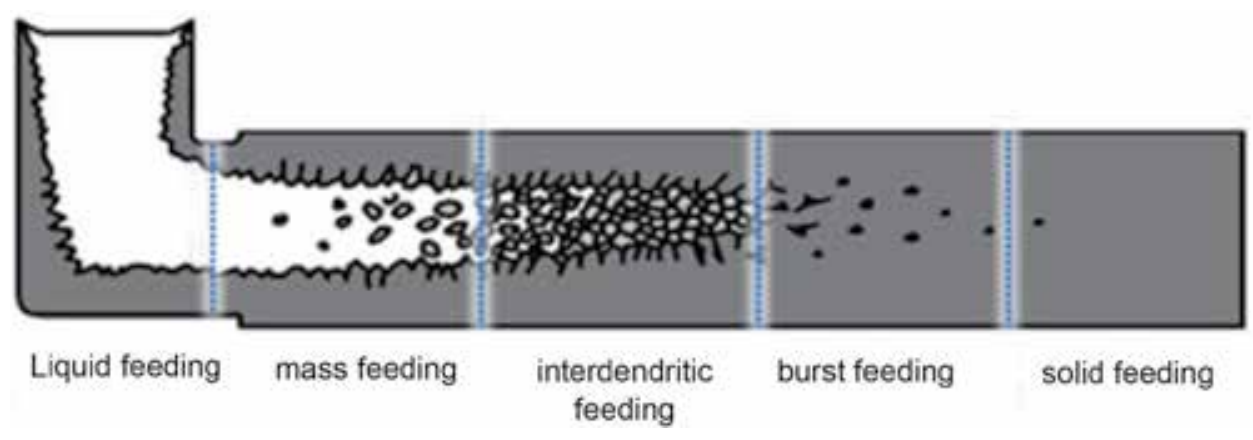

Figure 1.

Five feeding mechanisms recognized during directional solidification.

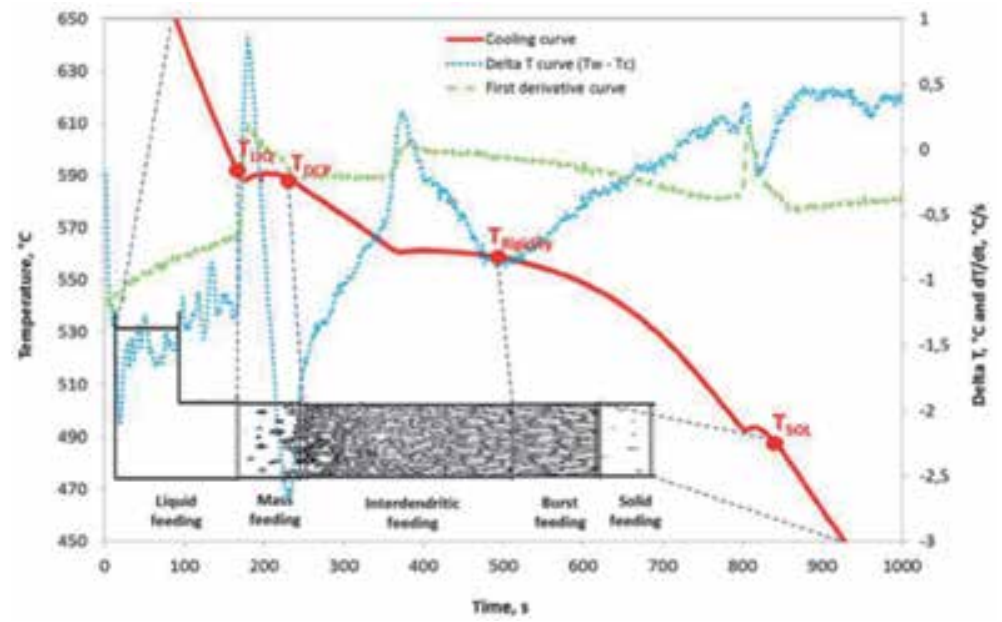

Figure 2.

Characteristic solidification temperatures, determined from the cooling curve, are bordering five feeding mechanisms. 
applied at numerous aluminum foundry plants. The TA method is simple, inexpensive and provides consistent results. Applying thermal analysis technique some fundamental relationship between cooling or its derivatives curves characteristics, alloy composition and melt treatment can be easier recognized and even better understood. Additionally, the first derivative of the cooling curve has been applied to calculate solid fraction distribution between $T_{\text {liq }}$ and $T_{\text {sol }}$ emperatures $[29,30]$.

Depending on the solidification interval of alloys, chemical compositions, cooling rates, amount of master alloys, hydrogen content and other, $\mathrm{Al}-\mathrm{Si}-\mathrm{Cu}$ alloys are prone to developing a considerable amount of shrinkage porosity. The solidification interval of $\mathrm{Cu}$ free alloys is very narrow; typically around $60^{\circ} \mathrm{C}$, containing approximately $50 \%$ eutectic liquid. Usually, the level of porosity in such type of aluminum alloys is very low due to no feeding constraint during solidification of the last portion of eutectic liquid. The presence of $\mathrm{Cu}$ in the aluminum silicon alloys considerably extend their solidification range (reaching more than $100^{\circ} \mathrm{C}$ ), making them more prone to the formation of shrinkage porosity [31].

Recently, it has shown [31, 32] sensitivity of aluminum-silicon alloys to porosity based on the content of $\mathrm{Cu}$ in these alloys. Addition up to $1 \mathrm{wt} . \%$ of $\mathrm{Cu}$ resulted in a significant increase in the porosity level. Surprisingly, further $\mathrm{Cu}$ addition up to $4 \mathrm{wt} . \%$ did not have such a significant impact on the porosity level at the same aluminum silicon alloy. It looks that development of porosity by cast aluminumsilicon alloys does not depend only on the concentration of $\mathrm{Cu}$. It is also still not entirely clear which feeding regions is more responsible for the formation of shrinkage porosity. The impact of various major alloying elopements ( $\mathrm{Si}$ and $\mathrm{Cu}$ ) on the feeding regions has not yet been fully analyzed. There is a lack of data, in the available literature, regarding quantification of feeding regions. The objective of this work is to examine how variation in chemical composition of Al- $(5,7,9)$ $\mathrm{Si}-(0-4) \mathrm{Cu}$ (wt.\%) alloy may affect its characteristic solidification temperatures and corresponding fraction solid related to each temperature, as well as to quantify the effect of various contents of $\mathrm{Si}$ and $\mathrm{Cu}$ on the corresponding feeding regions. This analysis should help foundry professionals to understand better which feeding regions are more responsible for the formation of shrinkage porosity. To accomplish this, several experimental tests were carried out by applying the TA technique.

All experimentally obtained data (the characteristic solidification temperatures and solid fraction) will be applied to quantify the five feeding regions of these alloys.

\section{Experimental procedure}

Twenty-five different Al-Si-Cu alloys with the chemical compositions, as presented in Table 1, are synthetically produced. Pure aluminum (commercial purity 99.7 wt.\%) and pure copper (commercial purity 99.9 wt.\%) have been used as impute materials. The content of the main alloying elements varied between $4.96-8.93$ wt.\% of Si and 0.0-4.30 wt.\% of $\mathrm{Cu}$. Their chemical compositions have been determined using optical emission spectroscopy (OES).

The alloys were melted in an electric resistance furnace, capacity $8 \mathrm{~kg}$. No grain refining and modifier agents were added to the melt. During all experiments, degassation was not applied. Samples with masses of approximately $250 \mathrm{~g}$ were poured into coated stainless-steel cups. The height of the thermal analysis test cup was $60 \mathrm{~mm}$, its diameter was $50 \mathrm{~mm}$, while the weight of the steel test cup was $50 \mathrm{~g}$.

Two calibrated commercial $\mathrm{N}$ type thermocouples with an accuracy of $\pm 0.10^{\circ} \mathrm{C}$ were inserted into thermal analysis cup and used during all experiments. One thermocouple was placed in the center of the thermos analysis cup while second 


\begin{tabular}{lcc}
\hline Alloy & Si & Cu \\
\hline Al-5Si & 4.96 & 0 \\
\hline Al-5Si-1Cu & 5.22 & 1.12 \\
\hline Al-5Si-2Cu & 5.12 & 1.88 \\
\hline Al-5Si-3Cu & 5.08 & 3.11 \\
\hline Al-5Si-4Cu & 5.01 & 4.30 \\
\hline Al-7Si & 6.80 & 0 \\
\hline Al-7Si-1Cu & 7.32 & 0.89 \\
\hline Al-7Si-2Cu & 7.32 & 2.04 \\
\hline Al-7Si-3Cu & 7.32 & 3.28 \\
\hline Al-7Si-4Cu & 7.13 & 4.30 \\
\hline Al-9Si & 8.80 & 0 \\
\hline Al-9Si-1Cu & 8.93 & 0.92 \\
\hline Al-9Si-2Cu & 8.93 & 2.17 \\
\hline Al-9Si-3Cu & 8.82 & 2.93 \\
\hline Al-9Si-4Cu & 8.92 & 4.02 \\
\hline
\end{tabular}

Table 1.

Actual chemical composition (in wt.\%) of synthetic Al-Si-Cu alloys.

$5 \mathrm{~mm}$ away from the cup inner wall. They recorded temperature during solidification of an investigated alloy (especially between 750 and $400^{\circ} \mathrm{C}$ temperature range). The National Instrument data acquisition system has been applied to collect temperature-time data. During all trials, the sampling rate was five data per second. The cooling conditions were maintained constant during all experiments, but due to various $\mathrm{Si}$ and $\mathrm{Cu}$ contents, the solidification rates slightly varied between maximal $0.26^{\circ} \mathrm{C} / \mathrm{s}$ for $\mathrm{Al}-5 \mathrm{Si}-4 \mathrm{Cu}$ (wt.\%) alloy and minimal $0.11^{\circ} \mathrm{C} / \mathrm{s}$ for Al-9Si (wt.\%) alloy. The cooling rate has been calculated as the ratio of the temperature difference between $T_{\text {liq }}$ and $T_{\text {sol }}$ to the total solidification time between these two temperatures. Each TA trial was repeated two times. Consequently, a total of 50 cooling curves were gathered.

\section{Results and discussion}

Porosity is one of the most common defects in aluminum cast parts caused mostly due to insufficient feeding and hydrogen precipitation during solidification. The amount of dissolved hydrogen in cast Al-Si alloys can be kept very low by degassing the melt. However, shrinkage porosity can still be a problem in the cast parts caused by non-proper feeding ability. Consequently, understanding the feeding behavior of hypoeutectic $\mathrm{Al}-\mathrm{Si}-\mathrm{Cu}$ alloys is an important aspect of sound casting production. In this paper, the impact of various contents of $\mathrm{Si}$ and $\mathrm{Cu}$ on different feeding regions has been analyzed by applying the TA technique. The main objective of this work was to better understand their impact on the feeding ability of Al$\mathrm{Si}-\mathrm{Cu}$ alloys and to quantify each feeding region regarding the characteristic solidification temperatures and/or the corresponding amount of fraction solid precipitated between those temperatures. 
Quantification of Feeding Regions of Hypoeutectic Al-(5, 7, 9)Si-(o-4)Cu (wt.\%) Alloys Using... DOI: http://dx.doi.org/10.5772/intechopen.90337

\subsection{Analysis of characteristic solidification temperatures}

The results of the cooling curve analysis are summarized in Table 2 . The values of characteristic solidification temperatures $\left(T_{\text {liq }}, T_{\mathrm{DCT}}, T_{\text {Rigidity }}\right.$ and $\left.T_{\text {sol }}\right)$ have been determined from the cooling curves or their corresponding first derivatives curves. The dendrite coherency [3] and rigidity [12] temperatures have been determined by applying the two thermocouples method (one thermocouple located at the center

\begin{tabular}{|c|c|c|c|c|}
\hline Alloy & $T_{\text {liq }}$ & $T_{\mathrm{DCP}}$ & $T_{\text {Rigidity }}$ & $T_{\text {sol }}$ \\
\hline \multirow[t]{2}{*}{$\mathrm{Al}-5 \mathrm{Si}$} & 632.9 & 624.1 & 575.7 & 553.4 \\
\hline & 634.2 & 624.9 & 576.7 & 555.5 \\
\hline \multirow[t]{2}{*}{$\mathrm{Al}-5 \mathrm{Si}-1 \mathrm{Cu}$} & 631.5 & 623.1 & 571.4 & 500.1 \\
\hline & 628.1 & 623.4 & 571.7 & 499.7 \\
\hline \multirow[t]{2}{*}{$\mathrm{Al}-5 \mathrm{Si}-2 \mathrm{Cu}$} & 625.4 & 619.5 & 567.2 & 497.8 \\
\hline & 624.9 & 619.1 & 568.0 & 496.8 \\
\hline \multirow[t]{2}{*}{$\mathrm{Al}-5 \mathrm{Si}-3 \mathrm{Cu}$} & 622.5 & 616.2 & 562.8 & 500.6 \\
\hline & 621.8 & 617.0 & 562.0 & 499.2 \\
\hline \multirow[t]{2}{*}{$\mathrm{Al}-5 \mathrm{Si}-4 \mathrm{Cu}$} & 617.0 & 613.2 & 558.7 & 498.5 \\
\hline & 617.1 & 613.2 & 558.7 & 501.9 \\
\hline \multirow[t]{2}{*}{$\mathrm{Al}-7 \mathrm{Si}$} & 617.8 & 610.7 & 576.7 & 552.0 \\
\hline & 617.6 & 611.5 & 576.8 & 553.4 \\
\hline \multirow[t]{2}{*}{$\mathrm{Al}-7 \mathrm{Si}-1 \mathrm{C}$} & 612.6 & 604.5 & 573.8 & 498.0 \\
\hline & 611.8 & 604.5 & 574.0 & 497.9 \\
\hline \multirow[t]{2}{*}{$\mathrm{Al}-7 \mathrm{Si}-2 \mathrm{Cu}$} & 607.4 & 602.3 & 570.6 & 495.3 \\
\hline & 607.2 & 603.3 & 570.2 & 495.0 \\
\hline \multirow[t]{2}{*}{$\mathrm{Al}-7 \mathrm{Si}-3 \mathrm{Cu}$} & 603.5 & 598.0 & 567.1 & 494.3 \\
\hline & 603.2 & 596.8 & 566.5 & 494.0 \\
\hline \multirow[t]{2}{*}{$\mathrm{Al}-7 \mathrm{Si}-4 \mathrm{Cu}$} & 599.6 & 594.0 & 563.4 & 497.1 \\
\hline & 599.1 & 593.6 & 563.8 & 496.1 \\
\hline \multirow[t]{2}{*}{$\mathrm{Al}-9 \mathrm{Si}$} & 600.2 & 595.7 & 575.0 & 549.3 \\
\hline & 600.5 & 597.6 & 575.2 & 552.3 \\
\hline \multirow[t]{2}{*}{ Al-9Si-1Cu } & 597.3 & 593.9 & 573.1 & 494.7 \\
\hline & 595.8 & 593.7 & 572.,4 & 493.6 \\
\hline \multirow[t]{2}{*}{$\mathrm{Al}-9 \mathrm{Si}-2 \mathrm{Cu}$} & 591.9 & $589 ., 2$ & 569.5 & 493.6 \\
\hline & 591.9 & 589.6 & 569.6 & 494.5 \\
\hline \multirow[t]{2}{*}{ Al-9Si-3Cu } & 589.4 & 587.2 & 567.1 & 492.7 \\
\hline & 588.7 & 587.0 & 566.5 & 493.7 \\
\hline \multirow[t]{2}{*}{ Al-9Si-4Cu } & 582.8 & 581.8 & 564.8 & 493.0 \\
\hline & 582.4 & 581.7 & 564.6 & 492.6 \\
\hline
\end{tabular}

Two sets of the characteristic temperatures have been collected for each analyzed alloy (two cooling curves have been collected for each alloy).

Table 2.

Characteristic solidification temperatures of $\mathrm{Al}-(5,7,9) \mathrm{Si}-(0-4) \mathrm{Cu}(w \mathrm{t} . \%)$ alloys determined using cooling curve analysis. 
( $\left.T_{\mathrm{c}}\right)$ and second $\left(T_{\mathrm{w}}\right)$ placed nearby the inner wall of test cup). Characteristic solidification parameter such as dendrite coherency point (DCP) has determined by identifying the first local minimum on the delta $T$ curve $\left(\Delta T=T_{\mathrm{w}}-T_{\mathrm{c}}\right)$ plotted versus time. The dendrite coherency temperature (DCT) has detected by reading the temperature on the cooling curve for the corresponding time related to dendrite coherency point [3]. It has recently been found that the second local minimum on the $\Delta T$ versus time curve is related to the $T_{\text {Rigidity }}[12]$. The reason that DCP and rigidity occur at these minimums of the $\Delta T$ curve is because the heat removal from the solid is faster than from the liquid phase. This is due to the significantly higher thermal conductivity of the solid dendrites by DCP and solid dendrites and eutectic cells by rigidity in comparison to the surrounding liquid metal.

The $T_{\text {liq }}$ specifies the maximal temperature at which the crystal can coexist with the melt in thermodynamic equilibrium. Above the $T_{\text {liq }}$ there is not a single crystal and the melt is liquid and homogeneous. From Table 2 and Figure 3, it is evident

a)
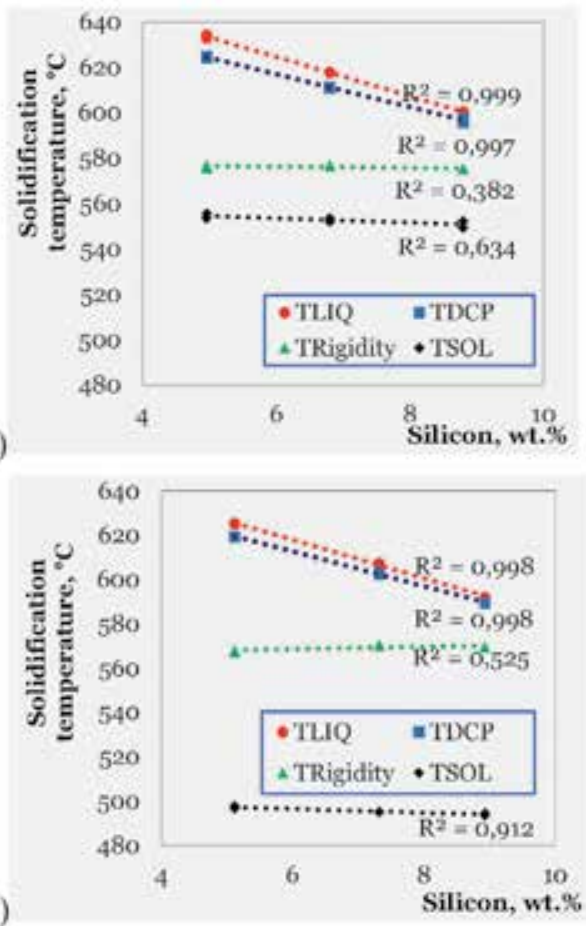

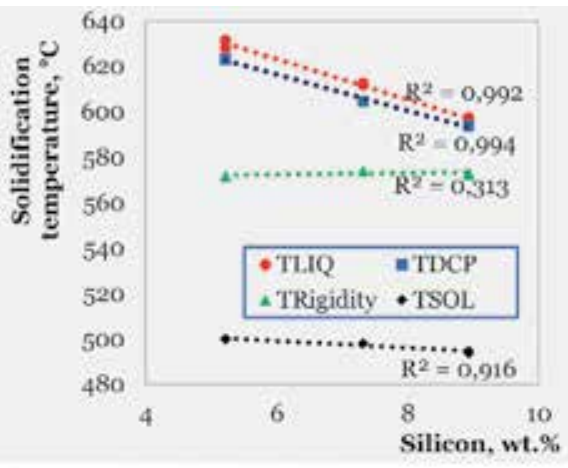

b)

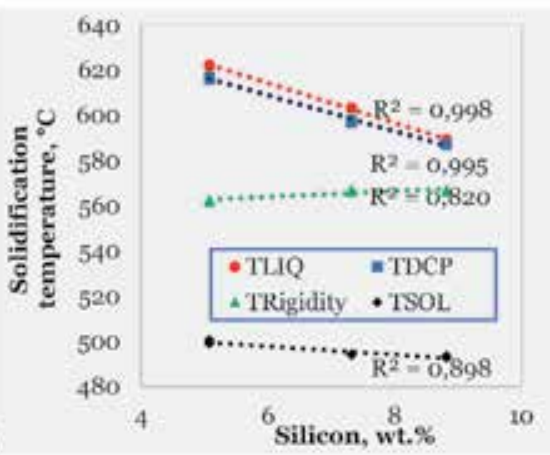

e)

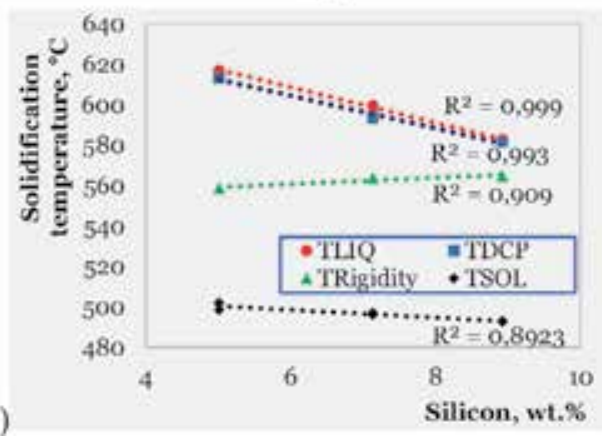

Figure 3.

The impact of Si on the characteristic solidification temperature: (a) Al-(5, 7, 9) Si-oCu (wt\%), (b) Al- (5, 7 , 9) $\mathrm{Si}-1 \mathrm{Cu},(\mathrm{c}) \mathrm{Al}-(5,7,9) \mathrm{Si}-2 \mathrm{Cu}(w t \%),(d) \mathrm{Al}-(5,79) \mathrm{Si}-3 \mathrm{Cu}(w t \%)$ and (e) $\mathrm{Al}-(5,7,9) \mathrm{Si}-4 \mathrm{Cu}(\mathrm{wt} \%)$ alloys. 
that any increase in the content of $\mathrm{Si}$ and $\mathrm{Cu}$ significantly depressed the liquidus, dendrite coherency, and rigidity temperatures, while solidus temperature is less prone to their influence. According to the results obtained using the cooling curve analysis, the increase in $\mathrm{Si}$ content by one weight percent depresses the $T_{\text {liq }}$ to $8.5^{\circ} \mathrm{C}$ by the constant content of $\mathrm{Cu}$. The experimental result indicated the stronger impact of $\mathrm{Si}$ on the $T_{\text {liq }}$ in comparison with that obtained using the binary Al-Si phase diagram. Calculated from the binary phase diagram, increase of Si content up to eutectic concentration $(\sim 12.0 \mathrm{wt} . \%)$ decreases the $T_{\text {liq }}$ by $83^{\circ} \mathrm{C}$ (the temperature drops almost linearly from 660 to $577^{\circ} \mathrm{C}$ ), which is approximately a decrease of $7^{\circ} \mathrm{C}$ per $1 \mathrm{wt} . \%$ of $\mathrm{Si}$. One weight percent of $\mathrm{Cu}$ by constant content of Si decreases the $T_{\text {liq }}$ by approximately $4.4^{\circ} \mathrm{C}$, which is a higher value than expected according to the equilibrium binary $\mathrm{Al}-\mathrm{Cu}$ phase diagram $\left(3.4^{\circ} \mathrm{C} / 1 \mathrm{wt} . \%\right.$ of $\left.\mathrm{Cu}\right)$. The most plausible reason for these differences can be found in the fact that in all experiments, a limited range of $\mathrm{Si}$ (up to $8.9 \mathrm{wt} . \%$ ) and $\mathrm{Cu}$ (up to $4.3 \mathrm{wt} . \%$ ) content has been analyzed in comparison with significantly broader concentration ranges (up to 12 wt.\% for $\mathrm{Si}$ and up to $33 \mathrm{wt} . \%$ for $\mathrm{Cu}$ ) taken from the binary $\mathrm{Al}-\mathrm{Si}$ and $\mathrm{Al}-\mathrm{Cu}$ phase diagrams. At the same time, the impact of higher cooling rates during some experiments $\left(\sim 0.26^{\circ} \mathrm{C} / \mathrm{s}\right)$ cannot be disregarded, which certainly depressed the $T_{\text {liq }}$ to a lower value.

During the solidification of any aluminum hypoeutectic Al-Si-Cu alloys, a dendritic network of primary $\alpha$-aluminum crystals will be developed. However, as the melt cools, the dendrite tips of the growing crystals begin to impinge upon one another until a coherent dendritic network is formed [4]. The temperature at which the dendrite tips start to touch each other is called dendrite coherency temperature $T_{\text {DCT. }}$. This temperature is a very important feature of the solidification process because it marks the moment when the "mass" feeding is transferred to the interdendritic feeding [33-42]. According to many researchers, casting defects such as macrosegregation, shrinkage porosity and hot tearing begin to develop after the $T_{\text {DCP }}$ [33-37]. The solidification conditions, the chemical compositions of alloy and the addition of grain refiners are major factors that have a significant impact on the DCT. Regardless of the applied measurement techniques, it has been verified that faster cooling rate and increase in solute concentration postponed the coherency point for the lower temperature [36, 37, 41]. From Table 2 and Figure 3, it is obvious that the higher $\mathrm{Si}$ and $\mathrm{Cu}$ contents progressively reduce the DCT. The impact of $\mathrm{Si}$ is more significant than that of $\mathrm{Cu}$. For the $\mathrm{Cu}$ free alloys, $1 \mathrm{wt} . \%$ of $\mathrm{Si}$ decreases the DTC to $\sim 7.2^{\circ} \mathrm{C}$, while by alloys with various content of $\mathrm{Cu}$ (from 1 to $4 \mathrm{wt} . \%)$ that decrease is slightly higher and is approximately $7.9^{\circ} \mathrm{C}$. Each increase in the $\mathrm{Cu}$ content by $1 \mathrm{wt} . \%$ in analyzed alloys will decrease the DCT to approximately $3.2^{\circ} \mathrm{C}$. These results are not unexpected and are consistent with the available literature data $[37,39]$. According to literature data, the size of secondary dendrite arms mostly depends on the local cooling rates and the amount of alloying elements present in the melt. The impact of the local cooling rate is very well studied; a higher cooling rate relates to the smaller dendrites and vice versa. The effect of alloying elements on the size of dendrite arm spacing needs to be also considered due to their not even distribution in the liquid and solid phases. Excess amount of solute displaced away from the solidification interface into the melt results in an increase in the volume of solute located between already formed dendrite arms. The resulted constitutional undercooling (supersaturation) is an additional driving force for the growth of the dendrites. In order to accommodate an excess amount of solute elements, the space between primary $\alpha$-aluminum dendrites must be increased. The higher concentration of alloying elements will reduce the growth of secondary dendrites and postpone their contact-coherency to lower temperature. Based on the 
previously mentioned, it could be assumed that elements with a lower solubility in the aluminum melt are more effective in reducing the size of secondary dendrite arm spacing (SDAS). Therefore, the effect of the same content of $\mathrm{Cu}$ (max. solubility in $\mathrm{Al}$ is $5.7 \mathrm{wt} . \%$ ) is significantly lower than the effect of the same amount of $\mathrm{Si}$ (max. solubility in $\mathrm{Al}$ is $1.6 \mathrm{wt} . \%$ ).

The rigidity point/temperature indicates the moment during solidification at which the flow of residual melt through interdendritic channels is completely restricted. As Figure 2 shows, the $T_{\text {Rigidity }}$ has been determined as the second minimum on the $\Delta T$ curve $\left(\Delta T=T_{w}-T_{c}\right)$ that are identified in the region of primary precipitation of Al-Si eutectic. Again, the most likely main reason for this difference is due to different thermal conductivity in solid and liquid phases. The rigidity point indicates the moment when the interdendritic feeding is transferred to burst feeding. According to Campbell [11], after the rigidity point, the stress will exceed the network strength and the dendritic network will collapse.

From Table 2 and Figure 3, it is obvious that any changes in the content of $\mathrm{Si}$ have no significant impact on the value of $T_{\text {Rigidity. }}$. Small changes in this temperature $\left( \pm 0.5^{\circ} \mathrm{C}\right)$ could be related to the accuracy of applied thermocouples. On the contrary to that, the addition of $\mathrm{Cu}$ (up to $4 \mathrm{wt} . \%$ ) to $\mathrm{Al}-\mathrm{Si}$ alloys depressed this temperature to approximately $3.2^{\circ} \mathrm{C}$ per one weight percentage of $\mathrm{Cu}$. It is interesting to note that by a lower content of $\mathrm{Si}(5 \mathrm{wt} . \%)$ the depression is stronger $\left(\sim 4.0^{\circ}\right.$ $\mathrm{C} / 1 \mathrm{wt} . \% \mathrm{Cu})$ than by alloys with higher $\mathrm{Si}(9 \mathrm{wt} . \%)$ content $\left(2.5^{\circ} \mathrm{C} / 1 \mathrm{wt} . \%\right.$ of $\left.\mathrm{Cu}\right)$.

Finally, the $T_{\text {sol }}$ identifies the temperature at which the last portion of the liquid has been transformed into a solid. Below this temperature, the given alloy is stable in the solid phase. The results presented in Table 2 and Figure 3 indicate that various $\mathrm{Si}$ and $\mathrm{Cu}$ contents in investigated alloys have the lowest impact on solidus temperature. The average $T_{\text {sol }}$ determined using cooling curve analysis, for all investigated alloys, was approximately $500^{\circ} \mathrm{C}$.

The addition of $\mathrm{Si}$ and $\mathrm{Cu}$ into aluminum alloys considerably changes the solidification ranges of these alloys (the difference between $T_{\text {liq }}$ and $T_{\text {sol }}$ ). The Al-Si alloys free of $\mathrm{Cu}$, as Figure 3 illustrates, solidified in the temperature range between 80 and $50^{\circ} \mathrm{C}$ depending on the content of Si. The lower Si content corresponds to the wider solidification interval of these alloys and vice versa. Addition of $\mathrm{Cu}$ into Al-Si alloys, as Figure 3 shows, significantly increases their solidification intervals. By lowering the contents of $\mathrm{Si}$ (e.g., $5 \mathrm{wt} . \%)$ and $\mathrm{Cu}$ (e.g., $1 \mathrm{wt} . \%)$ this interval is approximately $130^{\circ} \mathrm{C}$, getting narrower $\left(\sim 90^{\circ} \mathrm{C}\right)$ by increasing the contents of $\mathrm{Si}$ (e.g., up to 9 wt.\%) and $\mathrm{Cu}$ (e.g., up to 4 wt.\%). It is well known that casting characteristics of $\mathrm{Al}-\mathrm{Si}-\mathrm{Cu}$ alloys are generally influenced upon adding $\mathrm{Cu}$. The $\mathrm{Cu}$ precipitate in the eutectic form during the last stage of solidification prolonging solidification interval of those alloys [31]. It is also well known from the foundry practice that alloys with wider solidification intervals are more prone to the formation of shrinkage porosity.

\subsection{Fraction solid analysis}

The term fraction solid is related to the amount of solid phase(s) formed during melt solidification between liquidus and solidus temperatures, expressed in percentage. Correct information regarding fraction solid is necessary to accomplish computer simulation of casting feed ability as well as to characterize the solidification process and make a prediction concerning the casting structure.

Various methods for determining the fraction solid of casting alloys are presented in the literature [30-38]. The most commonly used technique employs quantitative metallography. The image analysis system is used to measure the 
volume fraction of phases formed prior to quenching in a set of melt specimens obtained between the $T_{\text {liq }}$ and $T_{\text {sol }}$. This technique requires the use of small samples that have rapid cooling rates in order to preserve the structure present at a given temperature. Small test samples and rapid cooling rates minimize structural transformation during quenching and thus maximize the accuracy of this measurement procedure. Another approach for determining fraction solid makes use of the TA technique $[3,4,17,25,26,28-30,43-52]$. The amount of heat evolved from a solidifying test sample can be calculated as the integrated area between the first derivative curve and the zero line. The amount of heat is proportional to the fraction solid. Differential thermal analysis (DTA) and differential scanning calorimetry (DTC) have also been used for the determination of solid fraction. However, these techniques are not suitable for industrial applications because they require complicated and expensive instrumentation as well as rigid and precise test procedures that are only possible in a laboratory environment. The literature also suggests a number of models for the calculation of fraction solid (more details can be find in Table 3). Most of them are based on parameters derived from the fundamental analysis of the solidification process for simple alloy systems. Due to the highly complex nature of alloy solidification, many questionable assumptions (see Table 3, comments) have been made in these models.

The TA technique has been applied in this work to calculate the distribution of fraction solid between the $T_{\text {liq }}$ and $T_{\text {sol }}$ during solidification of investigated alloys.

\begin{tabular}{|c|c|c|c|}
\hline No & Type of models & Method & Comments \\
\hline 1. & $\begin{array}{l}f_{\mathrm{s}}=\frac{T_{\mathrm{liq}}-T}{T_{\mathrm{liq}}-T_{\mathrm{sol}}} \\
T_{\text {liq }} \text {-liquidus temperature, }{ }^{\circ} \mathrm{C} \\
T_{\text {sol }} \text {-solidus temperature, }{ }^{\circ} \mathrm{C} \\
T \text {-instantaneous temperature, }{ }^{\circ} \mathrm{C}\end{array}$ & LINEAR [30] & $\begin{array}{l}\text { Latent heat is assumed to vary } \\
\text { linearly between liquidus and } \\
\text { solidus temperatures. This } \\
\text { model has no theoretical basis } \\
\text { but is frequently used due to its } \\
\text { simplicity. }\end{array}$ \\
\hline 2. & $\begin{array}{l}f_{\mathrm{s}}=\frac{1}{1-k} \frac{T_{\mathrm{liq}}-T}{T_{\mathrm{m}}-T} \\
k=\frac{T_{\mathrm{m}}-T_{\mathrm{liq}}}{T_{\mathrm{m}}-T_{\mathrm{sol}}} \\
k \text {-distribution coefficient of binary alloys } \\
T_{\mathrm{m}}-\text { melting temperature of pure aluminum }\end{array}$ & $\begin{array}{l}\text { LEVER RULE } \\
{[30\}}\end{array}$ & $\begin{array}{l}\text { Solidification in this model is } \\
\text { assumed to progress very slowly } \\
\text { and the solid and liquid phases } \\
\text { coexist in equilibrium in the } \\
\text { mushy zone. }\end{array}$ \\
\hline 3. & $\begin{array}{l}T_{E, \mathrm{G}}^{\mathrm{AlSi}}<T<T_{\text {liq }} \\
f_{\mathrm{s}}=1-\left(\frac{T_{\mathrm{m}}-T}{T_{\mathrm{m}}-T_{\text {liq }}}\right)^{\frac{1}{k-1}} \\
T_{E, \mathrm{G}}^{\mathrm{AlISi}} ; f_{\mathrm{s}}=1\end{array}$ & SCHEIL’S [30] & $\begin{array}{l}\text { In this model, it is assumed that } \\
\text { no solute diffusion occurs in the } \\
\text { solid phase and also that the } \\
\text { liquid is perfectly } \\
\text { homogeneous. }\end{array}$ \\
\hline 4. & $\begin{array}{l}f_{\mathrm{s}}=1-\exp \left(-\frac{4}{3} \pi R^{3} N\right) \\
R \text {-average grain radius, } \mathrm{m} \\
N \text {-average grain density, } \mathrm{m}^{-3}\end{array}$ & $\begin{array}{l}\text { GRAIN } \\
\text { NUCLEATION } \\
{[32,37]}\end{array}$ & $\begin{array}{l}\text { The calculation of fraction solid } \\
\text { is based on the grain nucleation } \\
\text { law and on the assumption that } \\
\text { the shape of the grains is } \\
\text { spherical. }\end{array}$ \\
\hline 5. & $\begin{array}{l}f_{\mathrm{s}}=\frac{\int_{0}^{t}\left[\left(\frac{d T}{d t}\right)_{\mathrm{CC}}-\left(\frac{d T}{d t}\right)_{\mathrm{ZC}}\right] d t}{\int_{0}^{t s}\left[\left(\frac{d T}{d t}\right)_{\mathrm{CC}}-\left(\frac{d T}{d t}\right)_{\mathrm{ZC}}\right] d t}=\frac{c_{\mathrm{p}}}{L} \int_{0}^{t}\left[\left(\frac{d T}{d t}\right)_{\mathrm{CC}}-\left(\frac{d T}{d t}\right)_{\mathrm{ZC}}\right] d t \\
c_{\mathrm{P}} \text { - specific heat of an alloy } \\
L \text { - latent heat of solidification } \\
\frac{d T}{d t} \text { - cooling rate }\end{array}$ & $\begin{array}{l}\text { HEAT } \\
\text { BALANCE } \\
{[9,10,35,37]}\end{array}$ & $\begin{array}{l}\text { Fraction solid can be calculated } \\
\text { by determining the cumulative } \\
\text { area between the first derivative } \\
\text { of the cooling curve (cc), and } \\
\text { the "zero" cooling curve } \\
\text { (hypothetical cooling curve } \\
\text { without phase transformations) } \\
\text { (zc). }\end{array}$ \\
\hline
\end{tabular}

Table 3.

Review of models for calculation of fraction solid. 
There are two known methods in the literature, Newtonian [29, 30, 52] and Fourier, $[29,30,52]$ that have been successfully used to calculate fraction solid distribution using cooling curve analysis. In order to be capable of applying both methods, it is necessary to define the so-called baseline $[29,30,52]$. The baseline denotes the first derivative curve of the investigated alloy, assuming that melt during solidification process does not undergo any phase transformation. Therefore, it is to expect that base and first derivative curves are overlapping each other in the areas before liquidus (single liquid phase) and after solidus (single solid phase) temperatures. In this paper only the Newtonian method has been applied for calculating the base line using cooling curve analysis.

Table 4 and Figure 4 summarize the impact of various content of $\mathrm{Si}$ and $\mathrm{Cu}$ on the distribution of fraction solid at characteristic solidification temperatures $\left(T_{\text {liq }}\right.$, $T_{\mathrm{DCT}}, T_{\text {Rigidity }}$ and $\left.T_{\text {sol }}\right)$. For Cu free Al-Si alloys, as Table 4 and Figure 4 shows, an increase in the content of Si from 5 up to 9 wt.\% lowering the amount of fraction solid at DCT for $50 \%$, while the amount of fraction solid at $T_{\text {Rigidity }}$ is only for $5 \%$ lower by higher silicon content. Addition of $\mathrm{Cu}$ into Al-Si alloys drastically changes the distribution of the fraction solid at characteristic solidification temperatures. By increasing the content of $\mathrm{Cu}$ from $1 \mathrm{up}$ to $4 \mathrm{wt} . \%$, the fraction solid at $T_{\text {Rigidity }}$ decreased independently from the Si content to approximately $30 \%$ (from almost 90 to approximately 60\%). At the same time, the addition of $\mathrm{Cu}$ does not have such a significant impact on the amount of fraction solid precipitated at the DCP. At lower content of $\mathrm{Si}$, this impact is much stronger (fraction solid by adding $\mathrm{Cu}$ decreased to almost $10 \%$ ), while by a higher content of $\mathrm{Si}$, the impact is negligible (about 1\%). According to Table 4 and Figure 4, it appears that the alloy with a shorter solidification range (e.g., Al-9Si-4Cu (wt.\%)) achieves both Dendrite Coherency and Rigidity points at a lower fraction solid (12\% and 56\%, respectively) compared to the alloy with wider freezing range (e.g., Al-5Si-1Cu (wt.\%)) and consequently higher fraction solid values for these two points $(\sim 24 \%$ and $\sim 84 \%$, respectively).

From Figure 4, it is obvious that with the $\mathrm{Cu}$ free $\mathrm{Al}-\mathrm{Si}$ alloys, the interdendritic feeding region is dominantly independent of the content of $\mathrm{Si}$ in the investigated alloy. Increase in the Si content from 5 to 9 wt.\% decreased the amount of fraction solid at the DCT from approximately $27 \%$ up to $13 \%$. For the same increase of the $\mathrm{Si}$ content, the amount of fraction solid which precipitated at Rigidity point decreased from $94 \%$ to $89.5 \%$. This means that around $70 \%$ of fraction solid precipitated during solidification between Dendrite Coherency and Rigidity temperatures. At the same time, an increase in the content of silicon from 5 to $9 \mathrm{wt} \%$ decreases the amount of fraction solid by almost $50 \%$, which precipitated between $T_{\text {liq }}$ and $T_{\mathrm{DCT}}$. The burst feeding region is getting slightly wider by adding Si into aluminum alloys. Addition of $\mathrm{Cu}$ into these $\mathrm{Al}-\mathrm{Si}$ hypoeutectic alloys considerably changes the distribution of the fraction solid among feeding regions. The $\mathrm{Cu}$ significantly increases the presence of the burst feeding. With Al-5Si-5Cu (wt.\%) alloy, the amount of fraction solid formed between Rigidity and Solidus temperatures was about 15\%, while at Al-9Si-4Cu (wt.\%) that amount was above $40 \%$.

Simultaneously, the amount of fraction solid formed between $T_{\mathrm{DCP}}$ and $T_{\text {Rigidity }}$ was noticeably reduced from $60 \%$ by $\mathrm{Al}-5 \mathrm{Si}-1 \mathrm{Cu}$ (wt.\%) alloy up to $44 \%$ by $\mathrm{Al}-9 \mathrm{Si}-$ $4 \mathrm{Cu}$ (wt.\%) alloy. Generally, it can be noticed that the higher content of $\mathrm{Cu}$ significantly increases the existence of the burst feeding region, decreases the domain of interdendritic region and slightly reduces the mass feeding region. It is evident from Figure 3 that the various Si content significantly depressed the DCT, while its impact on $T_{\text {Rigidity }}$ could be neglected. Higher Si content decreased the solidification interval ( $\left.T_{\text {liq }}-T_{\text {sol }}\right)$ of those alloys, changing also their solidification mode. It is 
Quantification of Feeding Regions of Hypoeutectic Al-(5, 7, 9)Si-(o-4)Cu (wt.\%) Alloys Using... DOI: http://dx.doi.org/10.5772/intechopen.90337

\begin{tabular}{|c|c|c|c|c|}
\hline \multirow[t]{2}{*}{ Alloy } & \multicolumn{4}{|c|}{$F_{\mathrm{s}}$ at } \\
\hline & $T_{\text {liq }}$ & $T_{\mathrm{DCP}}$ & $T_{\text {Rigidity }}$ & $T_{\text {sol }}$ \\
\hline \multirow[t]{2}{*}{$\mathrm{Al}-5 \mathrm{Si}$} & 0 & 27.5 & 95.2 & 100 \\
\hline & & 24.6 & 93.1 & \\
\hline \multirow[t]{2}{*}{$\mathrm{Al}-5 \mathrm{Si}-1 \mathrm{Cu}$} & & 26.0 & 85.7 & \\
\hline & & 23.2 & 82.5 & \\
\hline \multirow[t]{2}{*}{$\mathrm{Al}-5 \mathrm{Si}-2 \mathrm{Cu}$} & & 24.0 & 79.7 & \\
\hline & & 21.3 & 76.7 & \\
\hline \multirow[t]{2}{*}{$\mathrm{Al}-5 \mathrm{Si}-3 \mathrm{Cu}$} & & 19.3 & 73.7 & \\
\hline & & 17.6 & 74.7 & \\
\hline \multirow[t]{2}{*}{$\mathrm{Al}-5 \mathrm{Si}-4 \mathrm{Cu}$} & & 15.4 & 65.3 & \\
\hline & & 16.5 & 68.7 & \\
\hline \multirow[t]{2}{*}{$\mathrm{Al}-7 \mathrm{Si}$} & & 17.8 & 91.9 & \\
\hline & & 17.5 & 91.2 & \\
\hline \multirow[t]{2}{*}{$\mathrm{Al}-7 \mathrm{Si}-1 \mathrm{Cu}$} & & 16.7 & 76.4 & \\
\hline & & 18.7 & 78.2 & \\
\hline \multirow[t]{2}{*}{$\mathrm{Al}-7 \mathrm{Si}-2 \mathrm{Cu}$} & & 14.7 & 65.6 & \\
\hline & & 14.5 & 66.7 & \\
\hline \multirow[t]{2}{*}{$\mathrm{Al}-7 \mathrm{Si}-3 \mathrm{Cu}$} & & 14.5 & 61.8 & \\
\hline & & 15.8 & 65.5 & \\
\hline \multirow[t]{2}{*}{$\mathrm{Al}-7 \mathrm{Si}-4 \mathrm{Cu}$} & & 13.9 & 56.4 & \\
\hline & & 14.1 & 55.4 & \\
\hline \multirow[t]{2}{*}{$\mathrm{Al}-9 \mathrm{Si}$} & & 14.1 & 89.1 & \\
\hline & & 12.3 & 90.2 & \\
\hline \multirow[t]{2}{*}{$\mathrm{Al}-9 \mathrm{Si}-1 \mathrm{Cu}$} & & 12.2 & 73.1 & \\
\hline & & 13.1 & 77.8 & \\
\hline \multirow[t]{2}{*}{$\mathrm{Al}-9 \mathrm{Si}-2 \mathrm{Cu}$} & & 12.3 & 65.8 & \\
\hline & & 12.8 & 63.1 & \\
\hline \multirow[t]{2}{*}{$\mathrm{Al}-9 \mathrm{Si}-3 \mathrm{Cu}$} & & 13.3 & 61.3 & \\
\hline & & 13.8 & 60.1 & \\
\hline \multirow[t]{2}{*}{$\mathrm{Al}-9 \mathrm{Si}-4 \mathrm{Cu}$} & & 12.6 & 56.0 & \\
\hline & & 12.3 & 57.1 & \\
\hline
\end{tabular}

Fraction solid values for the characteristic solidification temperatures have been collected for each analyzed alloy.

Table 4 .

Characteristic fraction solid values of $\mathrm{Al}-(5,7,9) \mathrm{Si}-(0-4) \mathrm{Cu}(w t . \%)$ alloys determined using cooling curve analysis.

evident that the alloying element may change feeding ranges ability by shifting the alloy characteristic solidification temperatures. This may cause either a widening or narrowing of the corresponding feeding ranges of the alloy. The $\mathrm{Cu}$ has an impact on both dendrite coherency and $T_{\text {Rigidity, }}$, as shown in Table 2, by depressing them to lower values. It is also well known that copper increases the solidification interval of $\mathrm{Al}-\mathrm{Si}$ alloys. It can be seen from Figure 4 that increase in the content of $\mathrm{Si}$ 

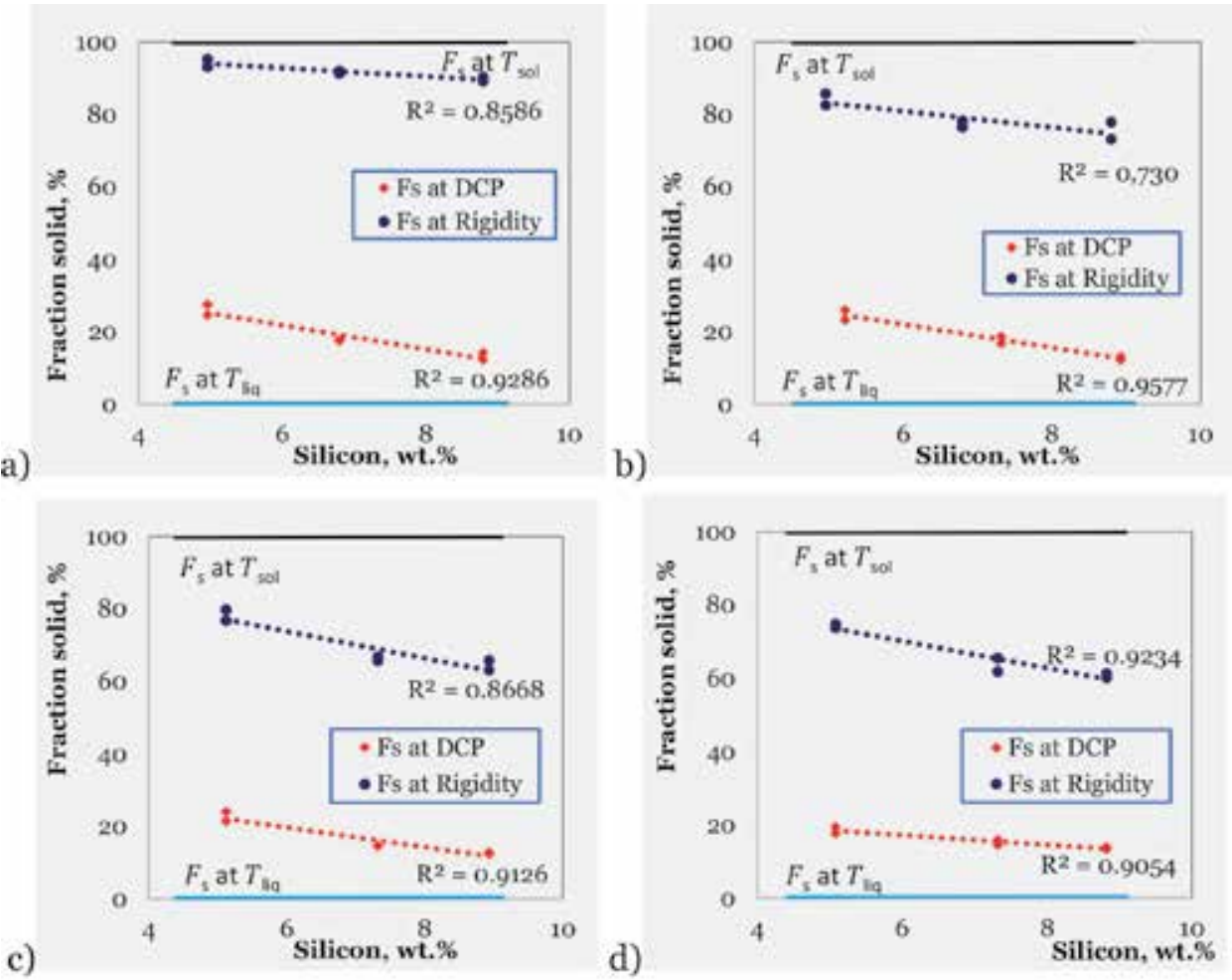

b)
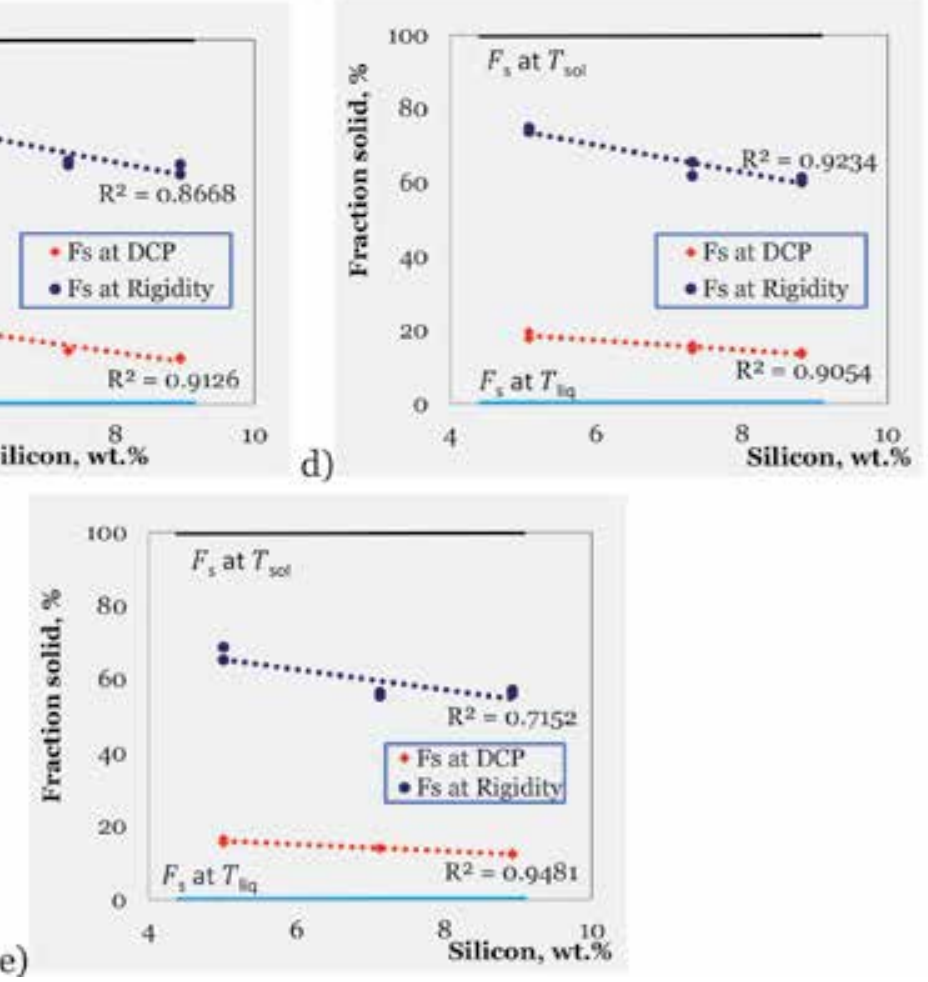

Figure 4.

The impact of Si on the fraction solid: (a) Al-(5, 7, 9) Si-oCu (wt\%), (b) $\mathrm{Al}-(5,7,9) \mathrm{Si}-1 \mathrm{Cu}$ (wt\%), (c) $\mathrm{Al}-(5,7,9) \mathrm{Si}-2 \mathrm{Cu}(w t \%),(d) \mathrm{Al}-(5,7,9) \mathrm{Si}-3 \mathrm{Cu}(w t \%)$ and $(e) \mathrm{Al}-(5,7,9) \mathrm{Si}-4 \mathrm{Cu}$ (wt\%) alloys at the characteristic solidification temperatures.

(from 5 to 9 wt.\%) and $\mathrm{Cu}$ (from 0 to 4 wt.\%) significantly dropped down the

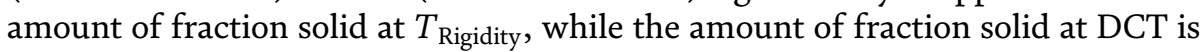
slightly reduced. Besides chemical compositions, it is well known that other parameters have also been identified to affect the feeding capability of aluminum alloys [35-43]. Among these are melt superheat, temperature gradients during solidification, the influence of chemical composition, eutectic modification, grain refinement and hydrogen solubility. All these factors need to be taken into consideration in order to be able to properly answer which feeding region is more significant for the formation of cast defects. The correct answer could only be achieved if additional experimental techniques were introduced, such as the Tatur test sample, the measurement of the collecting temperature and the Hubler test sample, in addition to the thermal analysis. This paper has shown that applying cooling curve analysis to 
all five feeding regions proposed by Campbell can be accurately quantified by either the temperature or corresponding fraction solid precipitated at those temperatures.

\section{Conclusion}

In the available literature, information related to a quantitative description of the five feeding mechanisms proposed by Campbell is limited. In this paper, the impact of the main alloying elements $\mathrm{Si}$ and $\mathrm{Cu}$ on different feeding regions of hypoeutectic Al-Si-Cu cast alloys has been studied using the TA technique. It has been shown that both elements have a significant impact on the characteristic solidification temperatures as well as on the amount of fraction solid precipitated at given temperatures. This work has also shown that TA is a valuable tool widely used in aluminum foundries that can collect numerous parameters (characteristic solidification temperatures, fraction solid distribution and others), which are beneficial for a better understanding of the solidification path of hypoeutectic Al-Si-Cu alloys. Applying TA technique as presented in this paper, it is now possible to describe each feeding region quantitatively through a temperature difference related to the total solidification interval or through a different amount of fraction solid that precipitated in each region. It can be assumed that calculated fraction solid at the DCT and fraction solid at $T_{\text {Rigidity }}$ together with corresponding characteristic solidification temperatures are useful parameters for performing computer simulations of casting feed ability and for the characterization of the solidification process of cast $\mathrm{Al}-\mathrm{Si}-\mathrm{Cu}$ alloys.

\section{Acknowledgements}

Publication of the manuscript is funded by the Lola Institute Ltd. (www.li.rs).

\section{Conflict of interest}

All authors declare that they have no conflict of interest in this research.

\section{Author details}

Gerhard Huber $^{1}$, Mile B. Djurdjevic ${ }^{1}$ and Srećko Manasijević ${ }^{2 *}$

1 Nemak Linz GmbH, Linz, Austria

2 Lola Institute Ltd, Belgrade, Serbia

*Address all correspondence to: srecko.manasijevic@li.rs

\section{IntechOpen}

(C) 2019 The Author(s). Licensee IntechOpen. This chapter is distributed under the terms of the Creative Commons Attribution License (http://creativecommons.org/licenses/ by/3.0), which permits unrestricted use, distribution, and reproduction in any medium, provided the original work is properly cited. (c) BY 


\section{References}

[1] Mondolfo LF. Aluminum Alloys, Structure and Properties. London: Butterworths; 1979. pp. 213-614

[2] Crossley PB, Mondolf LF. Modern Casting. 1966;49:53-64

[3] Bäckerud L, Chai G, Tamminen J. AFS/Skanaliminium. 1986;2:95

[4] Arnberg L, Backerud L. Solidification Characteristics of Aluminum Alloys, Vol. 3: AFS. Illinois USA: Des Plaines; 1996

[5] Djurdjevic BM, Manasijevic S. Impact of alloying elements on the solidification parameters of cast hypoeutectic AlSi6Cu (1-4) and AlSi8Cu (1-4) alloys. Journal of Metallurgical and Materials

Engineering. 2014;20(4):235-246

[6] Huber G, Djurdjevic BM. Impact of silicon, magnesium and strontium on feeding ability of AlSiMg cast alloys. In: THERMEC; ; 29.05-03.06. 2016, Graz, Austria. 2016. p. 249

[7] Djurdjevic BM, Manasijevic S, Odanovic Z, Radisa R. Influence of different contents of silicon and copper on the solidification pathways of cast hypoeutectic AlSi(5-9 wt.\%) Cu(1-4 wt. $\%)$ alloys. International Journal of Materials Research. 2013;104(9):865-873

[8] Djurdjevic BM, Huber G.

Determination of rigidity point/ temperature using thermal analysis method and mechanical technique. Journal of Alloys and Compounds. 2014; 590:500-506

[9] Djurdjevic BM, Odanovic Z, Zak H. Detection of dendrite coherency temperature by aluminum alloys using single thermocouple technique. Praktische Metallographie. 2012;49(2):86-98

[10] Vicario I, Villanueva E, Djurdjevic BM, Huber G. Determination of dendrite coherency point characteristics using two new methods. Journal of Applied Sciences. 2018;8:1-14

[11] Campbell J. AFS Cast Metal

Research Journal. 1969;5(1):1-8

[12] Djurdjevic MB, Huber G. Journal of Alloys and Compounds. 2014;590: 500-508

[13] Huber G, Djurdjevic MB. Erweiterte Thermoanalyse mit Dendrite Coherency und Rigidity Punkt und deren mögliche neue Anwendungsgebiete. Giesserei Rundschau. Heft. 2014;7(8):223-234

[14] Djurdjevic BM, Manasijević S, Dirnberger F. Macroscopic characterization of aluminum cast alloys using cooling curve analysis. LivarstvoFoundry. 2013;52(2):2-11

[15] Djurdjevic BM, Vicario I, Huber G. Review of the thermal analysis application in aluminum casting plants. Revista de Metalurgia. 2014;50:1-12

[16] Huber G, Djurdjevic BM. Benefit of cooling curve analysis for simulation of aluminum casting process. In:

Proceedings of MSE Congress: 25-27 September 2012, Darmstadt, Germany. 2012. pp. 1-12

[17] Djurdjevic BM, Odanovic Z, Talijan N. Characterization of the solidification path of $\mathrm{AlSi} 5 \mathrm{Cu}(1-4$ wt.\%) alloys using cooling curves analysis. Journal of Metals. 2011;63(11):51-57

[18] Huber G, Djurdjevic BM, Odanovic Z. Synergy between thermal analysis and simulation. Journal of Thermal Analysis and Calorimetry. 2013;111:1365-1373

[19] Djurdjevic BM, Manasijević S. Primena termičke analize u livnicama aluminijuma. Livarstvo-Foundry. 2013; 52(1):28-36 
[20] Cibula A. Journal of the Institute of Metals. 1949;76:321-360

[21] Krohn BR. Modern Casting. $1985 ; 75: 21$

[22] Gruzleski JE, Closset BM. The Treatment of Liquid Aluminum-Silicon Alloys. Des Plaines, Illinois, USA: AFS; 1990

[23] Tenekedjiev N, Mulazimoglu H, Closset B, Gruzleski J. Microstructures and Thermal Analysis of StrontiumTreated Aluminum-Silicon Alloys. Des Plaines, Illinois, USA: AFS; 1995. pp. 40-41

[24] Ananthanarayanan L, Gruzleski JE. AFS Transactions. 1992;141:383-391

[25] Sparkman DA. AFS Transactions. 2011;1199:1-8

[26] Upadhya KG, Stefanescu DM, Lieu K, Yeager DP. AFS Transactions. 1989;47:61-66

[27] Apelian B, Sigworth GR, Wahler KR. AFS Transactions. 1984;161: 297-307

[28] Djurdjevic MB, Kasprzak W, Kierkus CA, Kierkus WT, Sokolowski JH. Quantification of cu enriched phases in synthetic $3 \mathrm{xx}$ aluminum alloys using the thermal analysis technique. AFS Transactions. 2001;24:1-8

[29] Fras E, Kapturkiewicz W, Burbielko A, Lopez HF. AFS. 1993;101: 505-511

[30] Kierkus WT, Sokolowski JH. AFS Transactions. 1999;66:161-167

[31] Cáceres CH, Djurdjevic MB, Stockwell TJ, Sokolowski JH. Scripta Materialia. 1999;40(5):631-637

[32] Cho JI, Jeong CY, Kim YC, Choi SW, Kang CS. The effect of $\mathrm{Cu}$ on feeding characteristics of aluminum casting alloys. In: Proceedings of the 12th International Conference on Aluminium Alloys. September 5-9, Yokohama, Japan, Japan Institute of Light Metals. 2010. pp. $745-750$

[33] Chai G. Dendrite coherency during equiaxed solidification in aluminum alloys. In: Chemical Communications., No. 1. Stockholm University: Stockholm, Sweden. p. 1994

[34] Chai G, Bäckerud L, Rolland T, Arnberg L. Metallurgical and Materials Transactions A: Physical Metallurgy and Materials Science. 1995;26A:965-970

[35] Claxton R. Journal of Metals. 1975; 27(2):14-16

[36] Arnberg L, Chai G, Bäckerud L. Materials Science and Engineering A. 1993;173:101-103

[37] Veldman N, Dahle A, John D. St: Determination of dendrite coherency point. In: Proceedings of the Die Casting \& Tooling Technology Conference; 22-25 June, Melbourne, Australia. 1997

[38] Tamminen J. Thermal analysis for investigation of solidification mechanisms in metals and alloys. In: Chemical Communications. Vol. 2. Stockholm, Sweden: Stockholm University; 1988

[39] Jiang H, Kierkus WT, Sokolowski JH. Dendrite coherency point determination using thermal analysis and rheological measurements. In: Proceedings of TPPM '99, The International Conference on Thermophysical Properties of Materials, 17-19 November 1999, Singapore. 1999

[40] Zamarripa RC, Ramos-Salas JA, Talamantes-Silva J, Valtierra S, Colas R. Metallurgical and Materials Transactions A: Physical Metallurgy and Materials Science. 2007;38A:1875-1879

[41] Djurdjevic MB, Byczynski G. The impact of chemistry on the dendrite 
coherency point of the $3 \mathrm{XX}$ series of $\mathrm{Al}$ alloys. In: Proceedings of ICAA_11; vol. 1. September, Aachen, Germany. 2008.

pp. 1-12

[42] Arnberg L, Dahle A, Paradies C, Syvertsen F. AFS Transactions. 1995;115: 753-759

[43] Flemings MC. Solidification Processing. New York: McGraw-Hill Inc.; 1974. pp. 60-166

[44] Ohta S, Asai K. Transactions of the Japan Welding Society. 1993;24(2): 131-139

[45] Saunders N. Materials Science Forum. 1996;217(2):667-672

[46] Chen JH, Tsai HL. AFS

Transactions. 1990;98:539-546

[47] Kantekar CS, Stefanescu DM. AFS Transactions. 1988;60:591-598

[48] Huang H, Suri VK, Hill JL, Berry JT. AFS Transactions. 1991;54:685-689

[49] Rapaz M. International Materials Reviews. 1989;34(3):93-123

[50] Stefanescu DM, Upadhya G, Bandyopaadhyay D. Metallurgical and Materials Transactions A: Physical Metallurgy and Materials Science. 1990; 2:997-1005

[51] Jeng S, Chai S. Materials Science Forum. 1996;217:283-288

[52] Emadi D, Whiting L, Djurdjevic MB, Kierkus W, Sokolowski J. Metallurgical and Materials Engineering. 2004;10:91-106 
Section 2

\section{Advanced Production Systems}





\title{
A Methodology to Design and Balance Multiple Cell Manufacturing Systems
}

\author{
Luis Valdivia and Pedro Palominos
}

\begin{abstract}
Manufacturing cell formation and its balance in just-in-time (JIT) type production environments have usually been studied separately in the literature. This practice is unrealistic since both problems interact and affect each other when the cells are operating. This chapter proposes a methodology to design multiple manufacturing cells and simultaneously balance their workload. The cells considered are U-shaped and process mixed models of product families. A nonlinear integer programming mathematical model is proposed, which integrates cell formation and their balancing, considering various production factors. For illustration, the method is applied to the redesign of a rack manufacturing process.
\end{abstract}

Keywords: manufacturing cells, assembly line balancing, N U-lines, mathematical programming, mixed model production

\section{Introduction}

Group technology (GT) can be defined as a manufacturing philosophy identifying similar parts and grouping them together to take advantage of their similarities in manufacturing and design $[1,2]$. Cellular manufacturing (CM) is an application of GT and has emerged as a promising alternative manufacturing system [3]. When a productive system is changed to make it cellular, it implies solving the manufacturing cell formation problem (MCFP), which means identifying groups of machines and associating them with product families so that the intercellular traffic that the products can have within the productive system is minimized. This problem has been approached historically by analyzing the machine-product incidence matrix (A), where each row represents a machine and each column represents a product, with each element $a_{i j}$ equal to one if machine i processes product $j$, and equal to zero otherwise. When this matrix is partitioned arbitrarily, it is usual to have products that remain outside the diagonal blocks (cells), which are called exceptional elements, since they carry out intercellular movements. Papaioannou and Wilson [3] reviewed the approaches between 1997 and 2008 to solve the above problem, proposing taxonomy based on the solution methodologies. It must be kept in mind that the latter approaches have started taking into account production factors other than the incidence matrix, like processing time, demanded production volumes, and operation sequences. Most recent works [4-7] are oriented mainly to the heuristic and metaheuristic approach to solve the problem, without considering 
other factors that appear when there are exceptional products that carry out intercellular movements, implying that these different production cells are linked with one another due to the precedence restrictions of these exceptional products, without considering their cost and work under way. This means that in most real cases, it is not possible to analyze the manufacturing cells independently at the time of attempting to balance the load of their work stations, and furthermore, since those cells would be related with families of products, it is therefore possible to introduce the balancing concept of multiple manufacturing cells for mixed models. This happens because cellular manufacturing is commonly used in JIT-type productive systems, in which setup times can be reduced in such a way that each cell works by operating over a family of mixed product models. These cells can also be configured in $U$ shape to use the advantages generated by this configuration. An approach to the above situation is the work of Kumar et al. [8], who propose implementing heuristic cell formation, having the capability to handle production data, operation sequence, production volume, and inter-cell cost simultaneously, taking up some of the previously described elements.

On the other hand, the problem of balancing N U-shaped lines has been studied mainly by Sparling [9] and Miltenburg [10], both of whom considered that all the cells operate with a common cycle time (C), but they assume that each cell is independent of the rest and furthermore process a single product. The problem of balancing U-shaped lines for mixed product models (denoted by MiMULBP) was proposed for the first time by Sparling and Miltenburg [11], who used the classical combined precedence graph proposed by Thomopoulos [12] and considered as cycle time (C) the quotient of the time period (T) and the total product demand (D). These authors focused only on the problem of balancing a single cell, making in the appendix the observation that it is possible to consider systems with multiple manufacturing cells, although once again they considered that those cells are independent of one another. More recently, in $[13,14]$, new heuristics are introduced to solve the problem, and Turkay [15] proposes models of integer linear programming (MILP) considering restrictions that express the precedence of the tasks.

A very recent work [16] proposes a novel configuration of assembly lines, namely parallel adjacent U-shaped assembly lines (PAUL), but none of the revised works integrate the balancing of U-lines with the design of the manufacturing cell. In the present chapter, what is being sought is to integrate these problems, proposing a methodology that delivers cells more applicable to reality, thereby introducing the problem of the formation and balancing of $\mathrm{N}$ in $\mathrm{U}$-shaped cells for mixed models (denoting it by N-MiMUCFBP). The rest of this chapter is organized as follows: Section 2 introduces a methodology based on a mathematical model for the N-MiMUCFBP; Section 3 illustrates the proposed methodology using a real case, showing its results; and Section 4 gives the conclusions of the study.

\section{Methodology}

The proposed methodology is based on formulating a new model for the problem of balanced formation of production cells. From the viewpoint of formation of the cells, the model must consider the aspects associated with their design, such as processing and preparation of machines, inefficiencies in the handling of materials or inventories of products being processed, and cell imbalance [17], which includes processing times, sequences, and production volumes, directly related with the mixed model assembly line balancing problem (MiMALBP). Because of this, and in agreement with the heuristic proposed by [12] for the MiMALBP, first it is necessary to group the precedence graphs of each final product in a single combined 

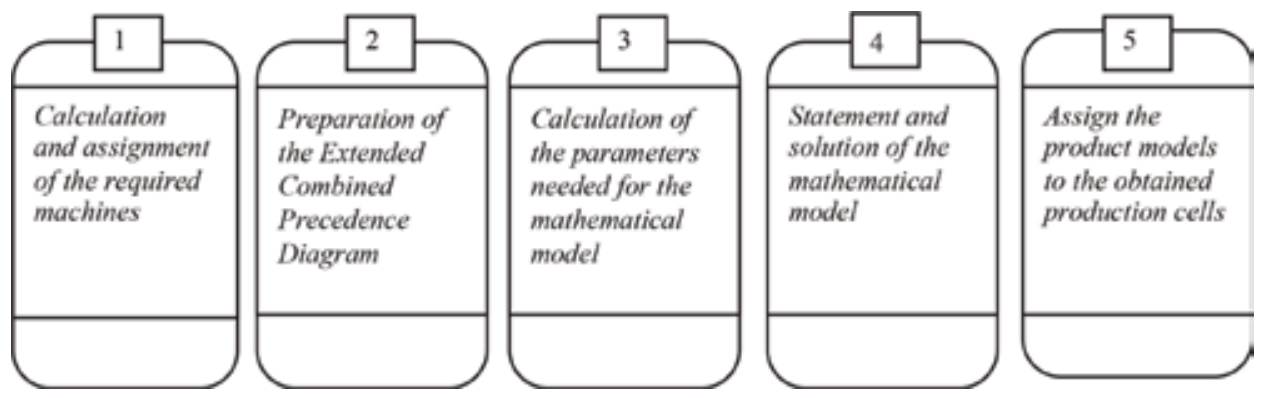

Figure 1.

Stages in the methodology proposed for the N-MiMUCFBP problem.

precedence diagram. This is possible, because in this type of mixed model assembly lines, the products that are processed in each cell have only small differences in processing times or in the elimination or addition of activities but always keeping the consistency among the precedence of these activities for the different product models. Therefore, the idea is for each manufacturing cell to process a family of products. In turn, using this combined precedence diagram will allow reducing the number of variables at the time of tackling the model for the formation of manufacturing cells. The methodology proposed for the N-MiMUCFBP problem considers five consecutive stages that are presented in Figure 1.

\subsection{Calculation and assignment of the required machines}

First it is necessary to determine the number of machines, $q_{m}$, required per type of machine $m$. This number is obtained from (Eq. (1)).

$$
q_{m} \geq\left|\frac{\sum_{j=1}^{n} d_{j} t_{m j}}{C A P_{m}}\right|
$$

where $q_{m}$, number of machines of type $m ; j$ product number; $d_{j}$ production volume demanded of each product $j$ within the planning horizon (in units); $t_{m j}$ unit processing time for product $j$ that is processed in a type $m$ machine (in hours per unit produced); $C A P_{m}$ capacity of each type of machine $m$ within the planning horizon (in available machine hours).

It should be noted that when a machine of a certain type can work simultaneously on a product together with another machine of the same type and $q_{m}>1$, the machines will operate as a single "virtual machine," i.e., that $q_{m}$ machines of type $m$ (denoted by $i=m$ ) will work simultaneously in it and that the unit processing time of each of these machines will be $t_{i j}=t_{m j} / q_{m}$, provided that the products processed on that virtual machine are similar to each other. On the other hand, for that type of machine in which $q_{m}>1$ and which furthermore can operate simultaneously on a product together with another machine of its same type, it is necessary to assign first which products will be processed on each machine of type $m$. For that purpose, let us use the following notation:

- $C A P_{i}^{U s e f u l}=$ capacity used by machine $i$.

- $C A P_{m}^{L e v e l}=\frac{\sum_{j=1}^{n} d_{j} \cdot t_{m j}}{q_{m}}=$ leveled reference capacity used by $q_{m}$ machines of type $m$. 
- $w_{m j}=$ workload to be assigned of model of product $j$ on the type of machine $m$.

- $d_{j}^{(i)}=$ fraction assigned to machine $i$ of the demand for product $j$.

- $B_{m}=$ arrangement that contains the models of products similar to each other processed on type $m$ machine, arranged in decreasing order according to $w_{m j}$.

- $t_{i j}=$ Unit processing time on machine $i$ due to product $j$.

$$
M=M^{\text {pop }}
$$

- FFOR each type of machine $m$ do:

IF qm = 1 THEM:

Assign a machine to type $m$, denoting it by $i=m ; t_{g}=t_{m j} \wedge d_{j}^{(i)}=1 \forall j$ produced in $m$

\};

$-\left\{\right.$ IF $q_{m}>1$ AND type $m$ machines can work simultaneously THEN:

Assign a virtual machine to type $m$, denoting it by $i=m$; do $t_{i j}=t_{m j} / q_{m} \wedge d_{j}^{(i)}=1 \forall J$ produced in $m\}$;

4:

\{ IF $q_{m}>1$ AND the type $m$ machines cannot work simultaneously THEN:

Assign $q_{m}$ machines to type $m$, denoted by $i=m, M+1, \ldots, M+q_{m}-1$ and do $t_{i y}=t_{m y} \forall i$ of type $m$ and $\forall j$ produced on a type $m$ machine;

$w_{m j}=d_{j} \cdot t_{m j} \quad \forall j$ produced on a type $m$ machine;

Determine $C A P_{m}^{\text {Level }}$ and $B_{\mathrm{si}} ; \quad p=1$;

- FOR $i=m, M+1, \ldots, M+q_{m}-1$ do:

$C A P_{i}^{\text {Urofu }}=0$;

$\Gamma^{\text {WWHILE } C A P_{i}^{\text {lisefid }}<C A P_{\text {m }}^{\text {Levd }} \text { do: }}$

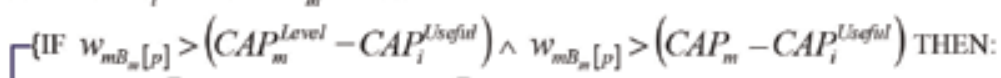

Assign $\left\lceil\frac{C A P_{m}^{\text {lewi }}-C A P_{i}^{\text {lisefi }}}{t_{m j}}\right\rceil$ units of product $B_{m}[p]$ to machine $i$;

$d_{B_{m}[p]}^{(i)}=\frac{1}{d_{j}}\left\lceil\frac{C A P_{w}^{\text {level }}-C A P_{i}^{\text {liseful }}}{t_{m j}}\right\rceil ;$

$w_{m B_{m}[p]}=w_{m B_{m}[p]}-t_{m j}\left\lceil\frac{C A P_{m}^{\text {Level }}-C A P_{i}^{\text {Uscoful }}}{t_{m j}}\right\rceil ;$

$C A P_{i}^{\text {thit }}=C A P_{i}^{\text {tind }}+t_{\text {m }}\left\lceil\frac{C A P_{\text {m }}^{\text {Lewel }}-C A P_{i}^{\text {tiseful }}}{t_{\text {m }}}\right\rceil$;

OTHERWISE do:

$$
\begin{aligned}
& \text { Assign }\left\lceil\frac{w_{m B_{m}}[p]}{t_{m j}}\right\rceil \text { units of product } B_{m}[p] \text { to machine } i \\
& d_{B_{m}[p]}^{(i)}=\frac{1}{d_{j}}\left\lceil\frac{w_{m B_{m}[p]}}{t_{m j}}\right] ; \quad C A P_{i}^{U \text { ssoful }}=C A P_{i}^{L \text { sefiul }}+w_{m B_{m}[p]} ; \quad p=p+1 ;
\end{aligned}
$$

;

$M=M+q_{m}-1$

\};

Figure 2.

Procedure for assigning products to machines. 
Then the following procedure, shown in Figure 2, is proposed as a formal assignment rule.

In particular, when $q_{m}>1$ and the type $m$ machines cannot work simultaneously, the above procedure aims to assign similar products to each of the $q_{m}$ machines, so that they have a workload as close as possible to the leveled load for that type, and it also attempts to have the demand for each product as little fractionated as possible, so that each product is assigned to a single machine when it has sufficient capacity.

This procedure is followed in order to not incorporate directly in the mathematical model the alternative processes and routes, because in this way its complexity and number of variables are reduced. Special care must be taken when assigning similar products (with respect to their precedence relations) to the different machines, to minimize probable intercellular motions.

\subsection{Preparation of the extended combined precedence diagram}

With the machines required to satisfy the capacity restrictions, and the assignment of each product to them, an extended combined precedence diagram called GUG' must be created, and the weighted average processing times for each machine must be calculated. The process for preparing this diagram will be described now by combining the precedence diagrams of each model in a single precedence diagram where the nodes represent the operations and the arcs represent the precedence restrictions between the operations. A formal description of the combination of $n$ product models in a combined precedence diagram was made by Macaskill [18]. This procedure, adapted to our problem, is summarized as follows: Represent the precedence diagram of product model $j$ by means of the graph $G_{j}=\left(V_{j}, E_{j}, t_{j}\right)$, where the set of nodes $V_{j}$ represents the set of tasks of product model $j$, the set of arcs $E_{j}$ represents the precedence relations $(a, b)$ between tasks $a, b \in V_{j}$, and the weighting vector $t_{j}$ contains the processing times $t_{i j}$ of task $i \in V_{j}$.

As an example, in Figure 3 the precedence diagrams for six models are represented, remarking the virtual machines in which more than one machine operate simultaneously on the products.

Furthermore, by specifying the demanded volumes of each product model within the planning horizon $\left(d_{j}\right)$, it is possible to determine the demand fractions $d f^{\prime}{ }_{j}$ of each model $j$ with respect to the total demand $D$ of the product mix, where $0 \leq d f^{\prime}{ }_{j} \leq 1$ is fulfilled, and they are calculated by the following equation (Eq. (2)):

$$
d f_{j}=\frac{d_{j}}{D}=\frac{d_{j}}{\sum_{j=1}^{n} d_{j}}
$$

Therefore, the combined precedence diagram can be represented by the graph $G=(V, E, \bar{t})$, which is derived from the following definitions (Eqs. (3)-(5)):

$$
\begin{gathered}
V=\bigcup_{j=1}^{n} V_{j} \\
\bar{t}_{i}=\sum_{j=1}^{n} d f_{j} \cdot\left(d_{j}^{(i)} \cdot t_{i j}\right) \forall i \in V \\
E=\bigcup_{j=1}^{n} E_{j} \backslash\{\text { redundant arcs }\}
\end{gathered}
$$

As a prerequisite for the generation of the combined set of nodes $V$ in Eq. (3), the tasks that are common to different models, even though they have different processing times, receive a consistent number of nodes for all the models. This 
prevents assigning these tasks to different stations, which otherwise would need multiple investments in the resources required at each station in which a duplicate task has been assigned. Tasks that are not required by a product model receive a processing time (weight of the node) equal to zero, so the average processing times $\bar{t}_{i}$ can be calculated simply by weighting every specific task fractionated time according to model $d_{j}^{(i)} \cdot t_{i j}$ with its corresponding demand portion $d f_{j}^{\prime}$ of the model in Eqs. (4) and (5), which determines the combined precedence restrictions by joining the arc sets of each model. This can lead to redundant arcs $(a, b)$, which represent the transitive precedence relations. An arc is redundant and can therefore be deleted without loss of information, if there is another way from node $a$ to node $b$ by means of more than one arc.

The combined precedence diagram for the example is shown in Figure 4. Note that the redundant arcs are denoted by dotted lines.

A particular action should be considered if there is no consistency among the precedence of the activities, i.e., if there are conflictive precedence relations between different models that lead to a cyclic (that repeats itself over and over) combined precedence graph. To allow a single sequence of task operations, those
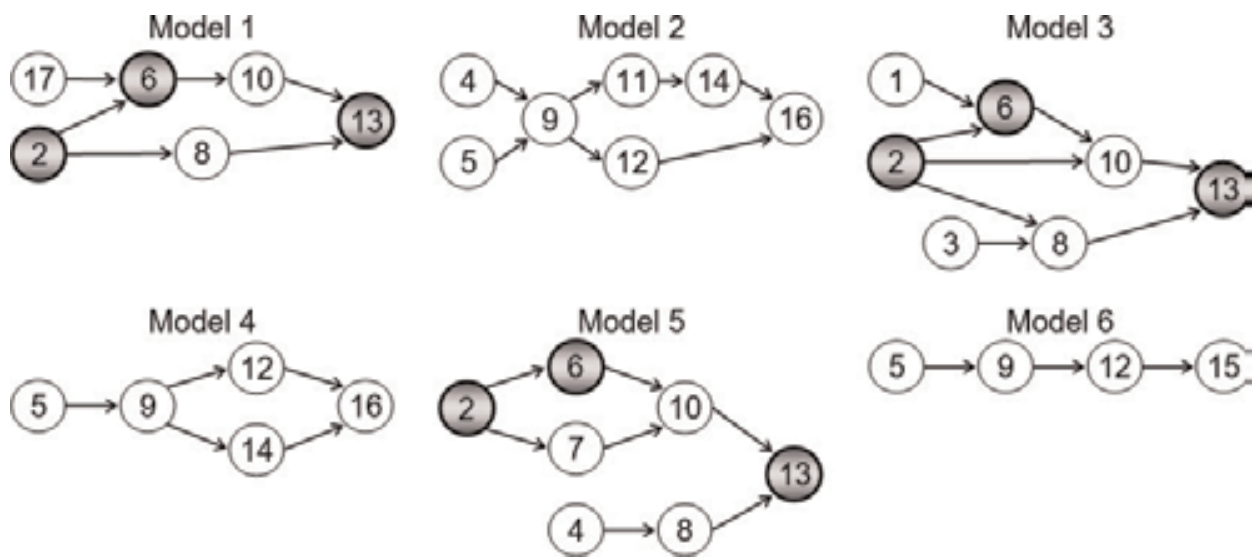

Figure 3.

Precedence diagrams for six product models.

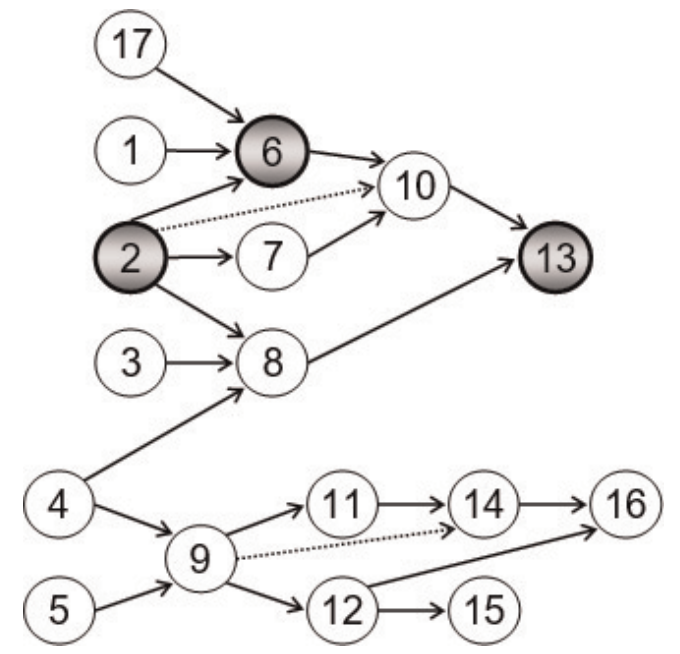

Figure 4 .

Combined precedence diagram for the example. 


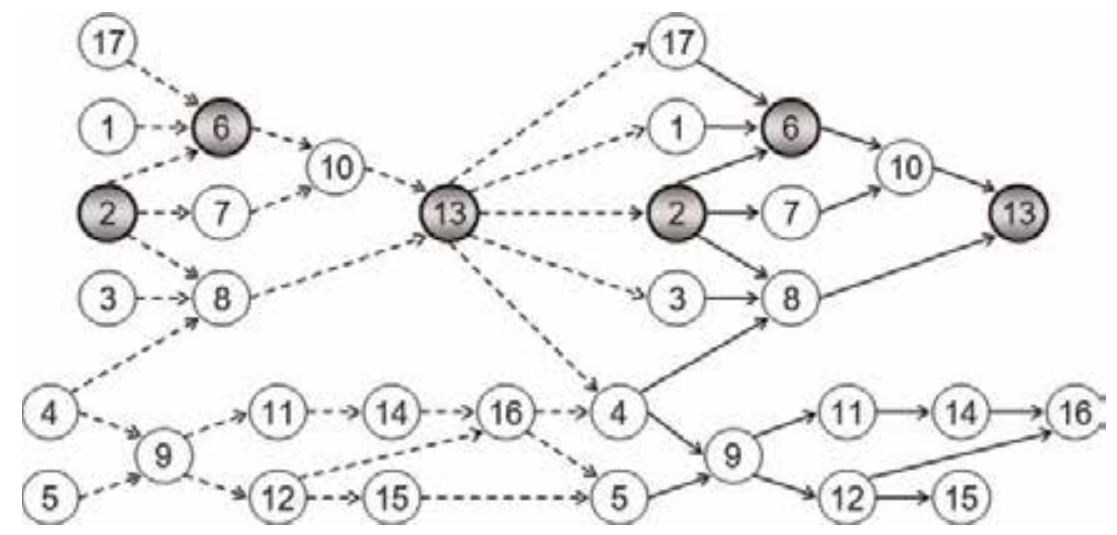

Figure 5 .

Diagram of extended combined precedence.

loops must be deleted by means of one of the following actions proposed by Ahmadi and Wurgaft [19]:

- The models must be separated into subsets so that two or more acyclic precedence graphs can be formed. In practice, this leads to machine preparation operations that must be performed every time the production changes from one subset of models to another.

- With the purpose of assigning the tasks to a single station, the loops in the precedence graphs can be deleted duplicating these nodes. To minimize the number of duplicate nodes and, in this way, reduce the danger of assigning equal tasks to different stations, an optimization problem must be solved [19].

To model what is related to the problem of balancing the $N$ U-shaped lines, we will consider the concepts developed by Urban [20] to formulate the problem mathematically. For this we set up an auxiliary graph, connecting it with the original combined precedence graph. This is illustrated in Figure 5, denoting with dotted lines the auxiliary combined precedence graphs. If we start in the middle of this extended graph, it is possible to perform assignments to stations forward through the original graph, backward through the auxiliary graph, or simultaneously in both directions, and in this way, it is possible to create stations that have machines at the beginning and at the end of the " $U$ " line. Special care must be taken when joining the auxiliary precedence diagram with the original. For example, final task 15 is joined only with initial task 5 , because task 15 is finished only from task 5 for model 6 (see Figure 3).

\subsection{Calculation of the parameters needed for the mathematical model}

From the input information and the extended combined precedence diagram produced in the previous point, we must calculate the total costs for intercellular transport between machines $i$ and $i$ ' $\left(c_{i i}\right)$, which are determined by means of Eq. (6):

$$
c_{i i^{\prime}}=\sum_{j=1}^{n} c o_{j} \cdot e_{i i^{\prime} j} \cdot d_{j} \cdot\left(\frac{d_{j}^{(i)}+d_{j}^{(i \prime)}}{2}\right) \cdot a_{i j} \cdot a_{i^{\prime} j}
$$


where

$c_{i i}$ ' = cost of intercellular transport between machines i and i' (within the

planning horizon).

$\mathrm{Co}_{\mathrm{j}}=$ intercellular transport cost of product $\mathrm{j}$.

$e_{i i^{\prime}}= \begin{cases}1 & \text { if machines } i \text { and } i^{\prime} \text { are directly or indirectly related to the GOUGA graph } \\ 0 & \text { otherwise }\end{cases}$

$a_{i j}= \begin{cases}1 & \text { if machine } i \text { processes product } j \\ 0 & \text { otherwise }\end{cases}$

$a_{i^{\prime} j}= \begin{cases}1 & \text { if machine } i^{\prime} \text { processes product } j \\ 0 & \text { otherwise }\end{cases}$

$d_{j}=$ production volume demanded by product model $j$.

$d_{j}^{(i)}=$ fraction assigned to machine $i$ of the demand for product $j$.

$d_{j}^{\left(i^{\prime}\right)}=$ fraction assigned to machine $i^{\prime}$ of the demand for product $j$.

Other parameters to be used in the model, some of which must be calculated, are the following:

$\mathrm{cs}=$ unit cost per work station (within the planning horizon).

$\mathrm{V}=$ set of machines of the combined precedence diagram, $V=\bigcup_{j=1}^{n} V_{j}$.

$\mathrm{E}=$ set of precedence relations between the machines that belong to $\mathrm{V}$,

$E=\{1, \ldots, e, \ldots,|E|\}$. For example, $\mathrm{e}=(\mathrm{a}, \mathrm{b})$ is the ordered pair that indicates that machine a precedes machine $\mathrm{b}$ immediately,

$$
E=\bigcup_{j=1}^{n} E_{j} \backslash\{\text { redundant arcs }\} .
$$

$\mathrm{T}=$ period of time available for planning.

$t_{i j}=$ processing time on machine $\mathrm{i}$ of product model $\mathrm{j}$.

$\mathrm{d}_{\mathrm{j}}=$ production volume demanded by product model $\mathrm{j}$.

$\mathrm{D}=$ total demand for the product models, $D=\sum_{j=1}^{n} d_{j}$.

$\bar{C}=$ common average cycle time, $\bar{C}=T / D$.

$\mathrm{df}_{\mathrm{j}}=$ fraction of total demand for product model $\mathrm{j}, d f_{j}=d_{j} / D$.

$\theta=$ maximum number of production cells to which a multicellular station can belong $2 \leq \theta \leq K_{\max }$.

$\mathrm{K}_{\max }=$ maximum number of production cells $\left(\mathrm{K}_{\max } \leq \mathrm{m}\right)$. It can be specified based on diagram $G$, or the maximum bound $\left(K^{\prime}\right)$ proposed by Al Kattan [21] can be used as reference:

$$
K^{\prime}=\frac{W}{\max _{i=1, \ldots, m}\left\{w_{i}\right\}} \Rightarrow K_{\max }=\left\lfloor K^{\prime}\right\rfloor
$$

where

$w_{i}=$ marginal workload of machine $i, w_{i}=\sum_{j=1}^{n} d f_{j} \cdot\left(d_{j}^{(i)} \cdot t_{i j}\right)$

$W=$ total workload, $W=\sum_{i=1}^{M} w_{i}$.

$\mathrm{K}_{\min }=$ minimum number of production cells. It can be specified based on diagram

G, or a modification of the bound proposed by Al Kattan [21] can be considered:

$$
K_{\min }=\left\lceil\frac{\max _{i=1, \ldots, m}\left\{w_{i}\right\}}{(W / m)}\right\rceil .
$$


$\bar{t}_{i}=$ weighted average processing time of machine $\mathrm{i}$,

$$
\bar{t}_{i}=\sum_{j=1}^{n} d f_{j} \cdot t_{i j} .
$$

$\mathrm{GO}=$ original combined precedence diagram. $\mathrm{G}=\left(\mathrm{V}, \mathrm{E}, \bar{t}_{i}\right)$.

$\mathrm{GA}^{\prime}=$ auxiliary combined precedence diagram. $\mathrm{G}^{\prime}=\left(\mathrm{V}, \mathrm{E}^{\prime}, \bar{t}_{i}\right)$.

$\mathrm{M}_{\min }=$ minimum number of machines that a cell must contain,

$M_{\min }=\left\lfloor m / K_{\max }\right\rfloor$.

$\mathrm{M}_{\text {max }}=$ maximum number of machines that a cell must contain,

$M_{\max }=\left\lceil m / K_{\min }\right\rceil$.

$\mathrm{S}_{\min }=$ minimum number of work stations required, $S_{\min }=\sum_{i=1}^{m} t_{i} / \bar{C}$.

$\mathrm{S}_{\max }=$ maximum number of work stations required $\left(S_{\text {max }} \leq m\right)$.

\subsection{Mathematical model}

\subsubsection{Model assumptions}

The assumptions of the proposed model are presented below:

- Multiple similar models of a product are produced if possible in a single manufacturing cell.

- The processing times of the tasks are known and constant.

- Each task of the combined precedence diagram is performed for at least one product model.

- The average time of each task is not greater than the average cycle time $\bar{C}$.

- Each machine is assigned to a single work station for each product.

- The operators can work in or out of the " $U$ " cell.

- In a manufacturing cell, the precedence restrictions are consistent among the different product models produced in it, i.e., if task $a$ precedes task $b$ in some model, then there is no other model in the cell in which task $b$ precedes task $a$.

- The precedence graphs of the product models are not fractionated, i.e., all the tasks to produce a product model are joined together directly or indirectly.

- The mix of models, i.e., the demands for models within the planning horizon, is known with certainty (static problem).

- There are no buffers between the work stations, so it is not possible for the work stations to operate at different production rates.

- The workers are capable of performing any task in the manufacturing cell, i.e., they are capable of operating any machine.

- The setup times of the machines are not significant. 
- The displacement times of the workers in a manufacturing cell are not significant, but not so out of them.

- The machines related by some intercellular product movement must belong, if possible, to the same work station.

\subsubsection{Notation}

The following points present the notation and the proposed model:

a. Indexes

$$
\begin{aligned}
& h=\text { work station }\left(h=1, \ldots, S_{\max }\right) . \\
& i, i=\text { machine }(i=1, \ldots, m) . \\
& j=\text { product model }(j=1, \ldots, n) . \\
& k=\text { production cells }\left(k=1, \ldots, K_{\max }\right) .
\end{aligned}
$$

b. Decision variables

$$
\begin{aligned}
& x_{i k}=\left\{\begin{array}{l}
1 \text { if machine } \mathrm{i} \text { is assigned to cell } \mathrm{k} \\
0 \text { otherwise }
\end{array}\right. \\
& \mathrm{y}_{\mathrm{k}}=\left\{\begin{array}{l}
1 \text { if production cell } \mathrm{k} \text { is used, i.e., if it is assigned machines } \\
0 \text { otherwise }
\end{array}\right. \\
& \mathrm{u}_{\mathrm{ihG}}=\left\{\begin{array}{l}
1 \text { if machine } \mathrm{i} \text { of graph } \mathrm{G} \text { is assigned to work station } \mathrm{h} \\
0 \text { otherwise }
\end{array}\right. \\
& \mathrm{r}_{\mathrm{h}}=\left\{\begin{array}{l}
1 \text { if } \text { work station } \mathrm{h} \text { is used, i.e., it is assigned machines } \\
0 \text { otherwise }
\end{array}\right. \\
& \mathrm{f}_{\mathrm{kh}}=\left\{\begin{array}{l}
1 \text { if } \text { cell } \mathrm{k} \text { is used by work station } \mathrm{h} \\
0 \text { otherwise }
\end{array}\right. \\
& \mathrm{g}_{\mathrm{h}}=\left\{\begin{array}{l}
1 \text { if work station } \mathrm{h} \text { is multicellular } \\
0 \text { otherwise }
\end{array}\right.
\end{aligned}
$$

\subsubsection{Model}

\subsubsection{Objective function}

The objective of this formulation is to minimize the total cost of intercellular transport between machines, which will appear every time there are finished products between machines $i$ and $i$ ' and they belong to different production cells. Decision variables $x_{i k}$ define the set of groups of machines, while the product families will be defined after the solution of this model, supported by the information of the extended combined precedence graph (GOUGA):

$$
\min Z=\sum_{i=1}^{m-1} \sum_{i^{\prime}=i+1}^{m} \sum_{k=1}^{K_{\max }} c_{i i^{\prime}}\left(1-x_{i k} \cdot x_{i^{\prime} k}\right)+c s \cdot \sum_{h=\left\lceil S_{\min }\right\rceil+1}^{S_{\max }} r_{h}
$$


Restrictions for the formation of manufacturing cells:

$$
\begin{gathered}
\sum_{k=1}^{K_{\max }} x_{i k}=1 ; \quad \forall i=1, \ldots, m \\
\sum_{i=1}^{m} x_{i k} \leq M_{\max } \cdot y_{k} ; \quad \forall k=1, \ldots, K_{\max } \\
\sum_{i=1}^{m} x_{i k} \geq M_{\min } \cdot y_{k} ; \quad \forall k=1, \ldots, K_{\max }
\end{gathered}
$$

Restrictions for the balance of U-shaped cells:

$$
\begin{gathered}
\sum_{h=1}^{S_{\max }}\left(u_{i h G O}+u_{i h G A}\right)=1 \quad \forall i=1, \ldots, m \\
\sum_{i=1}^{m} \bar{t}_{i}\left(u_{i h G O}+u_{i h G A}\right) \leq \bar{C} \cdot r_{h} \quad \forall h=1, \ldots, S_{\max } \\
\sum_{h=1}^{S_{\max }}\left(S_{\max }-h+1\right)\left(u_{a h G O}-u_{b h G O}\right) \geq 0 \quad \forall(a, b) \in G O \\
\sum_{h=1}^{S_{\max }}\left(S_{\max }-h+1\right)\left(u_{b h G A}-u_{a h G A}\right) \geq 0 \quad \forall(a, b) \in G O
\end{gathered}
$$

Linking restrictions between the formation and the balance of the cells:

$$
\begin{gathered}
\sum_{i=1}^{m}\left(u_{i h G O}+u_{i h G A}\right) \cdot x_{i k} \leq m \cdot f_{k h} \quad \forall k=1, \ldots, K_{\max } ; h=1, \ldots, S_{\max } \\
\sum_{h=1}^{S_{\max }} g_{h} \cdot f_{k h} \leq 2 \quad \forall k=1, \ldots, K_{\max } \\
\sum_{k=1}^{K_{\max }} f_{k h} \leq(\theta-1) \cdot g_{h}+1 \quad \forall h=1, \ldots, S_{\max }
\end{gathered}
$$

Restrictions for defining binary variables:

$$
x_{i k}, y_{k}, u_{i h G}, r_{h}, f_{k h}, g_{h} \in\{0,1\} \quad \forall h, i, j, k
$$

The set of restrictions (8) restricts each machine to a single cell. The set of restrictions (9) restricts each created cell to a maximum of $M_{\max }$ machines, while the set of restrictions (10) restricts them to a minimum of $M_{\min }$ machines; the value of $y_{k}$ is equal to one for the first $K_{\min }$ restrictions, since it is known that these cells are required. As to the balance of the lines, the objective is to minimize the cost per required work station in addition to the theoretical minimum, avoiding the need to have $r_{h}$ variables for stations 1 through $\left\lceil S_{\min }\right\rceil$. The set of restrictions (11) ensures that each machine is assigned to only one station, either in the original precedence graph or in the auxiliary one [18]. The set of restrictions (12) ensures that for every station, the sum of the weighted average processing times of their assigned machines does not exceed the average cycle time; the values of $r_{h}$ are equal to one 
for the first $\left\lceil S_{\min }\right\rceil$ restrictions. The set of restrictions (13) and (14) force the precedence restrictions between the machines; these relations are reversed for the auxiliary graph.

The set of restrictions (15) makes each variable $f_{k h}$ be equal to one when cell $k$ is used by station $h$. The set of restrictions (16) allows a maximum of two multicellular work stations for each manufacturing cell, so that there are not many interferences between stations [9]. The set of restrictions (17) limits to $\theta$ the number of cells to which a multicellular work station can belong, and it also makes every variable $g_{h}$ equal to one when $h$ is a multicellular station. The set of restrictions (18) defines the decision variables $x_{i k}, y_{j k}, u_{i h}, r_{h}, f_{k h}$, and $g_{h}$ as binary.

\subsection{Assigning the product models to the obtained production cells}

With the groups of machines obtained, we must now assign the product models to each resultant cell. For this, let:

$P_{k j}=$ Number of machines of cell $k$ that process product $j$,

$$
P_{k j}=\sum_{i=1}^{m} a_{i j} \cdot x_{i k}
$$

$\Omega_{j}=$ Set of cells that have the maximum number of machines that process $j$,

$$
\Omega_{j}=\left\{k \mid P_{k j}=\max _{k=1, \ldots, K}\left\{P_{k j}\right\}\right\}
$$

$W_{j}^{(k)}=$ Total workload (in hours) of cell $k$ due to product $j$,

$$
W_{j}^{(k)}=\sum_{i=1}^{m} d_{j} \cdot t_{i j} \cdot x_{i k}
$$

$\Psi_{j}=$ Set of cells having maximum total workload due to product model $j$ and belonging to $\Omega_{j}$,

$$
\Psi_{j}=\left\{k \mid W_{j}^{(k)}=\max _{k \in \Omega_{j}}\left\{W_{j}^{(k)}\right\}\right\}
$$

Then, to assign to which production cell each product $j$ belongs, the following formal procedure is defined, where three cases can occur:

Case 1: If $\left|\Omega_{j}\right|=1 \Rightarrow j \in J_{k} \Leftrightarrow P_{k j}=\max _{k=1, \ldots, K}\left\{P_{k j}\right\}$; assign each product to the cell where it will be processed by more machines.

Case 2: If $\left|\Omega_{j}\right|>1 \wedge\left|\Psi_{j}\right|=1 \Rightarrow j \in J_{k} \Leftrightarrow W_{j}^{(k)}=\max _{k=1, \ldots, K}\left\{W_{j}^{(k)}\right\}$; if there is a tie it must be assigned to the cell in which the product spends most processing time.

Case 3: If $\left|\Omega_{j}\right|>1 \wedge\left|\Psi_{j}\right|>1 \Rightarrow$, assign $j$ arbitrarily to a cell that belongs to $\Psi_{j}$; if a tie occurs, assign the product to the cell with a smaller number of machines or randomly.

\section{Application of the methodology: illustrative case}

The company in which the proposed methodology will be applied is of the metalworking type, making storage products (racks) for the retail industry. The 
final products are assembled at the customer's facilities, so the work orders are divided considering the final product's components, which are generally pillars, beams, struts, slotted angles (ANRA), and accessories. Each of them can have various modifications in size, processing times, and complexity in its operations (precedence restrictions), so it is possible to identify them previously as families of products, therefore complying with the observations proposed by Burbidge [22], who says that a system can be naturally susceptible to be transformed into one of the cellular manufacturing type.

The company has a factory in the commune of Quilicura, in the Metropolitan Region of Chile, and has 31 machines that can be classified into 17 types, processing 67 different product models. The place where the methodology will be applied has a job shop-type configuration.

This study will consider a time planning horizon of 3 months, in which the plant operates $16 \mathrm{~h} / \mathrm{d}$ from Monday to Saturday. According to the company's policies, 1 day per month is devoted to preventive maintenance operations of each machine, so it will be considered that each machine has a capacity of $1248 \mathrm{~h}$, within a

\begin{tabular}{lccc}
\hline $\boldsymbol{m}$ (type of machine) & Identification characteristic & Present number & Simultaneous machine \\
\hline 1 & Sheet metal cutter & 3 & No \\
\hline 2 & Strippit & 1 & No \\
\hline 3 & Punching machine & 1 & No \\
\hline 4 & 25 tons press & 2 & No \\
\hline 5 & 45 tons press & No \\
\hline 6 & 55 tons press & No \\
\hline 7 & 90 tons press & 2 & No \\
\hline 8 & Pneumatic press 160 tons & 2 & No \\
\hline 9 & Sheet metal bender $2000 \mathrm{~m}$ & 2 & No \\
\hline 10 & Sheet metal bender $3000 \mathrm{~m}$ & 2 & No \\
\hline 11 & Sheet metal bender $4000 \mathrm{~m}$ & 2 & No \\
\hline 12 & Sheet metal bender 160 ton & 2 & Yes \\
\hline 13 & Welder accessories & 2 & No \\
\hline 14 & Beam welder & No \\
\hline 15 & Connector welder & 2 & No \\
\hline 16 & Pillar welder & 2 & No \\
\hline 17 & Forming machine ANRA & 1 & 2 \\
\hline
\end{tabular}

Table 1.

Information on the types of machines.

\begin{tabular}{lc}
\hline$J$ (products) & Identification characteristic \\
\hline $1-4$ & Strut \\
\hline $5-29$ & Beam \\
\hline $30-51$ & Accessory \\
\hline $52-59$ & Pillar \\
\hline $60-67$ & Slotted angle (ANRA) \\
\hline
\end{tabular}

Table 2.

Information on the types of products. 
planning horizon of $\mathrm{T}=1296 \mathrm{~h}$. Tables 1 and 2 present general information with respect to the types of machines and the different product models, respectively.

\subsection{Step 1: calculating and assigning the required machines}

Applying Eq. (1) to determine the number of machines of type $\left(q_{m}\right)$ needed to satisfy the capacity restrictions, the values presented in Table 3 are obtained.

Comparing these results with the actual values of the number of machines of a given type present in the plant, we get that they are equal for almost all the values of $m$, except in the following two cases:

a. $m=3$, which means that one more machine must be bought to fulfill the required capacity of this type of machine.

b. $m=15$, where there is currently one extra machine.

Case (a) explains in some way why machine 3 punching machine has become a bottleneck in the plant when "accessory"-type products are made. Maintain, in this study use will be made of the current excess capacity produced by the two type 15 machines (connector welder) reflected in case $(b)$, assigning products to both machines.

Applying the proposed assignment procedure of Figure 2, we get the assignment of machines $(i)$ to the $(m)$ machine types and of products $(j)$, which are presented in Table 4, where the fact that machine 12 will function as a "virtual machine" in which two machines will operate simultaneously is pointed out.

\subsection{Step 2: preparation of the extended combined precedence diagram}

With the determination of the number of types of machines, and the assignment of products to machines obtained in the previous stage, the precedence restrictions deliver the extended combined precedence diagram shown in Figure 6, where the virtual machine 12 differs from the rest because in it the two benders with the largest capacity operate simultaneously in the production of pillar-type products. These products have a larger size, so it is advisable to use both benders one next to the other to mechanize the product and, in this way, reduce the processing time of this operation.

\subsection{Step 3: calculation of the parameters needed for the mathematical model}

The intercellular transport costs are shown in Table 5. The rest of the parameters to be used in the mathematical model were the following: average cycle time $\bar{C}=0.15$ gives a value of $S_{\min }=6$, and a value of $S_{\max }=10$ was also considered. The number of cells obtained from the combined precedence diagram gave values of $K_{\min }=4$ and $K_{\max }=6$, which are adequate for the groups of machines that can be visualized previously, giving values of $M_{\max }=8$ and $M_{\min }=5$, respectively. All this information is presented in Tables 6-8.

\begin{tabular}{cccccccccccccccccc}
\hline$m$ & 1 & 2 & 3 & 4 & 5 & 6 & 7 & 8 & 9 & 10 & 11 & 12 & 13 & 14 & 15 & 16 & 17 \\
\hline$q_{m}$ & 3 & 1 & 2 & 2 & 2 & 2 & 1 & 2 & 2 & 2 & 2 & 2 & 2 & 2 & 1 & 2 & 1 \\
\hline
\end{tabular}

Table 3.

Values of $q_{m}$ obtained for the industrial problem. 
A Methodology to Design and Balance Multiple Cell Manufacturing Systems DOI: http://dx.doi.org/10.5772/intechopen.89463

\begin{tabular}{cccccc}
\hline $\mathbf{i}$ & $\mathbf{m}$ & $\mathbf{j}$ & $\mathbf{i}$ & $\mathbf{m}$ & $\mathbf{j}$ \\
\hline 1 & 1 & $1-4,10-19$, and $60-67$ & 17 & 17 & $60-67$ \\
\hline 2 & 2 & $60-67$ & 18 & 1 & $5-9$ and 20-34 \\
\hline 3 & 3 & $30-38$ & 19 & 1 & $35-51$ \\
\hline 4 & 4 & $15-23$ & 20 & 3 & $39-47$ \\
\hline 5 & 5 & $30-34$ & 21 & 4 & $22-29$ \\
\hline 6 & 6 & $5-9$ and $20-23$ & 22 & 5 & $43-51$ \\
\hline 7 & 7 & $60-67$ & 23 & 6 & $22-29$ \\
\hline 8 & 8 & $52-55$ & 24 & 8 & $56-59$ \\
\hline 9 & 9 & $30-34$ & 25 & 9 & $43-51$ \\
\hline 10 & 10 & $30-38$ & 26 & 10 & $39-51$ \\
\hline 11 & 11 & $1-4$ and $10-23$ & 27 & 11 & $5-9$ and 22-29 \\
\hline 12 & 12 & $52-59$ & 28 & 13 & $39-51$ \\
\hline 13 & 13 & $30-38$ & 29 & 14 & $5-9$ and 22-29 \\
\hline 14 & 14 & $10-23$ & 30 & 15 & 43 and 44 \\
\hline 15 & 15 & $45-47$ & 31 & 16 & $56-59$ \\
\hline 16 & 16 & $52-55$ & & & \\
\hline
\end{tabular}

Table 4.

Results of the assignment of machines and products.

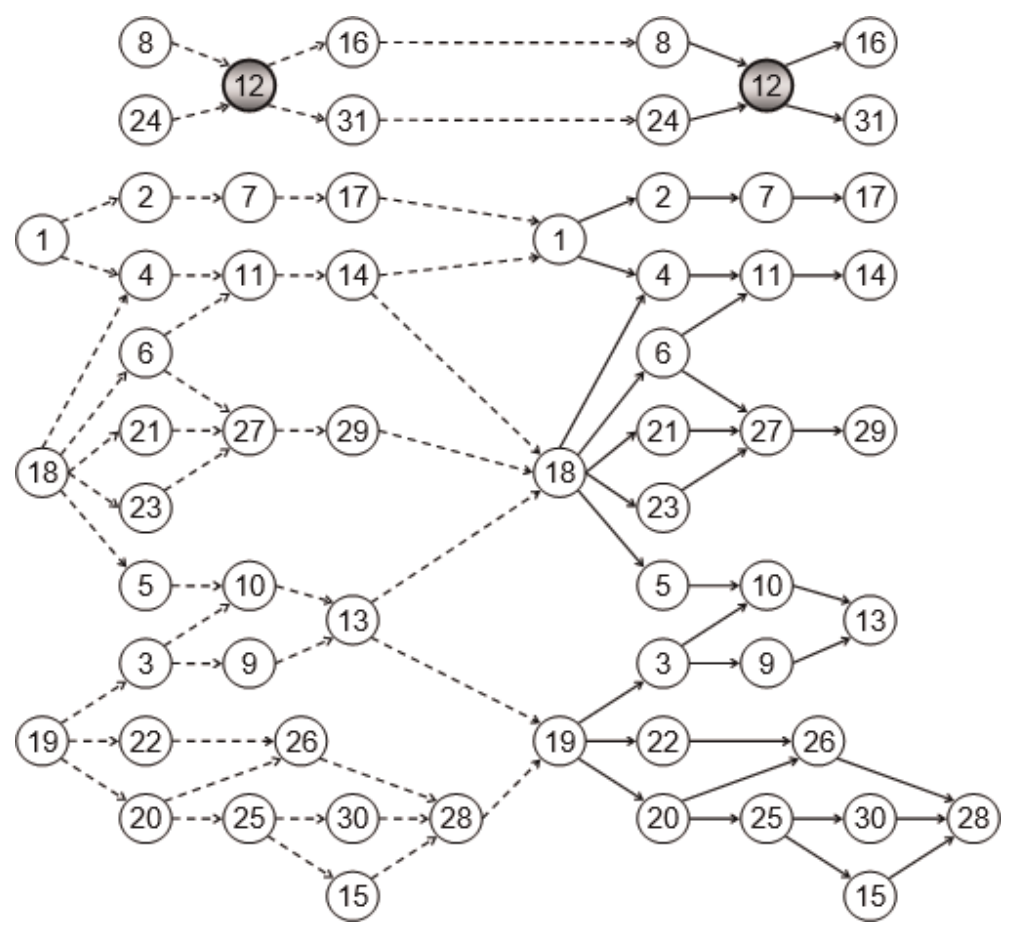

Figure 6.

Extended combined precedence diagram for the industrial problem. 


$$
\begin{aligned}
& \mid
\end{aligned}
$$

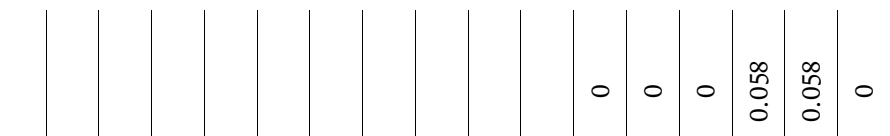

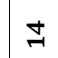

$$
\begin{aligned}
& \stackrel{m}{\sim} \\
& \approx \\
& \text { ○ } \\
& \text { F }
\end{aligned}
$$

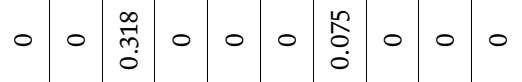

$$
\begin{aligned}
& \text { 오 }
\end{aligned}
$$

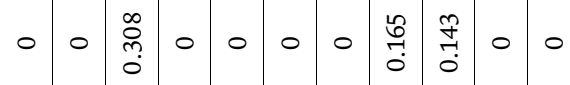

$$
\begin{aligned}
& \text { a }
\end{aligned}
$$

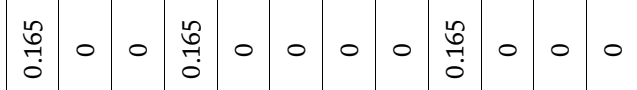

$$
\begin{aligned}
& \infty
\end{aligned}
$$

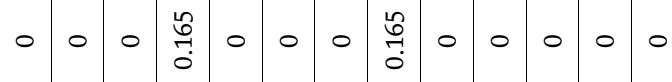

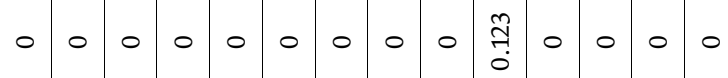

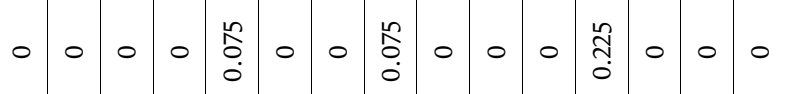

$$
\begin{aligned}
& 6
\end{aligned}
$$

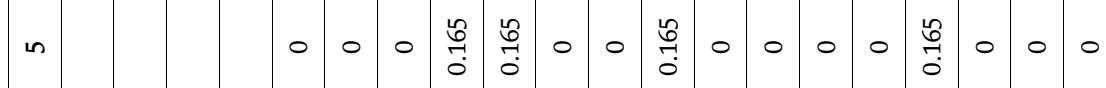

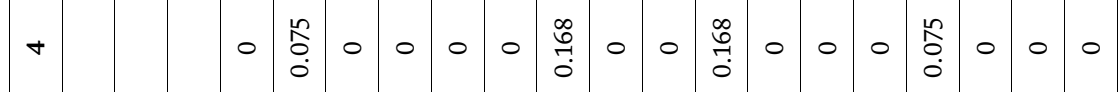

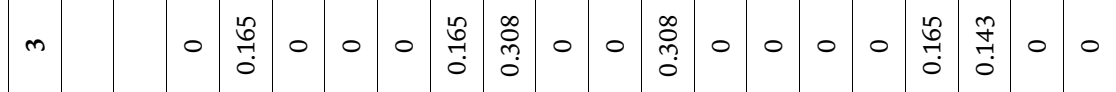

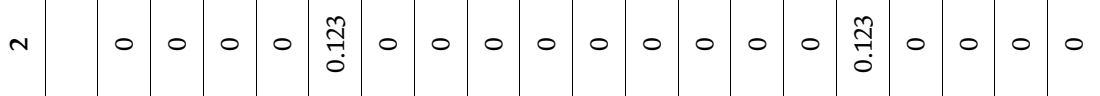

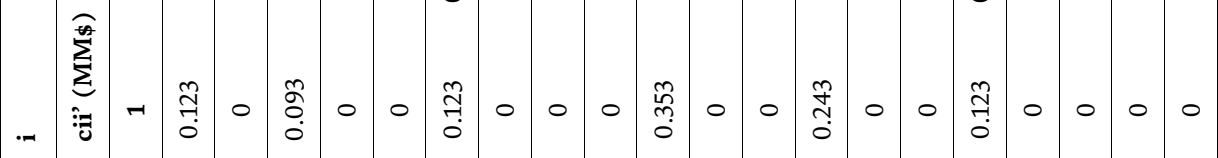

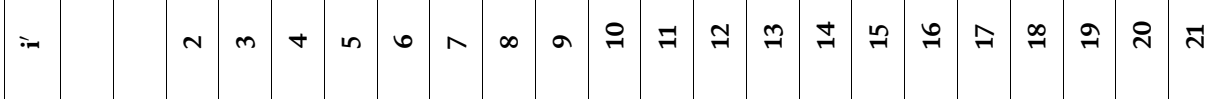




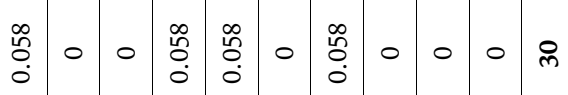

$$
\begin{aligned}
& \begin{array}{lllllllllll}
0 & 0 & 0 & 0 & 0 & 0 & 0 & 0 & 0 & 0 & 4
\end{array} \\
& \begin{array}{lllllllllll}
0 & 0 & 0 & 0 & 0 & 0 & 0 & 0 & 0 & 0 & \text { ஸे }
\end{array} \\
& \text { - } 0 \text { : } \\
& \begin{array}{llllllllllll}
0 & 0 & 0 & 0 & 0 & 0 & 0 & 0 & 0 & 0 & 4
\end{array}
\end{aligned}
$$

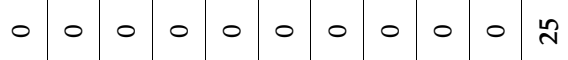

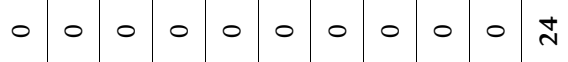

$$
\begin{aligned}
& \begin{array}{llllllllllll}
0 & 0 & 0 & 0 & 0 & 0 & 0 & 0 & 0 & 0 & n
\end{array} \\
& \begin{array}{lllllllllll}
0 & 0 & 0 & 0 & 0 & 0 & 0 & 0 & 0 & 0 & 4
\end{array}
\end{aligned}
$$

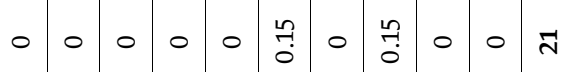

$$
\begin{aligned}
& \begin{array}{lllllllllll}
0 & 0 & 0 & 0 & 0 & 0 & 0 & 0 & 0 & 0 & 0
\end{array} \\
& 0 \begin{array}{lllllll}
-1 & 0 & 0 & -1 & \stackrel{n}{n} \\
0
\end{array}
\end{aligned}
$$

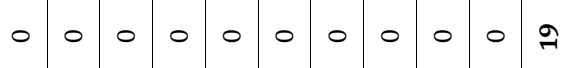

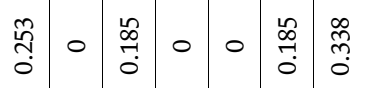

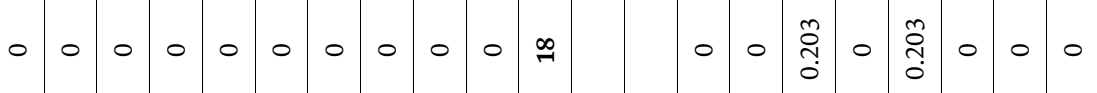

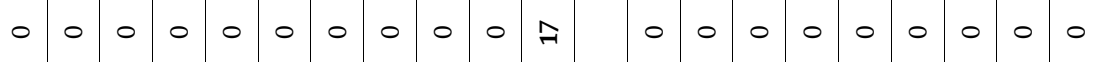

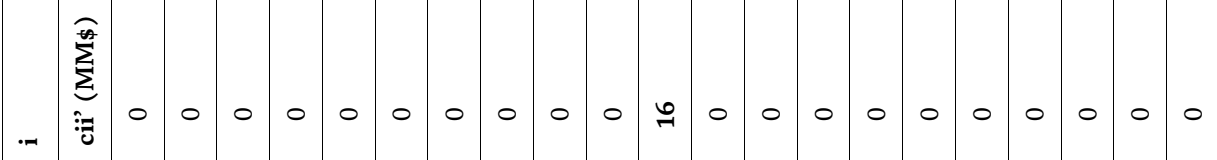

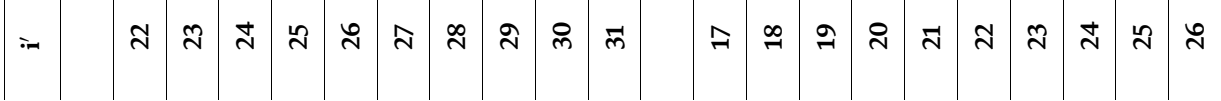




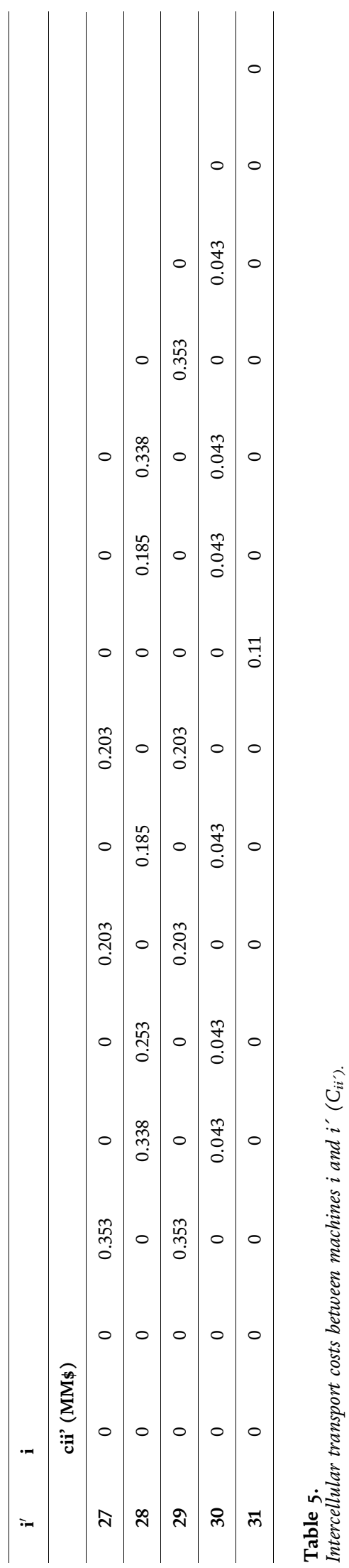




\begin{tabular}{cccccccccccccccc}
\hline $\mathbf{i}$ & $\mathbf{1}$ & $\mathbf{2}$ & $\mathbf{3}$ & $\mathbf{4}$ & $\mathbf{5}$ & $\mathbf{6}$ & $\mathbf{7}$ & $\mathbf{8}$ & $\mathbf{9}$ & $\mathbf{1 0}$ & $\mathbf{1 1}$ & $\mathbf{1 2}$ & $\mathbf{1 3}$ & $\mathbf{1 4}$ & $\mathbf{1 5}$ \\
\hline $\bar{t}_{i}$ & 0.033 & 0.03 & 0.03 & 0.031 & 0.033 & 0.034 & 0.031 & 0.021 & 0.02 & 0.031 & 0.034 & 0.028 & 0.029 & 0.03 & 0.014 \\
\hline $\mathbf{i}$ & $\mathbf{1 6}$ & $\mathbf{1 7}$ & $\mathbf{1 8}$ & $\mathbf{1 9}$ & $\mathbf{2 0}$ & $\mathbf{2 1}$ & $\mathbf{2 2}$ & $\mathbf{2 3}$ & $\mathbf{2 4}$ & $\mathbf{2 5}$ & $\mathbf{2 6}$ & $\mathbf{2 7}$ & $\mathbf{2 8}$ & $\mathbf{2 9}$ & $\mathbf{3 0}$ \\
\hline $\bar{t}_{i}$ & 0.022 & 0.031 & 0.034 & 0.028 & 0.023 & 0.034 & 0.034 & 0.034 & 0.014 & 0.02 & 0.034 & 0.034 & 0.026 & 0.033 & 0.011 \\
\hline
\end{tabular}

Table 6.

Weighted average processing times $\left(\bar{t}_{i}\right)$ for each machine $i$.

\begin{tabular}{cccccccccccc}
\hline$K_{\min }$ & $\boldsymbol{K}_{\max }$ & $\boldsymbol{\theta}$ & $\boldsymbol{M}_{\max }$ & $\boldsymbol{M}_{\min }$ & $\mathbf{M}$ & $\overline{\mathbf{C}}$ & $\mathbf{A}$ & $\left\lceil S_{\min }\right\rceil$ & $S_{\max }$ & $\mathbf{c s}(\mathbf{M M} \mathbf{})$ & $\mathrm{cb}(\mathrm{MM} \mathbf{})$ \\
\hline 4 & 6 & 4 & 8 & 5 & 31 & 0.15 & 0.005 & 6 & 10 & 0.45 & 0.05 \\
\hline
\end{tabular}

Table 7.

Parameters to be used in the model.

E (8,12), (24,12), (12,16), (12,31), (1,2), (1,4), (2,7), (4,11), (7,17), (11,14), (18,4), (18,6), (18,21), $(18,23),(18,5),(6,11),(6,27),(21,27),(23,27),(27,29),(5,10),(3,10),(3,9),(10,13),(9,13),(19,3)$, $(19,22),(19,20),(22,26),(20,26),(20,25),(25,30),(25,15),(26,28),(30,28),(15,28)$

Table 8.

Set of precedence relations between machines.

\subsection{Step 4: statement and solution of the mathematical model}

With the parameters calculated above, we state the mathematical model. The model was then solved using the Extended LINGOC version 8.0 software, getting an optimal global solution in $2 \mathrm{~h}$ and $32 \mathrm{~min}$, after 121 iterations, giving as a result 5 manufacturing cells and 9 work stations, 3 of them multicellular, because they process exceptional products. This solution is represented in Figure 7.

\subsection{Step 5: assigning the product models to the production cells}

With the groups of machines obtained thanks to the model's solution, the product models were assigned to each of these production cells. This solution is represented in Table 9.

The proposed cellular manufacturing system that results from the application of the methodology shows the resultant cells and the product families assigned to them, where it is seen that cell 1 processes products of the beam and slotted angle type, cells 2 and 3 process only accessories, cell 4 processes only beams, and cell 5 processes only pillars. In this way, it is easier to improve the obtained balance by sequencing mixed product models, because in a cell there are no different types of products that compete for the same resources (machines), but they rather process the same types of products, grouped in families. Only work stations 1, 2, and 8 turn out being multicellular, because they process exceptional products that undergo intercellular movements, most of which are associated with the operation of the cutter type machines, since they are those that are mostly shared by the different products.

To analyze the results, it is necessary to have performance measures of the solution, but since the present study has taken up a new problem that is part of the manufactured cell formation problem (MCFP) and the general assembly line balancing problem (GALBP), we must use measures of performance commonly employed for both problems separately, such as group capability index (GCI), for 
example, proposed by Seifoddini and Hsu [23], and the grouping efficacy (GE) proposed by Kumar and Chandrasekharan [24], as well as balancing measures like "total line imbalance" proposed by Thomopoulos [12]. Table 10 presents a comparison of results of the case study by the proposed methodology versus the model of Won and Currie [25], considering the latter as an MCFP-type problem. The

Cell 1

Cell 4

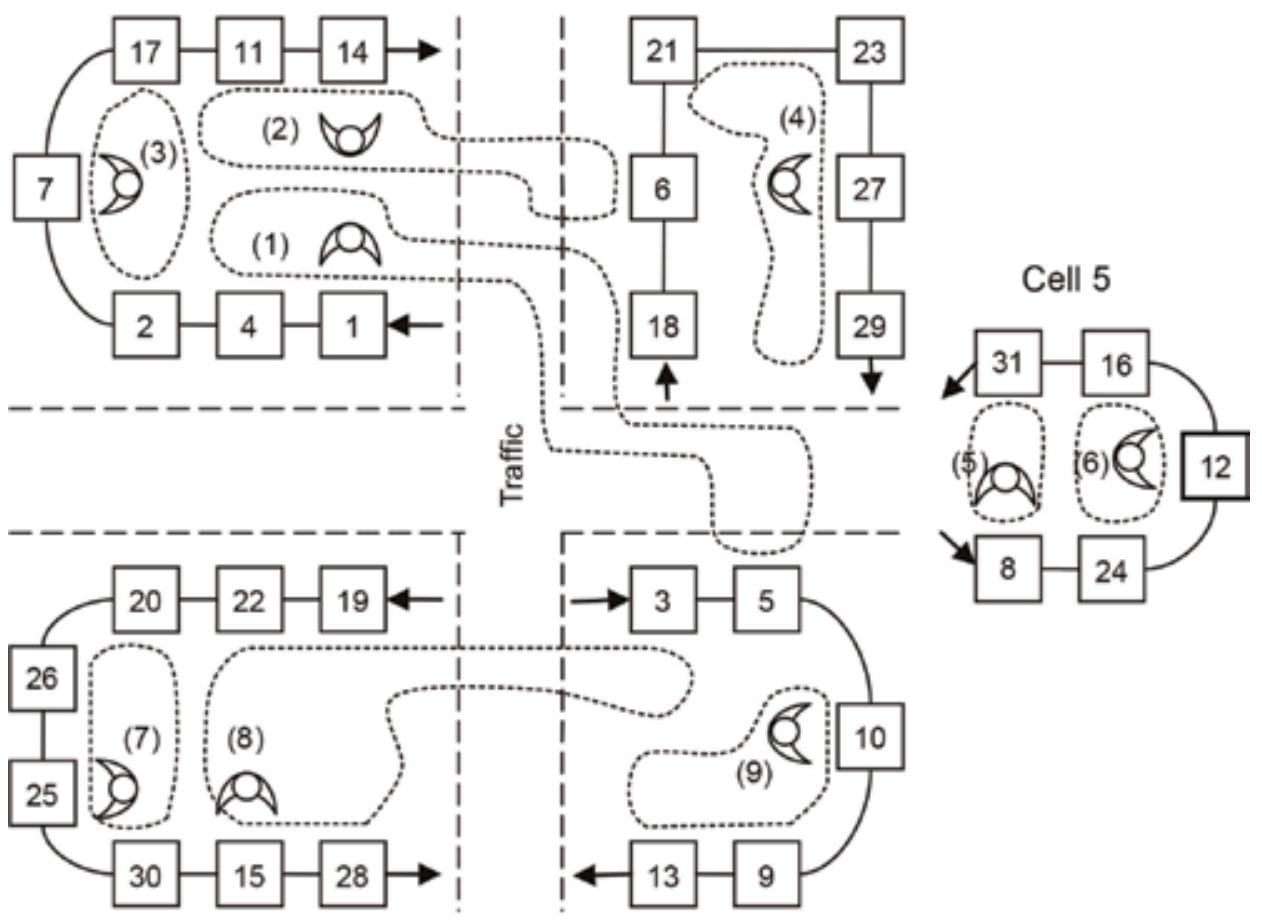

Cell 3

Cell 2

Figure 7.

Representation of the resultant cells and stations.

\begin{tabular}{|c|c|c|c|c|c|c|c|c|c|c|c|c|c|c|c|c|c|c|c|c|c|c|c|c|c|c|c|c|c|c|c|}
\hline $\begin{array}{c}\text { Cell } \\
\text { number }\end{array}$ & \multicolumn{7}{|c|}{1} & \multicolumn{5}{|c|}{2} & \multicolumn{8}{|c|}{3} & \multicolumn{6}{|c|}{4} & \multicolumn{5}{|c|}{5} \\
\hline & - & & & & & & & & & & & & $\cong$ & & & $y$ & $\approx$ & & సో స్ & & 0 & & & & 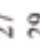 & & & & $\underline{\varphi}$ & ते ल & ल \\
\hline 1 a 4 & 1 & 0 & & 0 & 1 & 0 & & 0 & 0 & 0 & 0 & & 0 & 0 & 0 & 0 & 0 & 0 & 0 & 0 & 0 & $\overline{0}$ & $\overline{00}$ & 0 & 0 & & $\overline{0} 0$ & $\overline{0} 0$ & $\overline{0}$ & 0 & \\
\hline 10 a 14 & 1 & 0 & 0 & 0 & 1 & 1 & 0 & 0 & 0 & 0 & 0 & 0 & 0 & 0 & 0 & 0 & 0 & 0 & 0 & 0 & 0 & 0 & 0 & $\begin{array}{ll}0 & 0\end{array}$ & $\begin{array}{ll}0 & 0\end{array}$ & 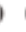 & $\begin{array}{lll}0 & 0\end{array}$ & $\begin{array}{ll}0 & 0\end{array}$ & 0 & 0 & 0 \\
\hline 15 a 19 & 1 & 0 & 1 & 0 & 1 & 1 & 0 & 0 & 0 & 0 & 0 & 0 & 0 & 0 & 0 & 0 & 0 & 0 & $0 \mathrm{c}$ & 0 & 0 & 0 & $\begin{array}{ll}0 & 0\end{array}$ & $\begin{array}{ll}0 & 0\end{array}$ & $\begin{array}{ll}0 & 0\end{array}$ & & $\begin{array}{lll}0 & 0\end{array}$ & $\begin{array}{ll}0 & 0\end{array}$ & 0 & 00 & \\
\hline a 23 & 0 & 0 & 1 & 0 & 1 & 1 & 0 & 0 & 0 & 0 & 0 & 0 & 0 & 0 & 0 & 0 & 0 & 0 & $0 \mathrm{c}$ & 0 & 1 & 1 & $\begin{array}{lll}0 & 0\end{array}$ & $\begin{array}{ll}0 & 0\end{array}$ & $\begin{array}{lll}0 & 0\end{array}$ & & $\begin{array}{lll}0 & 0\end{array}$ & $\begin{array}{ll}0 & 0\end{array}$ & 0 & $\begin{array}{ll}0 & 0\end{array}$ & 0 \\
\hline 60 a 67 & 1 & 1 & 0 & 1 & 0 & 0 & 1 & 0 & 0 & 0 & 0 & 0 & 0 & 0 & 0 & 0 & 0 & 0 & 0 & 0 & 0 & 0 & $\begin{array}{lll}0 & 0\end{array}$ & $\begin{array}{ll}0 & 0\end{array}$ & $\begin{array}{lll}0 & 0\end{array}$ & & 00 & $\begin{array}{ll}0 & 0\end{array}$ & 0 & $\begin{array}{ll}0 & 0\end{array}$ & 0 \\
\hline 30 a 34 & 0 & 0 & 0 & 0 & 0 & 0 & 0 & 1 & 1 & 1 & 1 & 1 & 0 & 0 & 0 & 0 & 0 & 0 & 0 & 0 & 0 & 1 & $\begin{array}{ll}0 & 0\end{array}$ & $\begin{array}{ll}0 & 0\end{array}$ & $\begin{array}{lll}0 & 0\end{array}$ & & $0 \quad 0$ & $\begin{array}{ll}0 & 0\end{array}$ & 0 & 0 & 0 \\
\hline 35 a 38 & 0 & 0 & 0 & 0 & 0 & 0 & 0 & 1 & 0 & 0 & 1 & 1 & 0 & 1 & 0 & 0 & 0 & 0 & 0 & $\underline{0}$ & 0 & 0 & $\begin{array}{ll}0 & 0\end{array}$ & $\begin{array}{ll}0 & 0\end{array}$ & 0 & 0 & 00 & $\begin{array}{ll}0 & 0\end{array}$ & 0 & 00 & 0 \\
\hline 39 a 42 & 0 & 0 & 0 & 0 & 0 & 0 & 0 & 0 & 0 & 0 & 0 & 0 & 0 & 1 & 1 & 0 & 0 & 1 & 1 & 0 & 0 & 0 & $\begin{array}{ll}0 & 0\end{array}$ & $\begin{array}{ll}0 & 0\end{array}$ & 0 & 0 & $\begin{array}{lll}0 & 0\end{array}$ & $\begin{array}{ll}0 & 0\end{array}$ & 0 & 0 & 0 \\
\hline 43 y 44 & 0 & 0 & 0 & 0 & 0 & 0 & 0 & 0 & 0 & 0 & 0 & 0 & 0 & 1 & 1 & 1 & 1 & 1 & 1 & 1 & 0 & 0 & 0 & $\begin{array}{ll}0 & 0\end{array}$ & 0 & & 0 & $\begin{array}{ll}0 & 0\end{array}$ & 0 & 00 & 0 \\
\hline 45 a 47 & 0 & 0 & 0 & 0 & 0 & 0 & 0 & 0 & 0 & 0 & 0 & & & 1 & 1 & 1 & 1 & 1 & 1 & 0 & 0 & 0 & 0 & $\begin{array}{ll}0 & 0\end{array}$ & 0 & & 0 & $\begin{array}{ll}0 & 0\end{array}$ & 0 & & 0 \\
\hline 48 a 51 & 0 & 0 & 0 & 0 & 0 & 0 & 0 & 0 & 0 & 0 & 0 & 0 & 0 & 1 & 0 & 1 & 1 & 1 & 10 & 0 & 0 & 0 & $\begin{array}{ll}0 & 0 \\
\end{array}$ & $\begin{array}{ll}0 & 0 \\
\end{array}$ & 0 & & 0 & $\begin{array}{ll}0 & 0\end{array}$ & 0 & $\begin{array}{lll}0 & 0\end{array}$ & 0 \\
\hline 5 a9 & 0 & 0 & 0 & 0 & 0 & 0 & 0 & 0 & 0 & 0 & 0 & 0 & 0 & 0 & 0 & 0 & 0 & 0 & 01 & 0 & 1 & 1 & 0 & & 1 & & 00 & $\begin{array}{ll}0 & 0\end{array}$ & 0 & & 0 \\
\hline 22 a 29 & 0 & 0 & 0 & 0 & 0 & 0 & 0 & 0 & 0 & 0 & 0 & 0 & 0 & 0 & 0 & 0 & 0 & 0 & 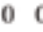 & 0 & 0 & 1 & 11 & 11 & 11 & 1 & $\begin{array}{lll}0 & 0 \\
\end{array}$ & $\begin{array}{ll}0 & 0 \\
\end{array}$ & $\underline{0}$ & $\begin{array}{lll}0 & 0 \\
0\end{array}$ & 0 \\
\hline & 0 & 0 & 0 & 0 & 0 & 0 & 0 & 0 & 0 & 0 & 0 & 0 & 0 & 0 & 0 & 0 & 0 & 0 & 0 & & 0 & 0 & $\begin{array}{ll}0 & 0\end{array}$ & $\begin{array}{ll}0 & 0\end{array}$ & 0 & & 11 & 11 & 1 & 00 & 0 \\
\hline & 0 & 0 & 0 & 0 & 0 & & 0 & 0 & 0 & 0 & 0 & 0 & 0 & 0 & 0 & 0 & & 0 & 0 & $\underline{0}$ & & & & & & & & & & & \\
\hline
\end{tabular}

Table 9.

Assignment of products to cells. 


\begin{tabular}{ccccccccc}
\hline $\begin{array}{l}\text { Problem } \\
\text { number } \\
(m \times n)\end{array}$ & $\begin{array}{l}\text { Computation time } \\
(\text { min) }\end{array}$ & \multicolumn{1}{l}{ Number of iterations } & GCI (\%) & \multicolumn{3}{c}{$G E(\%)$} \\
& $\begin{array}{l}\text { Proposed } \\
\text { methodology }\end{array}$ & $\begin{array}{c}\text { Won } \\
\text { and } \\
\text { Currie } \\
{[23]}\end{array}$ & $\begin{array}{c}\text { Proposed } \\
\text { methodology }\end{array}$ & $\begin{array}{c}\text { Won } \\
\text { and } \\
\text { Currie } \\
{[23]}\end{array}$ & $\begin{array}{c}\text { Proposed } \\
\text { methodology }\end{array}$ & $\begin{array}{c}\text { Won } \\
\text { and } \\
\text { Currie } \\
{[23]}\end{array}$ & $\begin{array}{c}\text { Proposed } \\
\text { methodology }\end{array}$ & $\begin{array}{c}\text { Won } \\
\text { and } \\
\text { Currie } \\
{[23]}\end{array}$ \\
\hline$(31 \times 67)$ & 152 & 140 & 121 & 114 & 89.45 & 85.45 & 86.45 & 84.25 \\
\hline
\end{tabular}

Table 10.

Comparison of the measures for the MCFP.

model of [25] was chosen because it considers a number of production factors and a complexity level relatively similar to the proposed methodology, and it can be solved in Lingo $@$ in a reasonable computation time.

In Table 10, it is seen that the proposed methodology takes more time to get the global optimal solution as well as a greater number of iterations compared to the model of [25]. This can be explained because in the proposed model of the methodology the first component of the formulation is of a quadratic type, so the LINGO(C) software uses an algorithm specialized in these types of problems which makes each iteration take longer time; on the other hand, the model of [25] is of the p-media type, which although linear, in terms of the quality of the solution, it is seen that the proposed methodology gives a group capability index (GCI) greater than the model of [25]. We believe that this is due to the fact that the proposed formulation puts emphasis in minimizing the costs of intercellular product movements, in contrast with the model of Won and Currie [25], which aims to maximize the similarity between the machines that constitute the production cells. On the other hand, with respect to the grouping efficacy (GE), the proposed methodology is better than the model of [25]. Making a deeper analysis of the results and getting more general conclusions is risky because it is necessary to do further research with study cases in which the indicators and models used can be compared. In relation to the comparison of indicators such as the total imbalance of the line proposed by Thomopoulos [12] under the viewpoint of the general assembly line balancing problem (GALBP), it was not done, and it is expected to be dealt with in an extension of the present work.

\section{Conclusions}

This work has proposed a new way of approaching balancing and cell formation problems, which were previously studied independently. In this way, it is possible to consider aspects that were previously avoided, such as production volumes, processing times, and operation sequences for the MCFP, and the fact that the production cells are not established yet and that they also share information among themselves, for balancing the lines. In the proposed methodology, a model is presented that has advantages at the time of solving it with a commercial software, because it does not need as many variables as other proposals. This approach delivers cells that are more amenable to be used in practice, although it will remain for future research to deliver immediately the layout of the cells as well as to integrate the problem of sequencing mixed models and, in that way, to improve the balance of each station.

In relation to the preliminary results obtained by comparing with another mathematical model from the viewpoint of a type MCFP problem, it must be pointed out 
that although the grouping efficacy indicators are better, they are not conclusive if a comparative study with more study problems as well as a sensitivity analysis of the parameters of the proposed model is not made. The same comparative study must be made from the viewpoint of a type GALBP problem in relation to the balancing of the resultant line, in such a way that the indicators can be compared with the proposed methodology with the techniques or methods applied separately for the same sets of study problems.

Finally, we believe that the proposed methodology responds to a problem of integrating two problems like the MCFP and GALBP under a same approach which is perfectible insofar as the results can be validated in future comparative work, as well as extending the proposed problem, integrating in the design, and balancing of manufacturing cells configured in " $U$ " the design of the family of products that one wishes to manufacture.

\section{Acknowledgements}

The authors would like to thank for the support of the Universidad de Santiago de Chile (031817 PB DICYT-USACH) and also thank all the teams of the Smart City Lab Program Centre of the same university.

\section{Author details}

Luis Valdivia* and Pedro Palominos

Department of Industrial Engineering, University of Santiago of Chile, Santiago, Chile

*Address all correspondence to: lvaldivialira@gmail.com

\section{IntechOpen}

(C) 2019 The Author(s). Licensee IntechOpen. This chapter is distributed under the terms of the Creative Commons Attribution License (http://creativecommons.org/licenses/ by/3.0), which permits unrestricted use, distribution, and reproduction in any medium, provided the original work is properly cited. (c) BY 


\section{References}

[1] Selim HM, Askin RG, Vakharia AJ. Cell formation in group technology: Evaluation and directions for future research. Computers and Industrial Engineering. 1998;34(1):3-20. DOI: 10.1016/S0360-8352(97)00147-2

[2] Deuse J, Konrad B, Bohnen F. Renaissance of group technology: Reducing variability to match lean production prerequisite. In: Proceedings of the 7th IFAC Conference on Manufacturing Modelling, Management, and Control International Federation of Automatic Control (IFAC); Saint Petersburg, Russia, 19-21 June. 2013. pp. 998-1003

[3] Papaioannou G, Wilson J. The evolution of cell formation problem methodologies based on recent studies (1997-2008): Review and directions for future research. European Journal of Operational Research. 2010;206: 509-521. DOI: 10.1016/j. ejor.2009.10.020

[4] Kashan A, Karimi B, Noktehdan A. A novel discrete particle swarm optimization algorithm for the manufacturing cell formation problem. The International Journal of Advanced Manufacturing Technology. 2014;73(912):1543-1556. DOI: $10.1007 /$ s00170-014-5906-4

[5] Karoum B, Elbenani YB. Discrete cuckoo search algorithm for solving the cell formation problem. International Journal of Manufacturing Research. 2019;14(3). DOI: 10.1504/ IJMR.2019.100991

[6] Patel J, Patel S. Approaches to solve cell formation, machine layout and cell layout problem: A review. Transactions on Machine Learning and Artificial Intelligence. 2014;2(5):80-96

[7] Anbumalar V, Sekar R. Methods for solving cell formation, static layout and dynamic layout cellular manufacturing system problems: A review. Asian Journal of Science and Technology. 2015;06(12):2107-2112

[8] Kumar S, Sharma R. Cell formation heuristic procedure considering production data. International Journal of Production Management and Engineering. 2014;2(2):75-84. DOI: 10.4995/ijpme.2014.2078

[9] Sparling D. Balancing JIT production units: The N U-line balancing problem. Information Systems and Operational Research. 1998;36(4):215-237. DOI: 10.1080/03155986.1998.11732360

[10] Miltenburg J. Balancing U-lines in a multiple U-line facility. European Journal of Operational Research. 1998; 109(1):1-23. DOI: 10.1016/S0377-2217 (97) 00169-0

[11] Sparling D, Miltenburg GJ. The mixed-model U-line balancing problem. International Journal of Production Research. 1998;36(2):485-501. DOI: $10.1080 / 002075498193859$

[12] Thomopoulos N. Line balancingsequencing for mixed-model assembly. Management Science. 1967;14(2): B59-B75

[13] Mustafa F, Kursad A, Mustafa Y. A new algorithm for U-shaped two-sided assembly line. Transactions of the Canadian Society for Mechanical Engineering. 2010;34(2):225-241

[14] Fathi M, Alvarez M, Rodriguez VA. New heuristic approach to solving U-shape assembly line balancing problems type. World Academy of Science Engineering and Technology. 2011;59:413-421

[15] Turkay AF. On the MILP-model for the U-shaped assembly line balancing problems. European Journal of 
Operational Research. 2015;242:

343-346. DOI: 10.1016/j.

ejor.2014.10.036

[16] Chutima P, Suchanun T.

Productivity improvement with parallel adjacent U-shaped assembly lines.

Advances in Production Engineering \& Management. 2019;14(1):51-64. DOI:

10.14743/apem2019.1.311

[17] Wemmerlöv U, Hyer N. Cellular manufacturing in the US industry: A survey of users. International Journal of Production Research. 1988;27(9):

1511-1530. DOI: $10.1080 /$

00207548908942637

[18] Macaskill JLC. Production-line balances for mixed-model lines.

Management Science. 1972;19(4): 423-434

[19] Ahmadi RH, Wurgaft H. Design for synchronized flow manufacturing. Management Science. 1994;40(11): 1469-1483

[20] Urban TL. Optimal balancing of Ushaped assembly lines. Management Science. 1998;44(5):738-741

[21] Al Kattan I. Workload balance of cells in designing of multiple cellular manufacturing systems. Journal of Manufacturing Technology

Management. 2005;16(2):178-196. DOI: $10.1108 / 17410380510576822$

[22] Burbidge JL. The Introduction to Group Technology. Nueva York: John Wiley \& Sons; 1975 267p

[23] Seifoddini H, Hsu CP. Comparative study of similarity coefficients and clustering algorithms in cellular manufacturing. Journal of Manufacturing Systems. 1994;13(2): 119-127

[24] Kumar KR, Chandrasekharan MP. Grouping efficacy: A quantitative criterion for goodness of block diagonal forms of binary matrices in group technology. International Journal of Production Research. 1990;28(2): 233-243. DOI: $10.1080 /$ 00207549008942706

[25] Won Y, Currie K. An effective pmedian model considering production factors in machine cell-part family formation. Journal of Manufacturing Systems. 2006;25(1):58-64. DOI: 10.1016/S0278-6125(06)80033-6 


\title{
A Sustainability Assessment of Smart Innovations for Mass Production, Mass Customisation and Direct Digital Manufacturing
}

\author{
Hana Trollman and Frank Trollman
}

\begin{abstract}
Smart production innovations are set to revolutionise manufacturing, yet little is known about their impact on sustainability. This chapter focuses on the evaluation of production innovations related to Industry 4.0 that may make products and processes more sustainable or less sustainable based on the application in different production systems. A review of current literature and use of sustainability hierarchies finds that, in the environmental dimension, mass production would benefit most from the introduction of a pull principle whereas for mass customization, machine to machine communication is recommended. The use of augmented reality is indicated as an asset to the sustainability of direct digital manufacturing. Results including the environmental, social and economic dimensions of sustainability are confirmed using value analysis.
\end{abstract}

Keywords: sustainable manufacturing, Industry 4.0, direct digital manufacturing, mass production, mass customisation

\section{Introduction}

The three main production methods are mass production (also known as flow production or continuous production), job production and batch production. Job production is custom work characteristic of craft production. Batch production makes specified groups or amounts of products so that changes in material or detail can happen between batches. Very small batch sizes are characteristic of mass customization.

Craft production dominated manufacturing prior to the mid-nineteenth century. Competitive priorities included cost and quality with low volume output, agility and individualised products. Craft, however, became unable to satisfy growing market demand, lost connection with industrial progress, and could not compete as identity and local uniqueness fell out of favour with the rise of low-cost mass production [1].

The first machine tools for mass production were developed in Britain in the mid-eighteenth century. These included precision lathes and measuring instruments such as the bench micrometre. Machine tool technology made it possible to have interchangeable parts, and this enabled mass production. The concept of mass 
production was refined by Henry Ford in the early twentieth century with the introduction of the moving belt assembly line. Mass production uses special-purpose machines for efficient high-volume production at the expense of flexibility [2].

The term 'mass customization' was introduced as 'companies try to reach the same large segment of customers in the market but by treating them individually like a customized market' [3]. The main characteristics of mass customization are variety that meets customer needs with prices comparable to mass production $[4,5]$.

Mass customization aims to provide personalised products in an industrial environment. With the introduction of Industry 4.0, mass customization is gaining popularity. Big data applications may provide insight into customer preferences and optimise current manufacturing configurations [6]. However, mass customization is associated with additional costs and end-of-life issues when compared to mass production.

Direct digital manufacturing (DDM) combines product modelling and manufacturing technology to eliminate the need for tooling as digital models are converted directly into physical objects [7]. The exploitation of DDM for mass production or mass customization is only just starting to be explored [8]. The new manufacturing paradigm of DDM comes with sustainability concerns that have not been fully investigated.

Industry 4.0 consists of four design principles: interconnection, information transparency, technical assistance and decentralised decisions. The Industry 4.0 production innovations that will be investigated are cobots (physical assistant systems), machine-to-machine communication (M2M), radio frequency identification (RFID) and near-field communication (NFC) technology, quick response (QR) codes, augmented reality, mobile devices, condition monitoring/predictive maintenance, production based on the pull principle, intelligent resource management connecting machines and plants, and localised sourcing of parts.

This chapter connects Industry 4.0 innovations with mass production, mass customization and DDM to optimise their sustainability in the environmental, social and economic dimensions. A literature review of mass production, mass customization and DDM is followed by analysis of Industry 4.0 innovations using manufacturer sustainability needs hierarchies. Value analysis is used to confirm the results. Manufacturers may use these results to strategically select Industry 4.0 innovations which complement their production for improved sustainability.

\section{Mass production characteristics}

\subsection{Economics}

Mass production during the Industrial Revolution brought highly automated factories capable of producing large quantities of products. Cost was reduced, but this type of production required a high degree of standardisation. Consumers had to be willing to purchase the same product - for viability, mass production requires mass consumption. Products and the demand for products was not synchronised and consumers had little influence on changes to design. Mass production in the original Fordist sense has largely been replaced by leaner and more flexible systems.

Mass production is both capital intensive and energy intensive. Mass production is based on economies of scale so that capitalization (using financing to purchase equipment which will increase capacity) is almost always the more profitable approach. Equipment is usually the largest fixed cost asset. The goal is to reduce overheads in the cost of production. 
Mass production systems are difficult to restructure and lack mobility to respond to changes in consumer demand. Classical material requirements planning (MRP) based production is a 'push' system that schedules the jobs in advance for work centres that push the completed jobs to succeeding work centres. Work in progress (WIP) queues and stock levels may be high and long delays often occur as this approach does not take into account the workload of the next work centre. This may be contrasted with just in time (JIT) which uses a 'pull' approach in which the next job is requested from the preceding work centre only when work is finished so that queues and WIP are greatly eliminated. Elements of JIT and MRP may be combined as 'mixed' systems.

Process manufacturing in industries such as chemicals and petrochemicals, gas processing, power generation or water and wastewater [9] uses two basic types of production: continuous and batch [10]. Discrete manufacturing produces distinct items such as units of piece goods, fluids and pasty products or bulk materials which are processed and packaged. The two basic types of production in discrete manufacturing are continuous and intermittent.

Process industries are usually large-scale operations with general purpose equipment, high levels of automation and system complexity, low speed processes and high product value. Discrete processing is small- to medium-scale with dedicated machines, medium to high levels of automation and low system complexity, very high-speed processes and low product value.

The items of significant cost involved in resource consumption in automated manufacturing systems are: machines and cutting tool holders, computer systems, robot and automated guided vehicles (AGV) systems, automated storage and retrieval systems (AS/RS), fixed assets, externally provided resources, direct and indirect labour, insurance and indirect material, cutting tools and fixtures, direct energy consumption, direct material, and other services such as maintenance, process planning, industrial engineering activities, accounting and finance, administration, and marketing [11]. Where the manufacturing environment is relatively unreliable due to equipment failure, interruptions in work feeding, missing cutting tools, operator absence, etc., push systems may provide better lead time and throughput time performance [11].

\subsection{Workforce}

At the beginning of the twentieth century, Frederick W. Taylor introduced scientific management to measure the output of workers [12]. The main goal of scientific management was to improve economic efficiency, particularly labour productivity. Monotony of labour may lead to high staff turnover. Taylor's work focused on the needs of the process as opposed to individual worker's needs which led to worker unrest, turnover and social conflict. In modern industry, analysis methods based on Rasmussen's abstraction hierarchy [13] may be used for work domain analysis to support operators.

There are fewer manufacturing jobs in post-industrial economies. Health and safety as well as quality are important considerations in modern manufacturing. In process industries the focus on safety is very high and severe accidents are rare whereas in discrete processing most faults and abnormal situations have only economic consequences and stoppages occur regularly. As a consequence of the different characteristics of the technical systems of process and discrete manufacturing, there are different demands on operators [14]. For example, discrete processing does not require highly educated operators, utilises migrant or seasonal workers with few permanent positions, and tasks are highly repetitive. Repetitive strain injury (RSI) is a common and serious health problem. In contrast, process 
manufacturing relies on operators with vocational training having an understanding of the process so that proactive measures may be applied to complex interactions in dealing with faults.

Workers in mass production are motivated to focus on functional performance to ensure reliability and efficiency. This may be evaluated quantifiably using measures such as scrap rates [15].

\subsection{Environment}

Mass production utilises less resources than mass customization, but may contribute to greater waste as consumer needs may not be completely satisfied. The consumers are generally anonymous and hence it is not possible to track products for recycling or remanufacture. End-of-life (EOL) strategies for products that are recovered are likely to be easier to apply due to the uniformity of the products.

\section{Mass customization characteristics}

\subsection{Economics}

Customization differs from personalization. Personalization is the identification of a product by the manufacturer based on consumer profile so that it is likely to be unique. Customization involves consumers selecting from a given set of product options so uniqueness is unlikely.

Mass customization aims to produce customised products for individual needs with mass production efficiency. To be successful, manufacturers of mass customised products need to be flexible and quick in responding to market conditions. Although mass customization provides more choice than mass production, the manufacturer retains control over what is produced in contrast to mass imagineering [16].

The 'pull' system drives mass customization. Digital infrastructures may facilitate co-creation via platforms and/or participation in events [17]. However, mass customization faces the challenges of overcoming the convenience of massproduced products [18], avoiding consumer confusion and overload from overwhelming choice [19], and individuals not confident about their creative abilities. It may not be a viable business model for all industries [20].

Mass customization requires different control systems for manufacturing operations than mass production. Such control systems need to cope with large varieties, very small batch size, random arrival of orders and spread due dates. Usually, the number of variants is predetermined; benefits in increased efficiency and reduced lead times may be related to the further downstream the customization order point is in the value chain $[21,22]$.

Flexible production technology, e-commerce and information communication technology enable easier customization at lower cost. Flexible logistics and distribution systems are also required. Close proximity to a supplier network of raw materials is important [23]. Information dissemination encompassing operations flows and customer knowledge may be the most important factor in implementing mass customization [24].

\subsection{Workforce}

Technology and operational systems may facilitate certain customization, but workforce characteristics are important to the development of strategic capabilities [25]. 
Workers must not only be proficient in their own jobs, but they should be able to integrate and coordinate across functions. In addition, multiple capabilities may be required of manufacturing resources (workers, robots, machines, workstations, etc.) [21].

Depending on the tasks, workers may still develop RSI, but the cause may be more difficult to identify. Similarly, it will be more difficult to establish correlation for other production related effects on health such as exposure to hazardous substances due to task and equipment variety.

Motivation is important so that employees engage in desirable behaviours [26] such as knowledge exchange and combination (KEC) [27] and positive emotions regarding customers [28]. Workers need to perform reliably as in mass production, but also cooperate with external functions to ensure compatibility of components and their integration [29]. Depending on the level of customization, being flexible, proactive and learning-oriented may also be required [25].

Consistent with total quality management (TQM), workers should have autonomy to make decisions regarding their tasks [30]. Task empowerment provides job enrichment and improves motivation and retention [29].

\subsection{Environment}

Mass customization may benefit from reduced returns and reduced inventory over mass production as more consumer desires are satisfied. Mass customization may be realised in any of the production process steps including design, fabrication, assembly or distribution [31].

Both mass production and mass customization may be modular, but modularity is a key enabler of efficient mass customization [4]. However, it is likely that more material resources will be necessary to make mass customised products compared to mass produced products since it is not possible to optimise modular products with regards to weight and thereby material usage [32].

Mass customization requires greater process flexibility compared to mass production due to greater product variety and subsequent process variety [33]. These different manufacturing processes compared to uniform production are consequently difficult to optimise with respect to energy and material consumption. On the product level, mass customised products may not be as easy to optimise for energy consumption as mass produced products. On the other hand, companies may invest in modules standardised across multiple products to potentially achieve greater energy efficiency than mass produced products.

Mass customised products are likely to be traceable back to a specific customer. This would make it easier to locate products at their end of life. However, end of life mass customised products may not fit another consumer's requirements, making them more difficult to reuse in original form unless the product is designed to be re-configurable or re-personalised [34].

It may be more difficult to determine if mass customised products, or which of their components, have negative environmental or health consequences. This may delay product recalls and other actions aimed at mitigation. An example is e-cigarette devices wherein the characteristics of the heating coils and atomizer may be customised by the users, each component may affect health outcomes independently, and components may interact to create effects different from the sum of their individual parts [35].

If a customised product is not suitable for reuse, the next consideration is to service or repair it. Custom fabricated components may not make it possible to remanufacture products. The variety of parts in a customised product may make it more difficult to service or replace them. A custom fabricated component is likely to be more expensive to replace than using standard components in a 
customised product. If the mass customised product is not self-reconfiguring and does not contain custom fabricated components, remanufacturing is a good EOL strategy.

The modularity of customised products would likely make them more amenable to upgrading than mass-produced products that do not have this modularity. Modularity would also assist with remanufacturing and recycling. Modular mass customised products may be easier to disassemble than mass produced products that are not modular. Modular product architecture may improve recyclability if it is possible to concentrate material fractions by module.

If a modular design is standardised across multiple products, considerations of material usage and end of life are likely to be issues of concern. If a modular design is assumed but cannot be standardised across multiple products, the most pressing environmental consideration for the manufacturer of mass customised products is likely to be process efficiency.

\section{Direct digital manufacturing characteristics}

\subsection{Economics}

Direct digital manufacturing (DDM) is the interconnection of decentralised additive manufacturing equipment and modern information and communication technology (ICT) [7]. DDM combines product design with manufacturing technology, usually $3 \mathrm{D}$ printing or additive manufacturing, to directly convert digital models into physical objects without the need for tooling. DDM uses 3D (CAD) models for direct fabrication of products without the need for process planning [36].

The use of DDM as a broad umbrella term encompasses applications in prototyping, tooling, low-volume parts manufacturing and customised product manufacture. Distributed production is a likely outcome of the use of DDM [37] with the expected emergence of agile supply chains [38]. The technology enables the matching of consumer demand and supply capacities in real-time, limited only by physical logistics.

Product characteristics for additive manufacturing are customisation, increased functionality through design optimisation and low volume. Investment in additive manufacturing may be seen as a structural investment which builds new manufacturing capabilities [39].

It is important to distinguish between personal fabrication and social manufacturing [40]. Personal fabrication is when individuals make products for their personal use employing, for example, home 3D printers. Social manufacturing occurs when individuals cooperate with organisations as part of production.

Industrial 3D printers cost around $£ 20,000$, but low-cost 3D printers, some of which are self-replicating, are available to the public [41] for about $£ 500$. One of the top-rated 3D printers currently on the market sells for about $£ 2600$. Some home 3D printers have the capability to print three different materials in one session for 3D prints that have moving parts.

The key perceived strengths of additive manufacturing are agility, in-process visualisation, novel business models, reduced upfront fixed cost and risk, potential for decentralised production, and a reduction in transports [42]. DDM has the potential to dramatically change conventional supply chains if the 'factory in every home that can make more factories' is achieved [41]. The only transport related to home use of products printed at home would be of the raw materials, usually in the form of wire or powder. Cost analysis indicates home manufacturing is a profitable proposition for U.S. households [43, 44]. 
Prices and times to print large objects increase exponentially. Even though 3D printed health aids are becoming available, regulating the conformity and quality of products in general is problematic [45]. Other technical challenges include timeconsuming $3 \mathrm{D}$ object design, limited types of usable materials, low precision and productivity [46]. Additional labour costs may be incurred for post processing such as removing residual powder - this is often underestimated or neglected [47].

It has been demonstrated that 3D printing may be applied to mass production/ mass customization $[46,48,49]$. The advantages of 3D printing over conventional mass production methods include saving time, money and effort in creating the dedicated capacity and materials, prototyping and moulding. A quicker response may be achieved by using multiple 3D printing facilities simultaneously in a local area using industrial Internet of Things (IIoT) technology and maximising the closeness to JIT [8].

Mass imagineering digital infrastructures may require a high level of technology awareness. Internet-enabled global networking may provide the means for financial rewards at almost no financial risk, but time may need to be invested. There may, however, be risks to personal reputation [50].

Research has found that the key driver for adoption of additive manufacturing is the capability of producing almost any complex design with economic motives being pivotal [51].

\subsection{Workforce}

The toxicological and environmental hazards of handling, using and disposing of materials used in DDM processes are not fully understood. Compared to processes such as casting, forging and machining, workers do not experience long-term exposure to noise and oil mist from metal working [52]. However, 3D printing is being associated with the release of volatile and very volatile organic chemicals and billions of airborne particles per minute with potential for inhalation and consequent health risks $[53,54]$. Although many industrial 3D printers are enclosed, workers may still be exposed to inhalation risks when retrieving the printed parts. Occupational exposure limits have yet to be established for 3D printer emissions [55]. As with any new technology, these issues should be resolved over time.

The premise behind DDM is that designs will be co-created through collaboration. Acquiring the necessary skills may be possible online using basic knowledge of computers. This may enable promises of equality, justice and self-actualization. But this may also lead to the exploitation of individuals who may or may not realise that digital infrastructures are collecting their personal data and that they are doing unpaid work $[56,57]$. Work that is paid may be poorly paid, precarious and intermittent. For profitable mass production using DDM, design is likely to be key and the extent to which co-created designs may outperform those of traditional mass production or mass customization remains to be seen.

Furthermore, there is no absolute geometric freedom and many considerations for eco-design which existing methods and guidelines for conventional manufacturing do not cover indicate that to realise the full potential of DDM for more complex products, specialist designers may be required [58]. Design for do-it-yourself is under-explored in academia [59].

\subsection{Environment}

Very little sustainability research has examined personal fabrication, social manufacturing or even the industrial use of DDM in distributed production [37]. The environmental implications of these evolving manufacturing processes have 
not been extensively examined [47]. The focus of research has been on sustainable development through additive manufacturing by (1) improved resource efficiency permitted by redesign of both products and processes for in-house waste minimisation; (2) product life extension using technical approaches and stronger personproduct relation; and (3) simplified value chains by reduction of logistic complexity and placing production nearer to the consumer [60].

Environmental effects such as biodegradability and ecotoxicity are not fully understood. Similarly, little is known about the chemical solvents used for removing excess material during the steriolitography (SLA) process as well as environmental effects related to selective laser sintering (SLS), laser additive manufacturing (LAM), dynamic magnetic compression (DMC) and direct metal fabrication (DMF) [61].

Evaluation of the energy consumption has not been thoroughly investigated [51] nor has water consumption and treatment [61]. Polymers, the most processed type of powders in SLS, have quite a low sintering temperature $\left(<200^{\circ} \mathrm{C}\right)$. A partial consideration of SLS which does not include the efficiency of the laser source or auxiliary energy finds a low energetic intensity of the process, but there is no direct comparison possible with other rapid prototyping techniques or conventional manufacturing processes from the quality perspective [62]. Smaller thickness layer and optimal part orientation may overcome surface quality issues, but processing time and thus energy consumption is increased [58].

Additive as opposed to subtractive manufacturing may help to reduce material input into production. Not all material from DDM is reclaimable. Powder bed processing of polymers causes up to $50 \%$ of the build volume in waste which cannot be reused. Significant energy may be required in the production of the required raw materials (feedstock), but there may be significant saving if recycling is possible [47]. There is potential to combine surplus agricultural materials such as soybean to create composites of comparable strength to those made from petroleum-based resins [63] or to utilise local waste streams (mussel shells) [64].

Energy savings may be obtained through reduced material demand and use phase savings due to lighter weight. However, the benefits of components produced through additive manufacturing versus traditional manufacturing are questionable for automotive components when considered in the context of additional manufacturing impacts caused by powder production, processing and post treatment [65]. Some authors have concluded that it is not possible to determine whether 3D printing is more environmentally friendly that machining or vice versa [66].

It is likely that hybrid additive manufacturing and subtractive manufacturing will be desirable so there will be a need for intelligent algorithms to determine process parameter combinations. With multiple additive manufacturing systems, an intelligent factory with resource allocation and self-organisation capabilities would be optimal [58]. An investigation of DDM-based operational practices to build sustainability capabilities anticipates increased local supply chain partners, reduced material flows, inventory and transport operations, and more sustainable product lifecycle management [67]. However, many of these operations are likely to be complex such as the addition of sensors to products, the extent of customer control over the production process and dynamic supply chain reconfiguration.

Distributed manufacturing may significantly reduce transports over centralised manufacturing [68], however, raw material transport may offset some of these benefits. There is a significant risk that additive manufacturing may trigger a rebound effect through an increase in overall consumption, especially in fashion products [69]. It is also not clear whether mass customization in DDM will precisely match consumer needs and thus eliminate waste, or if the availability of DDM will increase waste through trial productions. Environmental sustainability benefits are 
barely relevant to the decision of manufacturers to adopt additive manufacturing which contrasts with literature stating the considerable sustainability benefits [51].

The eco-design concept enabled by additive manufacturing has the most potential for providing sustainability improvements [58]. Symbiotic, life cycle and closed loop links could significantly reduce or eliminate the negative impacts of additive manufacturing. Improved design has the potential to increase market acceptance which may lead to reduced waste. Additive manufacturing has potential to provide spare parts and impact the modularity of products relevant to circular economy efforts [70]. As additive manufacturing may be used to repair or remanufacture damaged components, savings of up to $50 \%$ may be achieved [47]. More efficient designs may be possible with additive manufacturing as well as the integration of additional technical functionality [47].

\section{Smart production innovations}

Cyber-physical systems (CPS) facilitate the connection and communication of software and mechanical or electrical elements using wired or wireless data infrastructure. This technology makes it possible to monitor and direct production systems with complex processes at all hierarchy levels and with high product varieties. The anticipated paradigm shift in manufacturing to Industry 4.0 or smart factories and production systems will decentralise traditional centralised applications for production control [71]. Industry 4.0 innovations/technical developments which will enable this paradigm shift include [72]:

1. Cobots that will assist workers in handling physical objects.

2. M2M meaning machines will communicate with each other to improve process flow, do capacity planning and reduce process time. This will include the monitoring of components for wear to prevent or reduce breakdowns.

3. RFID and NFC technology enable wireless communication. This technology is currently used in warehouse management and logistics, product tracking in supply chains, product security, raw material tracking, point of sale, and other applications.

4. QR codes used to identify parts or tools, or provide more information about a product.

5. Augmented reality to display additional information such as instructions, or to help with visualisation of objects in a physical space. Simulation may enable quality control so that potential defects may be corrected prior to physical production.

6. Mobile devices that may be used to give instructions to workers, apps may monitor or control machines, machines may be tracked via QR codes, and images or videos may be sent as part of support or service.

7. Condition monitoring/predictive maintenance reduces unscheduled machine stoppages using electric motors to measure and track data about mechanical stress and operating temperature which are usually sent to a cloud for storage and analysis. This reduces waste as parts are replaced after they are worn as opposed to after a pre-defined life. 
8. Production based on the pull principle means that raw material or semi-finished production material is requested on demand automatically. Technology may be used to enable hybrid push-pull manufacturing based on customer order decoupling point (COPD) [73].

9. Intelligent resource management connecting machines and power plants can plan energy intensive activities when surplus energy is available.

10. Localised sourcing of parts has the benefit of providing local employment and reducing transports.

The effect of Industry 4.0 on sustainability is unknown in detail. Smart production systems are expected to reduce waste, overproduction and energy consumption. The following section will introduce the sustainability hierarchies and apply them to mass production, mass consumption and DDM to determine which of the above Industry 4.0 innovations would be of greatest benefit with respect to the financial, environmental and social sustainability needs of manufacturers.

\section{Hierarchies of sustainability dimensions}

Needs-based hierarchies for the sustainability dimensions reflecting the triple bottom line [74] are shown in Figure 1 below [75].

Environmental impact has been used to justify the hierarchy of end-of-life strategies [76]. The sustainability needs hierarchies in Figure 1 reflect the current sustainability discursive paradigm with respect to impact on the manufacturer.

The financial and social hierarchies may be considered in terms of time to failure if sufficient capability is not achieved, e.g. if a critical machine (tangible asset) fails, products cannot be made until it is repaired and business will be lost when current inventory is exhausted. The application of the environmental hierarchy is more complicated as the impacts are cumulative, e.g. reducing the amount of material input improves process efficiency and is likely to reduce waste.

The hierarchies connect to systems at higher levels and treat each dimension of sustainability individually unlike the general Corporate Social Responsibility (CSR) need-hierarchy [77]. The hierarchies also reflect the current view that sustainability is no longer considered at the self-actualization level of needs, but rather the necessary reorientation of manufacturers from profit toward the holistic well-being of all stakeholders so that sustainability is a consideration at all levels. It is important to note that needs at the lower levels should be satisfied to maximise impact, but as with Maslow's hierarchy of needs, it is possible to pursue needs at higher levels simultaneously.

A distance-to-target methodology may be used to determine indicators within the hierarchies as the sustainability impacts do not need to be converted to a unified form such as money, energy or ecological footprints [78]. An example of targets and their impact on the manufacturer if targets are not met corresponding to Figure 1 is shown in Table 1.

The examples of Table 1 indicate that the sustainability needs hierarchies arise primarily from a strategy perspective similar to the hierarchy of corporate resources [79].

\subsection{Extension of the hierarchies to mass production, mass customization and DDM}

The hierarchies may be applied to cases of individual manufacturers [75] or, more generally, to a method of production. Based on the preceding literature 


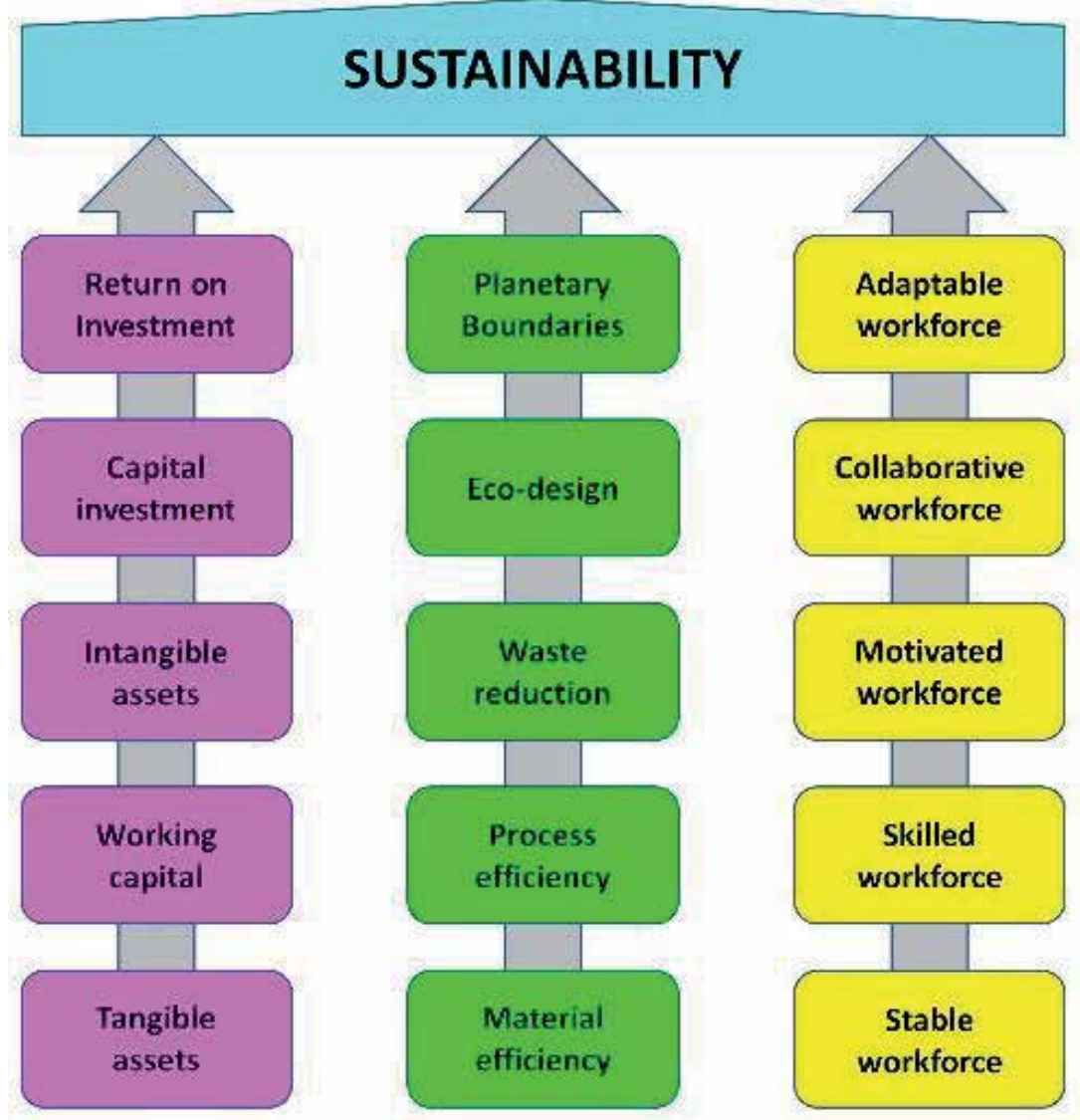

Figure 1.

Sustainability needs hierarchies for manufacturers [75].

\begin{tabular}{llllll}
\hline Financial needs & Environmental needs & Social needs & Impact if not \\
\hline Target & Impact if not met & Target & Target & $\begin{array}{l}\text { Impact if not } \\
\text { met }\end{array}$ \\
\hline $\begin{array}{l}\text { Dividend } \\
\text { payments }\end{array}$ & $\begin{array}{l}\text { Loss of investor } \\
\text { interest }\end{array}$ & $\begin{array}{l}\text { Emissions within } \\
\text { limits for planetary } \\
\text { boundaries }\end{array}$ & $\begin{array}{l}\text { Unsustainable } \\
\text { planet }\end{array}$ & $\begin{array}{l}\text { Innovation } \\
\text { (patents, IP) }\end{array}$ & $\begin{array}{l}\text { Industry } \\
\text { stagnation }\end{array}$ \\
\hline $\begin{array}{l}\text { No } \\
\text { obsolescence }\end{array}$ & $\begin{array}{l}\text { Years based on } \\
\text { depreciation } \\
\text { time to loss of } \\
\text { competitive-ness }\end{array}$ & $\begin{array}{l}\text { All products } \\
\text { and processes } \\
\text { co-designed for } \\
\text { environment }\end{array}$ & $\begin{array}{l}\text { Climate change, } \\
\text { severe weather } \\
\text { events, etc. }\end{array}$ & $\begin{array}{l}\text { Customer } \\
\text { satisfaction }\end{array}$ & Loss of \\
customers
\end{tabular}

Table 1.

Examples of targets and their related impacts. 


\begin{tabular}{|c|c|c|c|c|}
\hline Method of producti & & $\begin{array}{l}\text { Financial } \\
\text { needs } \\
\text { hierarchy }\end{array}$ & $\begin{array}{l}\text { Environmental } \\
\text { needs hierarchy }\end{array}$ & $\begin{array}{l}\text { Social needs } \\
\text { hierarchy }\end{array}$ \\
\hline \multirow[t]{2}{*}{ Mass production } & Discrete & Tangible assets & Waste & Stable workforce \\
\hline & Process & Tangible assets & Waste & Skilled workforce \\
\hline \multirow[t]{2}{*}{ Mass customization } & $\begin{array}{l}\text { Modularity } \\
\text { Across } \\
\text { products }\end{array}$ & $\begin{array}{l}\text { Intangible } \\
\text { assets }\end{array}$ & $\begin{array}{l}\text { Resource } \\
\text { efficiency }\end{array}$ & $\begin{array}{l}\text { Collaborative } \\
\text { workforce }\end{array}$ \\
\hline & $\begin{array}{l}\text { No modularity } \\
\text { across products }\end{array}$ & $\begin{array}{l}\text { Intangible } \\
\text { assets }\end{array}$ & $\begin{array}{l}\text { Material } \\
\text { efficiency }\end{array}$ & $\begin{array}{l}\text { Collaborative } \\
\text { workforce }\end{array}$ \\
\hline \multirow[t]{2}{*}{$\begin{array}{l}\text { Direct digital } \\
\text { manufacturing } \\
(\mathrm{DDM})\end{array}$} & Household & $\begin{array}{l}\text { Return on } \\
\text { investment } \\
\text { (ROI) }\end{array}$ & Eco-design & $\begin{array}{l}\text { Adaptable } \\
\text { workforce }\end{array}$ \\
\hline & Corporate & $\begin{array}{l}\text { Working } \\
\text { capital }\end{array}$ & Eco-design & $\begin{array}{l}\text { Adaptable } \\
\text { workforce }\end{array}$ \\
\hline
\end{tabular}

Table 2.

Hierarchy levels for mass production, mass customization and DDM.

\begin{tabular}{llll}
\hline $\begin{array}{l}\text { Method of } \\
\text { production }\end{array}$ & Industry 4.0 innovation/technical development & \\
\cline { 2 - 4 } & Financial need & $\begin{array}{l}\text { Environmental } \\
\text { need }\end{array}$ & Social need \\
\hline Mass production & $\begin{array}{l}\text { Condition monitoring/ } \\
\text { predictive maintenance }\end{array}$ & $\begin{array}{l}\text { Production based } \\
\text { on a pull principle }\end{array}$ & $\begin{array}{l}\text { Cobots (discrete)/ } \\
\text { augmented reality (process) }\end{array}$ \\
\hline $\begin{array}{l}\text { Mass } \\
\text { customization }\end{array}$ & $\begin{array}{l}\text { RFID, NFC technology/QR } \\
\text { codes }\end{array}$ & $\begin{array}{l}\text { M2M (resource } \\
\text { efficiency) }\end{array}$ & Mobile devices \\
\hline $\begin{array}{l}\text { Direct digital } \\
\text { manufacturing } \\
\text { (DDM) }\end{array}$ & $\begin{array}{l}\text { Intelligent resource } \\
\text { management connecting } \\
\text { machine and plant for mass }\end{array}$ & $\begin{array}{l}\text { Augmented } \\
\text { reality }\end{array}$ & $\begin{array}{l}\text { Localised sourcing of } \\
\text { material }\end{array}$ \\
\hline
\end{tabular}

Table 3.

Matching industry 4.0 innovations to methods of production.

review of mass production, mass customization and DDM, Table 2 indicates the corresponding level of most impact for each of these production systems in the hierarchies.

\subsection{Integrating manufacturer needs with industry 4.0 innovations}

Using Table 2 of the needs with the most impact on the method of production, it is now possible to use the descriptions of the Industry 4.0 innovations and match them to these needs to indicate where the greatest sustainability benefit may be achieved. The result is shown in Table 3.

\section{Value analysis}

The sustainable value analysis tool (SVAT) [80] is applied to each of the production systems to confirm the results of the hierarchies. The purpose of SVAT is to analyse multiple forms of value across the entire life cycle through the dimensions of economic, social and environmental sustainability. SVAT may be implemented in four steps: 
1. Product life cycle definition;

2. Description of value captured;

3. Identification of value uncaptured; and

4. Analysis of value uncaptured and exploration of value opportunities.

For the first step, a modular product is assumed. At the beginning of life, this modular product may be mass produced, mass customised or be the output of DDM in a business context. The use phase at the middle of life is assumed to be the same for all production processes. The modular product is also assumed to be fit for disassembly into modules for end of life treatment such as remanufacture, refurbishment or recycling.

Tables 4-6 describe value captured and value uncaptured for each production system based on the literature.

The value opportunity for each production system may be associated with an Industry 4.0 innovation. Value opportunities are identified through new activities and relationships. Each identified value uncaptured may be analysed to find its source. Reducing value uncaptured through potential solutions leads to value opportunities.

The value opportunities for mass production include incorporating 'pull' into the production system, finding an activity or relationship to utilise overproduction, entering into relationships to better enable product recovery as well as improving

\begin{tabular}{|c|c|c|c|c|}
\hline \multicolumn{2}{|c|}{ Mass production } & \multirow{2}{*}{$\begin{array}{l}\text { Beginning of } \\
\text { life (BOL) }\end{array}$} & \multirow{2}{*}{$\begin{array}{l}\text { Middle of life (MOL) } \\
\text { Economies of scale for } \\
\text { distribution and retail, standard } \\
\text { service and maintenance }\end{array}$} & \multirow{2}{*}{$\begin{array}{l}\begin{array}{l}\text { End of life } \\
\text { (EOL) }\end{array} \\
\text { Uniform } \\
\text { treatment }\end{array}$} \\
\hline Value captur & & & & \\
\hline \multirow[t]{4}{*}{$\begin{array}{l}\text { Value } \\
\text { uncaptured }\end{array}$} & $\begin{array}{l}\text { Value } \\
\text { destroyed }\end{array}$ & $\begin{array}{l}\text { Large } \\
\text { throughput } \\
\text { leading to more } \\
\text { pollution }\end{array}$ & Unsatisfied needs leading to waste & $\begin{array}{l}\text { Increased } \\
\text { capacity } \\
\text { required due } \\
\text { to waste from } \\
\text { MOL }\end{array}$ \\
\hline & $\begin{array}{l}\text { Value } \\
\text { missed }\end{array}$ & $\begin{array}{l}\text { Push } \\
\text { production, } \\
\text { inflexible } \\
\text { product and } \\
\text { process design }\end{array}$ & $\begin{array}{l}\text { Understanding of consumer, } \\
\text { product use data }\end{array}$ & $\begin{array}{l}\text { Information } \\
\text { about product } \\
\text { location }\end{array}$ \\
\hline & $\begin{array}{l}\text { Value } \\
\text { surplus }\end{array}$ & Overproduction & $\begin{array}{l}\text { Potential satisfaction of a large } \\
\text { number of consumers }\end{array}$ & $\begin{array}{l}\text { Product } \\
\text { availability } \\
\text { in large } \\
\text { quantities }\end{array}$ \\
\hline & $\begin{array}{l}\text { Value } \\
\text { absence }\end{array}$ & $\begin{array}{l}\text { Labour } \\
\text { shortages, } \\
\text { stoppages and } \\
\text { breakdowns, } \\
\text { high risk in } \\
\text { tangible asset } \\
\text { investment }\end{array}$ & $\begin{array}{l}\text { Lack of customization/ } \\
\text { personalization }\end{array}$ & $\begin{array}{l}\text { Product } \\
\text { recovery not } \\
\text { enabled - } \\
\text { reliance on } \\
\text { third parties }\end{array}$ \\
\hline
\end{tabular}

Table 4.

SVAT analysis for mass production. 


\begin{tabular}{|c|c|c|c|c|}
\hline \multicolumn{2}{|c|}{ Mass customization } & \multirow{2}{*}{$\begin{array}{l}\text { Beginning of life } \\
\text { (BOL) }\end{array}$} & \multirow{2}{*}{$\begin{array}{l}\text { Middle of life } \\
\text { (MOL) }\end{array}$} & \multirow{2}{*}{$\begin{array}{l}\text { End of life (EOL) } \\
\begin{array}{l}\text { Product and } \\
\text { consumer data }\end{array}\end{array}$} \\
\hline Value captur & & & & \\
\hline \multirow[t]{4}{*}{$\begin{array}{l}\text { Value } \\
\text { uncaptured }\end{array}$} & Value destroyed & $\begin{array}{l}\text { Input resource } \\
\text { inefficiencies, } \\
\text { changeovers } \\
\text { and process } \\
\text { inefficiencies, more } \\
\text { packaging }\end{array}$ & $\begin{array}{l}\text { Increased } \\
\text { transport for } \\
\text { distribution, more } \\
\text { complex service } \\
\text { and maintenance }\end{array}$ & $\begin{array}{l}\text { Complicated } \\
\text { product treatment }\end{array}$ \\
\hline & Value missed & $\begin{array}{l}\text { Complicated product } \\
\text { and process design }\end{array}$ & $\begin{array}{l}\text { Product } \\
\text { distribution } \\
\text { combined with } \\
\text { other distribution } \\
\text { or collection }\end{array}$ & $\begin{array}{l}\text { Product collection } \\
\text { combined with } \\
\text { other collection or } \\
\text { distribution }\end{array}$ \\
\hline & Value surplus & $\begin{array}{l}\text { Workforce } \\
\text { capabilities }\end{array}$ & Consumer use data & $\begin{array}{l}\text { Product location } \\
\text { for recovery }\end{array}$ \\
\hline & Value absence & $\begin{array}{l}\text { Lack of economy of } \\
\text { scale in production }\end{array}$ & $\begin{array}{l}\text { Lack of economy of } \\
\text { scale in distribution } \\
\text { and retail }\end{array}$ & $\begin{array}{l}\text { Lack of uniformity } \\
\text { in product } \\
\text { treatment }\end{array}$ \\
\hline
\end{tabular}

Table 5.

SVAT analysis for mass customization.

\begin{tabular}{|c|c|c|c|c|}
\hline \multicolumn{2}{|c|}{ Direct digital manufacturing (DDM) } & $\begin{array}{l}\text { Beginning of life } \\
\text { (BOL) }\end{array}$ & $\begin{array}{l}\text { Middle of life } \\
\text { (MOL) }\end{array}$ & End of life (EOL) \\
\hline \multicolumn{2}{|c|}{ Value captured } & $\begin{array}{l}\text { Personalization } \\
\text { of product, niche } \\
\text { applications, no } \\
\text { tooling or process } \\
\text { planning, localised } \\
\text { sourcing of materials, } \\
\text { minimal inventory }\end{array}$ & $\begin{array}{l}\text { Distributed } \\
\text { production, need } \\
\text { satisfaction }\end{array}$ & $\begin{array}{l}\text { Spare part } \\
\text { production }\end{array}$ \\
\hline \multirow[t]{4}{*}{$\begin{array}{l}\text { Value } \\
\text { uncaptured }\end{array}$} & Value destroyed & $\begin{array}{l}\text { Waste, resource and } \\
\text { process inefficiencies }\end{array}$ & $\begin{array}{l}\text { Traditional retail } \\
\text { and distribution, } \\
\text { potentially } \\
\text { complicated } \\
\text { service and } \\
\text { maintenance }\end{array}$ & Landfill \\
\hline & Value missed & $\begin{array}{l}\text { Need for new supply } \\
\text { chains, limited } \\
\text { material options, } \\
\text { expensive input } \\
\text { material, resource and } \\
\text { process inefficiencies, } \\
\text { slow production, small } \\
\text { batches, quality issues }\end{array}$ & $\begin{array}{l}\text { Increased } \\
\text { transports }\end{array}$ & $\begin{array}{l}\text { Complicated } \\
\text { collection and } \\
\text { treatment }\end{array}$ \\
\hline & Value surplus & $\begin{array}{l}\text { Potential overcapacity } \\
\text { of free/cheap labour to } \\
\text { exploit }\end{array}$ & $\begin{array}{l}\text { Potential excess } \\
\text { capture of } \\
\text { personal data }\end{array}$ & $\begin{array}{l}\text { Potential excess of } \\
\text { material available } \\
\text { for reprocessing }\end{array}$ \\
\hline & Value absence & $\begin{array}{l}\text { Lack of competent } \\
\text { designers, health risks }\end{array}$ & $\begin{array}{l}\text { Lack of facilities } \\
\text { for maintenance } \\
\text { and service }\end{array}$ & $\begin{array}{l}\text { Lack of suitability } \\
\text { for treatment }\end{array}$ \\
\hline
\end{tabular}

Table 6.

SVAT analysis for DDM. 
product design to reduce use phase impacts. Reducing labour shortages and lower risk related to the high tangible asset investment would also be a target.

The value opportunities for mass customization include improving resource efficiency, entering into relationships to fully utilise product distribution and collection, and the provision of suitable information to those engaged in end of life treatment of products.

The value opportunities for DDM centre on relationships with designers for improvements at all life cycle stages. New relationships should be developed for both supply chain and reverse logistics.

\section{Conclusion}

The main contribution of this chapter is the assessment of smart production innovations related to Industry 4.0 to determine the most beneficial for mass production, mass customization and direct digital manufacturing, respectively, taking into consideration the three dimensions of sustainability (Table 3).

SVAT yields the same conclusions, although less refined, as the manufacturer needs hierarchies in respect of Industry 4.0 innovation selection.

Manufacturers should consider their strategic sustainability needs based on their production system when selecting smart production innovations.

\section{Author details}

Hana Trollman ${ }^{1 *}$ and Frank Trollman ${ }^{2}$

1 Loughborough University, Loughborough, United Kingdom

2 University Hospitals of Leicester NHS Trust, Leicester, United Kingdom

*Address all correspondence to: h.trollman2@lboro.ac.uk

IntechOpen

(C) 2019 The Author(s). Licensee IntechOpen. This chapter is distributed under the terms of the Creative Commons Attribution License (http://creativecommons.org/licenses/ by/3.0), which permits unrestricted use, distribution, and reproduction in any medium, provided the original work is properly cited. (cc) BY 


\section{References}

[1] Alexandre C, Gomez E, Valente A. Interdisciplinary relationship between designer and craftsman based on integrated craft manufacturing systems. Procedia Engineering. 2015;132: 1089-1095. DOI: $10.1016 /$ j. proeng.2015.12.600

[2] Sabel C, Zeitlin J. World of Possibilities. Flexibility and Mass Production in Western Industrialization. Cambridge, United Kingdom: Cambridge University Press; 1997. 524 p. ISBN: 9780521495554

[3] Davis S. From 'future perfect': Mass customizing. Planning Review. 1989;17:16-21. DOI: 10.1108/eb054249

[4] Pine B. Mass Customization: The New Frontier in Business Competition. Harvard: Harvard Business Press; 1992. 368 p. ISBN: 9780875843728 r

[5] Du X, Jiao J, Tseng M. Architecture of product family: Fundamentals and methodology. Concurrent Engineering. 2001;9:309-325. DOI: 10.1177/1063293X0100900407

[6] Zakim M, Theodoulidis B, Shapira P, Neely A, Tepel M. Redistributed manufacturing and the impact of big data: A consumer goods perspective. Production Planning and Control. 2019;30:568-581. DOI: 10.1080/09537287.2018.1540068

[7] Chen D, Heyer S, Ibbotson S, Salonitis K, Thiede S. Direct digital manufacturing: Definition, evolution, and sustainability implications. Journal of Cleaner Production. 2015;107: 615-625. DOI: 10.1016/j. jclepro.2015.05.009

[8] Chen T-C, Lin Y-C. A threedimensional-printing-based agile and ubiquitous additive manufacturing system. Robotics and ComputerIntegrated Manufacturing.
2019;55:88-95. DOI: 10.1016/j. rcim.2018.07.008

[9] Smith C. Practical Process Control: Tuning and Troubleshooting. Hoboken: Wiley; 2009. 448 p. ISBN: 978-0-470-43149-8

[10] Fransoo J, Rutten W. A typology of production control situations in process industries. International Journal of Operations \& Production Management. 1994;14:47-57. DOI: 10.1108/01443579410072382

[11] Ozbayrak M, Akgun M, Turker A. Activity-based cost estimation in a push/pull advanced manufacturing system. International Journal of Production Economics. 2004;87:49-65. DOI: 10.1016/S0925-5273(03) 00067-7

[12] Taylor F. The Principles of Scientific Management. Eastford: Martino Fine Books; 1919. 84 p. ISBN: 9781614275718

[13] Rasmussen J. Information Processing and Human-Machine Interaction: An Approach to Cognitive Engineering. New York: Elsevier; 1986. 228 p. ISBN: 0444009876

[14] Müller R, Oehm L. Process industries versus discrete processing: How system characteristics affect operator tasks. Cognition, Technology \& Work. 2019;21:337-356. DOI: 10.1007/ s10111-018-0511-1

[15] Wright P, Snell S. Toward a unifying framework for exploring fit and flexibility in strategic human resource management theory. Academy of Management Review. 1998;23:756-772. DOI: $10.2307 / 259061$

[16] Fox S. Mass imagineering, mass customization and mass production: Complementary cultures for creativity, choice and 
A Sustainability Assessment of Smart Innovations for Mass Production, Mass Customisation... DOI: http://dx.doi.org/10.5772/intechopen.88897

convenience. Journal of Consumer Culture. 2019;19:67-81. DOI: $10.1177 / 1469540517705945$

[17] Carah N. Algorithmic brands: A decade of brand experiments with mobile and social media. New Media \& Society. 2017;19:384-400. DOI: $10.1177 / 1461444815605463$

[18] Andreasen A. Life status changes and changes in consumer preferences and satisfaction. Journal of Consumer Research. 1984;11:784-794. DOI: $10.1086 / 209014$

[19] Huffman C, Kahn B. Variety for sale: Mass customization or mass confusion. Journal of Retailing. 1998;74:491-513. DOI: $10.1016 /$ S0022-4359(99)80105-5

[20] Broekhuizen T, Alsem K. Success factors for mass customization: A conceptual model. Journal of Market-Focused Management. 2002;5:309-330. DOI: 10.1023/B:JMFM.0000008072.35988.ef

[21] Tseng M, Lei M, Su C, Merchant M. A collaborative control system for mass customization manufacturing. CIRP Annals. 1997;46:373-376. DOI: 10.1016/ S0007-8506(07)60846-4

[22] Comstock M, Johansen K, Winroth M. From mass production to mass customization: Enabling perspectives from the Swedish mobile telephone industry. Production Planning and Control. 2004;15:362-372. DOI: $10.1080 / 0953728042000238836$

[23] Kotha S. Mass customization: Implementing the emerging paradigm for competitive advantage. Strategic Management Journal. 1995;16:21-42. DOI: $10.1002 / \mathrm{smj} .4250160916$

[24] Reichwald R, Piller F, Moslein K. Information as a critical success factor for mass customization.
In: Proceedings of the ASAC-IFSAM 2000 Conference. Montreal; 2000

[25] Hong Y, Jiao H, Sturman M, Zhou Y. Competing through customization: Using human resource management to create strategic capabilities.

Organizational Psychology Review. 2014;4:124-147. DOI: $10.1177 / 2041386613504608$

[26] Wright P, McMahan G, McWilliams A. Human resources and sustained competitive advantage: A resource-based perspective. The International Journal of Human Resource Management. 1994;5:301-326. DOI: 10.1080/09585199400000020

[27] Collins C, Smith K. Knowledge exchange and combination: The role of human resources practices in the performance of high-technology firms. Academy of Management Journal. 2006;49:544-560. DOI: 10.5465/ amj.2006.21794671

[28] Sutton R, Rafaeli A. Untangling the relationships between displayed emotions and organizational sales: The case of convenience stores. Academy of Management Journal. 1998;31:461-487. DOI: $10.2307 / 256456$

[29] Coff R. Human assets and management dilemmas: Coping with hazard on the road to resource-based theory. Academy of Management Review. 1997;22:374-402. DOI: $10.2307 / 259327$

[30] Waldman D. The contributions of total quality management to a theory of work performance. Academy of Management Review. 1994;19:510-536. DOI: $10.2307 / 258937$

[31] Yetis H, Karakose M. A datadriven method for decision support systems in mass production and mass customization. In: 2018 International Conference on Artificial Intelligence and Data Processing (IDAP). Malatya, 
Turkey: IEEE; 2018. pp. 1-4. DOI: 10.1109/IDAP.2018.8620794

[32] Brunø T, Nielsen K, Taps S, Jørgensen K. Sustainability evaluation of mass customization. In: Prabhu V, Taisch M, Kiritsis D, editors. Advances in Production Management Systems. Sustainable Production and Service Supply Chains. APMS 2013. IFIP Advances in Information and Communication Technology. Vol. 414. Berlin: Springer; 2013. pp. 175-182. DOI: 10.1007/978-3-642-41266-0_22

[33] Berman B. Should your firm adopt a mass customization strategy? Business Horizons. 2002;45:51-60. DOI: $10.1016 /$ S0007-6813(02)00227-6

[34] AhlstromP,WestbrookR.Implications of mass customization for operations management: An exploratory survey. International Journal of Operations \& Production Management. 1999;19:

262-275. DOI: $10.1108 /$

01443579910249705

[35] National Academies of Sciences, Engineering, and Medicine; Health and Medicine Division; Board on Population Health and Public Health Practice; Committee on the Review of the Health Effects of Electronic Nicotine Delivery Systems. In: Eaton DL, Kwan LY, Stratton K, editors. Public Health Consequences of E-Cigarettes. Washington (DC): National Academies Press (US); 2018. 3, E-Cigarette Devices, Uses, and Exposures. Available from: https://www.ncbi.nlm.nih.gov/books/ NBK507187/

[36] Gibson I, Rosen D, Stucker B. Additive Manufacturing Technologies: Rapid Prototyping to Direct Digital Manufacturing. Boston: Springer; 2010. 459 p. DOI: 10.1007/978-1-4419-1120-9

[37] Kohtala C. Addressing sustainability in research on distributed production: An integrated literature review. Journal of Cleaner Production. 2015;106: 654-668. DOI: 10.1016/j.jclepro. 2014.09.039

[38] Durach C, Kurpjuweit S, Wagner S. The impact of additive manufacturing on supply chains. International Journal of Physical Distribution and Logistics Management. 2017;47:954-971. DOI: 10.1108/IJPDLM-11-2016-0332

[39] Mellor S, Hao L, Zhang D. Additive manufacturing: A framework for implementation. International Journal of Production Economics. 2014;149: 194-201. DOI: 10.1016/j.ijpe. 2013.07.008

[40] Hamalainen M, Karjalainen J. Social manufacturing: When the maker movement meets interfirm production networks. Business Horizons. 2017;60:795-805. DOI: 10.1016/j. bushor.2017.07.007

[41] RepRap. Welcome to RepRap. org [Internet]. 2019. Available from: RepRap: https://reprap.org/wiki/ RepRap [Accessed: 28 March 2019]

[42] Hopkinson N, Smith P. Industrial 3D inkjet printing/additive manufacturing. In: Zapka W, editor. Handbook of Industrial Inkjet Printing: A Full System Approach. Weinheim, Germany: Wiley; 2017. pp. 649-660. DOI: 10.1002/9783527687169.ch38

[43] Peterson E, Pearce J. Emergence of home manufacturing in the developed world: Return on investment for open-source 3-D printers. Technologies. 2017;5:7. DOI: 10.3390/ technologies 5010007

[44] Wittbodt B, Glober A, Laureto J, Anzalone G, Oppliger D, Irwin J, et al. Life-cycle economic analysis of distributed manufacturing with opensource 3-D printers. Mechatronics. 2013;23:713-726. DOI: 10.1016/j. mechatronics.2013.06.002 
[45] Rahman Z, Barakh Ali S, Ozkan T, Charoo N, Reddy I, Khan M. Additive manufacturing with 3D printing: Progress from bench to bedside. The AAPS Journal. 2018;20:101. DOI: $10.1208 / \mathrm{s} 12248-018-0225-6$

[46] Chen T, Lin Y-C. Feasibility evaluation and optimization of a smart manufacturing system based on 3D printing. International Journal of Intelligent Systems. 2017;32:394-413. DOI: $10.1002 /$ int.21866

[47] Kellens K, Baumers M, Gutowski T, Flanagan W, Lifset R, Duflou J. Environmental dimensions of additive manufacturing: Mapping application domains and their environmental implications. Journal of Industrial Ecology. 2017;21:S49-S68. DOI: 10.1111/ jiec.12629

[48] Schubert C, Van Langeveld M, Donoso L. Innovations in 3D printing: A 3D overview from optics to organs. British Journal of Ophthalmology. 2014;98:159-161. DOI: 10.1136/ bjophthalmol-2013-304446

[49] Tumbleston J, Shirvanyants D, Ermoshkin N, Janusziewicz R, Johnson A, Kelly D, et al. Continuous liquid interface production of 3D objects. Science. 2015;347:1349-1352. DOI: 10.1126/ science.aaa2397

[50] Serazio M. Shooting for fame: Spectacular youth, web 2.0 dystopia, and the celebrity anarchy of generation mash-up. Communication, Culture and Critique. 2013;3:416-434. DOI: 10.1111/j.1753-9137.2010.01078.x

[51] Niaki M, Torabi S, Nonino F. Why manufacturers adopt additive manufacturing technologies: The role of sustainability. Journal of Cleaner Production. 2019;222:381-392. DOI: 10.1016/j.jclepro.2019.03.019

[52] Huang S, Liu P, Mokasdar A, Hou L. Additive manufacturing and its societal impact: A literature review. International Journal of Advanced Manufacturing Technology. 2013;67:1191-1203. DOI: 10.1007/s00170-012-4558-5

[53] Byrley P, George B, Boyes W, Rogers K. Particle emissions from fused deposition modeling 3D printers: Evaluation and meta-analysis. The Science of the Total Environment. 2019;655:395-407. DOI: 10.1016/j. scitotenv.2018.11.070

[54] Gu J, Wensing M, Uhde E, Salthammer T. Characterization of particulate and gaseous pollutants emitted during operation of a desktop 3D printer. Environment International. 2019;123:476-485. DOI: 10.1016/j.envint.2018.12.014

[55] Druley K. 3D printing and worker safety [Internet]. 2019. Available from: https://www. safetyandhealthmagazine.com/ articles/18295-d-printing-andworker-safety [Accessed: 04 July 2019]

[56] Ritzer G. Prosumer capitalism. The Sociological Quarterly. 2015;56:413-445. DOI: $10.1111 /$ tsq.12105

[57] Zwick D. Defending the right lines of division: Ritzer's Prosumer capitalism in the age of commercial customer surveillance and big data. The Sociological Quarterly. 2015;56: 484-498. DOI: $10.1111 /$ tsq.12101

[58] Peng T, Kellens K, Tang R, Chen C, Chen G. Sustainability of additive manufacturing: An overview on its energy demand and environmental impact. Additive Manufacturing. 2018;21:694-704. DOI: 10.1016/j. addma.2018.04.022

[59] Bonvoisin J, Galla J, Prendeville S. Design principles for do-it-yourself production. In: Campana G, Howlett R, Setchi R, Cimatti B, editors. Sustainable Design and Manufacturing 2017. SDM 2017. Vol. 68. Cham: 
Springer; 2017. pp. 77-86. DOI: 10.1007/978-3-319-57078-5_8

[60] Ford S, Despeisse M. Additive manufacturing and sustainability: An exploratory study of the advantages and challenges. Journal of Cleaner Production. 2016;137:1573-1587. DOI: 10.1016/j.jclepro.2016.04.150

[61] Drizon A, Pegna J. Environmental impacts of rapid prototyping: An overview of research to date. Rapid Prototyping Journal. 2006;122:64-71. DOI: $10.1108 / 13552540610652393$

[62] Franco A, Lanzetta M,

Romoli L. Experimental analysis of selective laser sintering of polyamide powders: An energy perspective. Journal of Cleaner Production. 2010;18:

1722-1730. DOI: 10.1016/j. jclepro.2010.07.018

[63] McGraw L. Free-forming with soybean oil [Internet]. 2001. Available from: www.ars.usda.gov/is/AR/archive/ aug01/oil0801.htm [Accessed: 04 July 2018]

[64] Sauerwein M, Doubrovski E. Local and recyclable materials for additive manufacturing: 3D printing with mussel shells. Materials Today Communications. 2018;15:214-217. DOI: 10.1016/j.mtcomm.2018.02.028

[65] Kellens K, Mertens R, Paraskevas D, Dewulf W, Duflou J. Environmental impact of additive manufacturing processes: Does AM contribute to a more sustainable way of part manufacturing? Procedia CIRP. 2017;61:582-587. DOI: 10.1016/j. procir.2016.11.153

[66] Faludi J, Bayley C, Bhogal S, Iribarne M. Comparing environmental impacts of additive manufacturing vs traditional machining via lifecycle assessment. Rapid Prototyping Journal. 2015;21:14-33. DOI: 10.1108/ RPJ-07-2013-0067
[67] Holmström J, Liotta G,

Chaudhuri A. Sustainability outcomes through direct digital manufacturingbased operational practices: A design theory approach. Journal of Cleaner Production. 2017;167:951-961. DOI: 10.1016/j.jclepro.2017.03.092

[68] Senyana L, Cirmier D. An environmental impact comparison of distributed and centralised manufacturing scenarios. Advanced Materials Research. 2014;875-877: 1449-1453. DOI: $10.4028 / w w w$. scientific.net/AMR.875-877.1449

[69] Cerdas F, Juraschek M, Thiede S, Herrmann C. Life cycle assessment of $3 \mathrm{D}$ printed products in a distributed manufacturing system. Journal of Industrial Ecology. 2017;21(S1):S80-S93. DOI: $10.1111 /$ jiec.12618

[70] Frandsen C, Nielsen M, Chaudhuri A, Jayaram J, Govindan K. In search for classification and selection of spare parts suitable for additive manufacturing: A literature review. International Journal of Production Research. 2019. DOI: 10.1080/00207543.2019.1605226

[71] Almada-Lobo F. The industry 4.0 revolution and the future of manufacturing execution systems (MES). Journal of Innovation Management. 2015;3:16-21. DOI: 10.24840/2183-0606_003.004_0003

[72] Waibel M, Oosthuizen G, du Toit D. Investigating current smart production innovations in the machine building industry on sustainability aspects. Procedia Manufacturing. 2018;21:774-781. DOI: 10.1016/j. promfg.2018.02.183

[73] Olhager J. The role of the customer order decoupling point in production and supply chain management. Computers in Industry. 2010;61:863-868. DOI: 10.1016/j. compind.2010.07.011 
[74] Elkington J. Cannibals with Forks:

The Triple Bottom Line of 21st Century Business. Oxford: Capstone; 1997. 402 p. ISBN: 1-900961-27-X

[75] Trollman H. A novel approach to assessing manufacturer progress toward sustainability. Procedia CIRP. 2018;78:370-375. DOI: 10.1016/j. procir.2018.08.303

[76] Rose C. Design for environment: A method for formulating product end-of-life strategies [thesis]. Stanford: Stanford University; 2000

[77] Tuzzolino F, Armandi B. A needhierarchy framework for assessing corporate social responsibility. Academy of Management Review. 1981;6:21-28. DOI: $10.5465 / \mathrm{amr} .1981 .4287982$

[78] Song Z, Moon Y. Sustainability metrics for assessing manufacturing systems: A distance-to-target methodology. Environment, Development and Sustainability. 2018. DOI: 10.1007/s10668-018-0162-7

[79] Brumagim A. A hierarchy of corporate resources. In: Shrivastava P, Huff A, Dutton J, editors. Advances in Strategic Management 1994. Greenwich, Connecticut, USA: JAI Press; 1994. pp. 81-112. ISBN: 1559388501

[80] Yang M, Vladimirova D, Rana P, Evans S. Sustainable value analysis tool for value creation. Asian Journal of Management Science and Applications. 2014;1:312-332. DOI: 10.1504/ AJMSA.2014.070649 



\title{
Chapter 6
}

\section{The Use of Lean Manufacturing Tools to Improve the Production of Automobile Parts}

\author{
Jonathan-David Morales-Méndez and Ramón Silva-Rodríguez
}

\begin{abstract}
The competitiveness of the national and international market for automobile parts requires that delivery times, quantities and agreed upon quality standards for the ordered product are rigorously adhered to. This means that a company must use and keep up with strategies that allow for improvement while maintaining a high performance-level in its production processes. The company accepts their clients' challenge to increase the production capacity and improve levels of quality and productivity for their M300 wheel hub ${ }^{1}$ production line. The first step was to carry out a general analysis of the manufacturing process, identifying each of the activities and operations used to make the product. The critical path along with critical activities was identified and deficiencies were found in the execution of the activities along these critical paths. Next, the causes for low productivity and flaws in the production process were identified. This information was used to implement improvement proposals using "lean manufacturing" techniques with the respective results that were achieved. Conclusions and recommendations for continuous improvements in the manufacturing process are presented.
\end{abstract}

Keywords: wheel hub, productivity, production capacity, standard workflow, 5MQS, Kaizen, lean manufacturing

\section{Introduction}

The improvement initiative arose when it became clear that production capacity for the front and rear M300 wheel hub needed to increase in order to meet increased demand in Ecuador and Colombia. It is a business that holds potential to deal with SOFASA and General Motors, which required high production volumes compared with the current ones.

At the same time, General Motors demands that "lean manufacturing" be applied [1, 2] as a way of both increasing productivity and ensuring high quality. The goal is to make continuous improvement processes more robust.

These strategies must be applied to the manufacture of the front and rear M300 wheel hub supplied to General Motors.

The plant is divided into two main areas: forging and machining.

\footnotetext{
${ }^{1}$ Wheel Hub. The wheel hub supports the brake drum. The wheel studs and bearing bracket are affixed to it. This arrangement transmits the torque from the drive shaft to the vehicle's wheels thus enabling movement. The part is made from steel and weights $\sim 2.9 \mathrm{~kg}$.
} 


\begin{tabular}{lccc}
\hline Operation & Machine & $\begin{array}{c}\text { Standard time } \\
\text { (seconds) }\end{array}$ & $\begin{array}{c}\text { Goal (pieces } \\
\text { per hour) }\end{array}$ \\
\hline Forging & & & \\
\hline Cutting raw material of wheel hubs & Saw & 49.5 & 73 \\
\hline Heating and forging of wheel hubs & Furnace and press & 50.79 & 71 \\
\hline Heat treatment: standardization & Furnace & 15.45 & 233 \\
\hline Cleaning & Blasting machine & 18.33 & 196 \\
\hline Inspection for cracks & Magnaflux & 20.94 & 172 \\
\hline Machining & equipment & & \\
\hline Pre-mechanized exterior of the flange & Lathe-1 & 146.05 & 39 \\
\hline Roughing of interior diameter & Lathe-2 for roughing & 121 & 40 \\
\hline Broaching & Broaching machine & 61 & 59 \\
\hline Final lathing of exterior & Lathe-3 for finishing & $\mathbf{2 1 2}$ & $\mathbf{1 7}$ \\
\hline Boring and countersinking long holes for stay bolts & Drill 1 & 79 & 46 \\
\hline Threading holes & Tap drill & 65 & 56 \\
\hline
\end{tabular}

Table 1.

Main data related to plan operation.

Forge area: The smelting process is carried out under heat. In this area, the forging process is a closed one where the material is formed by applying compression forces. The steel is shaped by pressing it between two blocks (closed matrix) while raising the temperature in industrial furnaces. The furnaces work in the same cell as the corresponding presses. A normalization process and checking for cracks also takes place in this area.

Machining area: here chip removal operations are preformed that result in semi-finished products through roughing (which require subsequent processes), or finished products with their final diameter (finishing processes).

Table 1 shows the machines and the manufacturing process for each area of the plant. There are currently 14 operators working at the plant:

- Production capacity [3, 4]: The average real maximum production of M300 wheel hubs was 3000 units during the last half of 2017. Taking stock of performance flaws revealed that there was no record of machine stoppages or other short-comings in the process, and no standardized time tests to identify the maximum installed capacity of the plant along with bottle necks. This implies that no corrective planning and production programming is done leading to cost over-runs, delays and all kinds of waste [5].

- Time studies: In order to define the initial productivity level, a time study was done to find the standard time and number of pieces produced per hour in each operation. This can also be seen in Table 1 .

\subsection{Calculating initial installed capacity and OEE (overall equipment effectiveness)}

The initial installed capacity refers to the highest possible value given the initial standard times that are calculated. From Table 1 it can be concluded that the bottle neck [6] is at the final lathing of the exterior with a maximum of 17 pieces an hour (bold value in Table 1). 
As such, the maximum installed capacity is calculated as follows:

$$
17 \frac{\text { pieces }}{\text { hour }} * 7.5 \frac{\text { hours }}{\text { turns }} * \frac{3 \text { turns }}{\text { day }} * \frac{25 \text { days }}{\text { month }}=9562.5 \frac{\text { pieces }}{\text { month }}
$$

In order to calculate the $\mathrm{OEE}$, we compare the actual capacity to the maximum possible capacity [7]. According to the dispatch records for the second 2017 semester, the average monthly production for the plant was 3000 units. Calculating the OEE based on an average evaluation period of 30 days per month we get:

$$
\mathrm{OEE}=\frac{\text { actual units }}{\text { possible units }}=\frac{3000}{9562}=0.3137
$$

Since the OEE for the wheel hub is $31.37 \%$, it is clear that the reasons for low productivity need to be found.

\subsection{Identification of causes that lead to low productivity in the manufacturing process of the M300 wheel hub}

In order to identify the leakages and causes of low productivity, the 5MQS (methodology to identify waste related to machines, method, materials, man, management, safety and quality) [8] method was used. This was complimented with the use of an Ishikawa diagram to analyze root causes. The general findings were:

- Machines: A flow diagrams and switch travel diagrams were used as analysis tools leading to the conclusion that there is a very poor distribution within the plant. On top of that, there are constant stoppages for machine maintenance. No preventive maintenance programs are in place.

- Method: In accordance with the time studies, the critical activity (bottle neck) is the final lathing of the exterior, meaning that productivity needs to be increased at this work station [9].

- Making human-machine and machine-machine diagrams showed a workload imbalance for the different machines and operators.

- Constant time wasting was observed while tools and devices are sought since they are not kept in a specific place and are far away from the work station. A high level of loss is incurred due to movement of materials and people due to poor distribution of the machines in the plant.

- A space for raw materials is not demarcated and as such it often gets in the way of people and the flow of material in the production process.

- Checking the degree of compliance with the 5S. Check-lists were designed for the $5 \mathrm{~S}$ that were then used to measure compliance. The results are presented in Table 2 and the diagram of Figure 1.

The 55\% compliance level for the $5 \mathrm{~S}$ at the production plant indicate the necessity of implementing the 5S methodology.

- Material: There is a large accumulation of inventory at the bottle neck of the process, there is an imbalance in the line and lack of order for placing material. 


\begin{tabular}{lccc}
\hline 5S & Maximum score & \multicolumn{2}{c}{ Machining area } \\
\cline { 3 - 4 } & & Result & $\%$ \\
\hline Sort & 25 & 9 & 36 \\
\hline Set in order & 35 & 16 & 46 \\
\hline Shine & 20 & 8 & 40 \\
\hline Standardize & 45 & 35 & 78 \\
\hline Sustain & 35 & 20 & 57 \\
\hline Total & 160 & 88 & 55 \\
\hline
\end{tabular}

Table 2.

Results of the ${ }_{5} \mathrm{~S}$ check-list applied at the plant.

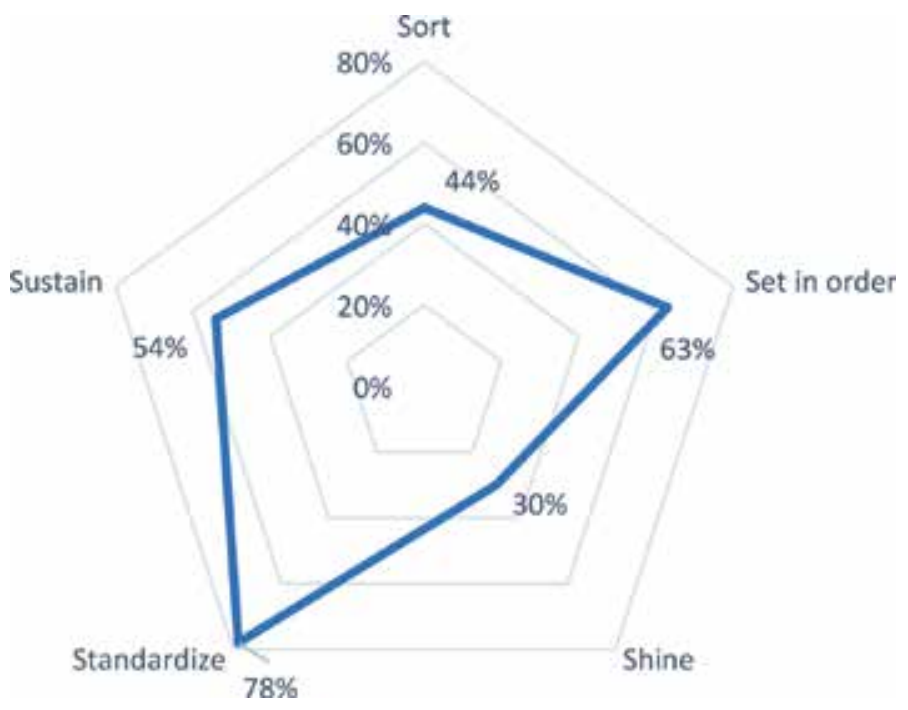

Figure 1.

Diagram of the 5 S network at the production plant.

- Man: What is seen as weaknesses in the method leads to the conclusion that there are no operation standards at the plant resulting in a lack of structured training and formation for operators at the plant.

- Management: Quality inspections were carried out on $100 \%$ of the finished products leading to a huge loss of time for the operator. In addition, there is low illumination in the inspection area where high visibility is needed to be able to read the instruments.

- Safety: There is no established place to keep safety gear which is one of main the reasons why it is hardly used. The lack of order and standard procedures also contribute to unsafe conditions.

- Quality: The level of defects found for the period under study (second semester of 2017) is 49,937 PPM (parts per million). Both the company and clients defined the goal as $<15,000$ PPM. 


\section{Materials and methods}

After examining the different continuous improvement methods available, it was decided to use those associated with "lean manufacturing" to improve the production process of the M300 wheel hub. The Kaizen framework was chosen to guide all the improvements. The project was done in seven steps as follows:

- Phase 1: Creation of Kaizen teams [10-13]: Awareness and training on how Kaizen teams work. Training on "lean manufacturing" techniques, especially: 5S's, time loss analysis, standardized work, visual management. Training was also done on OEE (overall equipment effectiveness).

- Phase 2: Initial situation assessment of work stations, using photographic evidence, data and analysis.

- Phase 3: Definition and approval of workplan: each Kaizen team presented their assessment from phase 2 along with a proposed workplan and schedule, goals (indicators), who was responsible and necessary resources to the company management who approved the plans.

- Phase 4: Development and implementation of standards: This phase consisted in documenting the operations in the manufacturing process that each Kaizen considered to be a best practice.

- Phase 5: Standardized training and implementing improvements [14]: The learning by doing method was used and adjustments were made to optimize.

- Phase 6: Managing and operationalization of the system. This is the last phase in developing the implementation and is comprised of standardizing the operationality of the new system and the administration to include continuous improvement.

- Phase 7: Closure of Kaizen first stage projects and commitment on the part of the Kaizen teams to develop new continuous improvement projects leading to the beginning of stage 2 .

\section{Implementing improvements through the strategic use of lean manufacturing tools}

Continuing with the use of the $5 \mathrm{MQS}$, the improvements that were achieved are described below.

- Machines: Starting with balancing the load, a new distribution was set up in the plant. This was complimented by establishing Standardized Work roundtables in each work cell. This guarantees that: the documentation of standardized work, visual aids, measurement instruments, necessary tools, identification of non-conforming material, a container for personal safety gear, and good lighting to aid readings.

A basic preventive maintenance plan was started with the goal of reducing unforeseen machine stoppages. 
- Method: The problem at the center of the critical activity was solved by using a human-machine diagram [15] to create a balanced lathe cell. This strategy was also applied to second level critical activity sectors at the plant.

A standardized form was designed and used to register daily production at the work stations and planned and unplanned machine stoppages. The goal was to have data to use in the on-going calculation of the OEE.

The OEE for each machine and production line became the standardized performance indicator. Pareto and Ishikawa diagrams were also used to analyze root causes and support the continuous improvement process.

A visual management strategy was used for the continuous display of the OEE and other vital production performance indicators.

Standardized work at work stations became the norm through the use of documentation designed by each of the Kaizen teams. These standards include:

$\circ$ Assessing the 5Ss: The 5S check-list was put in place for each machine. This document must be filled out by each operator at the start of their shift, evaluating the order and cleanliness found at the work station. The checklist is on one side of the sheet and on the other side the operator registers their findings (non-compliance) as a way to identify root causes. A person responsible for taking action is listed along with the date for compliance.

$\circ$ 5S standard card: There is one for each work station of manufacturing cell, indicating the elements needed for each operation: materials, measurements, tools, information and personal safety.

○ SMS sheet [16] (standard manufacturing sheet) for cyclical operations. And SMI sheet (standard manufacturing instructions) for every one of the processes.

○ The above standards include the optimization of process variable which resulted in another time study that showed increased capacity at the bottle neck.

- Material: Manipulation of material notably improved by the new arrangement of the plant plus the application of the $5 \mathrm{~S}$ along with standards for material control and trained personnel.

- Man: Standardized training was carried out using the standards developed by the Kaizen teams. This kind of material should be constantly updated and is useful for planned re-training as well as orienting new personnel to their posts. Five levels of verified training were established in the following order: operator with basic training (20\%), operator approved to carry out operations $(40 \%)$, operator approved to carry out fine tuning (60\%), operator approved to train or rework $(80 \%)$, operator that can apply lean manufacturing $(100 \%)$.

It was determined that by the end of the first semester (February to July) of working on improvements, the operative staff must have reached a minimum level of $40 \%$.

Multifunctionality matrix. $[17,18]$ The operation that each operator is trained in along with the percentage is entered, thus allowing everyone to see at any momento which people are qualified to do certain activities.

- Management: Statistical control of the process at the bottle neck was introduced, along with training and increased lighting. 
The Use of Lean Manufacturing Tools to Improve the Production of Automobile Parts DOI: $h$ ttp://dx.doi.org/10.5772/intechopen.88470

- Safety: Protective gear at the work station is guaranteed, as well as safety standards.

- Quality: The Kaizen teams carried out root cause analysis by way of the Ishikawa diagram and corrections were applied.

\section{Results}

Results of applying the 5S: After the 5S trainings at each of the work stations, their condition was assessed again using the check-list Table 3. The following results were attained:

See Figure 2 for the network diagram showing the results of the $5 \mathrm{~S}$ standards after the trainings. An increased level of compliance can be observed. However, more improvement is needed in the $\mathrm{S}$ with the lowest compliance level: shine.

Result for production capacity: Figure 3 shows the number of units produced from July 2017 through September 2018.

From the graph, it can be seen that production increased by $121.9 \%$ between the second semester of 2017 and April-September of 2018.

The installed capacity at the bottle neck increased to 19 pieces per hour which generated a monthly installed capacity of 10,687 units. Thus, using the new

\begin{tabular}{lccc}
\hline 5S & Maximum score & \multicolumn{2}{c}{ Machining area before 5S } \\
\cline { 3 - 4 } & & Result & $\%$ \\
\hline Sort & 25 & 18 & 72 \\
\hline Set in order & 35 & 28 & 80 \\
\hline Shine & 20 & 12 & 60 \\
\hline Standardize & 45 & 37 & 82 \\
\hline Sustain & 35 & 28 & 80 \\
\hline TOTAL & 160 & 123 & 77 \\
\hline
\end{tabular}

Table 3.

Results of the ${ }_{5} S$ check-list after the trainings.

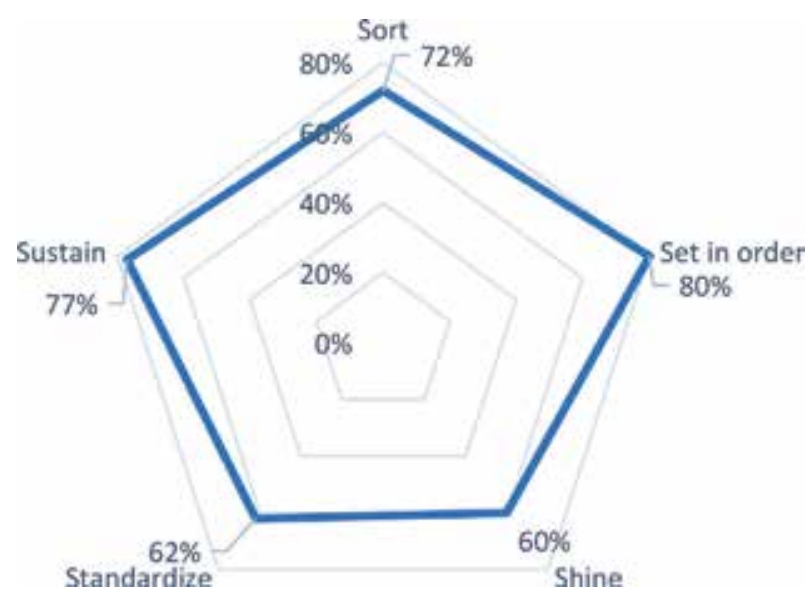

Figure 2.

Network diagram of the $5 S$ after trainings. 


\section{Units}

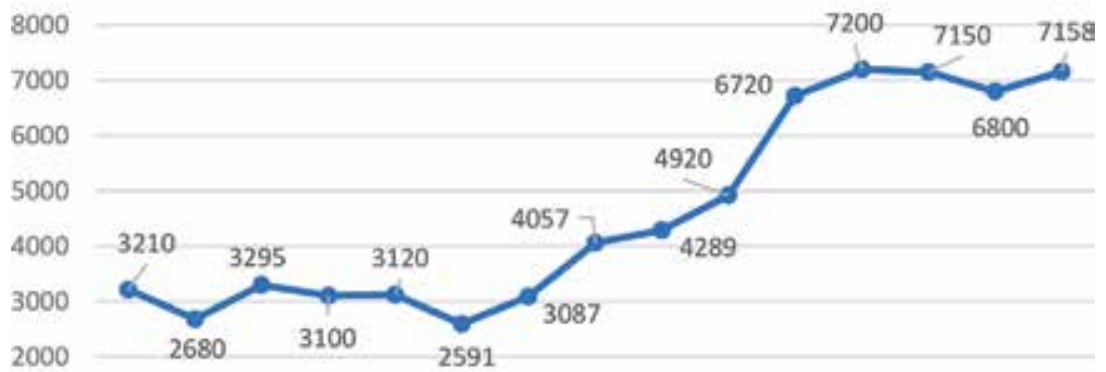

1000

0

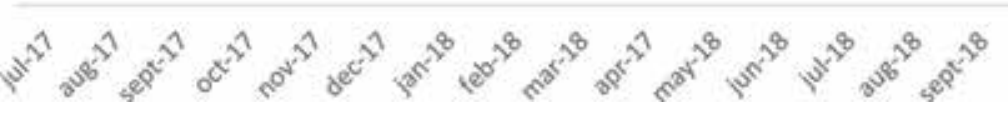

Figure 3.

Increase in production.

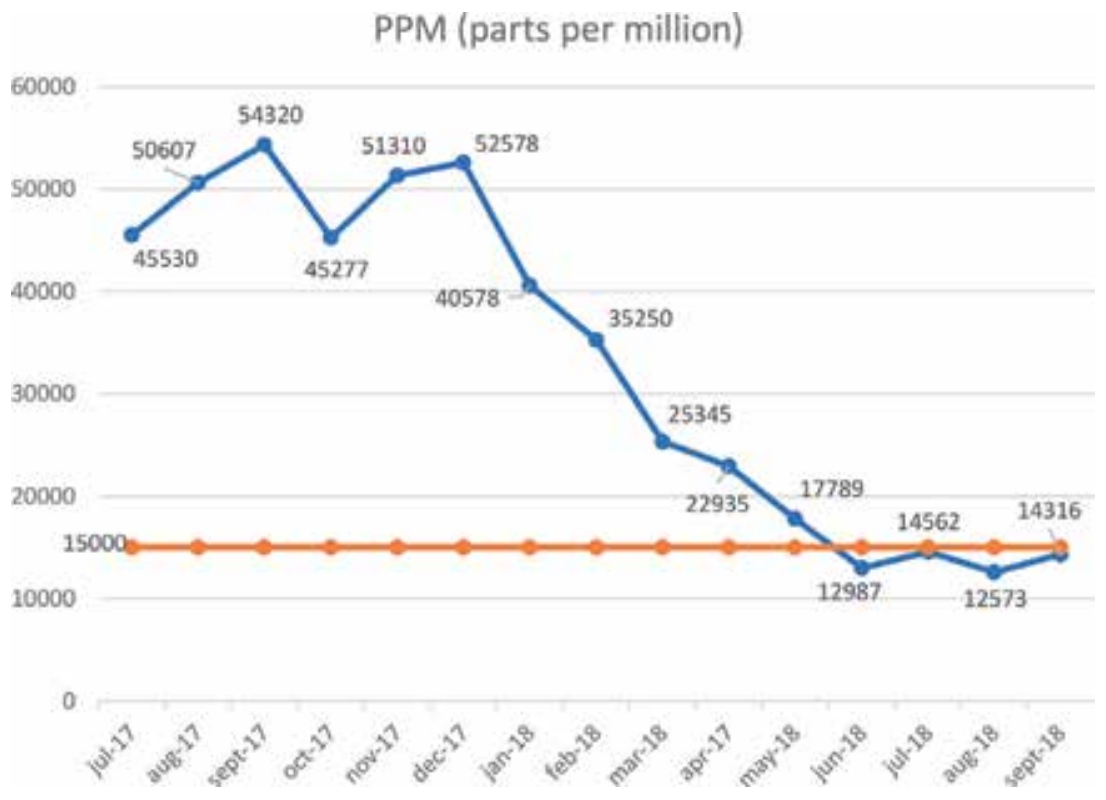

Figure 4 .

Flawed PPM.

maximum capacity and the actual monthly average for the previous 4 months (7077 units), the new value for the OEE is $66.21 \%$.

Results for the quality level: The quantity of non-conforming product since July 2017 until September 2018 can be seen in Figure 4. A decrease in number can be seen, and during the last 4 months the internal goal of no more than 15,000 PPM was surpassed.

Results for labor productivity [19] (relationship between the value of sales and the cost of labor required to produce the volume mentioned). By rearranging the plant and balancing workloads it was possible to reduce the number of operators from 14 to 11 , representing a reduction of $21.42 \%$. This contributed towards improvements in labor productivity from February through September 2018 as demonstrated in Figure 5. 


\section{Labor productivity (2018)}

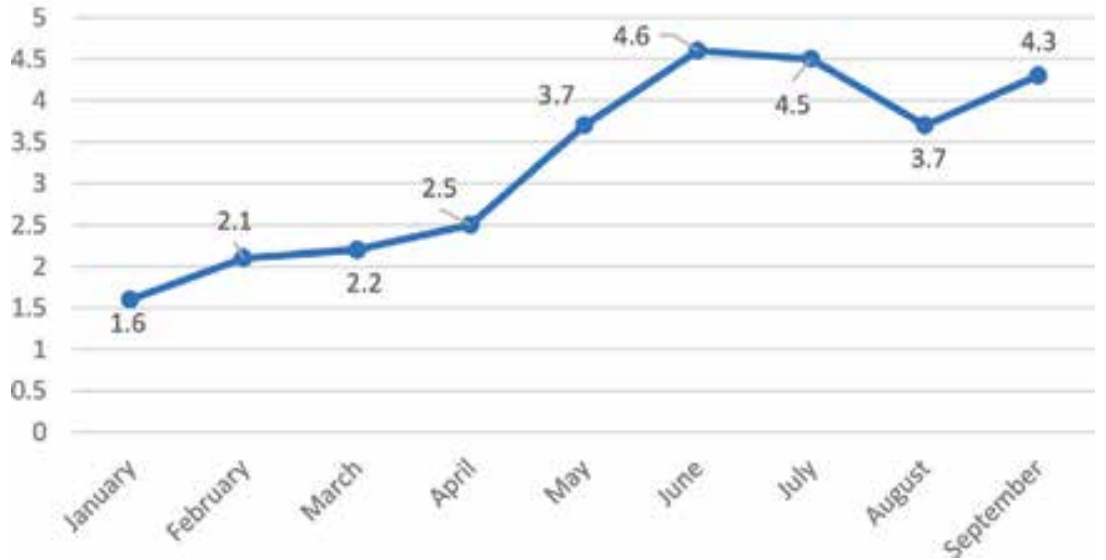

Figure 5.

Labor productivity.

Standardized documents: The OEE became the standardized indicator for measuring the performance of the productive process. The discipline of collecting the necessary date for calculating the OEE was established: machine availability, efficiency and quality.

As the improvements were implemented, but especially as the standards were being met during phase 6 , a plant administration was established that embraced the lean manufacturing philosophy.

Lastly, phase 7 was officially closed with the Kaizen teams presenting the goals that were met by using the data illustrated above, and the new projects designed by each constituted team.

\section{Conclusions}

- The 5MQS methodology was successfully used to identify waste as a reason for low productivity at the production plant.

- Through time studies and use of switch travel diagrams and diagraming operations it was possible to identify processes that add value and analyze the installed capacity of the critical activity or bottle neck. This facilitated focusing efforts on increasing production at this work station. The result was increased labor productivity and OEE.

- Balancing the work load at the roughing lathes and final machining, together with standardizing the operations, allowed for increased capacity at the bottle neck and improved the continuous flow in the process.

- The human-machine and machine-machine diagrams helped to balance the production line, especially at the bottle neck. This led to reducing distances covered and the inventory of product in process, while also taking better advantage of labor.

- By standardizing the use of the daily and monthly OEE indicator and the Ishikawa diagram, the root causes of stoppages can be identified and problems controlled, leading to efficient solutions. 
- Better safety at work and higher quality and productivity levels were seen in the results obtained as a result of implementing the standardized work strategy via the respective documents.

- Safe, clean and organized work stations resulted from applying the 5S methodology to the different operations in the production process. The round tables for standardized work attained a higher level of organization of work stations thus avoiding unnecessary movements to search for things.

- Standardized training was essential in preparing and instructing the operators. They were inducted tin the lean culture and that of standardization.

- Lastly, the results obtained also led to increased labor productivity due to reducing the number of operators and the progressive increase in pieces produced. At the same time, it was possible to be under the goal of a maximum of 15,000 PPM of flawed products during the last 4 months under study.

\section{Recommendations}

- It is recommended that company management continue to implement standardized work and standardized training with the other production processes at the plant.

- Continue to consolidate lean management at the production plant, placing priority on those products that have a higher propensity to be internationally competitive.

- It is also recommendable to introduce the lean manufacturing strategy into management processes as a way to support all the production processes, thus guaranteeing continuity and improvement in the system.

- The maintenance and general managers should strengthen the preventive maintenance plan even more in order to ensure higher levels of machine availability and trustworthiness. As much as possible, autonomous maintenance should be started sooner rather than later.

\section{Author details}

Jonathan-David Morales-Méndez ${ }^{1 *}$ and Ramón Silva-Rodríguez ${ }^{2}$

1 University Manuela Beltrán, Colombia

2 Servicio Nacional de Aprendizaje_-SENA, Centro Industrial de Mantenimiento Integral, Colombia

*Address all correspondence to: jonathan.morales@docentes.umb.edu.co

\section{IntechOpen}

(C) 2020 The Author(s). Licensee IntechOpen. This chapter is distributed under the terms of the Creative Commons Attribution License (http://creativecommons.org/licenses/ by/3.0), which permits unrestricted use, distribution, and reproduction in any medium, provided the original work is properly cited. (cc) BY 


\section{References}

[1] De Vin LJ, Jacobsson L, Odhe J, Wickberg A. Lean production training for the manufacturing industry: Experiences from Karlstad lean factory. Procedia Manufacturing. 2017;11:1019-1026

[2] Dudbridge M. First steps to lean manufacturing. In: Handbook of Lean Manufacturing in the Food Industry. 2011. pp. 21-27

[3] Huang D, Lin ZK, Wei W. Optimal production planning with capacity reservation and convex capacity costs. Advances in Production Engineering and Management. 2018;13(1):31-43

[4] Albey E, Bilge Ü, Uzsoy R. Multidimensional clearing functions for aggregate capacity modelling in multistage production systems. International Journal of Production Research. 2017;55(14):4164-4179

[5] Dylewski R, Jardzioch A. Scheduling production orders, taking into account delays and waste. Management and Production Engineering Review. 2014;5(3):3-8

[6] de Carvalho Gomes L, Gonçalves de Faria Corrêa R. Use of overall equipment effectiveness (OEE) in manufacturing cells considering takt time. Revista Gestão da Produção Operações e Sistemas. 2018;13(3):276-294

[7] Cesarotti V, Giuiusa A, Intro V. Using overall equipment effectiveness for manufacturing system design. In: Operations Management. Intech Open; 2013

[8] Shukla AC, Jha DK. Quality improvement using statistical quality control techniques: A case of plastic industry. Industrial Engineering Journal. 2017;10(1):6-14
[9] Joy B. Productivity improvement of an automobile inspection station. International Robotics and Automation Journal. 2018;4(3):33-41

[10] Kowalewski M. Kaizen and Kaizen costing in management of an enterpise. Zeszyty Naukowe Uniwersytetu Szczecińskiego Finanse Rynki Finansowe Ubezpieczenia. 2016;2:277-284

[11] Morales Méndez JD, Silva Rodríguez R. Set-up reduction in an interconnection axle manufacturing cell using SMED. The International Journal of Advanced Manufacturing Technology. 2015;84(9-12):1907-1916

[12] Lazorenko TV, Tymoshchuk SP. Kaizen: Japanese strategy for successful development of Ukrainian entrepreneurship. Young Scientist. 2018;64:283-287

[13] Murray L. Kaizen usage to drive continuous improvement. In: CFW Plexus, no. AACCI 2012 Annual Meeting; November 2012

[14] Ylipää T, Skoogh A, Bokrantz J, Gopalakrishnan M. Identification of maintenance improvement potential using OEE assessment. International Journal of Productivity and Performance Management. 2017;66(1):126-143

[15] Rosa C, Silva FJG, Ferreira LP, Pereira T, Gouveia R. Establishing standard methodologies to improve the production rate of assembly lines used for low added-value products. Procedia Manufacturing. 2018;17:555-562

[16] Li D, Mattsson S, Salunkhe O, Fast-Berglund $\AA$, Skoogh A, Broberg J. Effects of information content in work instructions for operator performance. Procedia Manufacturing. 2018;25:628-635 
[17] Neumann RWP, Medbo P.

Simulating operator learning during production ramp-up in parallel vs. serial flow production. International Journal of Production Research. 2016;55(3):845-857

[18] Aptel M et al. Proposal of parameters to implement a workstation rotation system to protect against MSDs. International Journal of Industrial Ergonomics. 2008;38(11-12):900-909

[19] Burda MC. Aggregate labor productivity. In: IZA World of Labor; 2018 


\title{
Rapid Prototyping for Sheet Metal Products
}

\author{
Nguyen Duc-Toan and Hoang Long
}

\begin{abstract}
The aim of this chapter is to evaluate and predict forming limit and then to improve and develop the incremental sheet metal forming (ISMF) processes for complex surface products of sheet metal. The theoretical study was first overviewed and synthesized in order to recognize the effect of geometry, technology parameters, and processing conditions on ISMF process. Finite element method (FEM) simulation study was then used to compare the accuracy of constitutive material models and fracture criteria and propose new equations in order to improve the prediction of FEM simulation for incremental sheet metal forming process. To develop a new technique for improving the formability of sheet metal using ISMF, FEM was also adopted to reduce the cost and time of research. The basic experimental studies were performed to determine the input data for FEM simulation such as tensile data, fracture parameters, and so on. To investigate and compare the simulation results, the incremental sheet metal forming processes for complex shapes were also conducted.
\end{abstract}

Keywords: rapid prototyping, ISMF, tool path generation, FEM simulation

\section{Introduction}

In recent years, various methods for sheet metal deformation have been developed including incremental sheet metal forming (ISMF). ISMF has been bringing about many effects for small series production and in rapid prototyping of products. ISMF now becomes the leading research and development (R\&D) topics in the manufacturing industry. ISMF is a sheet deformation method that uses simple settings: the deformation tool is a spherical round cylinder without a blade, and the metal sheet is fastened on a support to allow the sheet to deform according to the supported mold. The supported mold can be made of simple materials such as wood, plastic, composite, and so on, so that there is no need for expensive specialized molds. To receive tool paths for a complex shape, the CAD 3-D model of the finished part must be designed. The 3D model will be transferred to the CAM environment to simulate a reasonable tool path. Depending on the shape and complexity of the forming part, the machining process may or may not need a support mold. Table 1 lists the practical applications of the ISMF method that has been manufactured in different countries around the world. Figure 1 illustrates the rapid prototyping products of this technology [1].

ISMF processing is a continuous forming process until plastic deformation occurs locally in a small area beneath the forming tool. The deformed shape is a 


\begin{tabular}{l}
\hline Automotive cover panels \\
\hline Other chassis sheet metal parts of an automobile \\
\hline Sculpture, architecture, decoration \\
\hline Required shape by customers \\
\hline Cover for lighting equipment \\
\hline Dental, medical \\
\hline Special parts for aerospace and aviation \\
\hline Small ship body panels
\end{tabular}

Table 1.

Potential application areas for ISMF [1].

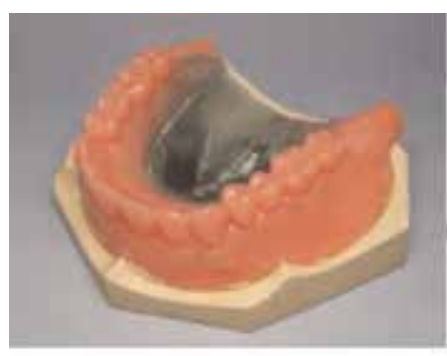

a)

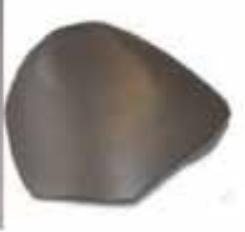

b)

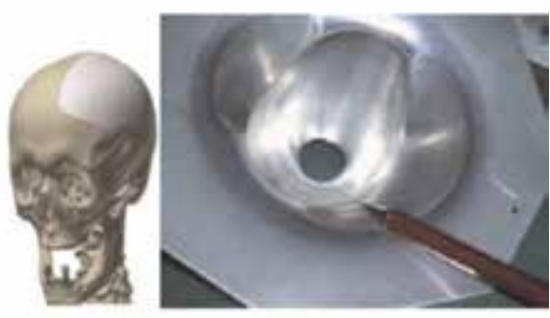

c)

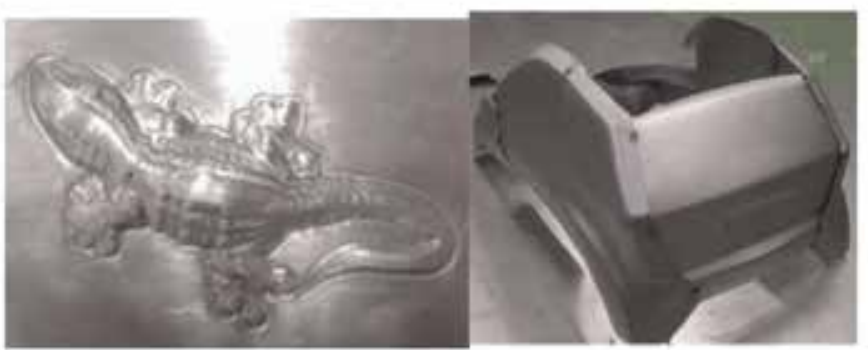

d)

e)

Figure 1.

Rapid prototyping products from ISMF: (a) dental, (b) medical, (c) headlight, (d) sculpture, (e) automotive cover.

combination of forming movements in the local plastic deformation region. The deformation process is slow and time-consuming, so it is only suitable for rapid prototyping of products or in series production. However, this method allows for greater formability than conventional deformation methods of material sheet. Forming tools are simple and inexpensive and develop products in a short time.

This method contains new and creative contributions in sheet metal forming such as:

- A new type of tool path generation in ISMF to create complex surfaces

- Improving the formability of sheet metal when comparing to the traditional forming process 


\section{Incremental sheet metal forming}

\subsection{Basic concepts}

ISMF is an innovative process for manufacturing sheet metal products by numerical control machines (CNC) based on simple forming tools for plasticity deformation to form metal sheets according to the desired shape. The controllable motion of the forming tool allows deforming three-dimensional profiles. This forming method offers many advantages in rapid prototyping of sheet metal products, which were directly constructed from CAD 3-D models to a complete traditional product without middle stages for designing and manufacturing molds. There are two main deformations of ISMF according to concave surfaces (Figure 2a) and convex surfaces (Figure 2b). They show the workpiece surface where the tool is shaping motion. The actual experimental setup used in ISMF is shown in Figure 3. The forming limit curve (FLC) of ISMF process is much higher than the forming limits calculated from the theory of plasticity as well as obtained from traditional test [2]. The forming limit curve from conventional deformations is V-shaped. But, recently studies have shown that ISMF process achieved greater formability and FLC shape almost like a straight line with negative slope in the principal limit strains (major strain, $\varepsilon 1$, and minor strain, $\varepsilon 2$ ). In order to estimate the forming limit curve at fracture (FLCF) in ISMF for a cold rolled, Nguyen et al. [3] proposed the combination method for predicting FLC based on in-plane test (M-K model) and ductile fracture criterion of Clift et al. [4]. In the previous study [5], cold rolled steel sheet improved formability by ISMF process and is also used to manufacture automotive structure [6] as shown in Figure 4. In ISMF process, the effects of parameters such as size-step, tool-down step, tool radius, etc. on formability are very
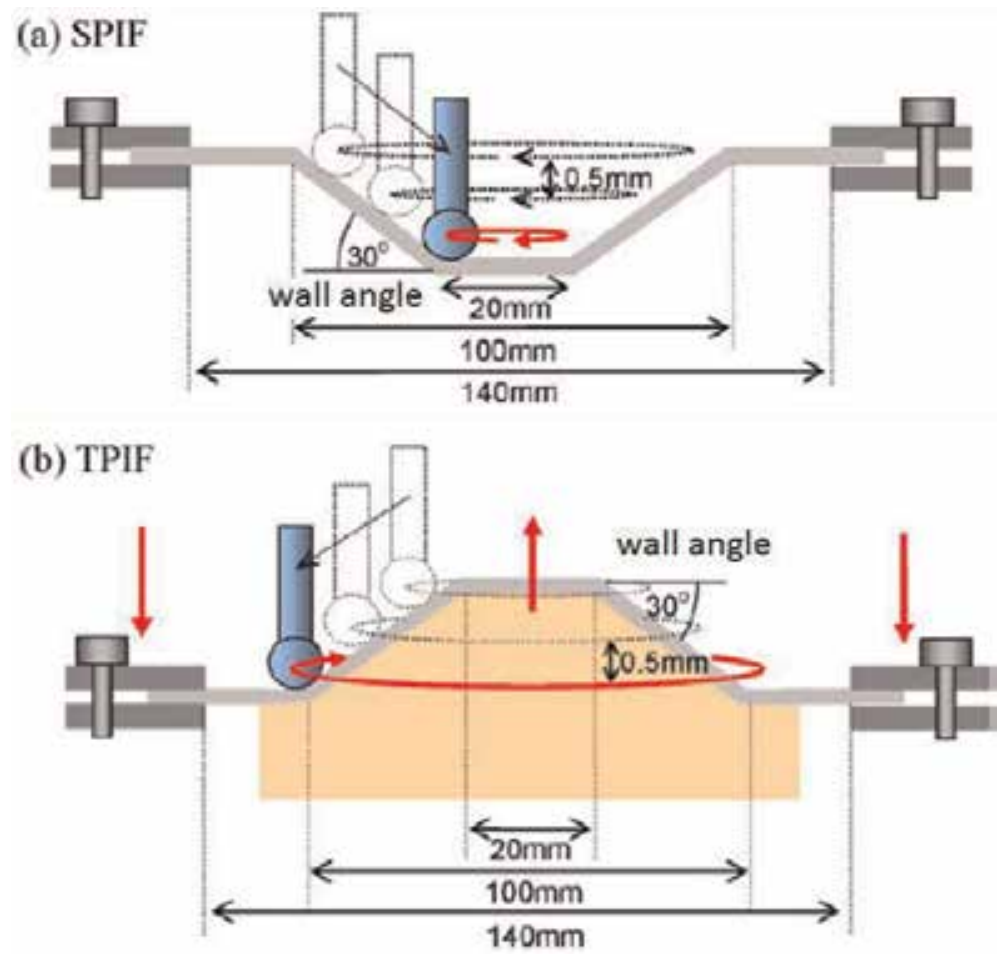

Figure 2.

Forming concave surface (a) and convex surface (b). 


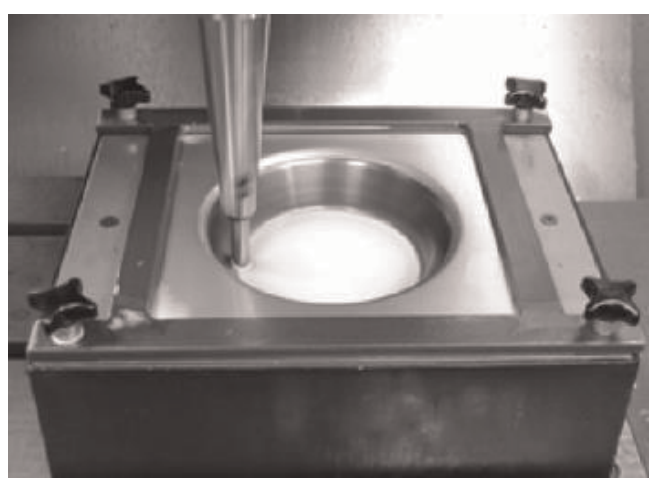

Figure 3.

ISMF experimental setup: lower mold, clamping, metal sheet and forming tool.

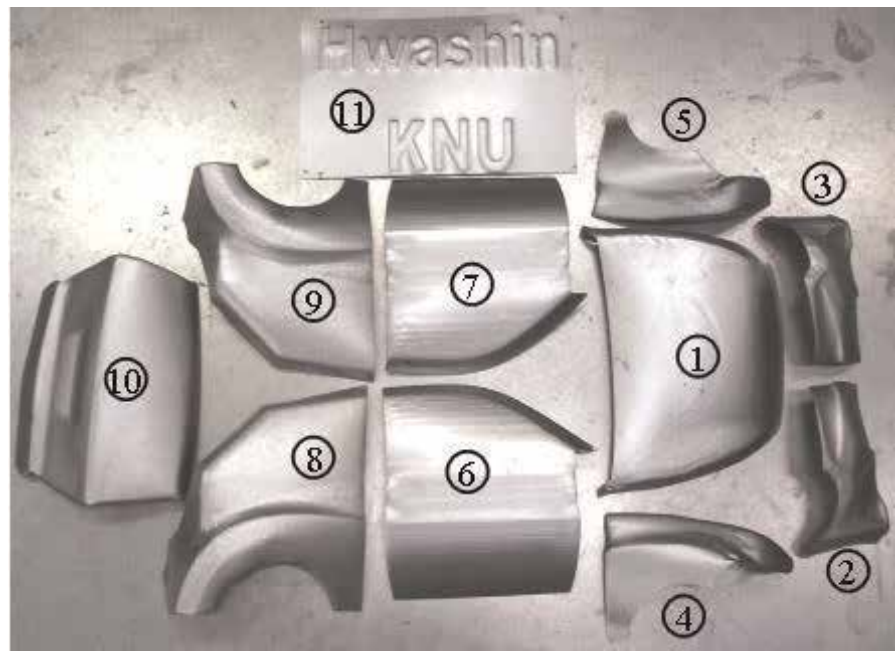

Figure 4 .

Incremental sheet forming for automobile shape [6].

important. The influences of the main material parameters of the sheet material on the formability of ISMF had been studied in several published papers. In order to demonstrate the formability improvement for sheet metal by ISMF process using rotational tool (RISF), both empirical and simulation studies $[7,8]$ have been carried out for a magnesium sheet alloy. They concluded that heat generation in the contact zone between forming tool and metal sheet would affect formability of light alloy sheet materials such as titanium and magnesium alloy. With light alloy structures, titanium alloy and magnesium alloy have many advantages when compared to steel, cast metal, and aluminum alloy. However, the structure of titanium and magnesium alloys is limited by the formability at room temperature due to the tightly packed hexagonal structure. In order to apply these light alloys widely in industry, many studies have investigated the ability of these alloys to form at elevated temperatures and concluded that magnesium and titanium alloys have the best formability in the temperature range of $200-800^{\circ} \mathrm{C}$ by experiments and corresponding simulations as shown in Figures 5 and $\mathbf{6}$, respectively.

When the mold has a convex surface shape, the forming device must be equipped with a hydraulic clamping system to hold the metal sheet firmly in the proper working position. In the case of concave molded surfaces, metal plates can 


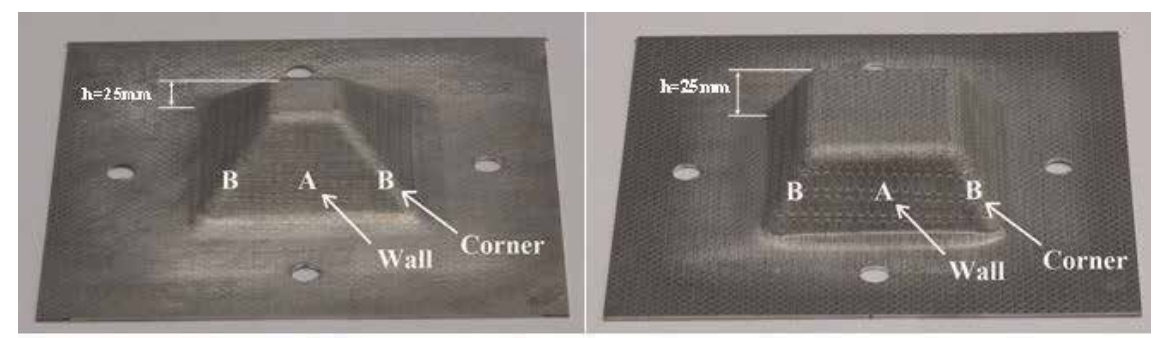

a) b)

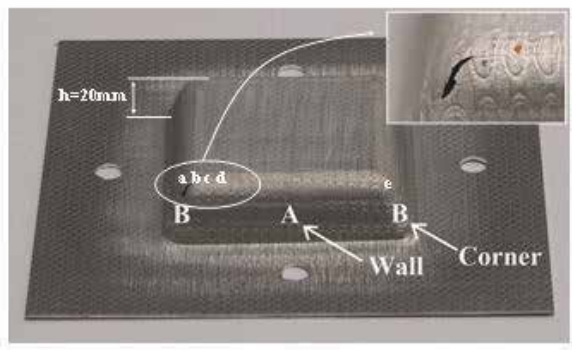

c)

Figure 5 .

Square cups formed by rotational incremental sheet forming: (a) $45^{\circ}$ wall angle, (b) $60^{\circ}$ wall angle, and (c) $70^{\circ}$ wall angle at which point cracks occurred [7].

be fixed on the clamping system. This is a suitable machining method for small series production, prototype production, and shaping of complex surfaces used in aerospace, automotive, shipbuilding, medical industries, and so on. This method is being applied to reduce costs related to specialized molds used for processing mass production in traditional deformation machining.

Table 2 lists the basic parameters used for ISMF. The influence of these parameters on the formability of different materials has been studied by many researchers around the world. The conclusions about the influence of parameters on various sheet materials are different, and there is no general rule for each specific effect except the effect of the tool diameter. In general, the conclusions can be generalized as follows: when increasing the thickness of sheet metal, reducing the size of the tool and reducing the down step will tend to increase the formability of the sheet metal. It can be explained why the results are not uniform because the parameter areas used for each research are different. In addition, there is a reciprocal interplay between the parameters that affect the formability of the sheet material.

\subsection{History of development}

The history of ISMF was started in 1967 when Leszak [9] obtained a patent for the solution: "Equipment and process of ISMF." The idea was to be ahead of its time, but subsequent studies were not conducted until the 1990s when studies were conducted mainly on circular-shaped workpieces and products could be shaped on horizontal lathes.

In 2001, along with the development of three-axis CNC milling centers, the method of ISMF was continuously deployed. Previously only specialized CNC machines were used for this shaping process. This is the starting point for studies conducted outside Japan. Some of the most active researchers since then can be listed as Jeswiet et al. [10]. Although it has been more than three decades of research and development, the technology of ISMF applied in rapid prototyping is still a hot 

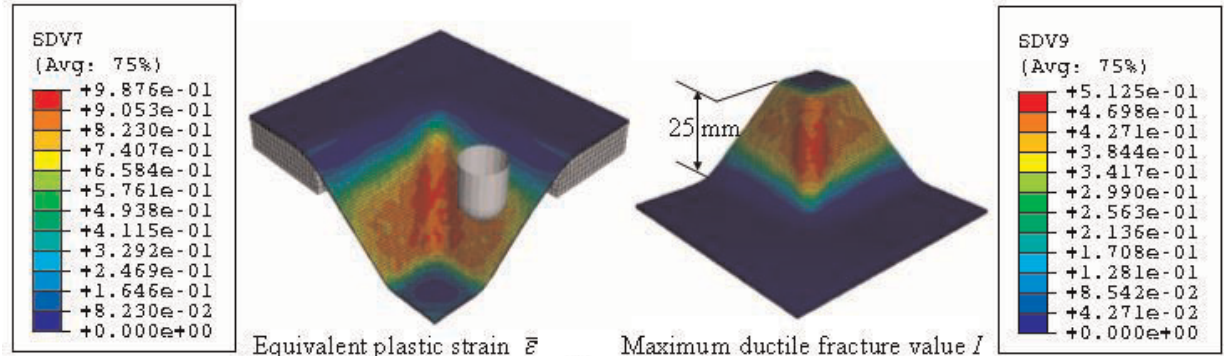

(a)
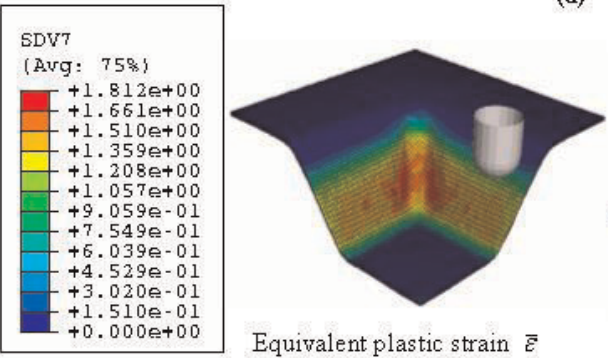

Equivalent plastic strain $\bar{\varepsilon}$

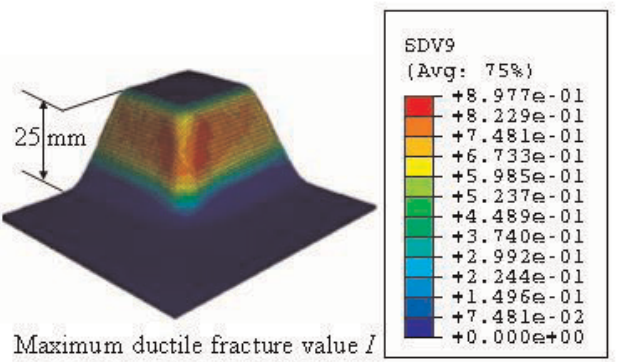

(b)
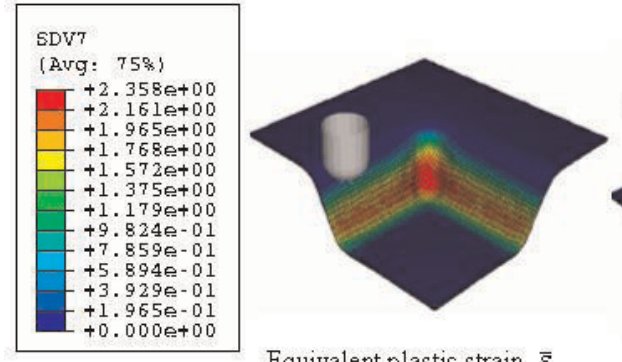

Equivalent plastic strain $\bar{\varepsilon}$

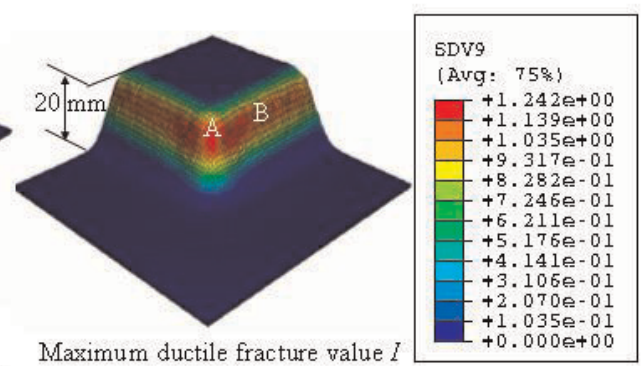

(c)

Figure 6.

Deformed shape in finite element simulation: (a) $45^{\circ}$ wall angle, (b) $60^{\circ}$ wall angle, and (c) $70^{\circ}$ wall angle [8].

\begin{tabular}{lcc}
\hline Parameters & Symbol & Value \\
\hline Radius of forming tools & $\mathrm{r}_{\mathrm{t}}$ & $5-15(\mathrm{~mm})$ \\
\hline Metal sheet thickness & $\mathrm{t}_{\mathrm{o}}$ & $0.5-3(\mathrm{~mm})$ \\
\hline Down step & $\mathrm{z}$ & $0.1-2(\mathrm{~mm})$ \\
\hline Tilt angle after deformation & $\psi_{\max }$ & to $90\left(^{\circ}\right)$ \\
\hline Deformation speed & $\mathrm{S}$ & $500-2000(\mathrm{~mm} / \mathrm{min})$ \\
\hline Axial force & $\mathrm{F}_{\mathrm{A}}$ & $300-1000(\mathrm{~N})$ \\
\hline Horizontal bending force & $\mathrm{F}_{\mathrm{b}}$ & $100-500(\mathrm{~N})$ \\
\hline
\end{tabular}

Table 2.

Basic parameters of ISMF.

topic to be further studied by the following reasons: Accuracy of deformed products are still limited; the heat generation by the contact and friction between the forming tool and the material sheet is significant; there are high surface roughness and low productivity. Some recent applications of ISMF process have been summarized by several researchers [11-16]. 


\subsection{Formability of ISMF}

When comparing the deformations of ISMF with other traditional forming process such as stamping, clawing, pulling, bending, and so on, researchers have shown that the forming limit diagram (FLD) of ISMF is raised much higher than the traditional forming limit diagrams calculated from the theory of plastic deformation as well as obtained from experiments through traditional testing methods. The forming limit diagrams of traditional deformations are V-shaped. But studies have shown that the formability in ISMF is larger and shaped almost like a straight line in the minor-major strain space. In order to obtain the FLDs of ISMF, they could be based on the ductile fracture criterion of Clift et al. as shown in Eq. (1). The points on FLDs are calculated based on the initial point of the minor-major strain point convergence at the equilibrium strain region; the following points are calculated according to the relationship between the minor-major strain ratios (Eq. (2)) and the equivalent strain function for the plane stress state (Eq. (3)):

$$
\begin{gathered}
\int_{0}^{\bar{\varepsilon}_{f}} \bar{\sigma} d \bar{\varepsilon}=C \\
\beta=\frac{\varepsilon_{2}}{\varepsilon_{1}} \\
\bar{\varepsilon}=\frac{R_{m}+1}{\sqrt{2 R_{m}+1}} \sqrt{1+\frac{2 R_{m}}{R_{m}+1} \beta+\beta^{2}} \varepsilon_{1}
\end{gathered}
$$

where $\bar{\varepsilon}_{f}$ is the equivalent strain at the ductile fracture strain point, $\bar{\sigma}$ is the equivalent stress, $\bar{\varepsilon}$ is the equivalent strain, $C$ is the constant of the material, $\beta$ is the minor-major strain ratio, $\mathrm{Rm}$ is the anisotropic coefficient, and $\varepsilon_{1}$ and $\varepsilon_{2}$ are the minor and major strains, respectively. In addition, material tensile tests give a relationship between stress and strain, and they are often expressed through hardening equations as indicated in Swift's Eq. (4):

$$
\bar{\sigma}=K\left(\varepsilon_{0}+\bar{\varepsilon}\right)^{n}
$$

where $K$ is the plastic deformation coefficient of the curve and $n$ is the hardening parameter of the curve. After substituting Eq. (4) into Eq. (1) and performing the integral calculation, we can solve the equivalent strain value at failure point of ISMF as a constant Eq. (5):

$$
\bar{\varepsilon}_{f}=C_{1}
$$

To determine $C_{1}$ parameter, the values of the minor-major strain at the equilibrium biaxial strain position are used in combination with the fracture values on the traditional forming limit curve. After determining the value of $C_{1}$, we can use this value to calculate the different points of the FLC during ISMF by giving the deformation ratio $\beta$ changes in the permissible zone and replace in Eqs. (2), (3), and (5). Figure 7 depicts the forming limit curves in ISMF based on the forming limit curves of the traditional method (V-shaped) for various experimental forming tools [3].

\subsection{Applications of ISMF method}

ISMF method can be considered a new rapid prototyping method without creating expensive molds, and the time to create parts from the idea of the final product is less than 24 hours. ISMS method can also be distinguished as a layered 


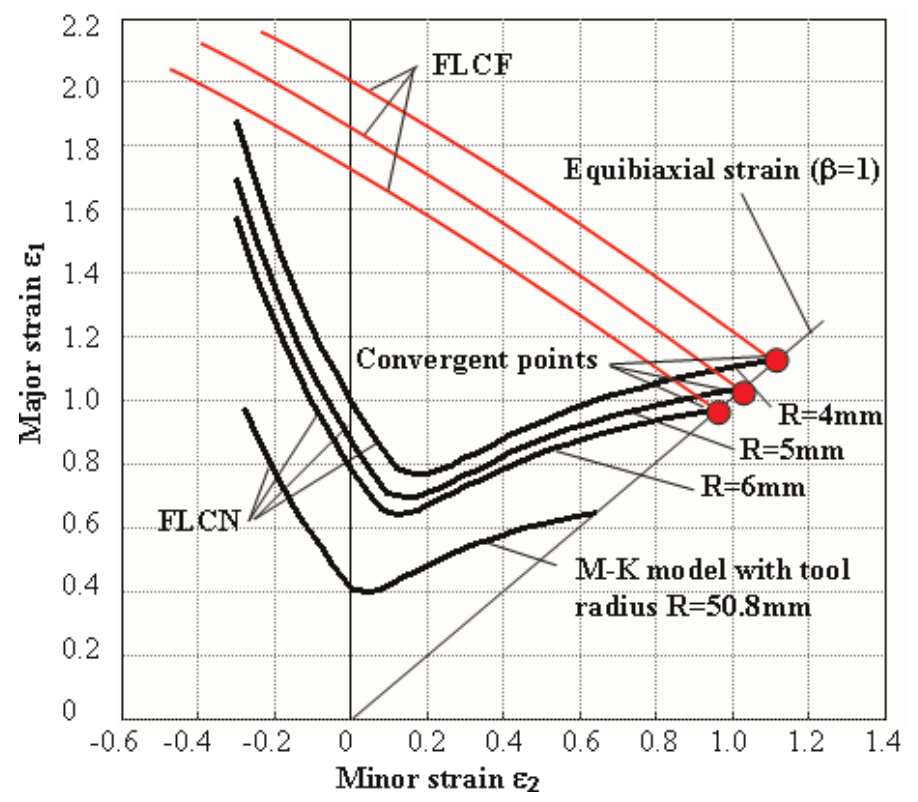

Figure 7.

Forming limiting curves of ISMF compared to traditional FLC methods [3].

technology process because the products are deformed according to the continuous layers of the tool path. Because the processing time for a product is large, this method could not be applied to mass production. However, the low initial cost makes it suitable for small series of products or rapid prototyping. The cost for a product of the ISMF method is difficult to identify and is often higher than the initial prediction. Products must be created in a CAD system, and tool paths are generated in a CAM system. It will consume about $2-5$ hours of continuous work by a technician for a product with complex shapes. The setup and operation times on a CNC machine will also take about 3 hours. Therefore, this method should not be used to manufacture simple products.

In the medical industry, this method can be used to make replacement parts of the human body. Specific examples are shown in Figure 1a and $\mathbf{b}$, where researchers have applied ISMF to create details such as teeth support plates and fragments of the skull with light titanium material. Recently, this method has been tested and applied in the automotive industry to make some new models of heatsink, headlamp, automotive cover, and some other products (Figure 1c and e). Currently, this processing method is still a hot topic in research for many different products and different materials.

\subsection{Tool path generation}

The tool path generation of ISMF method is similar to the tool path generation for finishing the surface with CNC machines by the cutting method, where the metal sheets are clamped on a dedicated jig. Along the depth of product will be divided into a number of required forming layers. At each forming layer, from the top to the bottom of the product, the sheet metal will be deformed step by step along with the shape profile of each layer. Every time a forming layer is completed, the elevation $Z$ is shifted a certain distance. The forming process will be finished when all the forming layers are completed. Obviously, the deformed shape and accuracy of the products are dependent on the position of the forming tool and the 
collection of all tool positions. As illustrated in Figure 8 to create tool paths, products must be divided into several layers. Each forming layer has the outline of the tool path that is similar to the boundary of the slice of the formed part. Therefore, the tool paths are generated based on the deformed shape of the product (Figure 6). In order to obtain forming location data (CL data) for a complex surface, a threedimensional scanner could be used to create point clouds on the surface of the specimen. These points can be used to extrapolate the shape of the object. Typically, point clouds received by 3D scanners will not be directly usable. Because most applications use 3D polygon, NURBS surface models, or editable CAD models. The process of converting point clouds into 3D models into any of the listed formats is called model refactoring. So, refactoring and editing methods are often done through 3D CAD software such as CATIA, SOLIDWORK, Pro-E, and so on to create surface models from point clouds. After the CAD model is available, there are two methods that can be used to obtain forming location data during the simulation as well as creating ISMF tool path as shown in Figure 8.

The first method is the basic programming through the use of MATLAB software which was implemented as follows: the initial CAD model is stored as standard triangular language (STL) files, which include a list of triangular shapes that describes the outer surface of the CAD object. These triangular surfaces are described by a set of $\mathrm{X}, \mathrm{Y}$, and $\mathrm{Z}$ coordinates for three vertices and a normal vector. To find the internal intersection points of the triangle used for calculating the tool

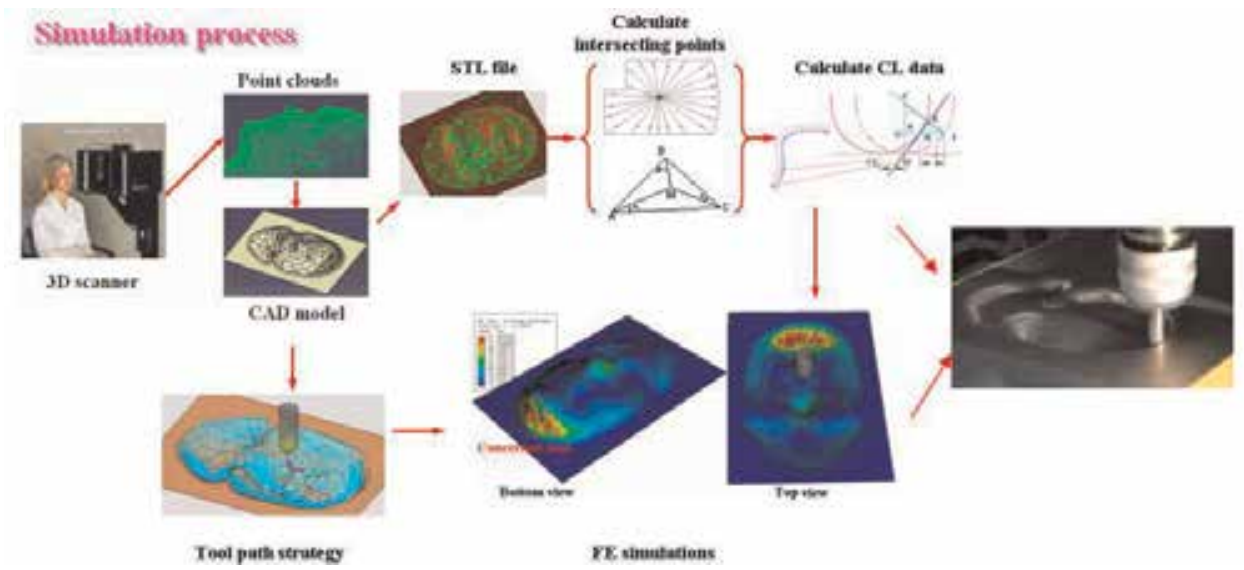

Figure 8.

Tool path generation ISMF simulation and experiment.
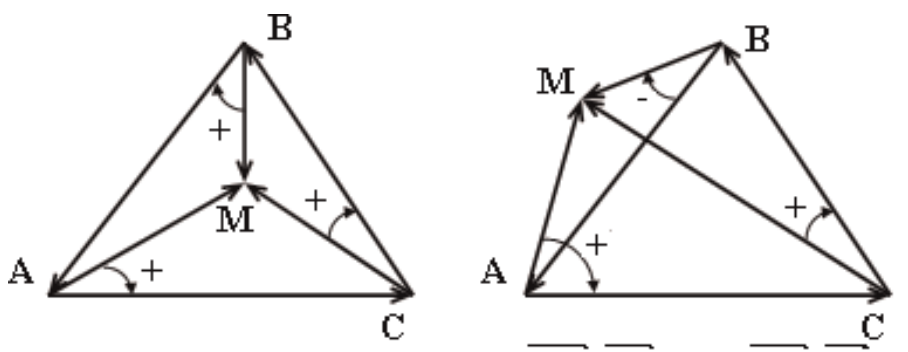

$\mathrm{M}$ is inside of $\triangle \mathrm{ABC}$ when $\operatorname{det}(\overrightarrow{A M}, \overrightarrow{A C}), \operatorname{det}(\overrightarrow{B M}, \overrightarrow{B A})$, and $\operatorname{det}(\overrightarrow{C M}, \overrightarrow{C B})$ are the same sign

Figure 9.

Intersection point recognition. 


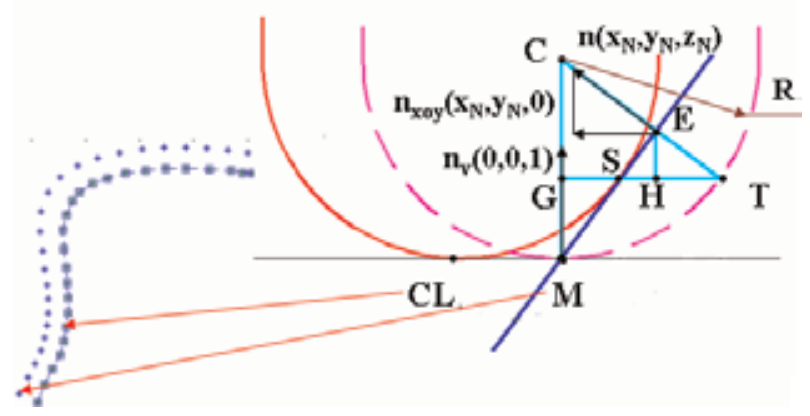

Figure 10.

Calculation of tool location points (CL data).

position at each $\mathrm{Z}$ layer, the points are projected in the radial direction from the center axis and calculate their intersection with the created surface. Those intersection points must be checked to see whether they are inside or outside of corresponding triangular elements as illustrated in Figure 9. After finding the points in the inner domain of the triangle, it is possible to calculate the position points of the tool according to Eq. (6) and Figure 10.

$$
\begin{aligned}
c & =m+R n_{v} \\
t & =c-R n \\
|C E| & =|C G|=\left|R n_{v} n\right| \\
e & =c-|C E| n \\
|E T| & =|E-T| \\
h & =e-|E T| n_{v} \\
|S T| & =\frac{(|E T|)^{2}}{|H T|} \\
c l & =m+|S T| n_{x o y}
\end{aligned}
$$

where $c, m, t, e, h$, and $c l$ are vectors corresponding to peak points of $C, M, T, E$, $H$, and $C L ; R$ is the radius of forming tool; $n_{n}$ is a unit normal vector; $n_{v}$ is the vector along the unit axis; and $n_{x o y}$ is a projection of the $n_{n}$ vector on the (XoY) bottom plane.

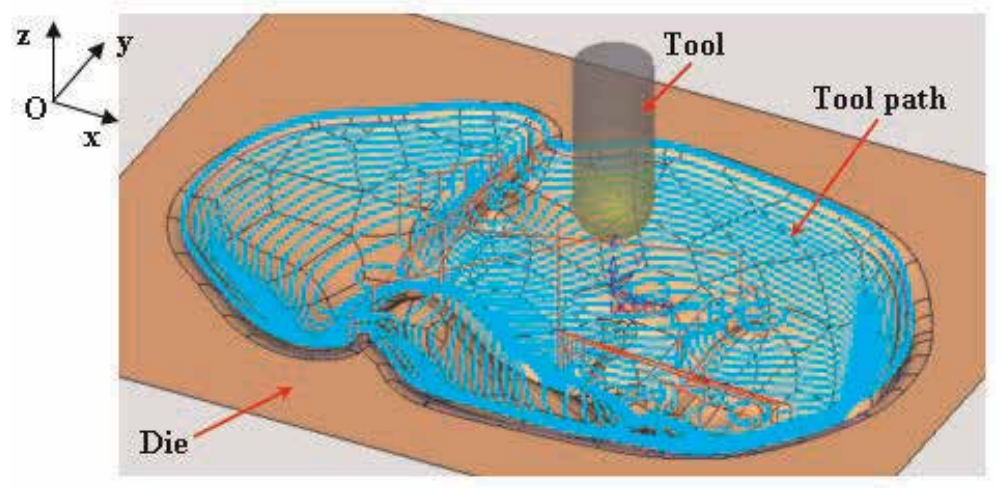

Figure 11.

Tool path generated from CAM software. 
The second method used to calculate tool position points is to immediately utilize the advantage of CAM software, where CAD models are stored in IGES file format and exported to CAM environment such as CIMATRON, DELCAM, MASTERCAM, etc. to conduct the simulation according to different types of tools. Usually, the selected tool path type will be a $Z$-level spiral-type and top-down method as shown in Figure 11.

\section{Numerical simulation in ISMF method}

Numerical simulations for ISMF are still one of the challenges that need to be solved due to the loss of time in the simulation process, and the contact between the tool and the forming surface is always replaced. Therefore, the meshed surfaces in the simulation should not be too complicated, and the tool paths must be programmed and imported into the input files of CAE software such as ABAQUS, DEFORM, LS-DYNA, and so on. This software can provide a simulation of elastic and plastic deformation of the sheet metal forming process. Characteristics such as stress distribution, deformation, ductile fracture, etc. can be easily inspected through the simulation process. The results of the simulation process can then be used to obtain the optimal shape as well as the material properties required for the final product. Before simulating the process of forming deformation, mechanical properties of 3D models, geometric profiles of products, and contact surfaces must be built. Elastoplastic model is often selected to simulate through material properties such as elastic modulus, Poisson's coefficient, and density of materials. The flow stress curve equations of materials and anisotropic models must be applied to describe the plastic flow rule of materials.

\subsection{Select simulation elements}

Meshed elements used in finite element simulation of ISMF are often shell element models with more than five integral points according to the thickness of the shell. Using the integral points in the thickness direction of the shell element could be replaced by the solid element and described the effects of the tension and compression area on the simulation results. Most shell elements consider the normal stress to be zero in the direction of the thickness, but because the shear stress in that direction may be not zero, then the stress state is not plane stress. Some shell elements consider the normal stress in the thick direction, and they are called thick shell elements. Figure 12 shows the finite element model for the ISMF simulation process, in which forming tools and supported molds are designed and calibrated with 3D software, the blank is modeled with shell elements (S4R), and tools and

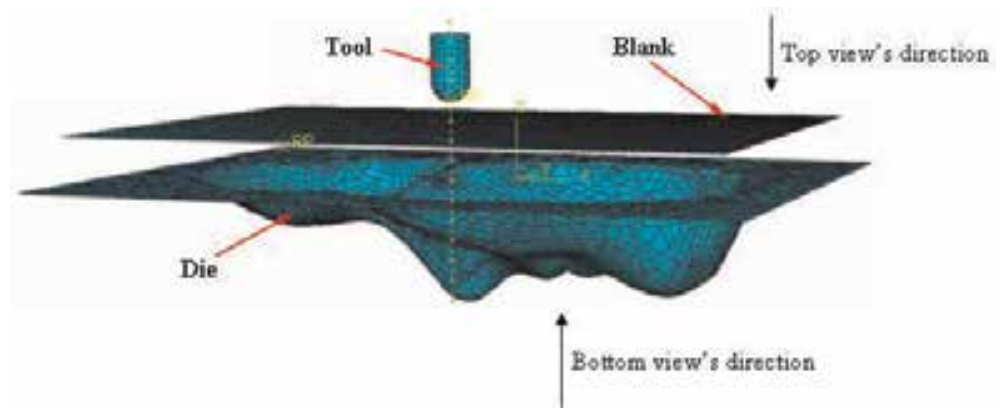

Figure 12.

Finite element model for simulation. 
molds are modeled by rigid surface elements (R3D4). The average size of the elements can be selected to suit the calculation time and desired accuracy.

\subsection{Material and friction coefficient}

Obtaining input data for the simulation of ISMF is not an easy task. The friction coefficients between the forming tool and the material sheet have hardly been measured and determined correctly by previous researches. Measuring forming forces and converting them into corresponding friction coefficients are also difficult. In general, the friction coefficient of the forming process could be assumed in the range from 0.05 to 0.2 depending on the specific conditions of the forming process. Another difficult issue is how to obtain reliable material data. Most studies use standard materials and conduct experiments using conventional tension or compression test methods. However, these experimental data only provide results with lower strain values than those observed during ISMF. Therefore, the representation of the stress-strain curve for higher deformation levels is necessary to simulate the ISMF process.

\subsection{Simulation of finite elements of square towers with different angles}

After collecting experimental data, this data is used as input parameters for the simulation process. To determine the accuracy of the simulation process compared to the corresponding experiment, the square tower shape with different angles was simulated to predict the forming height obtained until the appearance of the tear of products for materials.

Figure 13 describes the simulation results. From the simulation results, we can observe the ductile fracture phenomenon occurs with the wall angle of $80^{\circ}$ and the forming height of $25 \mathrm{~mm}$ (Figure 13a). While forming with a square shape with $45^{\circ}$ wall angle, the fracture is not observed even until the end of forming process with the final forming height of $40 \mathrm{~mm}$ (Figure 13b). In order to verify the predictability of the simulation process, the corresponding experiments were also conducted as shown in Figure 13. The experimental results are in good agreement with corresponding simulation results.

However, commercial software is inconvenient to simulate an incremental forming process for a complex shape because the various programs only support simple movements such as linear or circular motions. To overcome this inconvenience, the combination of CAM and computer-aided engineering (CAE)

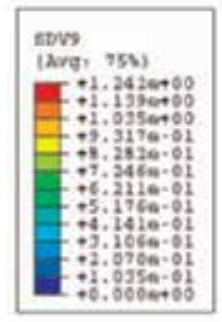

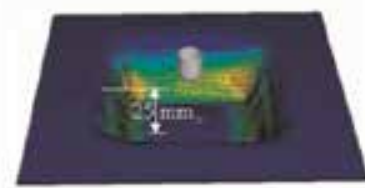

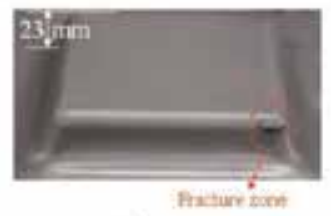

a)
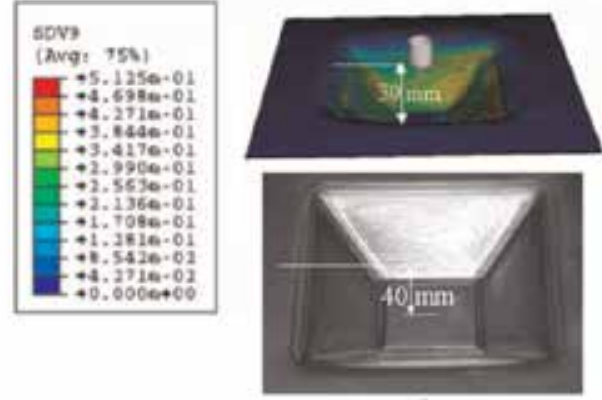

b)

Figure 13.

Simulation and experimental results for square shape with different wall angles. (a) The wall angle of $80^{\circ}$. (b) The wall angle of $45^{\circ}$. 


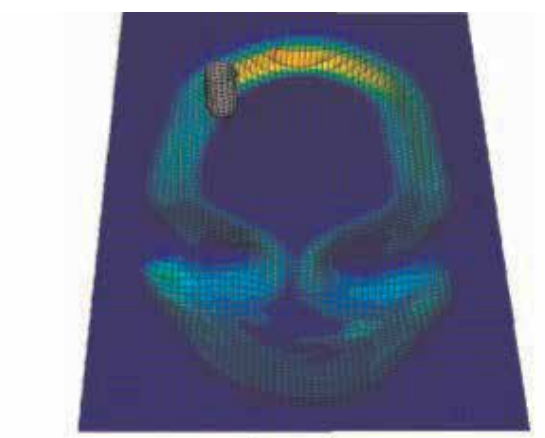

Top view

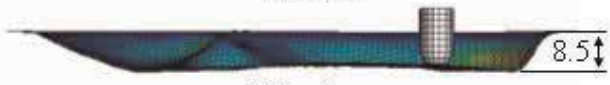

Side view

a)

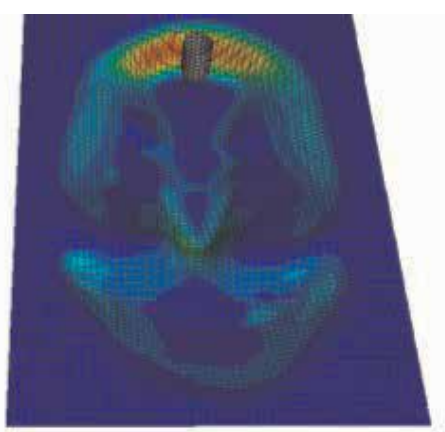

Top view

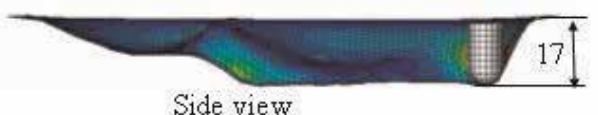

b)

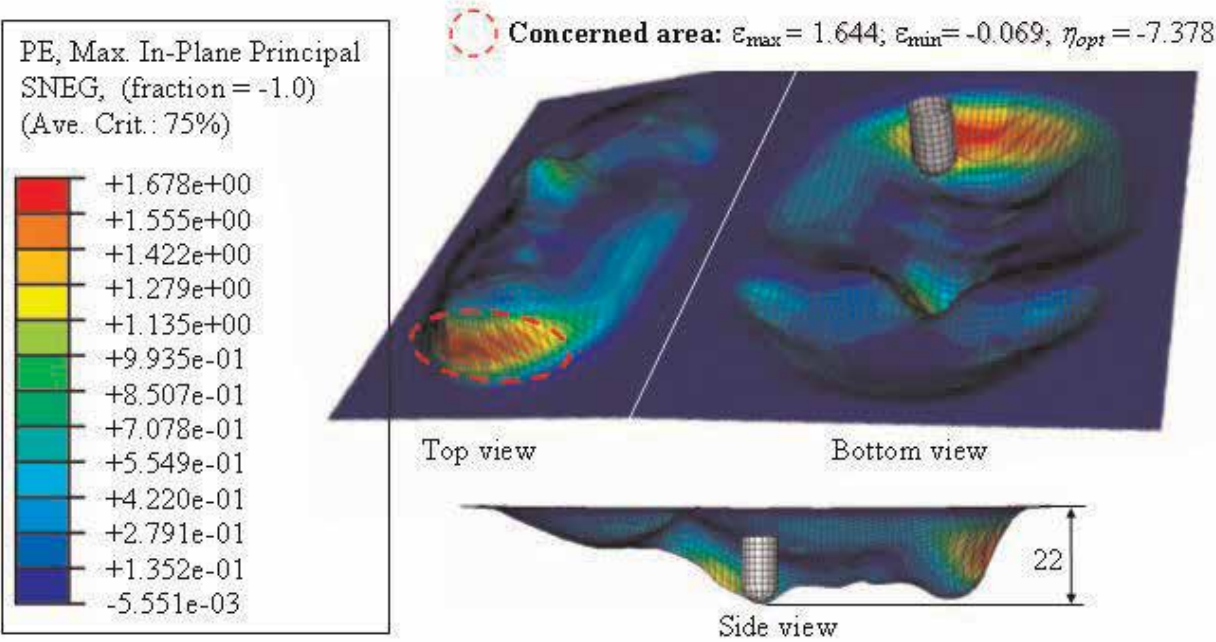

c)

Figure 14.

The evolution of deformed shape in FEM of ISMF [3]. (a) Deformation at tool stroke $h=8.5 \mathrm{~mm}$, (b) Deformation at tool stroke $h=17 \mathrm{~mm}$, and (c) Final results at tool stroke $h=22 \mathrm{~mm}$.

simulation using MATLAB programming to modify input ABAQUS file has been proposed. This method was also applied in previous study to simulate ISF for complex part (Figure 14).

Today, sheet metal forming methods based on the deformation of materials play an important role in mechanical production and metallurgy. The growing applications of numerical simulations in the field of sheet metal forming have helped engineers solve various problems in improving the formability and reducing the cost and time of products. Accurate simulation results are necessary for mold and product design. Many factors affect the final simulation results, but the most important input data for the ductile fracture prediction of a product is the forming limit curve of the sheet material. Several studies have been carried out to predict and evaluate the FLC by using experimental and theoretical methods. In addition, this concept has been widely applied in various commercial finite element software packages for technical studies. According to the experimental approach, Keeler $[15,16]$ tests are popular methods that have been widely used to clarify the levels of FLCs for sheet metals. However, time-consuming and high-cost computing is the 
main drawback of this testing method. Therefore, considerable effort has been made to obtain FLCs theoretically. Swift [17] can be recognized as a pioneering study on predicting FLC. Hill [18] then proposed a way to improve the accuracy of FLC prediction by adopting necking point criteria. Stören and Rice [19] developed a solution for FLC prediction by applying a force equilibrium between necking and uniform deformed regions. Banabic et al. [20] observed and developed a pre-defect in the material and developed a theory of limited deformation based on

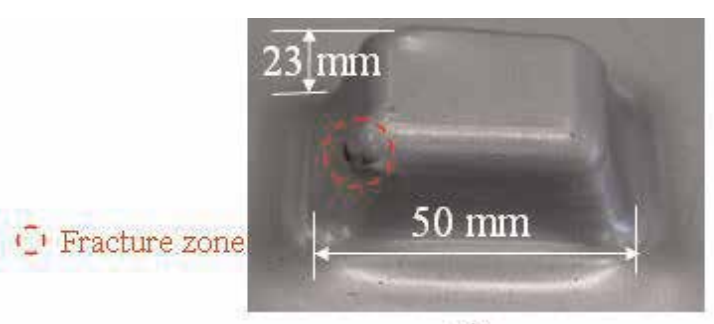

a)

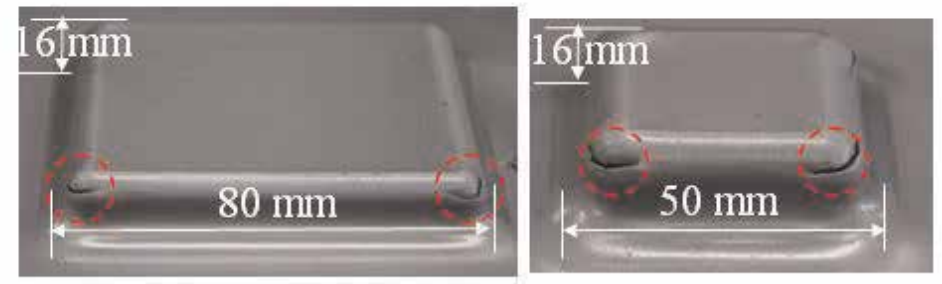

b)

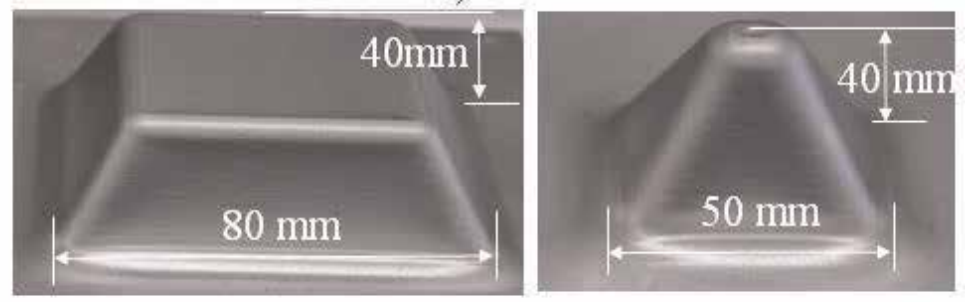

c)

Figure 15.

Experiments of incremental forming for various square shape sizes with (a) $80^{\circ}$ wall angle, (b) $85^{\circ}$ wall angle, and (c) $60^{\circ}$ wall angle.

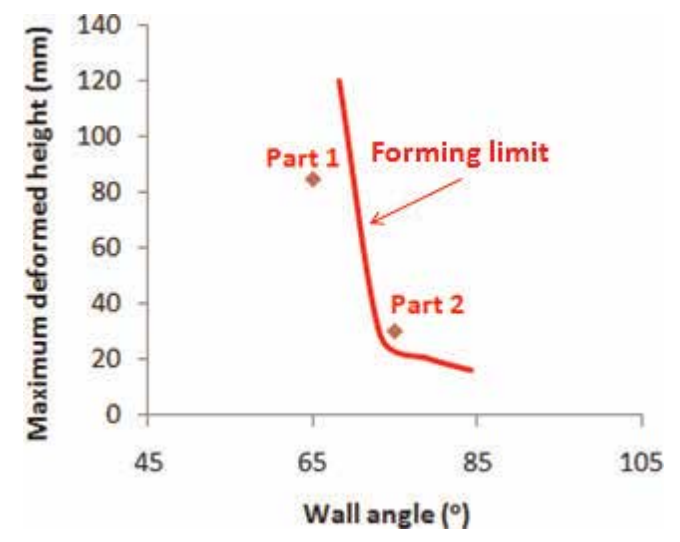

Figure 16.

Obtained forming limit based on the maximum wall angle versus maximum deformed height [18]. 
imperfections of material thickness. Hora et al. [21] upgraded the Swift diffuse necking criteria and set a modified maximum force criterion (MMFC) by effectively examining the instant deformation state changes until the forming force achieved a maximum value. Some new MMFC models proposed to improve the accuracy of FLC prediction based on theoretical models by solving systems of

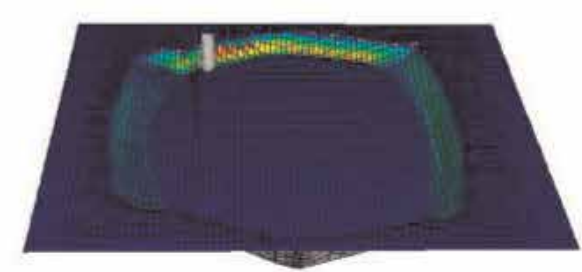

Top view

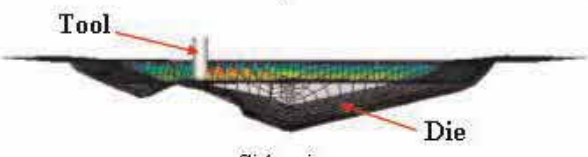

Side view

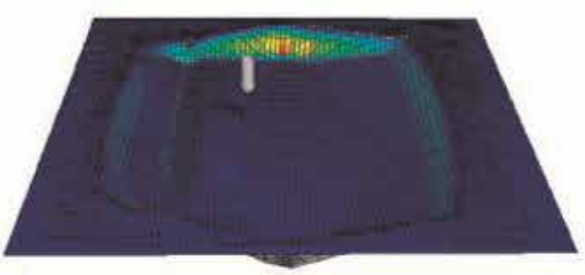

Top view

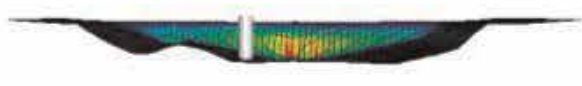

Side view

a)

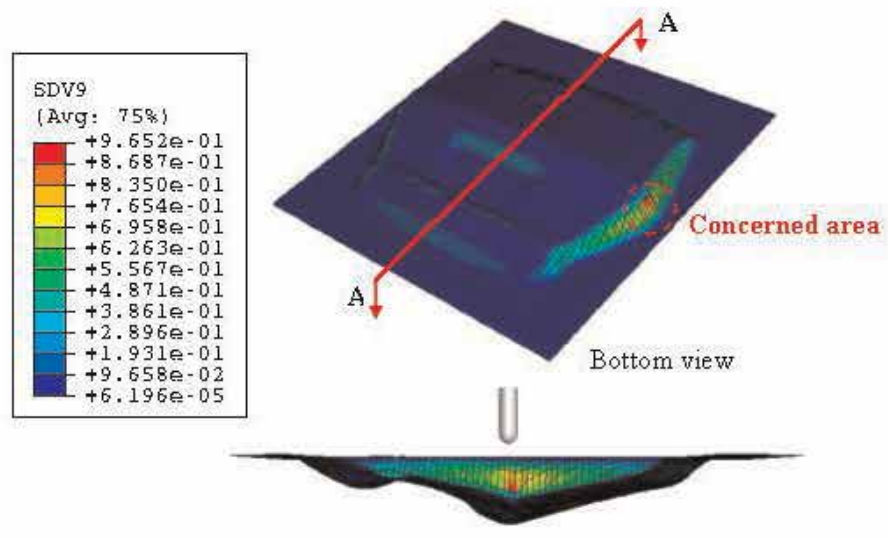

Side view

b)

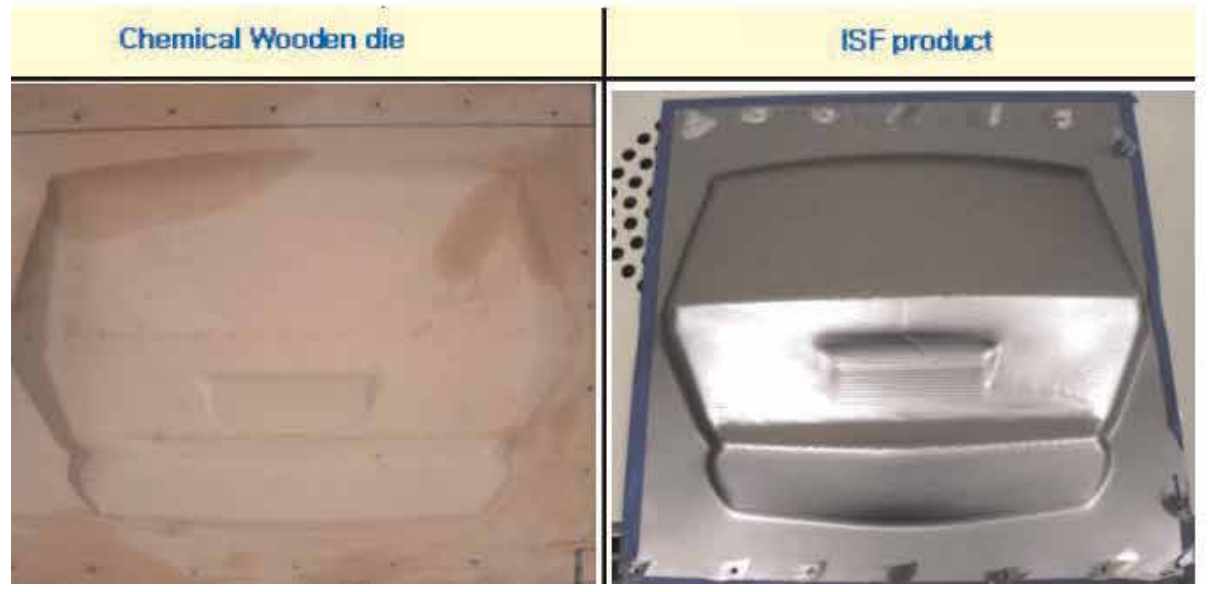

Figure 17.

Simulation and rapid prototyping of complex surfaces. (a) Intermediate deformations, and (b) Final shape. 
equations. Currently, the finite element (FE) simulation is an indispensable tool to research, evaluate, and discern physical phenomena modeled by various theoretical and experimental equations. However, the current FLC curves are inconsistent with the experimental results in ISMF. To improve the fitting of experimental data with numerical data, Nguyen and Kim [22] upgraded and introduced Swift's equation to MMFC and predict FLD curve for cold rolled steel material. They imported obtained forming limit diagram curves to FEM software [23] in order to predict fractures of various square shapes and compare them with corresponding experimental results. In order to verify the effect of tool dimension on FLD at fracture, ductile fracture criterion of Clift et al. [4] should be adopted to predict FLC, simulated and confirmed by corresponding experimental results. After experimentally verified, FLC data were used to simulate different square sizes to show the effect of the wall angle to the maximum height of the square shape and established limits of formability based on the relationship between the maximum destructive height and the corresponding wall angle (Figures 15 and 16). The obtained limit curves could be used to indicate the failure of sound products through the relationship between the wall angles and corresponding maximum height of complex shapes for ISMF process.

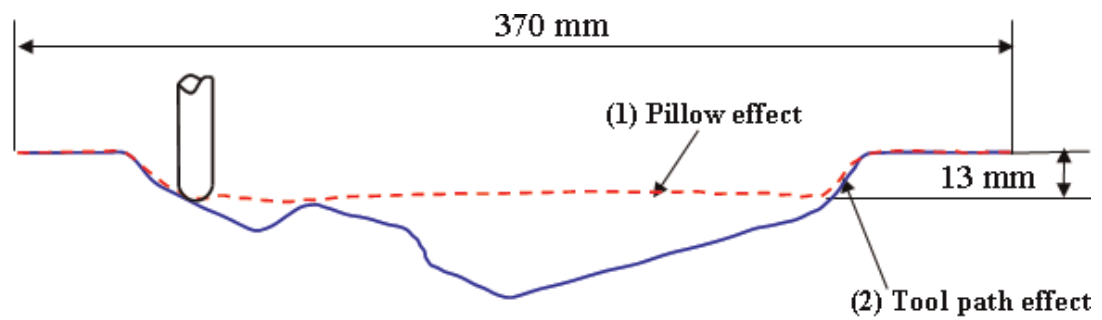

a)

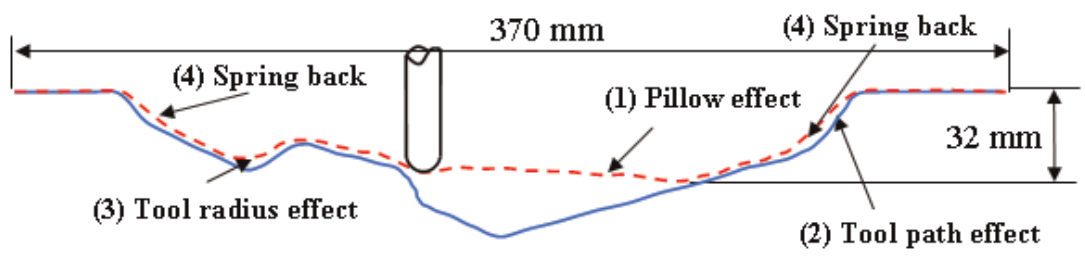

b)

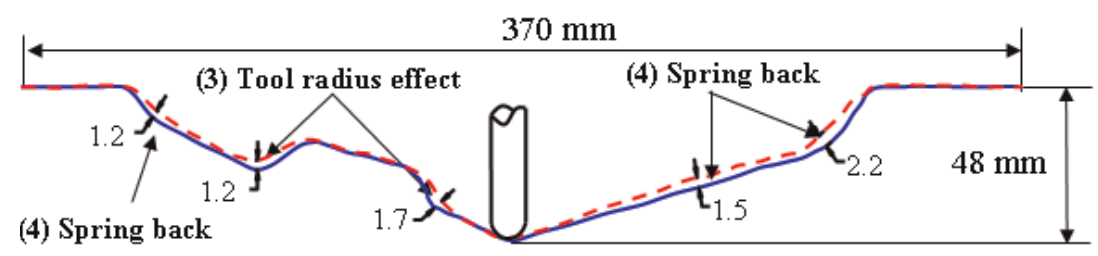

c)

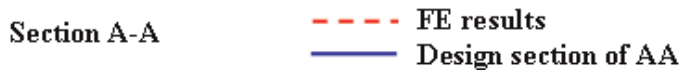

Figure 18.

Types of errors occurring during ISMF process. (a) Deformation at tool stroke $h=8.5 \mathrm{~mm}$, (b) Deformation at tool stroke $h=17 \mathrm{~mm}$, and (c) Final results at tool stroke $h=22 \mathrm{~mm}$. 


\subsection{Rapid prototyping application to complex surface products}

In order to perform ISMF for complicated surface products with various wall angles, the designed products must ensure the ability to be formed according to the following specific conditions:

- To accommodate with working space of CNC machine

- To satisfy the plastic deformation by comparing the large wall angles corresponding to the forming height

- To pre-simulate and verify the ductile fracture occurrence (Figure 16)

If it is found that there is a possibility of plastic destruction in a certain area, it is possible to conduct a simulation beforehand to check.

Figure 17 shows the simulation process and the obtained results after rapid prototyping of complex surface products by ISMF.

To verify and compare the accuracy of the final shape between simulation results, experimental products with CAD-designed surface in ISMF, we can use different sections and measure the shape distribution at different wall profiles and angles as shown in Figure 18. From that comparison, it can be seen that different deviations appear in the process of ISMF such as incorrect tool path generation, error due to tool radius, and error by springback and pillow effect.

\section{Conclusion}

Thus, it can be concluded that the simulation method is a particularly useful method for understanding, predicting, and evaluating the phenomena that occur in the ISMF process. This rapid prototyping method also proves that this is a new and innovative method. ISMF method satisfies the task of researching and developing new products. The proposal steps in this chapter can be applied to the actual manufacturing industry. Products of ISMF are continuously designed and ordered for rapid prototyping sample; when traditional forming methods are not applicable due to limitations on the formability, cost money, and the time for the fabrication of molds, then the ISMF using CNC machine with simple forming tools combined with FEM simulation will prove to be an effective and feasible method.

Some obtained scientific outcomes from proposal chapter are:

- The forming limit curves of sheet materials for ISMF will be increased when tool diameters decrease.

- The high-temperature generation at the contact area of the rotational incremental sheet metal forming process will improve the formability of light alloy sheet materials.

- To generate tool path for ISMF process in a simulation of complex surface, MATLAB code should be used to import to FEM input file.

- To predict and improve the formability of the ISMF process for industrial sheet products, pre-simulate based on the relationship between maximum wall angle versus maximum deformed height need to perform. 


\section{Author details}

Nguyen Duc-Toan* and Hoang Long School of Mechanical Engineering, Hanoi University of Science and Technology, Hanoi City, Vietnam

*Address all correspondence to: toan.nguyenduc@hust.edu.vn

\section{IntechOpen}

(C) 2019 The Author(s). Licensee IntechOpen. This chapter is distributed under the terms of the Creative Commons Attribution License (http://creativecommons.org/licenses/ by/3.0), which permits unrestricted use, distribution, and reproduction in any medium, provided the original work is properly cited. (c) BY 


\section{References}

[1] Allwood JM, King GPF, Duflou J. A structured search for applications of the incremental sheet forming process by product segmentation. Proceedings of the Institution of Mechanical Engineers, Part B: Journal of Engineering Manufacture. 2005;219:239-244

[2] Iseki H, Kumon H. Forming limit of incremental sheet metal stretch forming using spherical rollers. Journal-Japan Society for Technology of Plasticity. 1994;35:1336-1341

[3] Nguyen DT, Park JG, Lee HJ, Kim YS. Finite element method study of incremental sheet forming for complex shape and its improvement. Proceedings of the Institution of Mechanical Engineers, Part B: Journal of Engineering Manufacture. 2010;224: 913-924

[4] Clift SE, Hartley P, Sturgess CEN, Rowe GW. Fracture prediction in plastic deformation process. International Journal of Mechanical Sciences. 1990;32: 1-17

[5] Ushioda K, Takebayashi S, Abe YR. Control of structures and properties of cold-rolled sheet steels. Materials and Manufacturing Processes. 2010;25: 185-194

[6] Nguyen DT, Yang SH, Jung DW, Choi TH, Kim YS. Incremental sheet metal forming: Numerical simulation and rapid prototyping process to make an automobile white-body. Steel Research International. 2011;7:795-805

[7] Park JG, Kim JH, Park NK, Kim YS. Study of forming limit for rotational incremental forming of magnesium alloy sheet. Metallurgical and Materials Transactions A. 2010;41A:97-105

[8] Nguyen DT, Park JG, Kim YS. Ductile fracture prediction in rotational incremental forming for magnesium alloy sheets using combined kinematic/ isotropic hardening model.

Metallurgical and Materials

Transactions A. 2010;41A:1983-1994

[9] Leszak E. Apparatus and process for incremental dieless forming. Patent US3342051A1 [Accessed: 19 September 1967]

[10] Jeswiet J, Micari F, Hirt G, Bramley A, Duflou J, Allwood J. Asymmetric single point incremental forming of sheet metal. CIRP Annals. 2005;54(2):88-114. DOI: 10.1016/ s0007-8506(07)60021-3

[11] Duflou JR, Habraken A-M, Cao J, Malhotra R, Bambach M, Adams D, et al. Single point incremental forming: State-of-the-art and prospects. International Journal of Material Forming. 2018;11(6):743-773. DOI: 10.1007/s12289-017-1387-y

[12] Mohanraj R, Elangovan S.

Incremental sheet metal forming of $\mathrm{Ti}$ 6Al-4V alloy for aerospace application. Transactions of the Canadian Society for Mechanical Engineering. 2019. e-First Article. DOI: 10.1139/tcsme-2018-0276

[13] Maaß F, Hahn M, Tekkaya AE, Dobecki M, Poeche A, Brömmelhoff K, et al. Forming mechanisms-related residual stress development in single point incremental forming. Production Engineering. 2019;13(2):149-156. DOI: $10.1007 / \mathrm{s} 11740-018-0867-3$

[14] Hartmann C, Opritescu D, Volk W. An artificial neural network approach for tool path generation in incremental sheet metal free-forming. Journal of Intelligent Manufacturing. 2019;30(2):757-770. DOI: $10.1007 / \mathrm{s} 10845-016-1279-\mathrm{x}$

[15] Maqbool F, Hajavifard R, Walther F, Bambach M. Engineering the residual stress state of the metastable austenitic 
stainless steel (MASS) disc springs by incremental sheet forming (ISF). Production Engineering. 2019;13(2): 139-148. DOI: $10.1007 / \mathrm{s} 11740-018-$ 0864-6

[16] Keeler SP, Society of Automotive Engineers. Determination of Forming Limits in Automotive Stampings. United States: Society of Automotive Engineers; 1965. pp. 1-9

[17] Swift HW. Plastic instability under plane stress. Journal of the Mechanics and Physics of Solids. 1952;1(1):1-18

[18] Hill R. On discontinuous plastic states, with special reference to localized necking in thin sheets. Journal of the Mechanics and Physics of Solids. 1952; 1(1):19-30

[19] Stören S, Rice JR. Localized necking in thin sheets. Journal of the Mechanics and Physics of Solids. 1975;23(6):

421-441

[20] Banabic D, Aretz H, Paraianu L, Jurco P. Application of various FLD modelling approaches. Modelling and Simulation in Materials Science and Engineering. 2005;13(5):759-769

[21] Hora P, Tong L, Reissner J. A prediction method for ductile sheet metal failure in FE-simulation. In: Proceedings of the Numisheet International Conference; 1996. pp. 252-256

[22] Nguyen D-T, Kim Y-S. A numerical study on establishing the forming limit curve and indicating the formability of complex shape in incremental sheet forming process. International Journal of Precision Engineering and Manufacturing. 2013;14(12):2087-2093

[23] Simulia. Abaqus 6.10. Analysis User's Manual. Vol. 1; 2003 


\title{
Advanced Manufacturing Using Linked Processes: Hybrid Manufacturing
}

\author{
Katie Basinger, Caroline Webster, Carter Keough, \\ Richard Wysk and Ola Harrysson
}

\begin{abstract}
Hybrid Manufacturing Processes (HMP) can significantly reduce time to customer, waste, and tooling costs per part, while increasing possible part geometric complexity for small batch parts. In the following chapter, HMP is defined by the production of parts produced first with a near-net shape process using methods including: additive manufacturing, casting, injection molding, etc., which is then coupled with multi-axis computer numerical control (CNC) subtractive machining or some other secondary material removal process. Creating process plans for such hybrid manufacturing processes typically takes weeks rather than hours or days. This chapter outlines several hybrid manufacturing processes and the intricacies required to develop process plans for these complex linked processes. A featurebased advanced hybrid manufacturing process planning system (FAH-PS) uses feature-specific geometric, tolerance, and material data inputs to generate automated process plans based on user-specified feature precedence for additivesubtractive hybrid manufacturing. Plans generated by FAH-PS can optimize process plans to minimize tool changes, orientation changes, etc., to improve process times. A case study of additive-subtractive methods for a patient-specific bone plate, demonstrates system capabilities and processing time reductions as compared to the current manual process planning for hybrid manufacturing methodologies. Using the generated FAH-PS process plan resulted in a 35\% reduction in machining time from the current hybrid manufacturing strategy.
\end{abstract}

Keywords: hybrid manufacturing process (HMP), process planning, subtractive manufacturing, additive manufacturing

\section{Introduction}

Additive manufacturing (AM) can significantly reduce the development time for small batch parts or parts with complicated geometries, especially for polymer components [1]. Today, many polymer components are produced on a single AM machine, where the parts are manufactured directly to meet engineering requirements (e.g. geometric dimensions and mechanical properties). Producing a product on a single production resource yields significant benefits such as reducing material handling and in-process control. However, the most significant benefit associated with producing a product on a single production resource could be the reduction 
in process engineering time. For many of these polymer components, the mechanical properties come directly from the combination of the polymer material and the processing parameters. The geometric shape and dimensions comes from a combination of the computer-aided design (CAD) model developed during Product Engineering and the dimensional capabilities of the AM machine used.

Unfortunately, polymers have a limited use for only certain products. As better mechanical properties and finer geometric tolerances are required, the use of metals becomes necessary. Although metal AM has been around for two decades, the geometric accuracy of metal AM frequently falls short of the engineering specifications and the mechanical properties of AM produced metal parts are often highly dependent on the surface conditions. The result of these specifics is that metal AM production typically requires multiple post-production processes and machines. Metal AM machines have typically been used to create "near net-shape" components that require additional processes to enhance both the tolerances and surfaces as well as the mechanical properties of the AM printed component. This has slowed the adoption of metal AM for many high-performance components, especially those requiring certification.

To increase the performance of engineered parts with complex geometries which use processes such as metal AM, Hybrid Manufacturing Processes (HMP) are used which incorporate a secondary post process. HMP can significantly reduce time to customer, waste, and tooling costs per part while increasing possible part geometries and material availability for small batch parts. Examples of hybrid manufacturing for this chapter include Casting-Subtractive, Injection-MoldingSubtractive, and Additive-Subtractive processes. HMP usually have accurate results but require extra layers of complexity including process plan development.

This chapter outlines several hybrid manufacturing processes and the intricacies required to design parts and develop process plans for the complex processes. Although HMP is largely comprised of an additive process followed by a subtractive process, two other manufacturing methods are discussed since they have similar complexities in the process planning phase. Finally, a feature-based advanced hybrid manufacturing process planning system (FAH-PS) is discussed. This framework uses feature-specific geometric, tolerance, and material data input to generate automated process plans based on user-specified feature precedence for additivesubtractive hybrid manufacturing, a hybrid manufacturing process. Plans generated by FAH-PS can optimize process plans to minimize tool changes, orientation changes, etc., to improve process times. A case study of a patient-specific bone plate is described at the end of the chapter for proof of concept of the framework. Imploring a strategy of minimizing tool and orientation changes generated a process plan that demonstrated automation of an optimized process plan.

\section{Hybrid manufacturing processes (HMP)}

\subsection{Casting - subtractive}

While the modern definition of HMP focuses on the collection of production processes integrated together using computer-assisted systems engineering tools, the first instances of 'hybrid manufacturing' were originally much more sequential in nature. From literature, some of the first reported instances of using a sequential 'hybrid' approach were found in the finish machining of cast components (a.k.a. castings) [2,3]. When combined together, casting and subsequent machining provides numerous advantages including: reduced material waste, tighter achievable tolerancing, and increased overall geometric complexity. This is because this unique 
combination takes advantage of the capabilities of both processes. However, the material properties can be sacrificed compared to just machining.

Since the material flows into a mold cavity, casting enables the production of complex internal and external geometries that are net- or near-net shape. Parts fabricated using casting are often limited in other ways. For example, the surface roughness of castings is directly correlated to the roughness of the mold cavity walls, which in the case of sand casting is the roughness of the sand. Additionally, consideration must be given to process inherent defects that affect the mechanical performance and geometrical and dimensional accuracy of the casting such as shrinkage cavities, inclusions of air or foreign matter due to turbulence from pouring, etc. Machining can allow users to manufacture parts with increased accuracies as compared to casting alone. For example, parts often exhibit better flatness and smaller radiused corners when machined. Machining using computer numerical control (CNC), means that the process is highly repeatable and easily scalable due to the incorporation of computer-guided automation. While the accuracy is better for machined components, there is a sharp reduction of the geometric complexity possible, particularly with internal features, when compared to cast parts. This is because machining is limited to a straight line of sight from the cutting tool, which limits the features that are accessible for finishing. Additionally, unless combined with another process, machining is associated with larger amounts of material waste from transforming rectangular or cylindrical billets into final geometries.

Combined, these two processes can produce parts that are better able to meet the final part specifications in an economical way as outlined by the advantages mentioned previously. In this category of HMP, there are special considerations that must be given to the incorporation of machining after casting. For example, engineers should decide if small holes in the casting should be filled (i.e. not produced in the casting) to ensure drills would be able to accurately finish holes without tool walking. Another possible consideration is the method for fixturing cast parts to a milling machine, since each individual castings' defects (flash, shrinkage, pores, etc.) could impact this. Additional factors and where they should be addressed in the casting-subtractive category of HMP are outlined in Figure 1.

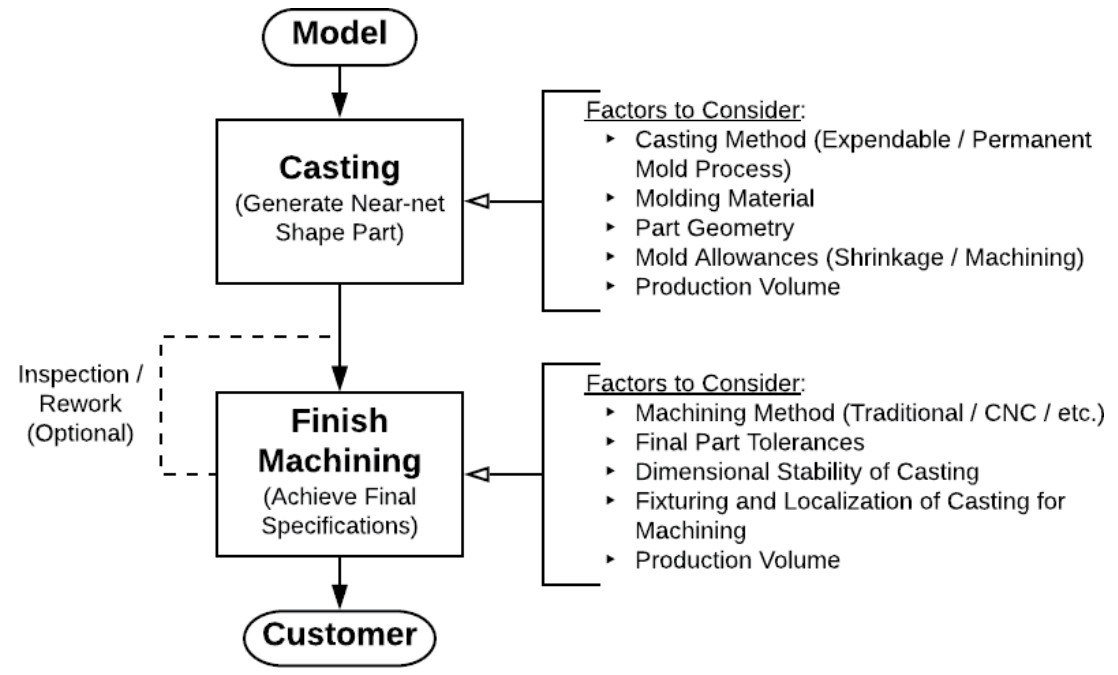

Figure 1.

Process flow of casting-subtractive category of HMP. 


\subsection{Injection molding - subtractive}

Injection molding is most commonly used to create small to large sized polymer, and in some cases metal, parts in large batches. The parts themselves are typically ready to use, once injection parameters have been optimized to reduce; voids, shrinkage, warping, short shots, burn marks, and flash. However, the most complex, expensive, and time-consuming part of the injection molding process lies in manufacturing the mold itself. There are many methods used to fabricate injection molds, including traditional machining, casting, and additive manufacturing methods. It is imperative for injection molds to maintain extremely tight tolerances and be manufactured of materials which can withstand the repeated pressures and temperature cycles from the injection molding process of large batch size parts. Traditionally machined molds satisfy these requirements but because machining is a line-of-sight finishing method there is often an inability for intricate or complex cooling geometries within the mold. Therefore, a more modern approach is to use additively manufactured molds with complex cooling features for large batches of parts. This approach is best suited for production of smaller batch sizes where lengthy mold manufacturing times are not cost effective on a per part basis. Both of these methods require post processing, usually machining, to achieve tolerance and surface finish requirements of an injection mold.

Although injection molds are typically made from metal, molds can be created from other materials such as UV cured polymer manufactured via vat photopolymerization processes or material jetting processes. These parts will need the appropriate post curing time and conditions. This recipe of post curing will directly affect the life of the mold and the accuracy of the parts [4].

Injection molding typically requires several large investments in machinery. Specifically, the process of creating the mold, although this is typically outsourced, have their own mold fabrication shop to cut down on costs. These fabrication shops require several milling and turning machines, tools to assist in fixturing and precise measuring, as well as experienced and competent operators to design and maintain the molds. Also required for injection molding is the injection molding machine itself. Injection molding machines are typically very large, even for small parts.

Although injection molding is a complex process, this chapter will focus on the methods for process planning of hybrid manufactured molds. Figure 2 depicts the flow in which injection molded parts are developed. Note the important considerations for process planning are related to the mold design and fabrication steps.

\subsection{Additive - subtractive}

With growing popularity and improving resultant parts, AM is driving renewed development in process planning and optimization for hybrid manufacturing processes. Additive manufacturing is classified by the layerwise addition of material to create a near-net-shape or final part. A variety of additive manufacturing processes exist that can manufacture polymers, ceramics, or metals with varying precision. Initially, AM was considered a prototyping technology that enabled accelerating design changes due to the relatively quick turnaround from CAD model to final part. Advances in additive manufacturing and design methods have facilitated growth in the area and additive manufacturing is now being adopted as a production manufacturing technology in aerospace, medical device, and automotive manufacturing among others.

Additive manufacturing allows for components that have highly complex designs or are made from materials that are difficult to process using other methods. This often allows for the reduction in the number of components, weight reduction, 
or the addition of features that cannot be manufactured using any other method. However, when compared to subtractive CNC finishing the achievable tolerances of an as-built AM component are much lower [5]. These tolerances may not be acceptable and require further finishing; however, the complex designs possible with additive manufacturing can pose challenges for subtractive CNC finishing, which requires the tool to have line of sight to the region that it is finishing [6]. Design considerations for Additive - Subtractive HMP include location of

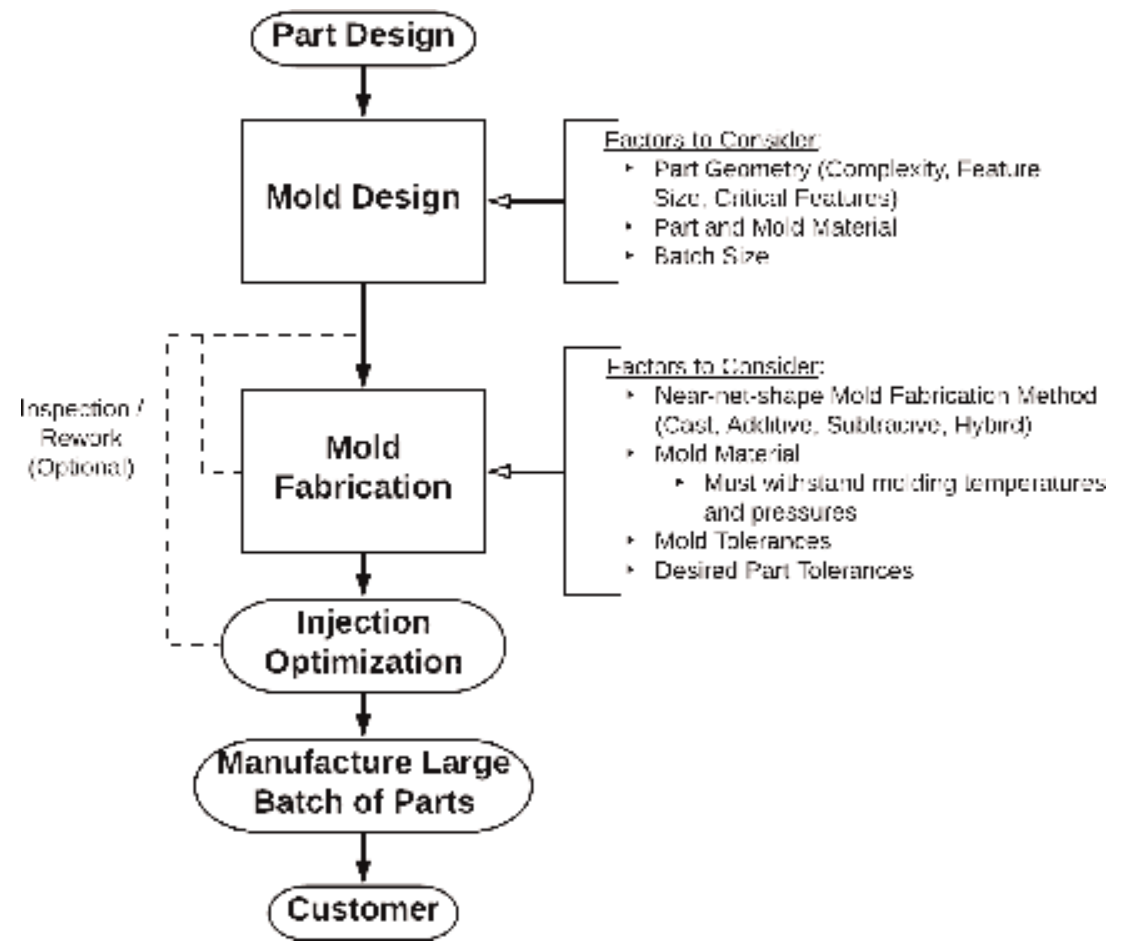

Figure 2.

Process flow for creating injection molded parts for large batch scenarios.

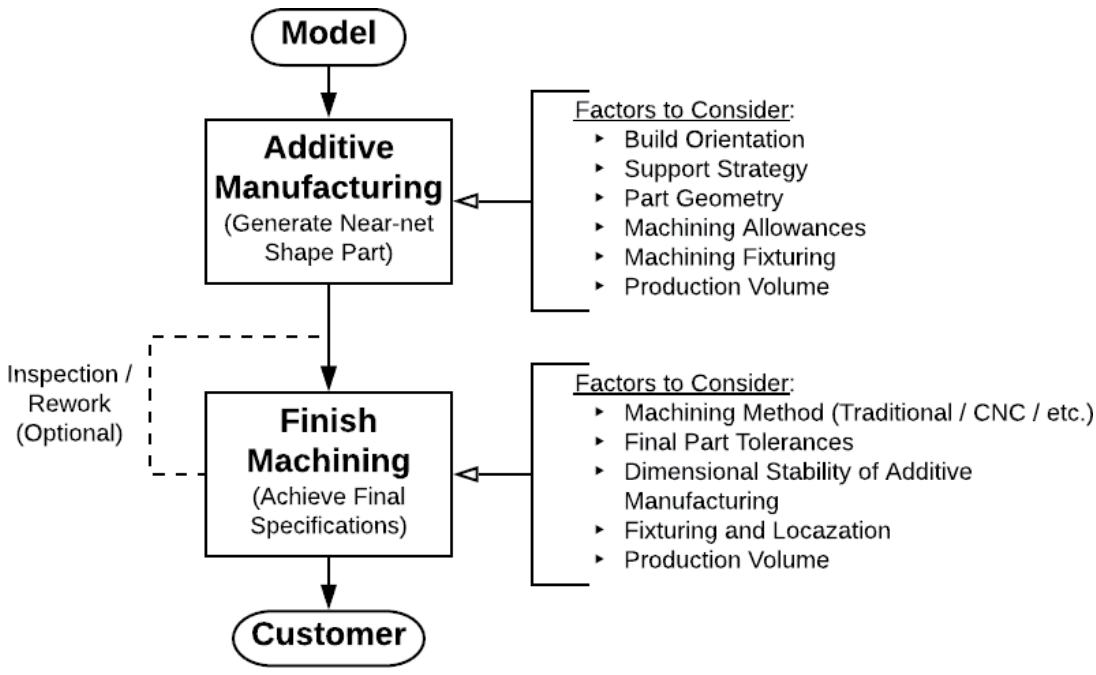

Figure 3.

Additive-subtractive HMP. 


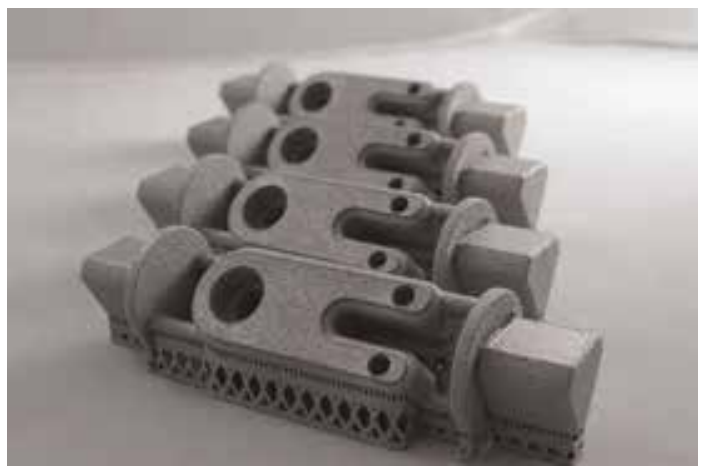

Figure 4.

Sample part which could replace multiple components and become part of an assembly after finishing (reproduced from [8]).

machining fixturing, part location in the machine due to variability in the AM processes, support structure removal, required tolerances, and required surface finish. Although there are additional considerations that must be made to accommodate the use of additive manufacturing in hybrid processes, the buy-to-fly ratio and costs can be lower than machining alone due to the material waste associated with subtractive only manufacturing [7]. Figure 3 shows the flow chart and key considerations for additive-subtractive HMP processes.

The component shown in Figure 4 is an excellent example of an additive manufacturing component that could be used in a functional assembly. However, the tolerances of the functional surfaces would not meet the requirements as is and would need to be finished before assembly.

\section{Process planning for HMP}

\subsection{Process planning}

Process engineering or process planning is the activity that determines how a product will be produced. That is, process engineering determines which manufacturing methods will be used in order to transform a product from one state (typically a part number) into another more valuable state (again, typically a new part number). In other words, it is the selection of the manufacturing method(s) to be used to convert a raw (or semi-finished) material into a final part requirement.

It is desirable to perform all processes at a single manufacturing station because material handling is eliminated (a non-value added process), but the use of multiple resources requires the scheduling/coordination of these resources. Unfortunately, most high-performance mechanical components are produced on a number of manufacturing resources, such as: casting processes, machining processes, heat treating processes, grinding, and other high-finishing processes. Determining which of these processes will be used, along with specifying what tooling and operating parameters will be executed, is the function of process planning. Process planning may also include defining what intermediate geometries, tolerances and material allowances are required between these processing steps. Process planning is a critical part of the engineering process because it determines the primary manufacturing cost for a product.

To illustrate this, we will use an engine block as an example. See Figure 5. Engine blocks are normally cast from gray iron. In order to plan a part like this 


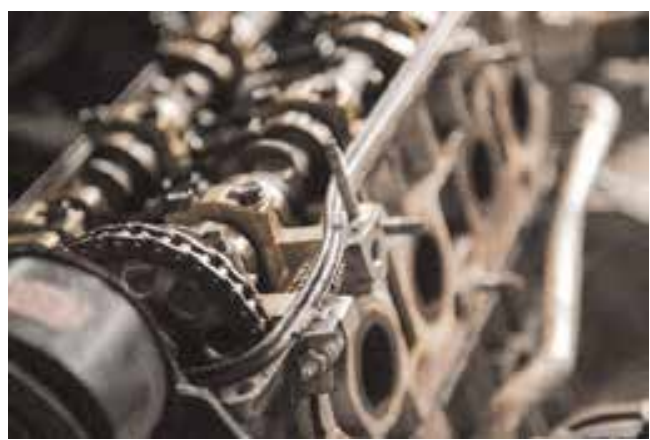

Figure 5.

Engine block with some assembled components. (reproduced from [9]. Photo by Garett Mizunaka on Unsplashed).

using traditional casting, machining, and then finishing, the process engineer would first determine how much additional material would be necessary to use in the near net-shape casting. Once this is done, the process engineer would create a "new pattern" that would be used in the green sand casting process. This pattern would allow for enough material of the critical features (faces and cylinders) for subsequent steps; this is the machining allowance. Next, the machining processes would be planned, where drilling, boring and milling operations would typically be used to create the next step in the production. Finally, finishing operations of the highly toleranced surfaces would be conducted. Planning each of these activities requires experience and a detailed understanding of the precision of each process. Tolerance stacks must be identified and used to properly sequence the operations that will be used.

The planning of each of these processes can be both time consuming and expensive. For each of the three production activities illustrated in this example (casting, machining and finishing), these activities represent "fixed costs" associated with each of these activities. Planning time for each of these activities would typically be on the order of 3-10 days depending on the complexity, tolerances and experience with similar products. For very small quantities of parts, process engineering can be the dominant cost component.

The final cost of any manufactured component will be the sum of the costs at each step of the production plus the materials, holding and overhead costs. At each step, the production cost must be determined. In general, we can define the cost of a product as:

Product Cost $=($ One - time Costs $)+($ Batch Setup Cost $)+($ Processing Cost $)$

In order to put cost as a function of volume, we can express this as cost per part or:

$$
\begin{aligned}
\text { Product Cost } / \text { Part }= & (\text { One }- \text { time Costs }) /(\text { Total Parts Produced }) \\
& +(\text { Batch Set }- \text { up Cost }) /(\text { Batch Size })+(\text { Processing Cost })
\end{aligned}
$$

Or in terms of variables:

$$
C_{p}=\frac{C_{1-t i m e}}{n_{t}}+\frac{C_{m o} t_{s e t-u p}}{n_{b}}+\frac{C_{m o}}{t_{p}}
$$


Where $C_{1-\text { time }}$, Total one-time costs; $n_{t}$, Total parts produced; $C_{m o}$, Cost of the machine resource and operator per unit time; $t_{\text {set-up }}$, Time required to set-up for a new batch; $n_{b}$, Parts per batch; $t_{p}$, Total time to process a part.

One can quickly see that to determine the production cost to plan a new product is a complex activity at each step. To make this even more difficult, the geometries and allowances at intermediate steps are also planned, and these specifics affect all downstream costs. This makes this a difficult engineering problem.

Multiple processes have been used to successfully produce mechanical parts for decades. The difference between traditional serial process planning and hybrid process planning and manufacturing is illustrated in Figure 6. This figure shows that in order to plan for hybrid processing, the process engineer must examine the effect of decisions made at each stage of manufacturing in order to develop the most efficient combination of processes and intermediate components.

\subsection{Process planning for HMP}

Process planning for hybrid manufacturing processes, is similar to that for single manufacturing method processes. Many of the key considerations are the same and include: how to minimize machining time, how to maximize tool life, how to minimize the number of tool changes, and how to minimize the number of times a part must be setup in a machine or machines. However, hybrid manufacturing processes require careful planning in design and development phases to ensure that parts and tooling are optimized for the full manufacturing flow that spans multiple manufacturing technologies.

\subsubsection{Process planning for casting-subtractive}

As mentioned previously, hybrid process planning is used to define how a product will be most efficiently produced by accounting for the effects of each manufacturing stage. While computer-aided process planning (CAPP) systems can be grouped into various subcategories of variants or generative approaches, such as feature-based technologies, knowledge-based systems, Petri nets (PN), agent-based technologies, internet-based technologies, neural networks, genetic algorithms (GA), or fuzzy set theory/logic, more recent interest has been shown in the development of feature-based planning approaches. Feature-based approaches are favored in many instances because large varieties of parts can be represented by individual features. Features used for plan generation are either specified manually

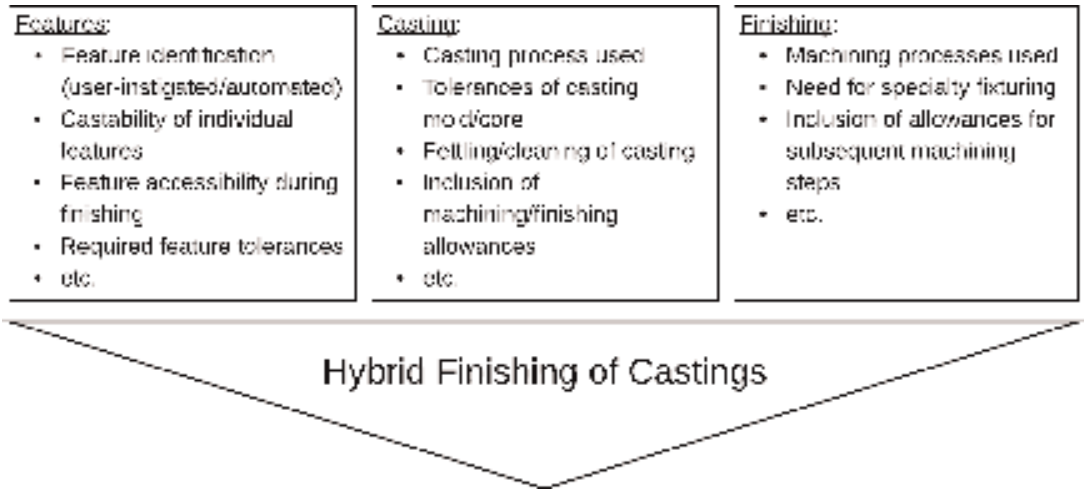

Figure 6.

Considerations for casting-subtractive HMP process planning. 
or are recognized automatically using a series of rules, topology maps, or the decomposition of volumes within the part $[10,11]$.

For instances of hybrid finishing of castings, where the near-net-shape component is produced using casting and later finished with machining, several factors must be taken into account during the planning stages. The numerous factors to be considered can be grouped into three categories which include those regarding: (1) which features need to be finished, (2) how cast parts are prepared for finishing, and (3) how the cast parts are finished. A general list of factors are shown in Figure 6.

Several scholars have attempted to address these areas primarily focusing on how to identify features for finishing stages and plan for the casting stage $[12,13]$. Some have also assessed the economic costs of finishing castings, which were briefly mentioned in previous sections [14]. Few scholars however, actually attempted to address the full complexity of the entire hybrid process [15]. Kim and Wang addressed this through an algorithm that has stages for feature recognition, casting allowance recognition, and machining volume selection [15]. From the author's understanding, a complete planning system is still required to span from feature identification in a computer-aided design (CAD) model and generation of intermediate models and process selections to the output of tool paths for the finishing of the final product.

\subsubsection{Process planning for injection molding-subtractive}

Traditionally the process planning for injection molds has relied heavily on the experience of past mold designers and fabricators. There have been significant strides to develop computer aided process plans for traditional mold making but not with the integration of multiple processes; these models are becoming more complex and time consuming [16]. As the molds are increasingly complex so are the need for better process planning techniques.

Considerations for feature based process planning are crucial in not only designing and manufacturing a mold from scratch but also repairing or refitting an injection mold. This is an iterative process in which molds are cycled through machining and testing. Many mold making facilities have an onsite injection molding machine for testing. However, some require shipment between the end customer and tool shop during this iterative process. In industry today, the most common method for process planning of injection molds is to allow experts to complete the task. However, there is a decreasing trend in qualified personnel to manufacture custom molds since the process is highly variable and requires strong problem solving skills and a high level of self-confidence [17].

The considerations specific to injection molding are similar to those mentioned previously for cast components, however there are some differences. Special factors include the identification of mold components, the development of the injection mold (including its material and tolerance specifications), and the finishing required for the mold and subsequent parts. This is further defined in Figure 7.

\subsubsection{Process planning for additive-subtractive}

Similar to the other hybrid process planning methods, process planning for additive-subtractive HMPs can either be feature-based or feature-less, and many methods utilize computer aided process planning. Utilizing CAPP methods is especially important when dealing with Additive-Subtractive HMPs due to the variability between parts manufactured both within a build and between builds. As with the other processes, the parts that are built in the first stage, must have the ability to 
be fixtured in the second and other subsequent stages of finishing. One such strategy is to create sacrificial supports that can be removed from the part once the components have been finished using CNC machining. Figure 8 shows an as-built component at the back left, a finished component with the sacrificial support still in-tact in the back right, and a finished component in the front center.

Additionally, hybrid finishing of additive manufacturing requires considerations that can be grouped into three key areas: feature considerations, additive manufacturing process considerations, and finishing process considerations. Figure 9 lists key example considerations for each area. Using the strategies

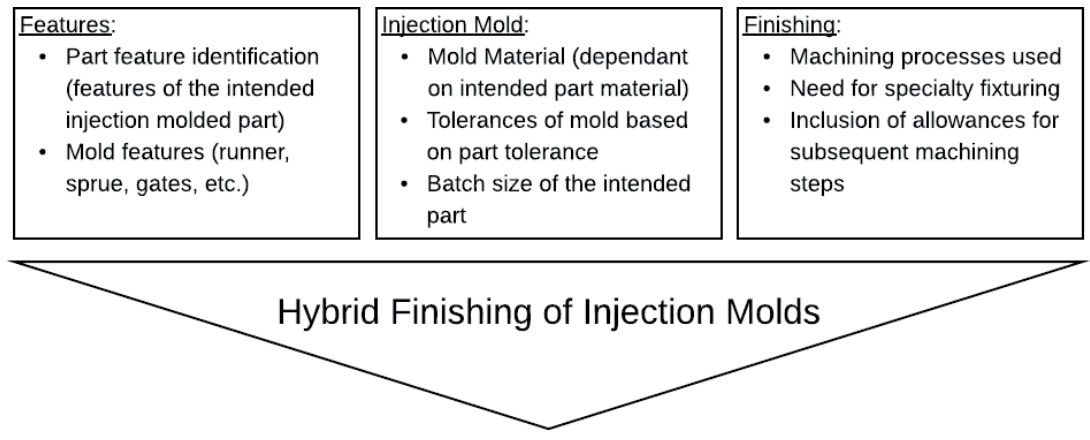

Figure 7.

Considerations for injection Mold-subtractive HMP process planning.

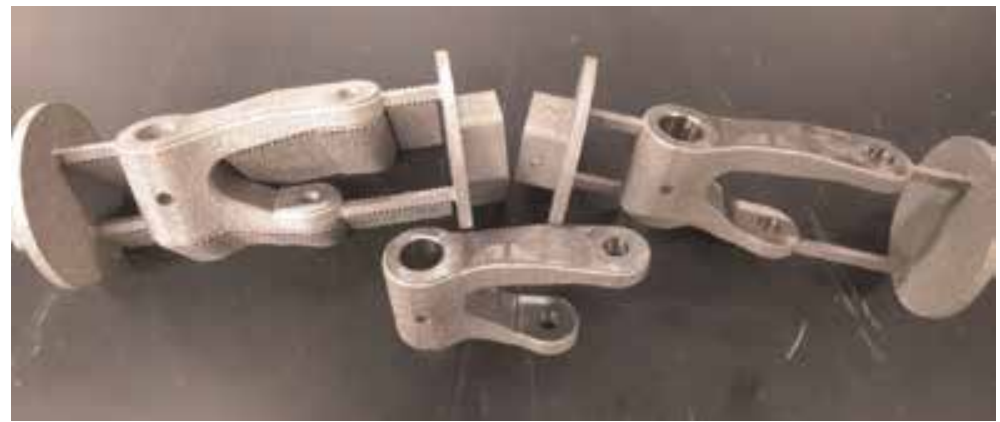

Figure 8.

Sacrificial support strategy example part (reproduced with permission from [18]).

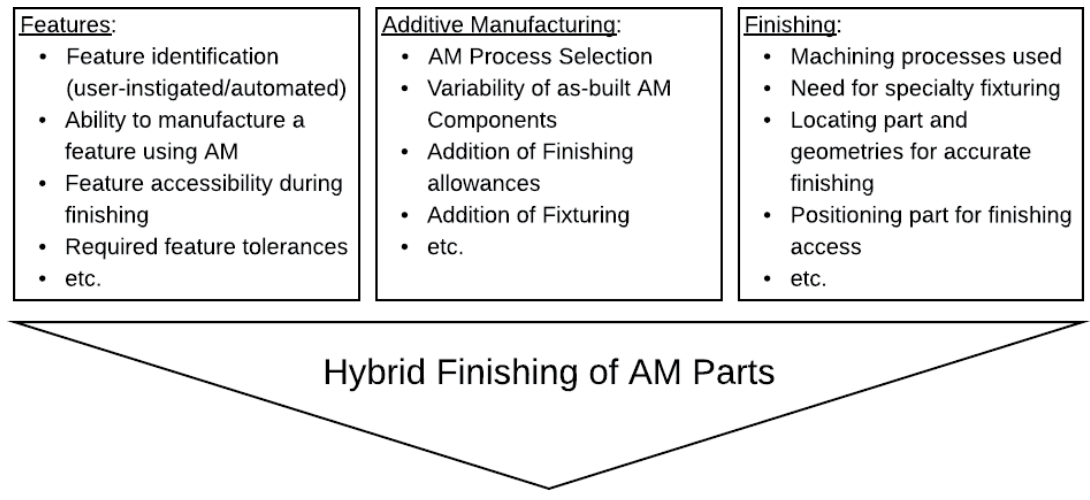

Figure 9.

Considerations for AM-subtractive HMP process planning. 
described above, the production costs and product costs can be calculated to determine if additive-subtractive HMP is the appropriate manufacturing solution for a particular part.

\subsection{Optimizing process planning for HMP}

When developing a process plan for any manufacturing method there are many avenues in which the plan can be developed. The most intuitive process plan can be developed from the perspective of the features themselves; this is a precedence based approach where higher precedence is given to more critical features for final part function. In this situation each feature is completely manufactured before the next feature is considered. This is the most logical method for creating a process plan.

However an optimized process plan might consider is the minimization of the number of tool changes. A tool change can occur multiple times in manufacturing a single feature. This can take a significant amount of time, especially if the tool change process is manual. In this situation the process plan is developed such that each tool is used on as many features as possible before changing tools. The drawback to this method is that multiple features may be in process at any given time. If features have critical tolerances based on each other this process plan can result in a part that does not meet standards.

Another optimized process plan may consider manufacturing parts one that reduces the number of orientation changes required. In an automated 5 axis CNC machine, orientation changes are often not a problem, however in a more manual process, changing the orientation of a part can take hours to re-fixture and re-center the part. In this scenario every feature in each orientation is machined before reorienting the part. Again, multiple features are in-process at the same time.

Even further optimized process plans can be developed combining any of the three techniques: precedence, minimizing tool change, or minimizing orientation changes. Each of these methods are important especially to HMP parts since often complex or unusual features are the driving force for choosing such complex and time consuming manufacturing methods. If the process plans are then developed manually this can take days, weeks, even months to develop an initial plan delaying a project entirely. If the plan needs to be optimized for precedence, tool changes, orientation changes, or a combination of the three the process planning phase can take an extremely lengthy amount of time delaying the project even further.

Therefore, there is a considerable need for computer aided process planning software which can account for the complex geometries of such HMP parts. An Excel based prototype has been developed and is described further in the next section.

\section{Feature-based advanced hybrid manufacturing process planning system (FAH-PS)}

The Feature-based Advanced Hybrid Manufacturing Process Planning System (FAH-PS) presented by [19] may be applied to multiple types of hybrid manufacturing processes such as casting-, injection molding-, and additivesubtractive. FAH-PS utilizes a modular and extensible software framework, which was intended to address: (1) the determination of operations final order in a process plan, (2) the types of processes supported in a hybrid process plan for holes, flats and slot features, and (3) the general extensibility of process planning systems for future program advancements [19]. The decision structure of FAH-PS uses feature specific geometric, tolerance, and material data inputs to generate automated 
process plans based on a user-specified critical feature precedence [19]. Individual modules are used to process machine information about specific feature types (hole, pocket, slot, etc.) and calculate required tooling and approximate machining times for each feature and part [19]. Based on user preference, FAH-PS can also generate additional process plans that aim to minimize tool changes, orientation changes, etc. to improve process times [19]. Figure 10 shows the decision tree that FAH-PS follows in the development of process plans.

A case study was completed using the FAH-PS framework of a HMP bone plate shown below in Figure 11. More information regarding the specifics of this study can be found in [19]. In summary, FAH-PS produced 4 automated process plans, the results shown in Table 1.

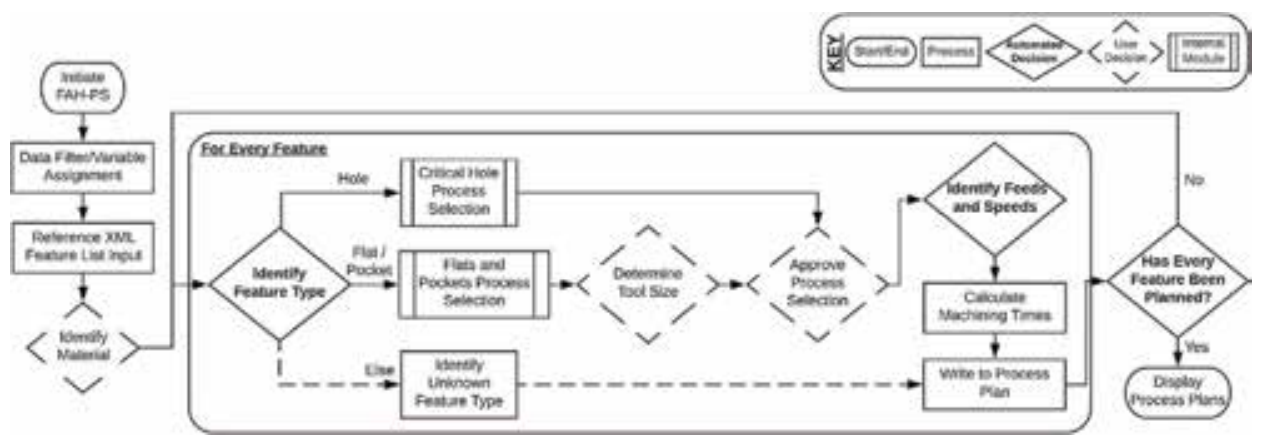

Figure 10.

FAH-PS decision structure (adapted from [19]).

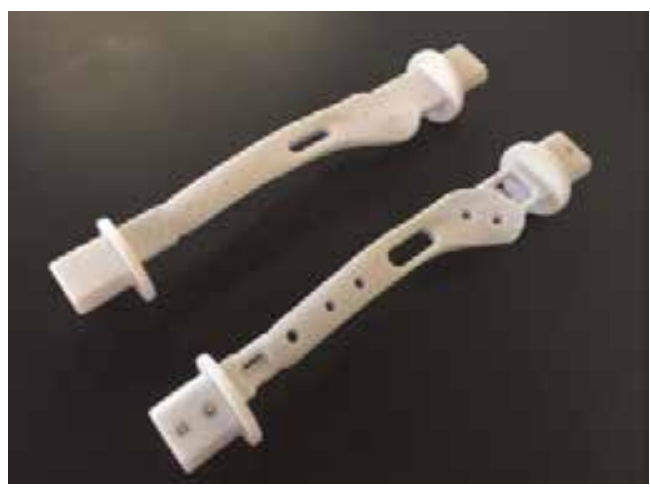

Figure 11.

Case study of using FAH-PS for finishing of a patient-specific bone plate (reproduced with permission from [16]).

\begin{tabular}{lcccc}
\hline Process plan & $\begin{array}{c}\text { Machining Time } \\
(\text { Min })\end{array}$ & $\begin{array}{c}\text { Time saved } \\
(\text { Min })\end{array}$ & $\begin{array}{c}\text { Tool Changes } \\
\text { count }\end{array}$ & $\begin{array}{c}\text { Orientation Change } \\
\text { count }\end{array}$ \\
\hline Manual & 17 & - & 2 & 26 \\
\hline Feature precedence & 11 & 6 & 16 & 4 \\
\hline Orientation change & 10 & 7 & 16 & 2 \\
\hline Tool change & 9 & 8 & 4 & 2 \\
\hline $\begin{array}{l}\text { Orientation and tool } \\
\text { change }\end{array}$ & 7 & 10 & 10 & \\
\hline
\end{tabular}

Table 1.

FAH-PS case study results (recreated results from [19]). 
This planning system is one example of the demonstrated feasibility of automated and semi-automated process planning for hybrid manufacturing systems of small batch parts. It was shown in [19] to be a valuable tool during the design and preparation stages of production as it reduced difficulties in obtaining optimal machining strategies quickly with improved levels of accuracy. Incorporation of other features and types of processes as well as detailed assessment of costs for the auto-generated process plans are still needed, however this planning system is a good guide for future developmental efforts.

\section{Conclusion}

Within this chapter several hybrid manufacturing processes were outlined and an overview of factors affecting the development of process plans for these processes was given. The complexities of process planning for multi-staged processes and optimization of such process plans was also explored. Effective planning for HMPs requires a shift from manual approach to an automated process planning system. The FAH-PS system was provided as one example of a system designed to plan for such HMP.

\section{Author details}

Katie Basinger ${ }^{2 *}$, Caroline Webster ${ }^{3}$, Carter Keough ${ }^{1}$, Richard Wysk ${ }^{1}$ and Ola Harrysson ${ }^{1}$

1 North Carolina State University, Raleigh, NC, United States

2 The University of Florida, Gainesville, FL, United States

3 Stryker, NJ, United States

*Address all correspondence to: katie.basinger@ufl.edu

\section{IntechOpen}

(C) 2019 The Author(s). Licensee IntechOpen. This chapter is distributed under the terms of the Creative Commons Attribution License (http://creativecommons.org/licenses/ by/3.0), which permits unrestricted use, distribution, and reproduction in any medium, provided the original work is properly cited. (cc) BY 


\section{References}

[1] Chong L, Ramakrishna S, Singh S. A review of digital manufacturing-based hybrid additive manufacturing processes. The International Journal of Advanced Manufacturing Technology. 2018;95(5):2281-2300. DOI: $10.1007 /$ s00170-017-1345-3

[2] Moohl JG. Applying jigs and fixtures to engine-block machining. The Society of Automotive Engineers. 1925;1:620627. DOI: $10.4271 / 250056$

[3] Pollard AFC. Precautions to be observed in the design of sand-cast and machined components. Journal of Scientific Instruments. 1933;10:265

[4] Colton J, Blair B. Experimental study of post-build cure of stereolithography polymers for injection molds. Rapid Prototyping Journal. 1999;5(2):72-81. DOI: $10.1108 / 13552549910267452$

[5] Manogharan GA. Hybrid Manufacturing: Analysis of Integrating Additive and Subtractive Methods. Raleigh, NC, US: North Carolina State University, Raleigh Dissertation Publishing; 2014

[6] Strong D, Kay M, Conner B, Wakefield T, Manogharan G. Hybrid manufacturing-Integrating traditional manufacturers with additive manufacturing (AM) supply chain. Additive Manufacturing. 2018;21: 159-173. DOI: $10.1016 / \mathrm{j}$. addma.2018.03.010

[7] Srinivasan HA. Automated Model Processing and Localization of Additively Manufactured Parts for Finish Machining. Raleigh, NC, US: North Carolina State University, Raleigh Dissertation Publishing; 2016

[8] Frank MC, Harrysson O, Wysk RA, Chen N, Srinivasan H, Hou G et al. Direct additive subtractive hybrid manufacturing (DASH)-An out of envelope method. Presented at the 28th Annual International Solid Freeform Fabrication Symposium. Austin, Texas; September 2017

[9] Unsplash. Garett Mizunaka Beautiful Free Images \& Pictures. Available from: unsplash.com/@garett3?utm_source= unsplash\&utm_medium=referral\& utm_content=creditCopyText

[10] Xu X, Wang L, Newman ST. Computer-aided process planning: A critical review of recent developments and future trends. International Journal of Computer Integrated Manufacturing. 2011;24(1):1-31

[11] Bard JF, Feo TA. The cutting path and tool selection problem in computer aided process planning. Journal of Manufacturing Systems. 1989;8(1):17-26

[12] Chougule RG, Ravi B. Casting process planning using case based reasoning. Transactions of the American Foundry Society. 2003;111:1321-1330. Available from: www.researchgate.net/ publication/237044001_Casting_proce ss_planning_using_case_based_rea soning

[13] Kailash SB et al. A volume decomposition approach to machining feature extraction of casting and forging components. Computer-Aided Design. 2001;33(8):605-617. DOI: 10.1016/ s0010-4485(00)00107-x

[14] Egbelu PJ et al. An economic model for the machining of cast parts. Journal of Manufacturing Systems. 1982;1(2): 207-213. DOI: 10.1016/S0278-6125(82) 80030-7

[15] Kim YS, Wang E. Recognition of machining features for cast then machined parts. Computer-Aided Design. 2002;34(1):71-87. DOI: 10.1016/ s0010-4485(01)00058-6 
[16] Lee R, Chen Y, Yu Cheng H, Kuo M. A framework of a concurrent process planning system for mold manufacturing. Computer Integrated Manufacturing Systems. 1998;11(1998): 171-190. DOI: 10.1016/S0951-5240(98) 00017-2

[17] Berg J. A Modern Moldmaking Trend. MoldMaking Technology. 2015. Available from: www.moldmakingtech nology.com/articles/a-modern-moldma king-trend

[18] Frank MC, Harrysson O, Wysk RA, Chen N, Srinivasan H, Hou G, et al. Direct additive subtractive hybrid manufacturing (DASH)_An out of envelope method. In: Solid Freeform Fabrication Symposium-An Additive Manufacturing Conference. 2017

[19] Basinger KL, Keough CB, Webster CE, Wysk RA, Martin TM, Harrysson OL. Development of a modular computer-aided process planning (CAPP) system for additivesubtractive hybrid manufacturing of pockets, holes, and flat surfaces. The International Journal of Advanced Manufacturing Technology. 2018;96: $1-14$ 



\title{
Quality Control Perspectives during Mass Production with a Focus on the Chemical Industry
}

\author{
Chike F. Oduoza
}

\begin{abstract}
Mass production was part of the industrial revolution in 1870 and, with it, a huge step change in manufacturing processes. Its impact was ground breaking and became even more remarkable with automation in a business production environment. The chemical industry is one of the manufacturing sectors that has benefited from the technology of mass production achieved through automating the business process. In this era of industry 4.0 and with the associated advanced technologies of smart manufacturing, cloud computing, cyber physical systems and internet of things, mass production has been revolutionised but still faced issues such as quality control of the production process which was affected by supply chain management, customised production of commodity and specialty chemicals and huge demand from other chemical industry manufacturers. This chapter has reviewed the evolution of mass production during traditional manufacturing to the present day and carried out a risk assessment to quality of production in a mass production environment with a view to recommending adequate quality control of the production process. The chapter also included a case study for mass production of a pharmaceutical drug-Amoxicillin which was partly batch produced into dry powder and then mass produced using tableting and encapsulating machine, highlighting sources of contamination and inconsistency in tablet weight if adequate control measures were not put in place.
\end{abstract}

Keywords: mass production, quality control, chemical industry, risk assessment, manufacturing, tableting/encapsulating

\section{Introduction}

Manufacturing is essential to a nation's economic well-being and quality of life for citizens because it creates wealth which is distributed through high-value jobs. Since its birth two centuries ago, the manufacturing industry has evolved through several paradigms [1]. The first paradigm was craft production which created the product requested by the customer at a relatively high cost. The reason is that there were no manufacturing systems associated with this paradigm. Also, craft production was confined to localised geographical regions and such production process was not scalable or interchangeable. Subsequently, the moving assembly lines then enabled the development of mass production which provided low-cost products through large scale manufacturing. However such production was limited in variety, as evidenced by the famous statement about colour that he wanted so long as it was black. 
Mass production evolved as a method of producing goods in large quantities at a low cost per unit. It was kicked off with a moving assembly line at Highland Park near Detroit, Michigan named after Henry Ford. Mass production was fully established and massively utilised at the end of the World War II when demand for consumer products became very high [1]. This technology was sought after because of the concepts of parts interchangeability, moving assembly lines and scientific management which are key enablers for mass production. While mass production created tremendous wealth for the U.S. and many individuals, it also had several weaknesses. Although massively revolutionised, it still faced issues such as quality control of the production process attributed to supply chain management, customised production of commodity speciality chemicals and huge demand from other chemical industry manufacturers. This book chapter therefore will review the evolution of mass production during traditional manufacturing to the present day and then carry out a risk assessment of quality of production in a typical chemical industry mass production environment with a view to managing and recommending adequate quality control of the mass production process.

In the late 1980s, global competition and consumer demand for high product variety led to the development of mass customisation. This was achieved by manufacturers designing the basic product architecture and possible options while customers selected the assembly combination of their choice. Product family planning then enabled manufacturers to share certain common components for a range of family of products.

Figure 1 shows how mass production with a key objective of economy of scale can be differentiated from mass customisation involving mass production of specific products for a large variety of customers while exploiting the economy of scope. Another option is personalisation which designs/produces products which are personalised for individuals thereby achieving a high level of value differentiation for specific users.

Figure 2 shows that the goal of mass production is scale while for mass customisation it is both scale and scope of production. For personalised production the goal is scale, scope and value derived. Overall, the desired product characteristics is quality and cost during mass production, quality, cost and variety for mass customisation and quality, cost, variety and efficacy for personalised production. It is therefore assumed that during mass production the customer buys the product while during mass customisation the customer chooses what they wish to buy. A request for personalised production requires the customer to design, choose and then buy the product.

During mass production, mass customisation and personalised production the emphasis and key objective is to produce very large quantities of the product within

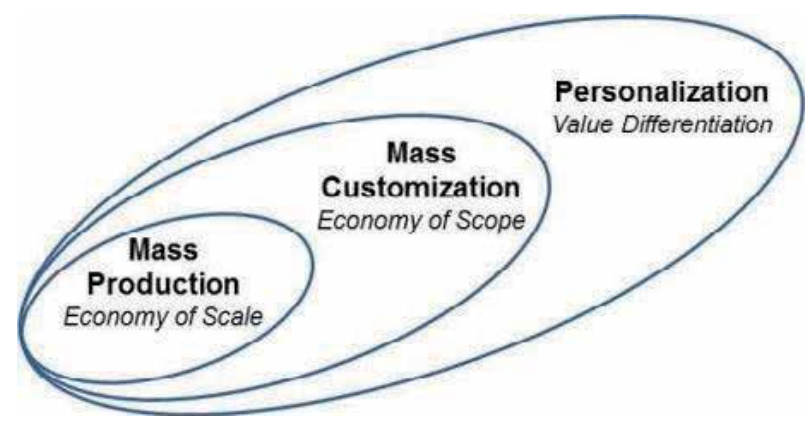

Figure 1.

Goals of the manufacturing paradigms [1]. 
Quality Control Perspectives during Mass Production with a Focus on the Chemical Industry DOI: http://dx.doi.org/10.5772/intechopen.90203

\begin{tabular}{|c|c|c|c|}
\hline & Mass Production & $\begin{array}{c}\text { Mass } \\
\text { Customlzation }\end{array}$ & $\begin{array}{c}\text { Personalized } \\
\text { Production }\end{array}$ \\
\hline Production Goal & Scale & $\begin{array}{c}\text { Scale } \\
\text { Scope }\end{array}$ & $\begin{array}{c}\text { Scale } \\
\text { Scope } \\
\text { Value }\end{array}$ \\
\hline $\begin{array}{c}\text { Desired Product } \\
\text { Characteristics }\end{array}$ & Cost & $\begin{array}{c}\text { Quality } \\
\text { Cost }\end{array}$ & $\begin{array}{c}\text { Quality } \\
\text { Cost } \\
\text { Variety } \\
\text { Efficacy }\end{array}$ \\
\hline $\begin{array}{c}\text { Customer } \\
\text { Role }\end{array}$ & Buriety & $\begin{array}{c}\text { Design } \\
\text { Choose } \\
\text { Buy }\end{array}$ \\
\hline $\begin{array}{c}\text { Production } \\
\text { System }\end{array}$ & Dedicated Mfg & Systems (DMS) & Reconfigurable Mfg \\
Systems (RMS) & $\begin{array}{c}\text { On-Demand Mfg } \\
\text { Systems (OMS) }\end{array}$ \\
\hline
\end{tabular}

Figure 2.

Differences between mass production, mass customization and personalised [1].

a limited time scale to satisfy customer demand. Monitoring manufacturing quality therefore could prove difficult considering that satisfactory product quality can only be achieved by rapid screening of materials at the input stage, transformation process stage within the manufacturing hub and finally at the output stage before shipment to the customer. The aim of this chapter therefore, is to review a typical mass production process, understand current practice to guaranteeing quality assurance during mass production and finally propose how this can be implemented in the chemical industry. It will also develop risk assessment that could guide process quality monitoring during mass production.

\section{Background and literature review}

There are four industrial revolutions so far [2] including first industrial revolution associated with discovery of water and steam power engine in 1784, the second industrial revolution in 1870 which involved mass production using electrical energy, the third industrial revolution in 1970 which introduced the use of information technology systems for automation and the fourth industrial revolution describing the present day which embraces Internet of Things (IOT) and cyber physical systems (CPS). The industrial revolutions which commenced over three centuries ago therefore have evolved and formed the backbone of manufacturing with each revolution providing a boost to productivity in the sector. Since the second industrial revolution mass production has sustained high volume production to satisfy global demand and needs. The manufacture of cars, guns and fast food are examples of mass production. It is the machine tool industry that gave rise to the idea of mass production because it motivated innovators in Britain and the United States to commence production of interchangeable parts.

Henry Ford was known to have invented an improved version of the assembly line for mass production when he mass produced the Curved Dash Oldsmobile. Ransom Eli Olds in 1901 in the USA. On this occasion he was said to have conceived the basic concept of the assembly line out of which 425 Curved Dash Oldsmobiles 
were manufactured. This significant development led the automotive manufacturing market over a period of 3 years from 1901 to 1904 [2]. It was also noteworthy that Henry Ford improved his design and installed the first conveyor belt assembly line around 1913 which reduced the building time of the Model T version to just 93 minutes. During that period, Ford became the world's-largest car manufacturer, having produced more than 15 million Model Ts by 1927 using the enhanced assembly line concept.

Other sectors have benefitted immensely from mass production such as the fast food and electronics industries to name a few. In the food industry, for instance, beverages, canned and bottled soft and alcoholic drinks and dried food packs are mass produced daily to satisfy huge global demand.

The advantages of mass production are [2]:

a. It is usually 'automated' to the highest extent possible.

b.Labour costs are reduced substantially.

c. It engenders a faster rate of production.

d.Although capital and energy investment are increased total expenditure per unit of product is decreased.

e. Rate of production is enhanced.

The disadvantages of mass production are:

a. Mass production infrastructure is very expensive to set up.

b. The workers are not highly motivated, since their work is very repetitive.

c. Manufacturing system is not very flexible, and production line is difficult to adapt.

d.If one part of the line breaks, the whole production process will halt until it is repaired.

\subsection{Quality management during mass production}

During mass production, mass customisation and personalised production the emphasis and key objective is to produce very large quantities of the product within a limited time scale to satisfy demand. Monitoring the entire manufacturing process in terms of quality therefore could prove difficult considering that satisfactory manufacturing quality can only be achieved by rapid screening of materials at the input stage, transformation process stage within the manufacturing hub and finally at the output stage before shipment to the customer.

Recalls from mass production such as for cars, processed food and aircrafts have frequently been reported, even for the case where the rate of defects is only of the order of ppm or less. Even if the defect rate is of the order of ppm or less, most of the remaining safe products would also need to be recalled and may be destroyed or replaced by new ones. Such recalls are always cost intensive. During mass production it is very difficult using conventional quality control methods to find defects of the order of ppm or less at the stage of design and production. 
Murakami [3] researched on a solution that could obviate the recall problem of the order of ppm during mass production. His new quality control method detects defects of the order of ppm or less for mass production products. This was based on the statistics of extremes successfully applied to the fatigue strength evaluation of defective materials. He confirmed that the same method could be applied, not only to mass production, but also for large machine components produced in large numbers.

Figure 3 shows hypothetical model of an input, manufacturing transformation and output for a production process. Input to the process could be in form of raw materials, catalysts and information; the transformation process involves a transition stage where the input materials are combining under the relevant conditions, such as temperature, pressure, etc. to produce the target output. The model shows that for each of the three stages there would need to be control in place to achieve the target/desired quality. In a mass production/continuous processing environment it may not be feasible to evaluate every single item going through the process and also at the output. Rather, acceptance sampling is used for quality assurance.

Siddiqui et al. [4] have reviewed the applications of analytical techniques including acceptance sampling in pharmaceutical analysis of drugs. They confirmed that pharmaceuticals may develop impurities at various stages of their development, transportation and storage, Consequently they need to be characterised and components quantified.

Table 1 shows common analytical techniques for quality control during mass production of chemicals. During chemical manufacture process analytical techniques are used to measure bulk materials, intermediates, impurities and degradation products. The aim is to characterise the quality of materials by setting limits of their active ingredient content [4].

The common analytical methods presented in Table 1 include titrimetry, chromatography, spectroscopy, electrophoresis, electrochemical methods and electrophoresis.

Acceptance sampling as a statistical method is also used to inspect bulk materials and mass-produced products to determine if they meet the required specifications. Acceptance sampling plan guarantees that the average quality level or percent defectives actually produced for consumers will not exceed a specified limit. It is therefore an effective way to ensure the high quality of mass-produced products and is usually conducted on the basis of a reference standard, or system of inspection rules [4].

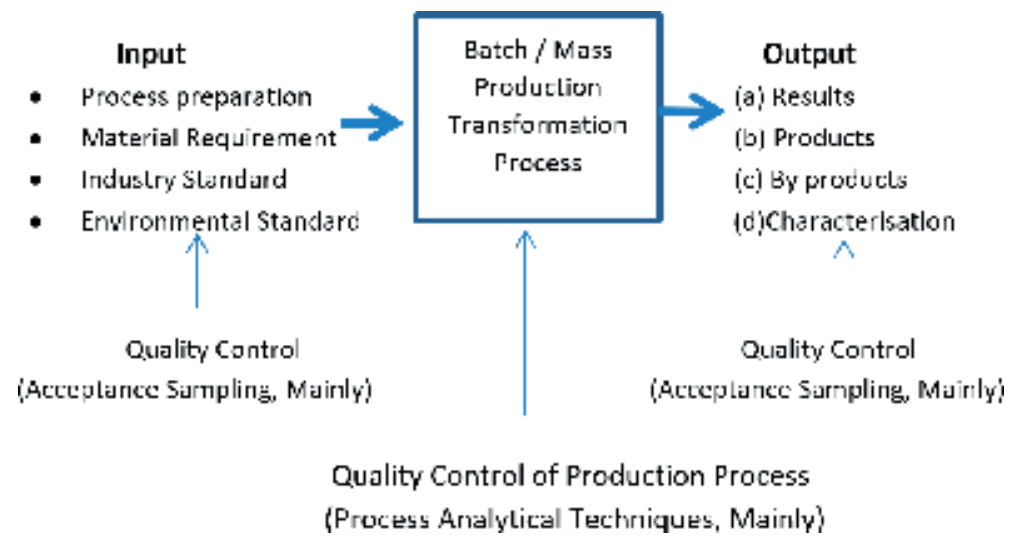

Figure 3.

Model for quality control during mass production. 


\begin{tabular}{ll}
\hline Process analytical technique (PAT) & Variants of the technique \\
\hline (1) Chromatography & a. High performance thin layer chromatography \\
& b. Thin layer chromatography \\
& c. High performance liquid chromatography \\
& d. Gas chromatography \\
\hline (2) Spectroscopy & a. Nuclear magnetic resonance spectroscopy \\
& b. Infra-red spectroscopy \\
& c. Near infra-red spectroscopy \\
& d. Spectrophotometry \\
& e. Flourimetry \\
& f. Phosphorimetry \\
\hline (3) Electrochemical method & a. Voltammetry \\
& b. Polarography \\
& c. Amperometry \\
& d. Potentiometry \\
\hline
\end{tabular}

(4) Flow injection and sequential injection analysis

(5) Electrophoresis

(6) Titrimetry

Table 1.

Common analytical techniques used for quality control during batch and mass production.

Quality analysis by acceptance sampling is measured by the following variables [5]:

a. Acceptable quality level (AQL): this is the desired quality level at which the probability of acceptance is high. It is described as the maximum proportion of defectives which the consumer finds acceptable. it is therefore the maximum percent defectives that can be considered satisfactory during sampling.

b.Lot tolerance percent defective (LTPD) or reject able quality level (RQL): this is the quality level at which the probability of acceptance is low and below this level the batch is rejected. This could be described as the dividing line between good and bad lots. Lots at this quality level however, are considered to be poor and are classed as average outgoing quality (A.O.Q)

\section{Advantages of acceptance sampling:}

i. It is applicable to industries where there is mass production which follows a set production procedure.

ii. The method is economical and easy to understand.

iii. Products that are delicate to handling during inspection can be inspected by sampling.

iv. Acceptance sampling enhances scheduling and delivery times.

\section{Limitations of acceptance sampling:}

i. Sampling does not guarantee $100 \%$ batch quality and there is risk of substandard output. 
ii. Success of the system is dependent on, sampling randomness, quality characteristics to be tested, batch size and criteria of acceptance of lot.

- Producer's and consumer's risk: the acceptance or rejection of the whole batch of products in acceptance sampling depends upon the results of the sample inspected. There is always a chance that a sample may not be true representative of the batches or lots from which it is drawn. Consequently, there are two types of risk;

- Producer risk $(\alpha)$ : probability of a batch being good overall or even better than acceptable quality level (AQL) but due to bad sampling it is rejected. So this probability of rejection of a good lot which otherwise would have been accepted is known as producer's risk $(\alpha)$.

- Consumer risk $(\beta)$ : probability of a bad batch or substandard quality being accepted however produces a good sample and consequently accepted. So this probability of a defective lot being accepted which otherwise would have been rejected is known as consumer risk $(\beta)$.

Guoa et al. [6] designed a quality control mechanism by scoring the quality of input, the transformation process and the output score. In their study they developed a six component process analysis turtle diagram quality scoring system. The assessment system is based on input material resources, the process support, quality control standard, quality manufacturing control method and the output, forming a quality control mechanism analysis model presented as a radar map.

Figure 4 adapted from [6] shows the radar model for quality control mechanism during manufacture. It shows the six variables that would need to be monitored during a production process as input, output, quality monitoring, quality control standards, process support and physical resources. It also shows the levels of expectation for the variables measured quantitatively.

Switching from batch to continuous pharmaceutical mass production offers several advantages, such as increased productivity, steady product quality and decreased costs. Kirchengast et al. [7] presented a control strategy for direct compaction on a continuous tablet production line consisting of two feeders, one blender and a tablet press (TP). They also applied a data-driven, linear modelling approach to develop a Smith predictor for active pharmaceutical ingredient concentration control and a model predictive controller responsible for the TP hopper level. In case of severe concentration variations the system could discard out-of-specification material before it entered the TP. The authors tested effectiveness of the control concept in a simulation as well as by implementing it on a real pilot plant.

Mass manufacture of micro products in the present day is quite challenging since tools, materials and technologies have to be scaled down from the macro to the micro domain. This is mainly because downscaling of the basic classical process would lead to unexpected process behaviour which poses new challenges for inprocess quality inspection desiring a reliable quality control. To implement this in a mass production environment therefore, new strategies to plan the process while focussing on the logistics of the quality parameters would become essential. Weimer [8] introduced a closed-loop quality control strategy for bulk production in micro cold forming. A discrete event simulation model incorporating characteristics of optical quality inspection and general process parameters allows the quantification of the system's performance. 

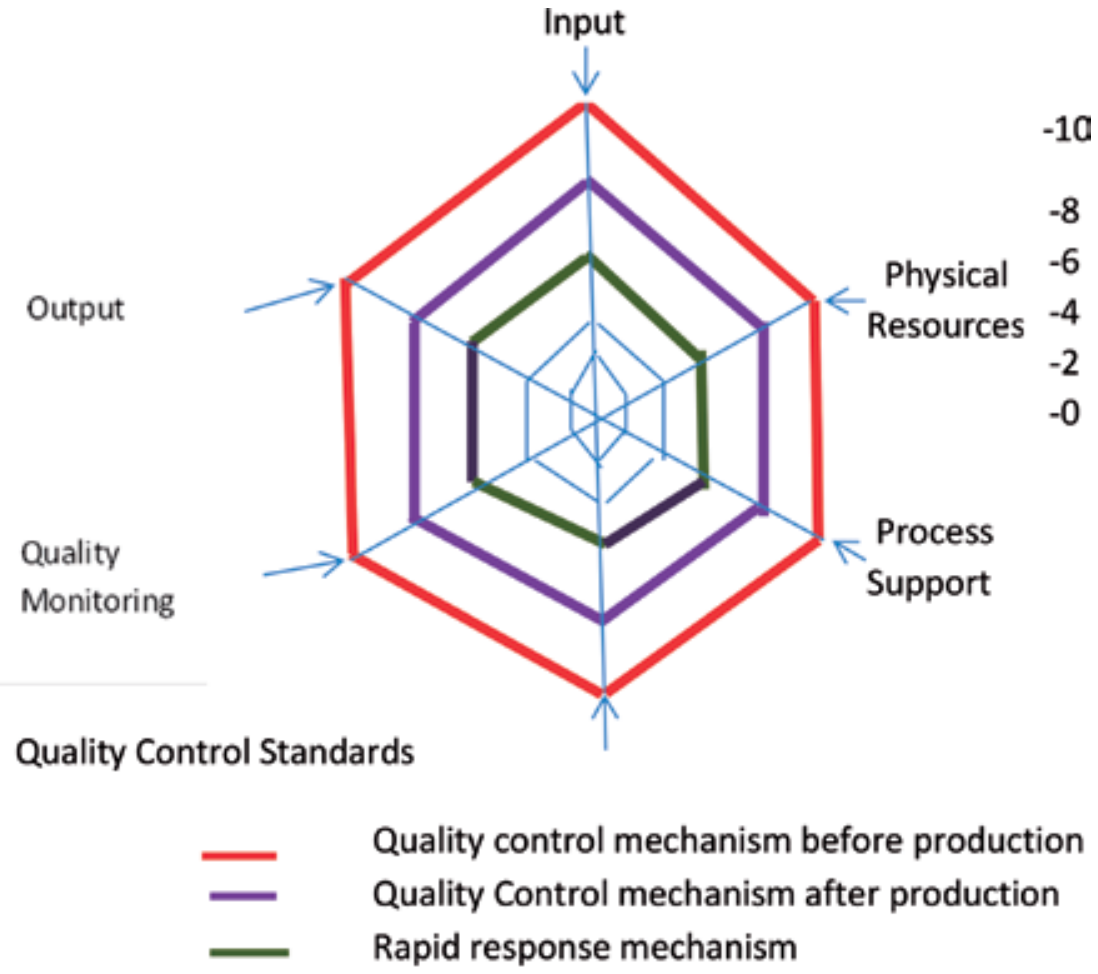

Where 10 - Fully satisfies requirements for quality control

8 - Mostly satisfies requirements for quality control

6 - Partial satisfaction of requirements for quality control

4 - Low satisfaction of requirements for quality control

0 - Failure to satisfy requirements for quality control

Figure 4.

Model for quality control mechanism.

\subsubsection{Quality control strategies for mass production}

A three-level quality control strategy for a continuous manufacturing process was proposed to maintain the quality of the product in response to potential variations or disturbance in the process, equipment conditions, incoming raw materials, or environmental factors over time Yu et al. [9]. A Level-3 quality control strategy imposes strict constraints on attributes and parameters that could affect product quality while also relying on rigorous end-product testing that should guarantee final product quality. Tight quality control of this nature is also used in a batch manufacturing environment and quality by testing (QbT) situation. This is managed by tracking a manufacturing operation to ensure that relevant parameters are maintained within the desired constraint. It is also necessary at the early stage of drug development to have a clear understanding of how raw material and process variability could affect product quality to fully appreciate the level of quality control. There is a perceived view that this approach is not feasible to be effectively implemented in continuous manufacturing processes.

The US Food and Drug Administration (FDA) recognised that increased testing does not necessarily improve product quality and thus quality must be built into the product [10], following the QbD concept. Consequently, pharmaceutical quality by 


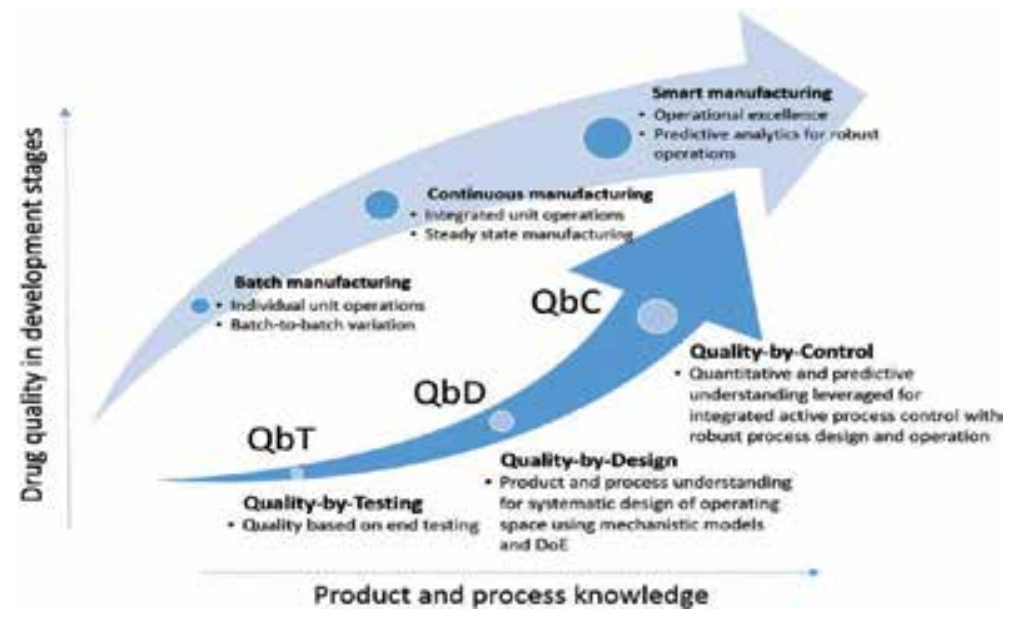

Figure 5.

The systematic progression in quality assurance via $\mathrm{QbT}, \mathrm{QbD}$ and $\mathrm{QbC}$ [10].

design (QbD) has now evolved guided by standardised documents associated with Pharmaceutical Development, Quality Risk Management, Pharmaceutical Quality System and Development and Manufacture of Drug Substances [10].

Quality by design (QBD) finally matured and evolved into quality by control (QbC) which describes the design and operation of a robust manufacturing system. This is normally achieved by an integrated and comprehensive process control underpinned by automation principles and also based on a clear understanding of the process. Overall therefore, Quality by Control enables a continuous monitoring and control of process operations and systematic release of the correct specification of manufactured products in real time.

Figure 5 shows a plot of drug quality in development stages vs. Product and Process knowledge. It demonstrates the evolutionary process of batch manufacturing through to continuous manufacturing and then smart manufacturing and the corresponding quality assurance checks in place. As drug quality development progresses from the batch to continuous and then smart manufacturing, quality assurance changes from quality by testing to quality by design and then consolidating to quality by control based on standards and requirements.

\subsubsection{Quality control during bulk pharmaceutical production}

In continuous chemical production lines, materials are transformed into final products and by-products and sometimes the activities take place in different departments. Overall, the quality of the final products is dependent on the quality of the input materials, the state of the relevant manufacturing equipment and the performance of the operators. However, out of control situations along production lines would normally lead to loss in operation time, material and financial resources. Sahebjamnia et al. [11] proposed a Fuzzy Q-learning Multi-Agent Quality Control System (FQL-MAQCS) to control a continuous chemical production line. The system manages unforeseen circumstances during production through a multiagent based system. It consists of quality control executor, process data analyst, central decision-maker, departmental decision-maker and knowledge/rule manager agents. The system is also self-learning, updated periodically and information gathered could be stored in a knowledge base. FQL-MAQCS has been tested in a real case study situation and the results demonstrate the usefulness, robustness and capability of the developed quality control system. 
Pharmaceutical production is now progressing more into mass personalization, down to lot size $N=1$. Each product is not only produced as part of a batch during mass production but it is also designed uniquely for the benefit of a specific patient. Based on demand certain drugs are custom designed and manufactured for large hospital or community pharmacies. An ongoing trend is an increased usage of contract manufacturing/filling by most pharmaceutical companies. Highly flexible aseptic production and filling lines have now become trendy until recently was not feasible through filling line concepts available in the present day but only through highly flexible automated systems driven by robotics [12]. The popular technology of individualised/customised mass production of cars in terms of colour, engine specification and performance, wheels, lighting and extras is still remote in current pharmaceutical production technologies. If successfully implemented, this would be a revolution in pharmaceutical manufacturing and also for the Food and Drug Administration (FDA). Bhaskar [13] designed an advanced model predictive control (MPC) architecture integrated with a novel real-time tablet weight measurement method aimed to develop and implement continuous direct compacting tablet manufacturing pilot-plant which has the potential to control tablet weight and tablet breaking force simultaneously by systematically decoupling and cascading the control loops. The predictive control algorithm (PCA) was superior to the proportional, integral and derivative (PID) controller and consequently could be utilised for a wide range of applications to improve the quality of pharmaceutical products during continuous manufacturing. The MPC enabled control of the main compression force and pre compression force using main compression height and fill depth respectively as the actuators. The researchers claimed that developing this technology made it possible to measure tablet weight and other variables that enhanced manufacturability of pharmaceutical tablets.

Lakerveld et al. [14] in a separate study designed a plant-wide control structure for a continuous pharmaceutical pilot plant used to classify control objectives. By means of simulation software they demonstrated that for selected parameters the critical quality attributes (CQAs) of the final product can be kept close to specification in the presence of significant and persistent disturbances. This shows flexibility to control CQAs independently of each other.

Mesbah et al. [15] developed a control strategy based on a non-linear moment model whose optimal operation was based on manipulation of heat input to a crystallizer such that a maximal allowable crystal growth rate was maintained during a production process. The feedback structure of the control framework enabled the optimizer to reject process uncertainties and accurately account for plant-model mismatch while fulfilling product quality requirements.

Advanced feedback control concepts which are capable of improving performance of batch processes, as well as enable technologies from batch to continuous manufacturing were developed by Nagy et al. [16]. These were used in the improvement of pharmaceutical particulates, especially in the application to continuous drug substance/product manufacturing. Mathematical modelling of the optimal design, start-up and control of anti-fouling and continuous crystallisation processes to achieve and maintain the desired controlled stage of operation was demonstrated. Su et al. [17] demonstrated the use of a rotary tablet press, integrated into a pilot scale continuous direct compaction process. The outcome was that active process control which was based on product and process knowledge and advanced model-based techniques, data reconciliation, model predictive control and risk analysis, appeared to be indispensable when implementing a comprehensive Quality by Control. It also appeared to guarantee robustness and production efficiency. Recently, Singh [18] developed an automated version of the continuous pharmaceutical manufacturing pilot plant. The feeder, comill, blender and tablet 
press unit operations of the pilot plant were integrated with a centralised control platform enabling the whole plant to be operated automatically. Data generated from all the unit operations were capable of being collected and stored systematically in a data base.

\subsubsection{Contamination quality control during manufacturing}

Contamination quality control is a huge challenge during manufacturing especially for products with ultra-low tolerance for impurities and contaminants. For instance during the manufacture of premium chemicals, highly sterile pharmaceuticals and hygienic products and other products with high purity requirements and specifications, it is essential to provide an environment that will obviate any form of contamination. A common source of contamination is from manufacturing machines and equipment that can conceal microscopic particles and microbes. Decontamination can be achieved through effective cleaning and disinfecting manufacturing equipment at regular intervals and ensuring that all surfaces exposed to raw materials and products can be reached by the cleaning and disinfection processes. Hydrogen peroxide is widely recommended for the cleaning and fumigation process and therefore all machine housing and operating components and interfaces need to be robustly designed to minimise any form of contamination from these. Manufacturing equipment therefore should be designed to be resistant to chemicals, display low adsorption affinity for hydrogen peroxide during fumigation and also its rapid desorption during aeration in order to speed up the production process [12].

Kraemer et al. [19] researched on clean ability test of a robot contamination with a water-based fluorescing test contamination. The researchers mixed riboflavin in ultra-pure water which was then allowed to dry onto the manufacturing surfaces. On inspection under UV light before ultra and after manual wipe cleaning with a pre wetted polyester knitting cleanroom wipe using ultrapure water, they observed areas that were difficult to clean because of the use of the fluorescing pigment riboflavin. This included depressions, indentations and edges.

\section{Case study: process flow diagram for the manufacturing process of amoxicillin}

Amoxicillin oral suspension is an antibiotic which most commonly utilised for first line treatment of middle ear infections and for pneumonia, skin infections and strep throat as well. Active compound used in its formulation has chemical formula $\mathrm{C}_{16} \mathrm{H}_{19} \mathrm{~N}_{3} \mathrm{O}_{5} \mathrm{~S}$ with molar mass of 365.4. It is also called phenoxymethyl penicillin.

Figure 6 shows a variety of Amoxicillin capsules and tablets while Figure 7 shows the structural formula of Amoxicillin. Figure 8 is GSK Manufacturing Plant at Irvine.

Figure 9 shows the process flow diagram for manufacture of Amoxicillin [20]. The process starts from stage A involving the reaction of the relevant raw materials [6-aminopenicillanic acid (6 APA), water and hydroxy phenyl glycine methyl ester (HPGME) and phenyl glycine acylase (PGA)] necessary for manufacture and finishes at stage $\mathrm{O}$ which is the drying process. Quality control of the manufacturing process takes place at every stage to ensure that the finished product in a dried form has the target consistency of $100 \%$ amoxicillin with minimum impurity. Most of the unit operations up till this stage are mainly batch manufacturing processes. The dried amoxicillin powder would need to be quality tested by acceptance sampling using relevant analytical techniques to establish conversion consistency and consequently any impurities beyond the recommended concentration in parts per million (ppm). 


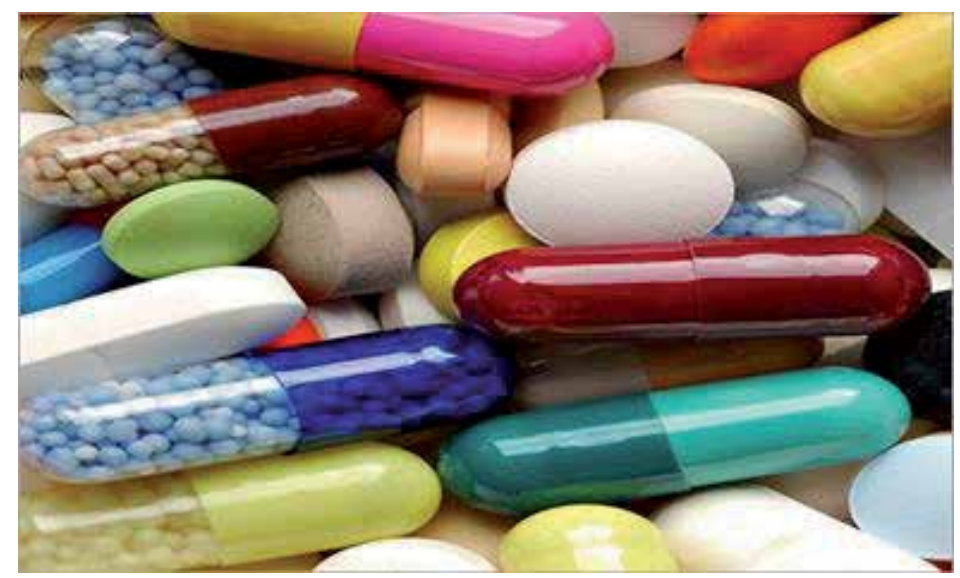

Figure 6.

Amoxicillin capsules and tablets.

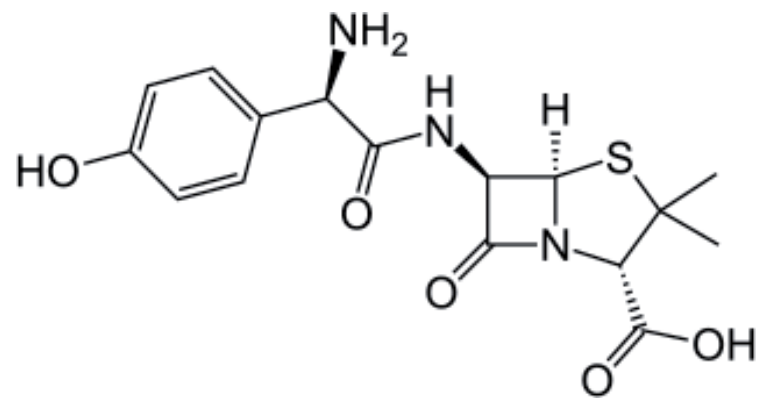

Figure 7.

Structural formula of amoxicillin (6-aminopenicillanic acid).

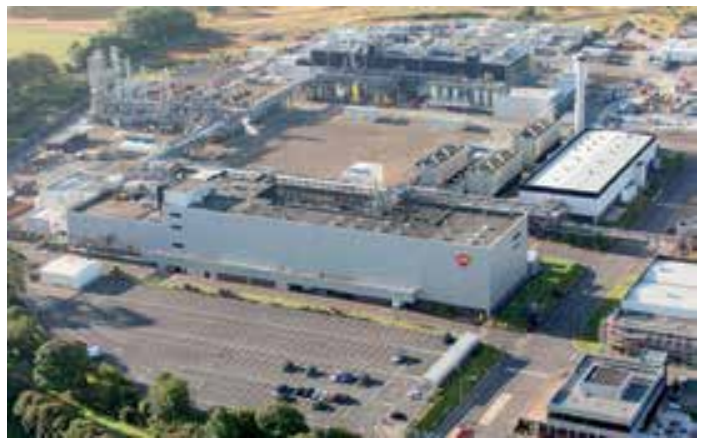

Figure 8.

GSK manufacturing Plant at Irvine (GSK Website).

\subsection{Quality control of the tableting/encapsulating process}

The dried amoxicillin produced according to Figure 9 will now be mass produced into tablets and capsules using automated tableting (Figure 10). Tablets are normally manufactured by direct compression or by granulation depending on material properties and the relevant requirements for formulation. During tablet manufacture the powder is fed to the machine and blended before tableting unit 

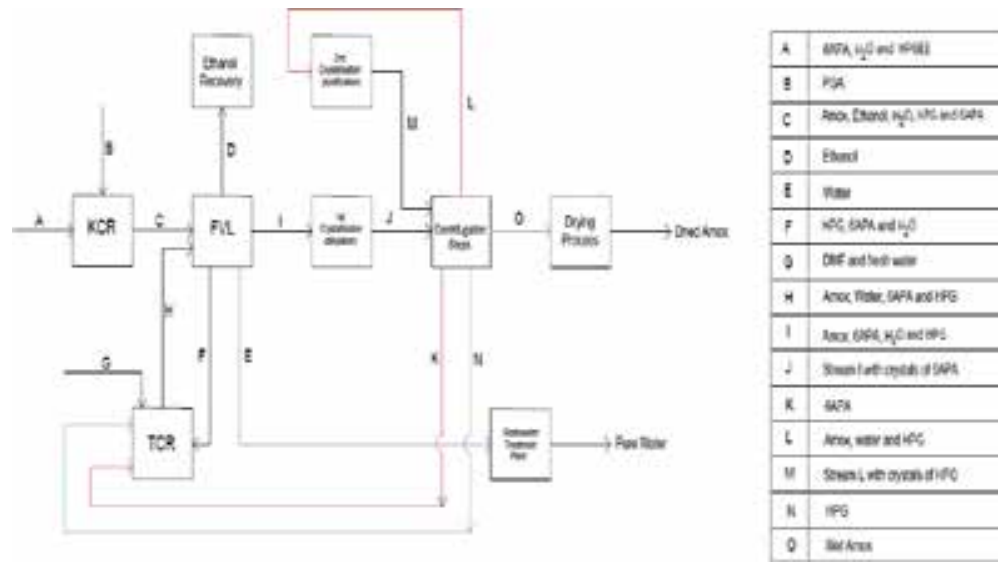

Figure 9.

Process flow diagram for the manufacture of amoxicillin [20].
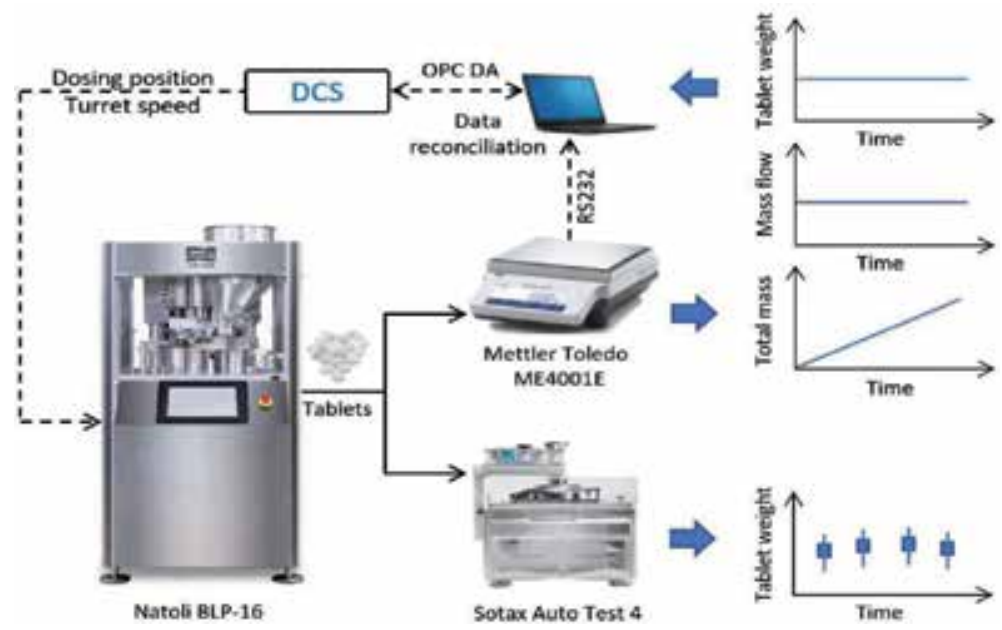

Figure 10.

Tablet weight measurement real-time monitoring and control [17].

operations kick off. The mass production process would also need to be monitored for consistency by strict quality control procedures.

The tablet press is a multi-stage process split up into stations with each station going through the routine of die filling, metering, pre-compression, maincompression, tablet ejection and take-off from lower punch, as shown in Figure 10. After the blend is fed into the die, the metering stage is adjusted to achieve the dosing position, i.e. the volume of powder inside the die. The powder is then locked between upper and lower punches during pre-compression and main-compression until the tablet ejection and take-off stages are reached. The pre-compression stage serves to remove air trapped in the die and to rearrange the particle packing, while the main compression stage compacts and transforms the powder bed into a tablet. The tablet weight can be controlled by changing the dosing position subject to variations in powder bulk density, and in filling time due to changes in turret speed, or in filling efficacy due to changes in powder flow properties. The in-die tablet thickness is determined by the punch displacement which is manually set before the tableting operation for the tablet press used in this study. Hence, the maximum 
main-compression force depends on the amount of powder in the die or, equivalently, on the tablet weight.

\subsection{Risk assessment of quality assurance and control during mass production of chemicals}

Table 2 shows potential risk variables associated with quality control during mass production. It ranges from issues associated with acceptance sampling of materials and products at the input/output stage to contamination from tableting machines, impure product and variation in tablet weight.

Tian et al. [21] carried out quality risk assessment and mitigation of pharmaceutical continuous manufacturing of a case study using flowsheet modelling approach (an engineering approach that can provide a framework to understand the impact of process dynamics on drug quality and associated risks during production, thereby facilitating the development of robust continuous processes) and identified a potential area for model improvement. Using sensitivity analyses they identified the significance of process parameters and material attributes on the dynamic responses and quality attributes of the tablet. They also conducted risk analysis using residence time distribution models to identify the impact of flowrate disturbances on product quality. Consequently, they were able to develop risk mitigation strategies to enable continuous production of high quality tablet.

\begin{tabular}{ll}
\hline Risk variables & Impact from risk negligence \\
\hline $\begin{array}{l}\text { (1) Use of acceptance sampling to evaluate input and } \\
\text { output materials }\end{array}$ & $\begin{array}{l}\text { (1) (a) Producer's risk } \\
\text { (b) Consumer's risk }\end{array}$ \\
\hline $\begin{array}{l}\text { (2) Inadequate cleaning of manufacturing equipment } \\
\text { (3) Chemicals used to decontaminate equipment can } \\
\text { react with materials }\end{array}$ & (2) Contamination of product with impurities \\
\hline (4) Change in powder bulk density during compaction & (4) Variation in tablet weight \\
\hline (5) Impurities in reactant chemicals & (5) Impure product \\
\hline (6) Inaccuracy in the dosing position of the tablet press & (6) Variation in tablet weight \\
\hline (7) Change in filling efficacy due to changes in powder \\
flow properties
\end{tabular}

Table 2.

Risk assessment of quality control during mass production.

\section{Conclusion}

This chapter discussed quality control of mass production process in the chemical industry. It reviewed a typical mass production process, identified current practice in the industry in order to guarantee quality assurance during mass production and finally proposed how this could be implemented in the chemical industry. A combination of acceptance sampling and process analytical techniques were deemed suitable for quality control during both batch and mass production.

Quality control during bulk pharmaceutical production was studied where robots and machines were subjected to decontamination quality control procedure. Tableting and encapsulating machines for drug production also needed to be properly calibrated and cleaned to ensure constant tablet weight, and also minimise contamination of products. 
Quality Control Perspectives during Mass Production with a Focus on the Chemical Industry DOI: http://dx.doi.org/10.5772/intechopen.90203

Risk assessment of quality control procedures was proposed in order to engender quality assurance during mass production.

\section{Dedication}

This book chapter is dedicated to my son Kelechi Peter Oduoza who died suddenly during the preparation of this manuscript. May his soul and those of all the faithful departed through the mercy of God rest in perfect peace, Amen.

\section{Author details}

Chike F. Oduoza

Faculty of Science and Engineering, University of Wolverhampton,

Wolverhampton, UK

*Address all correspondence to: c.f.oduoza@wlv.ac.uk

\section{IntechOpen}

(C) 2020 The Author(s). Licensee IntechOpen. This chapter is distributed under the terms of the Creative Commons Attribution License (http://creativecommons.org/licenses/ by/3.0), which permits unrestricted use, distribution, and reproduction in any medium, provided the original work is properly cited. (cc) BY 


\section{References}

[1] Hu S. Jack evolving paradigms of manufacturing: From mass production to mass customization and personalization. Procedia CIRP. 2013;7:3-8

[2] Vaidyaa S, Prashant A, Santosh B. Industry 4.0, A glimpse. Procedia Manufacturing. 2018;20:233-238

[3] Murakami Y. Book chapter-quality control of mass production components based on defect analysis. In: Metal Fatigue. San Diego, USA: Academic Press; 2019. pp. 669-687

[4] Siddiqui M, Al Othman ZA, Rahman N. Analytical techniques in pharmaceutical analysis - A review. Arabian Journal of Chemistry. 2017;10:1409-1421

[5] Montgomery D. Statistical Quality Control-A Modern Introduction. 6th Revised edition. John Wiley \& Sons; 2008

[6] Guoa H, Zhanga R, Xiangyue C, Zhengwei Z, Ting Q, Shi GHJ, et al. Quality control in production process of product-service system: A method based on turtle diagram and evaluation model. Procedia CIRP. 2019;83:389-393

[7] Kirchengast M, Celikovic S, Rehrl J, Sacher S, Kruisz J, Khinast J, et al. Ensuring tablet quality via modelbased control of a continuous direct compaction process. International Journal of Pharmaceutics. 2019;567:118457

[8] Weimer D, Rippel D, Hildebrandt T, Lütjen M, Scholz-Reiter B. A strategy for logistic quality control in micro bulk production. Procedia Technology. 2014;15:323-332

[9] Yu LX, Amidon G, Khan MA, Hoag SW, Polli J, Raju GK, et al. Understanding pharmaceutical quality by design. The AAPS Journal. 2014;16(4):771-783

[10] Su Q, Ganesh S, Moreno M, Bommireddy Y, Gonzalez M, Reklaitis GV, et al. A perspective on quality-by-control (QbC) in pharmaceutical continuous manufacturing. Computers in Chemical Engineering. 2019;125:216-231

[11] Sahebjamnia N, TavakkoliMoghaddam R, Ghorbani N. Designing a fuzzy Q-learning multi-agent quality control system for a continuous chemical production line-A case study. Computers and Industrial Engineering. 2016;93:215-226

[12] Keller M, Gabriella B, Marion S, Frank B, Udo G, Thomas B. Optimized robot systems for future aseptic personalized mass production. Procedia CIRP. 2018;72:303-309

[13] Bhaskar A, Barros FN, Singh R. Development and implementation of an advanced model predictive control system into continuous pharmaceutical tablet compaction process.

International Journal of Pharmaceutics. 2017;534:159-178

[14] Lakerveld R, Benyahia B, Braatz RD, Barton PI. Model-based design of a plant-wide control strategy for a continuous pharmaceutical plant. AICHE Journal. 2013;59(10):3671-3685

[15] Mesbah A, Nagy Z, Huesman A, Kramer H, Van den Hof P. Realtime control of industrial batch crystallization processes using a population balance modeling framework. IEEE Transactions on Control Systems Technology. 2012;20(5):1188-1201

[16] Nagy ZK. Quality-by-control (QbC) technologies for pharmaceutical 
process development. In: AIChE

Annual Meeting, San Francisco, CA, USA. 2016

[17] Su Q, Bommireddy Y, Gonzalez M, Reklaitis GV, Nagy ZK. Variation and risk analysis in tablet press control for continuous manufacturing of solid dosage via direct compaction. Computer Aided Chemical Engineering. 2018;44:679-684

[18] Singh R. Chapter 17: Automation of continuous pharmaceutical manufacturing process. Computer Aided Chemical Engineering. 2018;41:431-446

[19] Kraemer A, Lin S, Daniel B, Thomas B, Gisela L. Quality control in the production process of SMC lightweight material. Procedia CIRP. 2014;17(2014):772-777

[20] Al Qasimi W, Arshad M, Kra S, Mohamed F. Design Project for Chemical Engineering Degree. UK: University of Wolverhampton; 2019

[21] Tian G, Koolivand A, Nilou SA, Lee S, O'Connor TF. Quality risk assessment and mitigation of pharmaceutical continuous manufacturing using flowsheet modeling approach. Computers and Chemical Engineering. 2019, 2019;129:106508 

Section 3

\section{Industry 4.0 Applications}





\title{
Application of the Fourth Industrial Revolution for High Volume Production in the Rail Car Industry
}

\author{
Daniyan Ilesanmi, Oyesola Moses, Mpofu Khumbulani \\ and Nwankwo Samuel
}

\begin{abstract}
Some recent technological advances in line with the fourth industrial revolution (4IR) are rapidly transforming the industrial sector. This work explores the prospect of robotic and additive manufacturing solutions for mass production in the rail industry. It proposes a dual arm, 12-axis welding robot with advance sensors, camera, and algorithm as well as intelligent control system. The computer-aided design (CAD) of the robotic system was done in the Solidworks 2017 environment and simulated using the adaptive neuro-fuzzy interference system (ANFIS) in order to determine the kinematic motion of the robotic arm and the angles of joint. The simulation results showed the smooth motion of the robot and its suitability to carry out the welding operations for mass production of components during rail car manufacturing. In addition, the ability to fabricate several physical models directly from digital data through additive manufacturing (AM) is a key factor to ensuring rapid product development cycle. Given that AM is embedded in a digitally connected environment, flow of information as well as data processing and transmission in real time will be useful for massive turnout during mass production.
\end{abstract}

Keywords: 4IR, additive manufacturing, kinematics, robotic solution, simulation

\section{Introduction}

Previous industrial revolutions have given birth to various breakthroughs in the rail industry ranging from the development of trains powered by diesel to electric. In recent times, the advent of the fourth industrial revolution (4IR) and robust digital solutions have produced advance technology for manufacturing. As shown in Figure 1, this innovative advances in manufacturing relates to automation and robotics [1, 2], Additive Manufacturing (AM) including subsets like 3D printing, Rapid Prototyping, Direct Digital Manufacturing [3, 4], Cyber-physical systems (CPS) [5], Physical Internet (PI) and Internet of Things (IoT) in the logistics and transportation area $[6,7]$ as well as artificial intelligence (AI), augmented reality, 


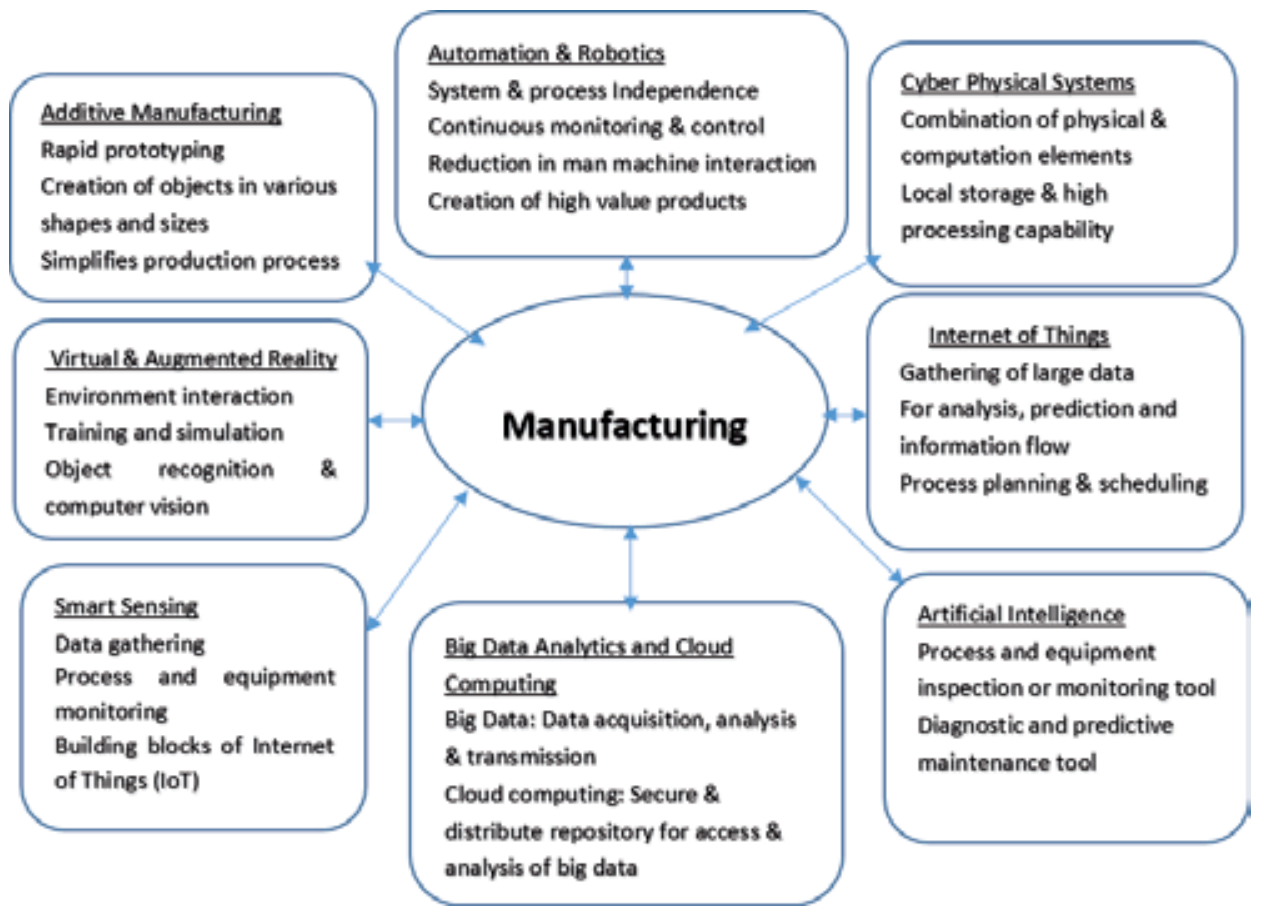

Figure 1.

Elements of the fourth industrial revolution relating to manufacturing.

big data analytics and digital solutions in the informatics field [8,9]. Many industries are now embracing the fourth industrial revolution known as Industry 4.0 amidst dynamic production challenges and increasing market forces. For instance, artificial intelligence (AI) find applications in process planning and optimization, robotic development, decision making, system control as well as pattern recognition involving automatic incident detection, image processing for traffic data collection and for identifying cracks in rail structures $[10,11]$. In the same vein, artificial intelligence can also be explored in rail car manufacturing for nonlinear prediction relating to traffic demand, the deterioration of rail infrastructure as a function of traffic, construction, and environmental factors. In addition, the quest for smart, high volume and intelligence systems is a major driver that propels manufacturers' into the development of new production technologies, which incorporates the concept of the FIR.

The aim of these technological advances in the manufacturing sector is to increase productivity, promote automation and control and enhance good product quality and conformity to standards. This will increase equipment reliability and availability thereby making the supply chain, assembly and production lines smarter. These have also brought about a tremendous growth and innovation potential for global value chain setups. These manufacturing technologies are enhancing high rates of production at an effective unit cost. One of the advantages of high volume production is that costs are expected to reduce as the volume of production increases.

This work focuses on the application of the Fourth Industrial Revolution (4IR) characterised by emerging robotic solutions with smart monitoring system and the exploration of additive manufacturing for rapid prototyping during assembly operations in the rail car industry. The use of monitoring systems will help in diagnosing and tracking the technical conditions during the assembly operation of the rail car using the online mode (in real time) in order to obtain the system 
and measurement performance [12-14]. The rail car manufacturers are increasingly testing the potential of additive manufacturing (AM) to break creative barriers within the three major trends driving the industry namely; product innovation, high-volume direct manufacturing and fuel efficiency with increased performance $[15,16]$. The complexity and intersecting technologies driving the fourth industrial revolution and the breadth of their impact necessitates the development of innovative approaches to implement and diffuse the current and emerging technologies for rail car development. The concept of mass production involves the development of tools and automated equipment for the production of interchangeable parts and products in order to strike the right balance among cost, quality and quantity.

The merit of mass production systems include the development of large products to a high degree of surface finish and precision, significant reduction in the cost of labour due to the automated nature of the assembly line and resultant reduction in the overall production cost. The effective production control and monitoring can increase process improvement with good information flow with data acquisition and management systems. This fast rate of production will enable prompt scheduling, realistic forecast and product distribution with overall increase in profitability. Although, the initial set up of mass production lines is energy and cost intensive but the initial cost are often offset as the business breaks even over time due to profit from high volume production. The major drawbacks of the mass production systems include; the replacement of personnel with automated systems and the fact that the system is relatively inflexible to production changes, which are integral part of the production processes.

\section{The developmental framework}

The fourth industrial revolution provides solutions for many complex problems in the rail industry. If adequately deployed, it has the potential to revolutionise the assembly and operation of rail car systems, leading to transformation in the development, operation and maintenance. This will deliver benefits to the rail industry and users as well as the wider economy, including innovative approach, increased capacity, improved performance and enhanced safety for passengers and workers. This means that while the rail industry will be able to save cost considerably at increased efficiency and delivery, the operational activities and maintenance will be more reliable and effective. The developed framework for rail car development with the inclusion of supply chain activities is presented in Figure 2.

The part manufacturer uses innovative material based solutions for parts development while the component manufacturers develops the parts into components which is supplied to the sub assembly manufacturer. The sub assembly manufacturer integrates different components into a sub assembly unit and develops a feasible framework for prototyping. The original equipment manufacturer (OEM) does the final assembly of various sub-systems into a system while the Information Communication technology unit (ICT) and logistics facilitates the supply chain relationships in order to keep the stakeholders abreast of advances in technology, demand and supply as well as planning and production. Some of the materials employed for the rail car manufacturing as well as the component parts developed into subassembly and final assembly are listed as follows:

a. Materials: Aluminium, fabrics, stainless steel, steel, rubber, plastic, glass, carbon fibre etc. 
b.Component parts: Compressor, brake parts, blower, cable, controls, indicators, rectifiers, inverters, carbon fibre etc. gears, sensors, printed circuit boards, bolsters, runners, bars etc.

c. Sub assembly: Mechanical: Wheelset, suspension system, bogie, brake, engine, body side, underframe, roof, body shell etc.

d.Electrical/electronic: Communication, security, power, integrated software etc.

e. System: Rail car, rolling stock, rail track, control unit

In order to maximise the benefits of the advanced manufacturing technologies, the perceived industrial key players can develop the theory driving the elements of the new industrial revolution into practical knowledge as stated in the following subsections.

\subsection{Welding operation in rail car assembly}

Welding is one of the methods usually employed for joining the components parts during rail car development. It is a complex manufacturing process, which requires the combination of a number of different factors such as material metallurgy, process parameters, welding sequence, power source, energy, speed, filler materials as well as the material combination and thickness for the design of an efficient process. Hence, an optimised welding process will bring about the development of reliable weld joints and shorter welding cycles via efficient process development.

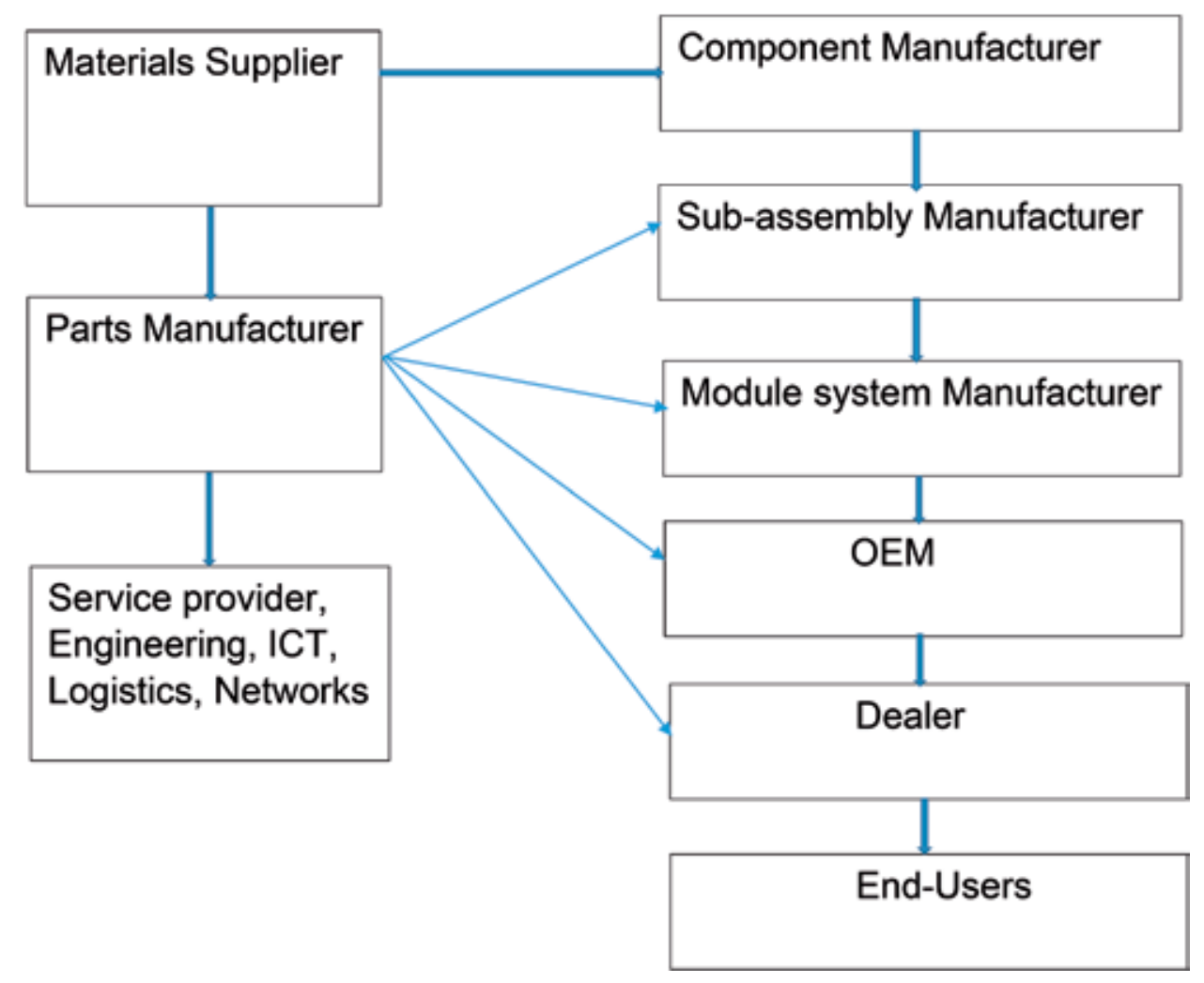

Figure 2.

The framework for rail car development and supply chain activities. 
The welding operation is usually employed for the assembly operations in the underframe, body side, side panel, bogie frame and roof among others. The underframe, which is the part of the body shell, has parts, which includes the bars, runners, bolsters etc. The upper and lower brackets are usually welded on to the underframe through arc welding while the friction stir welding (FSW), resistance spot welding (RSW), metal inert gas (MIG) or laser arc welding (LAW) are usually employed for joining the body side. The body sides are made from high strength stainless steel or light aluminium materials that are welded on a frame. The body shells are first welded before the fitting operations and the windows are either cut out of the body side panels or the sides assembled in sections through the pre-installed window frames. Furthermore, the side panel are welded on to the frame of the body side. The welding process is also employed in the joining of the roof with specialised contourshaped jigs, which holds the roof for welding operations, and ceiling installations. The bogie frame is also fabricated via welding operation before the assembly of the suspension systems. Different welding methods are employed for all the aforementioned processes depending on the design and performance requirements.

\subsection{Robotic solution for mass production}

A robot is a reprogrammable, multifunctional manipulator designed to move materials, parts, tools, or specialised devices, to variable programmed motions for the performance of a variety of tasks [17]. Robotic solutions for the assembly, maintenance and repair applications in the rail car and transit coaches is essential for performing activities such as welding, grinding, cleaning, and painting due to increasing complexities, repetitive, and high volume production requirement. Other advantages of the use of robots for assembly operations include; automation via less human involvement, increased precision and productivity, consistent weld penetration resulting in better quality and surface finish, safety, improved product quality, reduction in assembly interruptions, flexibility and reduced labour costs. This work proposes a dual arm, 12-axis welding robot with advance sensors, camera and algorithm as well as intelligent control system. It also has robotic manipulator with an end-effector for gripping, positioning and welding of various component parts during rail car manufacturing. The smart sensors, which are the basic building blocks of the Internet of Things (IoT), are incorporated for data collection to enhance the process condition and real time monitoring, diagnosis and efficient communication. A large amount of data gathered through the smart sensors and IoT for are often suitable for the analysis and development of predictive algorithm. The automation of the welding process via effective communication and intelligent coordination will improve the overall efficiency and safety of the assembly process. This will decrease the failure rate, interruptions, and enhance the reliability of manufacturing and maintenance activities. The dual arm is to allow multiple task to be carried out in order to reduce the assembly time with increase in the production rate while the sensors and intelligent control system are to monitor and provide necessary feedbacks relating to weld imperfections and quality. This will lead to significant reduction in the welding cycle time with higher deposition rate and consistent weld penetration. Since the overall production cost is partly a function of the welding cycle time and the production rates, the use of the dual arm-welding robot will bring about significant reduction in the overall production cost. Another advantage is that there will be significant reduction in the welding error and expensive rework due to less human involvement, leading to the production of assembly that meets design and customer's requirements. In addition, the choice of automated dual arm robot will sufficient address the issue of monotonous repetitive task as well as other safety and ergonomic issues relating to assembly operations in complex geometries as opposed to manual assembly lines. Depending on the type of 
assembly operations to be performed, the essential factors to be considered for the robotic configurations and selection include the degree of freedom, space geometry, motion characteristics as well as drive and feedback mechanism. In addition, with the process parameters specified and programmed in real time, the robot simply emulate the manual welding process by following a specified or desired trajectory to track the seam geometry and perform the welding operation. This is followed by the post weld assessment with the use of sensors and 3D cameras for the assessment of the weld integrity. The deployment of robotic solutions however is not without challenges. The use of robots for welding requires proper configuration and joint design with consistent gap conditions as variations may lead to time wasting and expensive rework. In addition, robotic welding sometimes is limited by workspace constraints and the need for sensors and intelligent systems for effective monitoring and control. In addition, robots cannot independently make corrective decisions because they are programmed.

Figure 3 shows the flowchart for the robotic assisted welding.

The design considerations for the robotic arm include the size of the component parts or sub assembly, welding method, welding cycle time, process parameters and repeatability. The robot is designed to move the welding torch along the weld path given the direction of motion and speed as programmed. To control the orientation of the end of the arm, the yaw, pitch and roll axes are added to the other $\mathrm{X}, \mathrm{Y}$, and $\mathrm{Z}$ axes to make 6 axes for each of the arm.

The specification of the designed dual arm robot is presented in Table 1.

For high volume production, the robot can be programmed with set of codes and instructions for the complete welding process and operation following the determination of the weld location, creation of robotic path and setting the process parameters and torch angle. The controller sends signals to the drivers and motors via computer programmes for the execution of the welding operation while the manipulator positions the component parts so that it could be easily accessed and worked upon by the robot. The CAD of the dual arm-welding robot and its exploded are shown in Figures 4 and 5 respectively.

For increased flexibility and productivity in a mass production setting, the robot is designed such that it can be mounted on a column in order to carry out welding

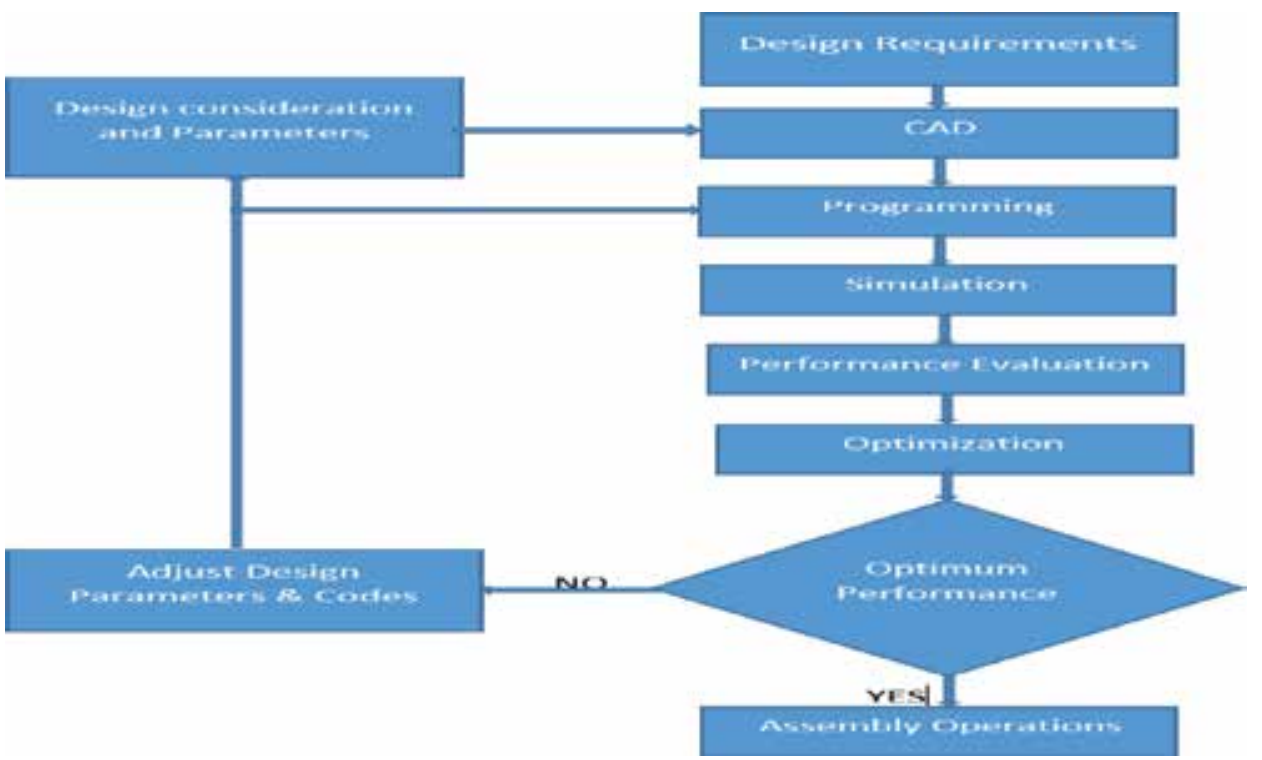

Figure 3.

The flowchart for the robotic assisted welding. 
Application of the Fourth Industrial Revolution for High Volume Production in the Rail Car.. DOI: http://dx.doi.org/10.5772/intechopen.88703

\begin{tabular}{ccc}
\hline S/N & Parameter & Value \\
\hline 1. & Reach height & $3 \mathrm{~m}$ (Max.) \\
\hline 2. & Repeatability & $0.0001 \mathrm{~m}$ (Max.) \\
\hline 3. & Velocity & $6 \mathrm{~m} / \mathrm{s}$ (Max.) \\
\hline 4. & Weight & $400 \mathrm{~kg}$ \\
\hline 5. & Payload & $500 \mathrm{~kg}$ \\
\hline 6. & Degree of freedom (DoF) & 12 \\
\hline
\end{tabular}

Table 1.

The specification of the designed dual arm robot.

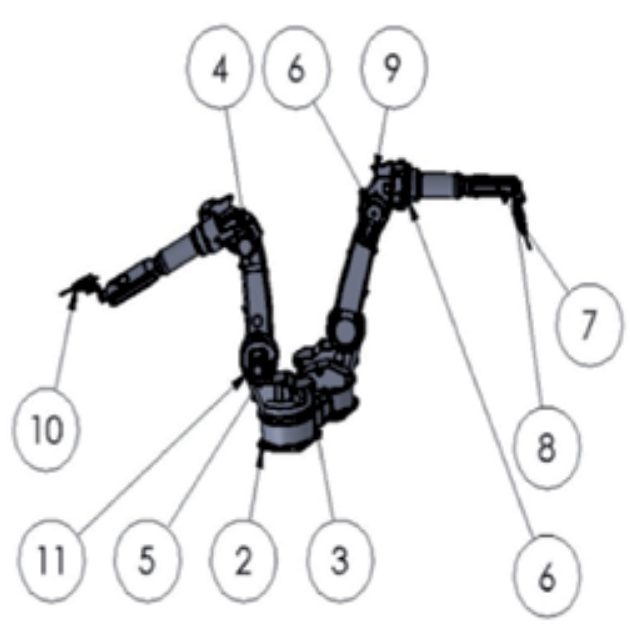

\begin{tabular}{|l|l|l|}
\hline Item No & Part & Quantity \\
\hline 1. & The dual arm robot & 1 \\
\hline 2. & Base connector & 1 \\
\hline 3. & $\begin{array}{l}\text { General control } \\
\text { module }\end{array}$ & 2 \\
\hline 4. & Elbow motor & 2 \\
\hline 5. & Shoulder motor & 2 \\
\hline 6. & Elbow control module & 2 \\
\hline 7. & End effector gripper & 2 \\
\hline 8. & $\begin{array}{l}\text { End effector with } \\
\text { soldering led }\end{array}$ & 2 \\
\hline 9. & $\begin{array}{l}\text { End effector gripper } \\
\text { motor }\end{array}$ & 2 \\
\hline 10. & Electrode holder & 2 \\
\hline 11. & Shoulder motor & 2 \\
\hline
\end{tabular}

Figure 4.

The CAD of the dual arm robot.

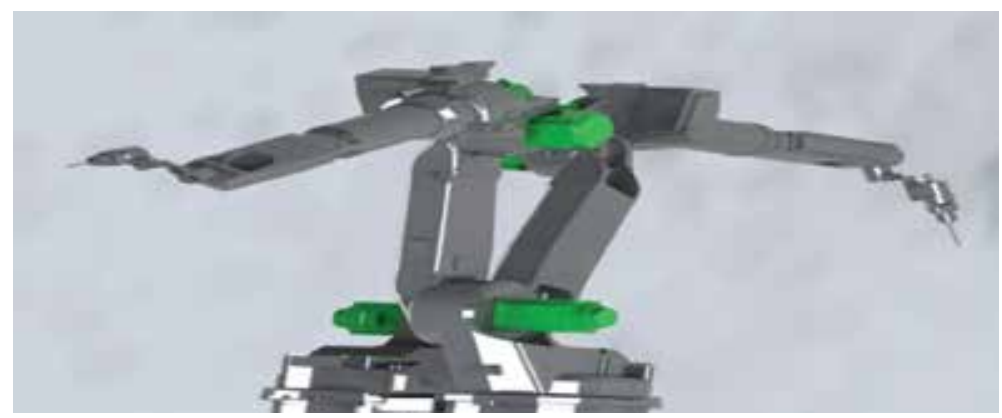

Figure 5.

The exploded view.

operations of complex geometries. In such instance, the work piece is clamped and kept stationary while the robot approaches it for welding operation. This will eliminate the idle as well as loading and unloading time. In order to ensure an efficient performance of the robot, the motion of the robot was simulated using the adaptive neuro-fuzzy interference system (ANFIS) modelling which comprises of a fuzzy system whose parameters are fine-tuned using the neuro adaptive learning (NAL) 
method. The essence of the modelling and simulation is to determine the kinematic motion of the robotic arm. The understanding of the kinematics will ensure the determination of the motion of robot, angles of the joint and arrangement of location of the tip of the arm at the desired position (Figure 6).

The predicted angles of joint for the robot are shown in Figure 7. The angle determines the rotation of the robot in the predetermined directions. Figure 7 indicates that the robot can rotate in both the clockwise and the clockwise directions with various angles corresponding to $0^{\circ}<\omega<450^{\circ}$ which the robot might be required to turn.

Most welding robots function semiautonomously. In order to function optimally most especially during assembly operations such as welding, there is need for the development of specialised jigs and fixtures for easy and accurate location, position and clamping of the component work piece. The production of components in mass depends upon the interchangeability that facilitates easy assembly. Mass production methods require fast and relatively simple method of work positioning for accurate operations. Specialised jigs are devices often employed to hold, support, guide and locate a work piece during manufacturing operations. For components or subassemblies produced in mass, the use of jigs saves machining time by eliminating the task of marking out, repetitive check or work set up, measuring and other set up before machining. With the automatic location of work piece, the assembly operation is carried out with high degree of precision and accuracy. The development of specialised but flexible jigs facilitates mass production with the simultaneous operation of different tools in a single set up thereby reducing the handling time. Hence, the use of assembly robot with specialised jigs will also reduce the overall labour and consequent fatigue as the handling operation and time is simplified and minimised. To a large extent, it saves labour cost and the overall cost of machining. The only limitation is that inaccurate location and clamping by the fixturing elements may cause variations in the dimensions of the work piece resulting in weld imperfections or distortions. However, this challenge can be solved with the use of advance sensor and intelligent systems for weld monitoring and control. The assembly of the rail car body requires the use of jigs to ensure rigid clamping and right position of the work piece during the assembly operations. The jigs are designed for specific purpose after the design of the rail car body and its specifications. Conventional jigs are not flexible enough to permit changes of work piece during machining operations. The rigidity of the conventional fixtures often reduces the volume of production, accuracy of surface finish while also increasing production time and cost. Jigs are reconfigured to provide an effective mix of flexible and dedicated equipment which is expandable and whose functionality and productivity can readily be changed

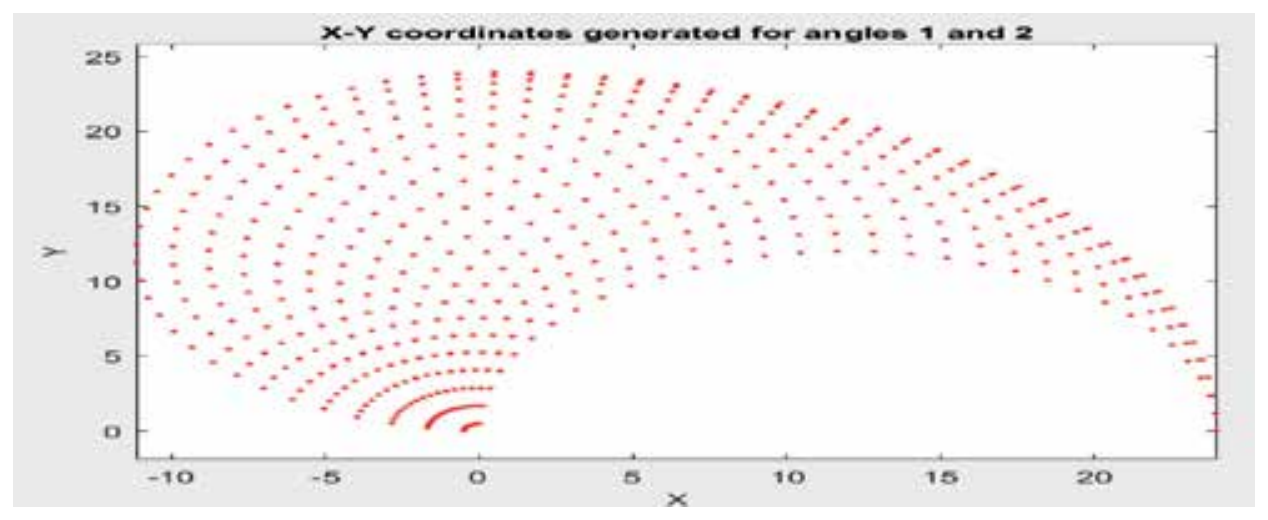

Figure 6.

Kinematic motion of the robotic arm. 


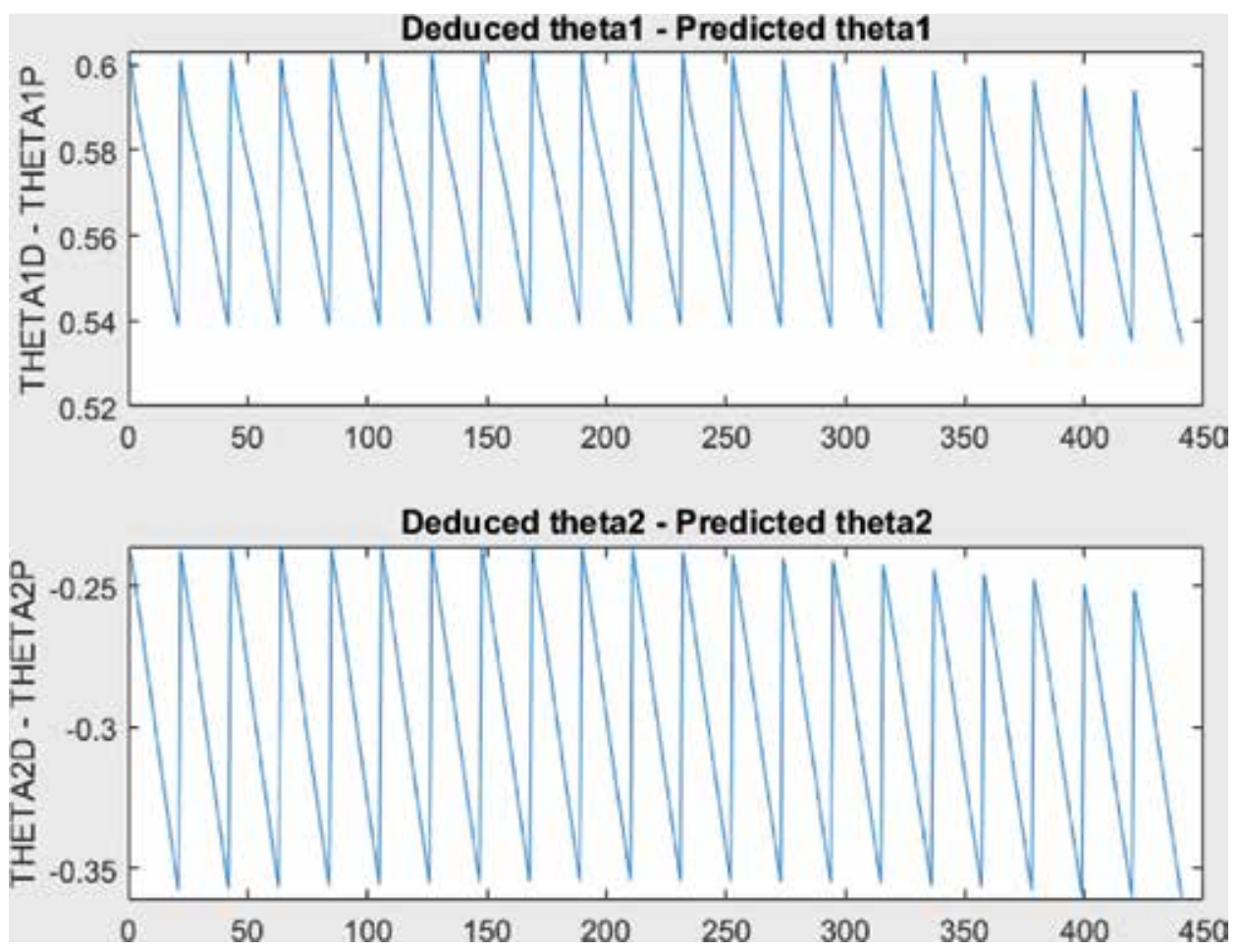

Figure 7.

Deduced and predicted angles of joint.

when needed $[18,19]$. Hence, the design of jigs for assembly operation takes into account the cost, time, safety, flexibility, degree of interchangeability, efficiency, surface finish among other factors. This will permit machining of complex geometries to the desired surface finish. For instance, during welding operations, the expansion of work piece and locator due to heat call for more clearance between the locator and the work piece to facilitate easy unloading. Following the supply of the part lists, which are the standardised elements to be held by a jig during the assembly operation, the sorting of the parts into their respective families, is made based on their differences and similarities. Different part families requires different jig orientation hence the need to sort the parts out into their respective families as parts of the same family can be held with the same jig. For instance, the upper and lower brackets of the rail car consists of hundreds of parts that need to be sorted out into part families, followed by the development of specialised jigs for each family before they are welded on to the underframe through arc welding.

The cost analysis of the robotic welding considers the following; the total welding time, weld size, arc on time, deposition rate of the weld and the labour cost.

The total welding time is the sum of the total arc time and the non-arc time as expressed by Eq. 1. While the arc time is the time spent by the robot during the welding operation, the non-arc time is the time spent on other activities such as set up (loading and unloading), inspection, changing wire, shielding gas or contact tips etc.

$$
T_{t}=A_{t}+N_{t}
$$

$T_{t}$ is the total welding time $(\mathrm{s}) ; A_{t}$ is the total arc time $(\mathrm{s})$ and $N_{t}$ is the non-arc time. 
The operating factor $(O F)$ is expressed by Eq. (2).

$$
O F=\frac{A_{t}}{T_{t}}
$$

\subsection{Additive manufacturing in mass production}

The additive manufacturing has opened up new design possibilities that would help meet the challenges relating to manufacturing processes. Manufacturing processes have shown a rapid development in this present day of industrialisation. As such, keeping up with the demands of sustainability, ever changing market dynamics, and environmental pressure, existing processes and practices are being improved and new technologies are being introduced resulting in an enormously expansion to the size and scale of industrial production [20]. Owing to the movement of mass production to developing countries, a rapid attention is paid to low volume innovative production of customised and sustainable products with high added value being observed with evolving manufacturing technologies to stabilise the economies of other domicile producing countries. In the same manner, competing with the ever-changing supply dynamics as a result of globalisation, manufacturing industries sought after new fabrication techniques to prepare themselves with the necessary tools for increased flexibility and economic low volume production. Additive Manufacturing is considered as one such technique of preparing for mass production due to its flexibility in manufacturing.

Additive manufacturing (AM) is defined as "the process of joining materials to make objects from 3D model data, usually layer upon layer, as opposed to subtractive manufacturing methodologies, such as traditional machining" according to American Society of Testing and Materials [21]. A lot have already been achieved on the way to the widespread application of AM technology. This is not limited to new design freedom, elimination of tools and fixtures, economic low volume production. However, the present and future development in the additive manufacturing industry should be adopted by industries as this new and potentially disruptive technology can be explored to produce high value products and generate new business opportunities [22].

The ability to fabricate several physical models directly from digital data is a key factor to ensuring product development cycle, hence, assisting in the intelligent manufacturing of products. This is in line with Industry 4.0 depicts smart production. Given that AM is an embedded technique in a digitally connected factory, it involves a lot of information and data processing and transmission between the manufacturing parties involved. Much of the information acquired and transmitted will be of great value during production, thereby, enhancing mass production [23].

In traditional means of production such as injection moulding, "tooling costs" are significant, accounting for as much as $93.5 \%$ of traditional manufacturing costs, while in AM the only outlay involved is in updating the design files [24]. Instead of economies of scale, AM can create "economies of scope". As there are, fewer costs associated with switching between making different things, adopting the technology makes it easier for companies to bring a range of products to market.

Adopting and modifying the architecture of the framework proposed by Mellor et al. [22] by focusing on technological variables. The technology factors in the production creation process through AM have been categorised into front-end factors comprising data-preparation and applied software, into machine related factors such as raw material supply, maintenance issues, production capacity and surface quality, and into back-end factors that comprise post-processing steps. The technological factors are as depicted in Figure 8. 
Application of the Fourth Industrial Revolution for High Volume Production in the Rail Car.. DOI: http://dx.doi.org/10.5772/intechopen.88703

Scanning technology $\begin{gathered}\text { Raw } \\ \text { material }\end{gathered}$ Maintenance $\begin{array}{r}\text { Inspection/tests, } \\ \text { quality assurance }\end{array}$

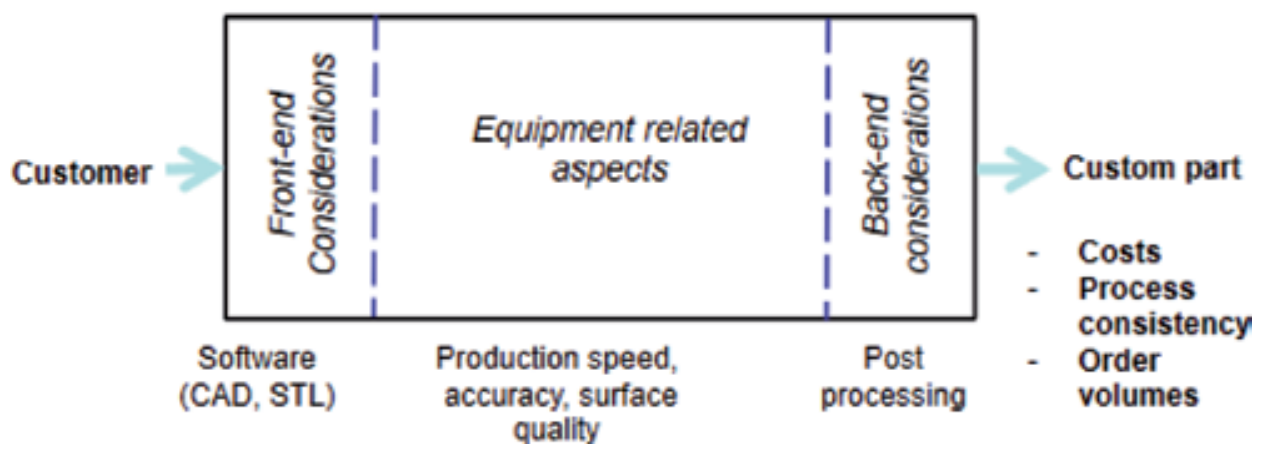

Figure 8.

Technology factors in the AM production creation process [22].

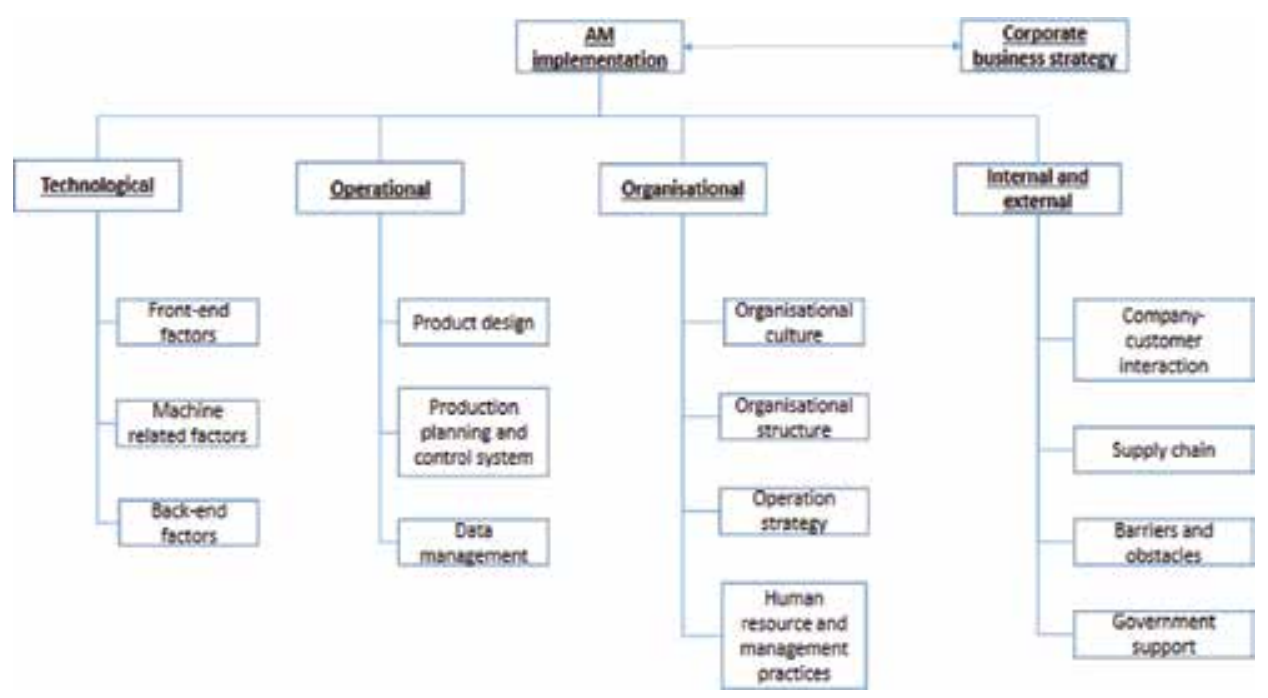

Figure 9.

Framework for influencing additive manufacturing implementation for mass production [22, 25].

Products suitable for AM production are desired to have one or more of the following characteristics: high degree of customisation, increased design optimised functionality and low volume production. The factors influencing AM implementation for mass production are categorised into technological, operational, organisational and internal/external factors according to Saberi et al. [25]. These are further enlisted in Figure 9.

\subsubsection{Factors influencing additive manufacturing implementation for mass production}

The factors influencing additive manufacturing implementation for mass production are as follow;

a. Technological factors: Additive manufacturing involves the elimination of tooling and fixturing, design modification for flexibility and function, lower material wastage and inventory etc. Hence, technological considerations are 
divided into front-end factors, machine related factors, back end factors and overall process challenges.

b. Operational factors: Production planning and control systems are crucial in all evaluated cases for controlling for the quality of the process output. The unique characteristics of the additive manufacturing processes require new design tools and practices to be developed. There is not an absolute geometric freedom and based on the specific process, different considerations have to be taken into account when designing products.

c. Organisational factors: The operation strategy for AM systems vendor is characterised by offering comprehensive customer support and by deriving revenues from powder supply and maintenance service. Organisational structure of a company, often defined by its size, is the key factor to successful implementation of new manufacturing technology and therefore it could be essential for an organisation to first re-design organisational structures and processes before adopting a new manufacturing technology [26].

d.Internal and external factors: The level of success in the implementation of a complex technology innovation is often related to the level of user-supplier interaction. Machine manufacturers and other additive manufacturing technology companies can play a role in effective implementation of the technology by advising on operational and organisational changes to the user geared towards mass production.

\subsubsection{Simplification of production processes, cost reduction prospects for mass enterprises}

AM technology also enables some manufacturers to alter their production processes, simplifying supply chains by reducing the number of assembly steps that a product must undergo to reach its final form. AM does this by giving designers the ability to redesign parts to take advantage of part and sub-assembly consolidation. Parts and sub-assemblies machined as separate pieces can be manufactured as single objects using AM. This can have major impacts on the supply chain, including reductions in labour inputs, the required tooling and machining centres, and workin-process inventory [27].

\section{Conclusions}

In this work, the deployment of recent technological advances relating to the fourth industrial revolution particularly the use of robotic and additive manufacturing solutions for mass production in the rail industry was discussed. A dual arm, 12-axis welding robot with advance sensors, camera and algorithm as well as intelligent control system was designed in the Solidworks 2017 environment and simulated using the adaptive neuro-fuzzy interference system (ANFIS) in order to evaluate the performance of the robot and determine the kinematic motion of the robotic arm. The simulation results showed the smooth motion of the robot and its suitability to carry out the welding operations for mass production of components during rail car manufacturing. In addition, the prospects of additive manufacturing for mass production in the rail manufacturing industry can be harnessed due to its ability to fabricate several physical models directly from digital data through additive manufacturing. This is a key factor in ensuring mass production and rapid product development cycle. 
Application of the Fourth Industrial Revolution for High Volume Production in the Rail Car.. DOI: http://dx.doi.org/10.5772/intechopen.88703

\section{Recommendations}

Furthermore, the deployment of virtual and augmented reality (VAR), with machine vision and light-based communication technologies ( $\mathrm{LiFi}$ ); artificial intelligence (AI) and digital solutions in rail car manufacturing as well as monitoring systems with low-cost sensor networks and smart algorithms are will boost mass production, cost effectiveness, process improvement, reliability and safety in the railway industry. It will also make the supply chain faster and flexible with attendant increase in productivity and efficiency due to access to real time data, digital business models and virtual simulation tools. This will also bring about significant improvement in the developmental stages of the rolling stock, which encompasses design, fabrication and optimization.

\section{Author details}

Daniyan Ilesanmi ${ }^{1 *}$, Oyesola Moses ${ }^{1}$, Mpofu Khumbulani ${ }^{1}$ and Nwankwo Samuel ${ }^{2}$

1 Department of Industrial Engineering, Tshwane University of Technology, Pretoria, South Africa

2 Department of Mechanical and Mechatronics Engineering, Afe Babalola University, Ado Ekiti, Nigeria

*Address all correspondence to: afolabiilesanmi@yahoo.com

\section{IntechOpen}

(C) 2019 The Author(s). Licensee IntechOpen. This chapter is distributed under the terms of the Creative Commons Attribution License (http://creativecommons.org/licenses/ by/3.0), which permits unrestricted use, distribution, and reproduction in any medium, provided the original work is properly cited. (cc) BY 


\section{References}

[1] Mikusz M. Towards an understanding of cyber-physical systems as industrial software-productservice systems. Procedia CIRP. 2014;16:385-389

[2] Zhang J, Ding G, Zou Y, Qin S, Fu S. Review of job shop scheduling research and its new perspectives under industry 40 . Journal of Intelligent Manufacturing. 2017:1-22

[3] Riedl M, Zipper H, Meier M, Diedrich C. Cyber-physical systems alter automation architectures. Annual Reviews in Control. 2014;38:123-133

[4] Bordel B, Alcarria R, Robles T, Martin D. Cyber-physical systems: Extending pervasive sensing from control theory to the internet of things. Pervasive and Mobile Computing. 2017;40:156-184

[5] Frazzon EM, Hartmann J, Makuschewitz T, Scholz-Reiter B. Towards socio-cyber-physical systems in production networks. Procedia CIRP. 2013;7:49-54

[6] Meech J, Parreira J. An interactive simulation model of human drivers to study autonomous haulage trucks. Procedia Computer Science. 2011;6:118-123

[7] Merat N, de Waard N. Human factors implications of vehicle automation: Current understanding and future directions. Transportation Research Part F: Psychology and Behaviour. 2014;27:193-195

[8] Bostrom N. SuperintelligencePaths, Dangers, Strategies. Oxford, UK: Oxford University Press; 2014. p. 2014

[9] Klumpp M. Automation and artificial intelligence in business logistics systems: Human reactions and collaboration requirements. International Journal of Logistics. 2017:1-19

[10] Armstrong S, Bostrom N, Shulman C. Racing to the precipice: A model of artificial intelligence development. AI \& Society. 2016;31:201-206

[11] Silver D, Schrittwieser J, Smionyan K, Antonoglou I, Huang A, Guez A, et al. Mastering the game of go without human knowledge. Nature. 2017;550:354-359

[12] Montreuil B. Towards a physical internet: Meeting the global logistics sustainability grand challenge. Logistics Research. 2011;3:71-87

[13] Gunsekaran A, Ngai EWT. Expert systems and artificial intelligence in the 21st century logistics and supply chain management. Expert Systems with Applications. 2014;41:1-4

[14] Zhang S, Lee CKM, Chan HK, Choy KL, Zhang W. Swarm intelligence applied in green logistics: A literature review. Engineering Applications of Artificial Intelligence. 2014;37:154-169

[15] Kosir A, Strle G. Emotion elicitation in a socially intelligent service: The typing tutor. Computer. 2017;6(14)

[16] Klumpp M. Innovative Produkte und Dienstleistungen in der Mobilität. In: Proff H, Fojcik TM, editors. Artificial Divide: The New Challenge of Human-Artificial Performance in Logistics. Heidelberg/Berlin, Germany: Springer Gabler; 2017b. pp. 583-593

[17] Lin W, Luo H. Handbook of Manufacturing Engineering Technology. London: Springer-Verlag; 2014. pp. 1-36

[18] Sequiera MA. Conceptual design of a fixture-based reconfigurable 
spot welding system [M. Eng thesis].

Department of Mechanical and

Mechatroics, University of Stellenbosch; 2008. pp. 1-116

[19] Koren Y, Heisel U, Jovane F, Moriwaki T, Pritschow G, Uslow G.

Reconfigurable manufacturing systems.

CIRP-annals manufacturing.

Technology. 1999;4(2):527-540

[20] Gebler M, M SJ, Schoot

Uiterkamp AJM, Visser C. A global

sustainability perspective on $3 \mathrm{D}$

printing technologies. Energy Policy.

2014;74:158-167

[21] ASTM. ASTM Standard.

Standard Terminology for Additive

Manufacturing Technologies, vol. 10.04

[22] Mellor S, Hao L, Zhang D. Additive manufacturing: A framework for implementation. International Journal of Production Economics.

2014;149:194-201

[23] Santos E, Shiomi M, Osakada K, Laoui T. Rapid manufacturing of metal components by laser forming. International Journal of Machine Tools and Manufacture. 2006;46(12-13):1459-1468

[24] Boubekri N, Alqahtani M.

Economics of additive manufacturing. International Journal of Advances in Mechanical and Automobile Engineering. 2015;2(1):12-15

[25] Saberi S, Yusuff N, Zulkifli N, Ahmad M. Effective factors on advanced manufacturing technology implementation performance: A review. Journal of Applied Sciences. 2010;10(13):1229-1242

[26] Millen R, Sohal A. Planning processes for advanced manufacturing technology by large American manufacturers. Technovation. 1998;18(12):741-750
[27] Atzeni E, Salmi A. Economics of additive manufacturing for end-usable metal parts. International Journal of Advanced Manufacturing Technology. 2012;62(9-12):1147-1155 



\title{
Chapter 11
}

\section{Revolution of Production System for the Industry 4.0}

\author{
Azrul Azwan Abdul Rahman
}

\begin{abstract}
Nowadays, good coordination of production and logistics at a production operational level is required to handle rapidly evolving technology, frequently changing customer demand and satisfaction, and remain competitive. Accelerated by exponentially growing technologies in information and communication technology, production industries are in the throes of a digital transformation, which is referred to as the fourth industrial revolution or Industry 4.0. The shorter product life cycles due to market-demand variables and volatile developments in the production system have forced manufacturing company to work flexibly in order to adapt to changing customer needs. These environments cannot be managed through traditional production systems such as job shops and dedicated production lines. Reconfigurable manufacturing system, which combines the versatility and capability to re-configure of job shops and the dedicated production lines, has been seen as a potential solution in such situations. As the main component of production systems, a new concept of material handling, a reconfigurable conveyor system is introduced.
\end{abstract}

Keywords: production system, Industry 4.0, reconfigurable, revolution

\section{Introduction}

Production industries are one of the important industries, which produce and manufacture various products. This industry makes a large influence in the country's economic growth and quality of life for its citizens because production creates lasting wealth while also distributes wealth through high-paying jobs.

The impact of globalization has created a new challenge for production industries. The possibility for greater integration within the world economy through movements of goods and services, capital, technology, and labor has been leading to a market situation that is difficult to predict. A rose only by $3.6 \%$ in the world manufacturing value-added in 2018, slightly lower than the $3.8 \%$ recorded in the previous year, has proved that production industries nowadays cannot depend on steady market demands any longer [1].

Production companies have been confronted with a dynamic and changing environment for a long time. The fast transfer of information and global open markets have increased the change frequency [2]. This has raised the pressure of time and costs.

Today's changing market climate has broadened up the horizon of competition for many companies. Dealing with a short innovation cycle of global competitors 
and a wide range of individualized product demands from customers all over the world, companies will need to provide quality and reliable products within the international competition needs. Only enterprises that react on changing markets and customer preferences quickly and cost-effectively are able to stay competitive in this environment [3]. On the other hand, the competition has opened up and provides an endless challenge to the researcher to provide a better solution.

As forecasting and planning become less and less reliable, the support for continuous changes is helpful. Short response times and high changeability in layout and in processes for the production and logistics systems are strongly required [2].

\section{Production system}

A production system, as a value creation module (Figure 1) is a system that transforms input in the form of material, energy, information, and monetary means, into value-created output such as a fabricated or assembled product [4]. This is achieved through the synergy of value creation factors: product, process, equipment, organization, and human [5]. The value creation of a product involves several processes, which require organization procedures to manage their execution. The processes consist of technical operations, which can be categorized as machining, assembly, testing, handling, conveying, storing, collecting, distributing, sorting, and packaging [6]. The operations are performed or supported by humans and equipment. Linking all the operations involved in the production, processing, and distribution of goods within specified areas is defined as a material flow [7]. It covers all forms of work objects' (e.g., substances, parts, and carriers) movement in the production system either by manual or using automation.

In order to sustain competitiveness in dynamic markets, new designs of production systems are required. Since its development two centuries ago, the production

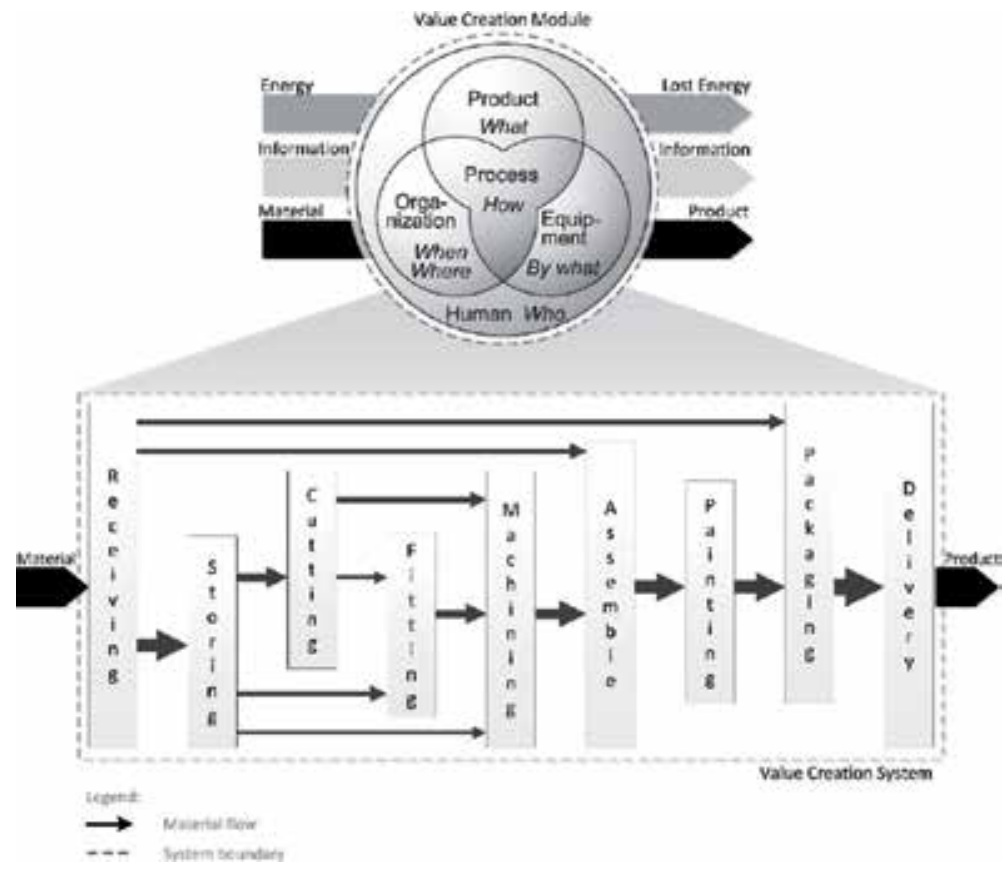

Figure 1.

Production systems as a value creation module. 
industry has revolved through several paradigms [8]. The first paradigm was Craft Production, which created the product the customer requested at a high cost. There were no production systems associated with this paradigm. Most of the production industries during this year used manual processes by handmade. In addition, the providers of craft products were confined to localized geographical regions, hence such production was not scalable.

After a certain century, a new moving assembly line was introduced in the 1913s. This year is the beginning of mass production, which provided low-cost products through large-scale production. However, the number of varieties offered by such production was very limited. The year 1955 shows the peak of mass production due to the highest rate of production. The production system during this era is called dedicated production line.

In the late 1980s, global competition and consumer demands for high-product variety led to the development of mass customization [3]. Manufacturers designed the basic product architecture and options while customers are allowed to select the assembly combination that they prefer the most. Dedicated production line is not able to cope with the product variations of product family. An invention of computer numerical control (CNC) technology was introduced in the year 1980s to support the high-frequency changes in customer's requirements. This production system can be called as flexible manufacturing system (FMS). Planning of the product family enabled manufacturers to share certain common components across the products in the family so that the economy of scale is achieved at the component level.

However, the process of manufacture and development of new products has become more challenging yet complicated [9]. While there are many changes and variations in customer requirements, the high flexibility of the system to produce a variety of products on a similar system is also required at the same time. In the 2000s, the production industry needs to face unpredictable, high-frequency market changes, and other challenges due to globalization in this twenty-first century [10].

Nowadays, customers' desire to influence and participate in the design of products is the key driver leading to the new emerging production paradigm, which we call personalization or personalized production. Therefore, a new type of production system is required in order to make the competition between companies in the production industry to make it become more responsive to all the market changes [11]. The concept of reconfigurability is introduced in production to support high-frequency market changes [10]. The revolution of production systems based on production paradigms is illustrated in Figure 2 using a product volume-product variety relationship.

\subsection{Dedicated production lines}

Producing large quantities of standardized products known as mass production is the American system of production. This production strategy began with the launch of the Henry Ford Moving Assembly Line, which culminated in a high product demand following World War II. In this production era, dedicated production lines represented a key paradigm in production industries. Dedicated production lines produced large quantities for a single part type and very profitable when demand for this part is high [12]. Figure 3 shows an example of dedicated production lines for the manufacture of cars. The dedicated production lines are costeffective as long as they can operate at full capacity. However, market pressure from global competition and over-capacity worldwide is increasing. In order to maintain the varieties of products, many dedicated production lines are required [13]. This increases the overall factory cost significantly. 


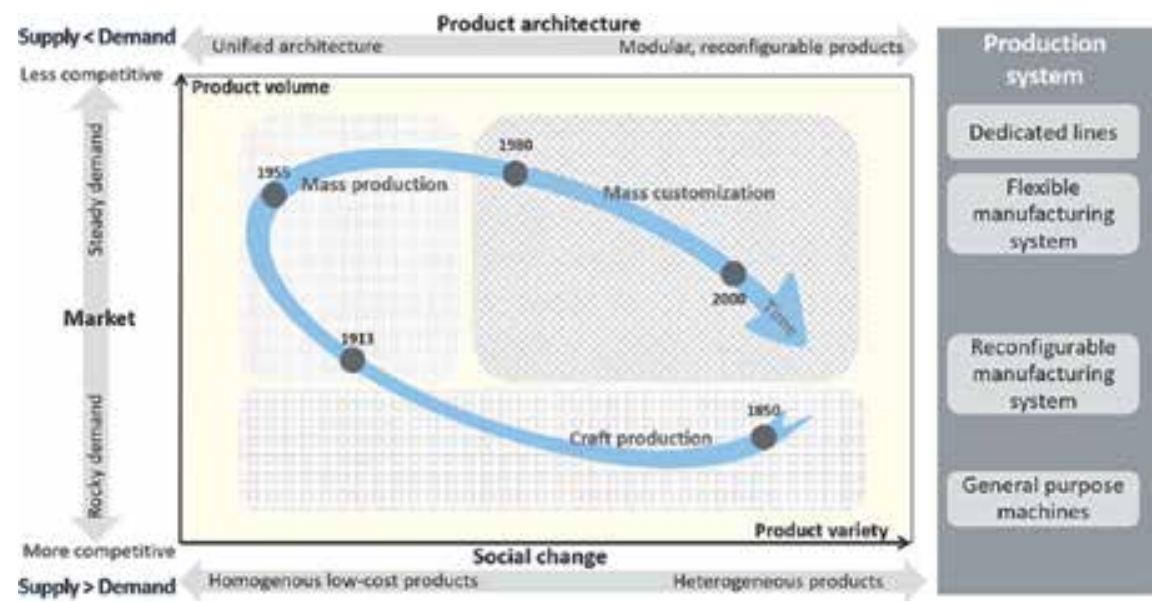

Figure 2.

The revolution of production systems.

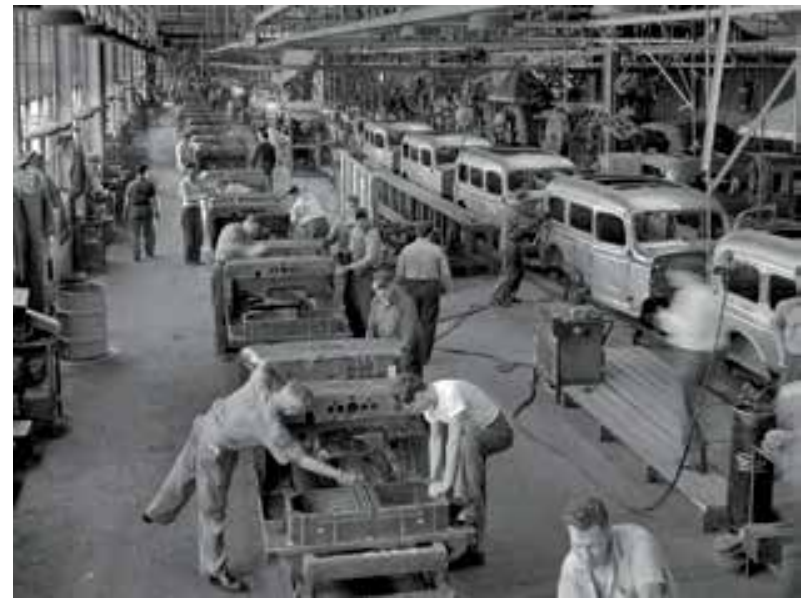

Figure 3.

Dedicated production lines for the manufacture of cars.

Dedicated production lines also have its disadvantages. According to Delorme et al. [14], a dedicated production line requires a large investment and needs to be used for a long time to be competitive. The dedicated line is very complicated to change, and if necessary, it will require a high cost and effort to reconfigure. In addition, breakdowns of the system are also a crucial issue. This is attributed to the interrelatedness of each station in the line where the entire line has to be halted if one of the stations fails. FMS was introduced to overcome these problems.

\subsection{Flexible manufacturing systems}

The demand for product variety rose in the late 1980s, which leads to the paradigm of mass customization [15]. Since then, there has been a major increase in the number of product variations offered by product manufacturers. This has been proven by the increment in numbers of different car models in the United States of America from 44 in 1969 to 165 in 2006 [16]; due to many choices of components and accessories combinations offered for each car model. The segmenting 
of product markets and international competition both led to the development of highly diversified and customized products that required FMS as their production system.

The FMS concept allows production companies to predefine a range of production processes within the context of the system capabilities (Figure 4). In a single system configuration, FMS enables production companies to quickly and easily activate a range of product models on request, thus improving their competitiveness and profitability through a highly efficient system design [17]. Companies can effectively manufacture a number of product types in the same system. However, when an unexpected production requirement arises, the adaptability of FMS is constrained by limitations and synchronization problems [18]. FMS are not designed for structural changes and therefore cannot respond to abrupt market fluctuations, such as varying user requirements and major equipment failures [19]. Similarly, a study by Koren and Shpitalni [11] showed that there is a growing need for FMS to be reconfigured and reused more efficiently in order to maximize return on investment.

\subsection{Reconfigurable manufacturing system}

The pervasive internet presence, computational and analysis software, and the introduction of modern responsive production systems, such as 3D printing, pose an opportunity for a new product development paradigm: personalizing products according to individual needs and preferences. Through collaboration with production companies and other consumers, customers are able to design and realize their innovative products. This co-development process enables customers to engage in design, product modeling and simulation, fabrication, and assembly processes that respond quickly to the needs and preferences of customers, by means of the open-product architecture [20], the on-demand production systems, and adaptive cyber-physical system.

The heterogeneity of consumer demands has forced enterprises to offer a higher number of product variants, produced in smaller batch sizes. A huge increase in product varieties in different product ranges and sectors can be noticed [21], and this trend will continue [22].

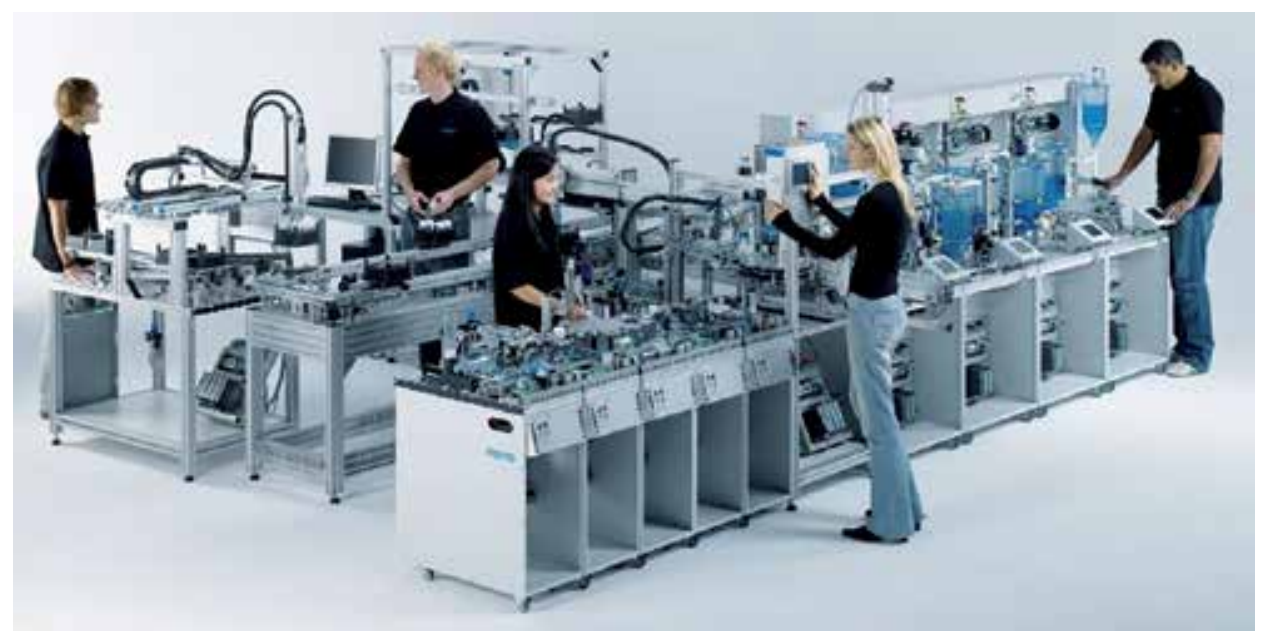

Figure 4 .

An example of an FMS developed by FESTO group. 
As a result of the high cost of reconfiguring the FMS, reconfigurable manufacturing system (RMS) concept has been introduced to tackle the issues in FMS. In earlier definitions of the RMS, [23] RMS is differentiated from dedicated production line and FMS by their adjustable system structure adaptability and the scalability to varying demands. The structural adjustment can occur at the system level, machine level, or both levels. RMS is a cost-effective production system paradigm when adapting frequent changes is required [24]. It reduces system costs by designing a production system for the whole part family and provides the necessary custom flexibility to produce all the components in the part family. It, therefore, has the ability to produce a broad range of components at varying levels of production and in high-economic-performance environments. An example of an RMS is shown in Figure 5.

Koren and Shpitalni [11] said that reconfigurable is designed at the outset for ability changes in software and hardware to a new circumference to response to a sudden change in market requirements. RMS has been proposed extensively in different industries and companies to produce modularized, customized, flexible, and scalable products.

Reconfigurability implies a responsive production engineering technology that is able to respond quickly to changes in the product market by designing production machines and systems that are cost-effective and quick to reconfigure. In the absence of reconfigurability design, the process to reconfigure the system and its machine shall be both long and ineffectual. There are three basic elements in designing the process for RMS, which are the control system, material handling system design, and layout design. Table 1 shows the details about each of the elements.

Figure 6 shows the type of configuration and reconfiguration system. Two different kinds of reconfigurable systems can be differentiated according to Pritschow et al. [26]. In type 1, machine modules are predefined in system architecture, while in type 2, machine modules are not designed within the architecture of the system. The type 2 reconfigurable system cannot be immediately or automatically reconfigured.

There are numerous aspects that can be definable in order to fully understand the reconfigurable material handling system: convertibility (functionality shift purpose), scalability (capacity change plan), modularity (modular elements), integrability (quick integration interfaces), customization (part family flexibility), and diagnosability (easy diagnostic design) [27]. Customization, scalability, and

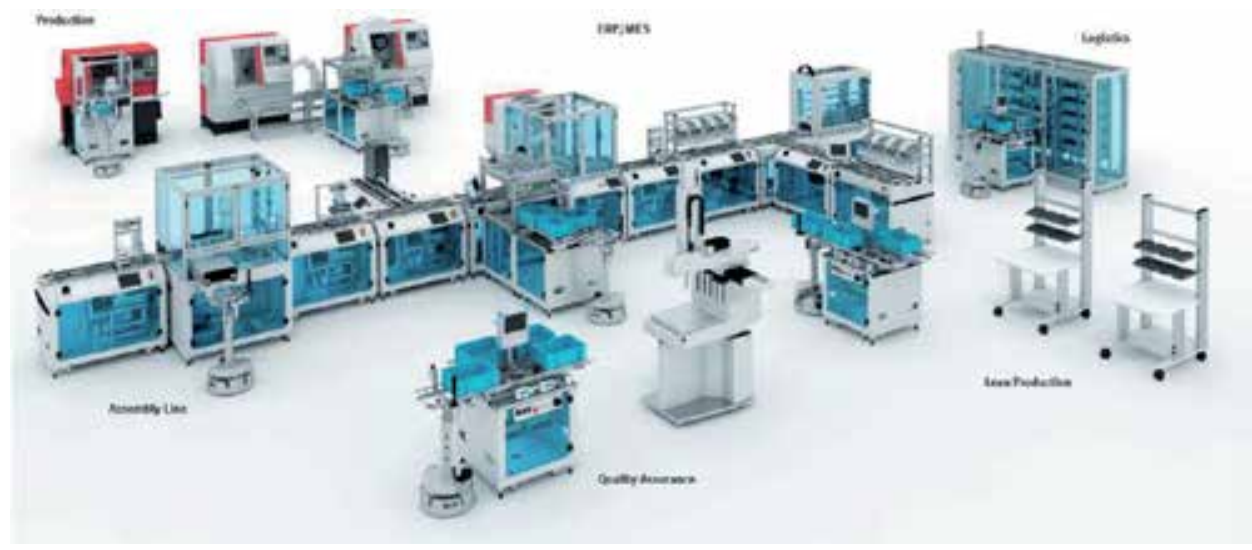

Figure 5.

An RMS system developed by FESTO group. 
Revolution of Production System for the Industry 4.0

DOI: http://dx.doi.org/10.5772/intechopen.90772

convertibility are critical reconfiguration characteristics, while modularity, integrability, and diagnosability allow rapid reconfiguration [25]. The detailed characteristics of reconfigurable material handling are shown in Table 2.

\begin{tabular}{ll}
\hline Element & Details \\
\hline Control system & The specification of the controller to form an automated material handling system \\
\hline $\begin{array}{l}\text { Material handling } \\
\text { system }\end{array}$ & $\begin{array}{l}\text { The selection of material transport equipment that relates to the movement of the } \\
\text { parts }\end{array}$ \\
\hline Layout design & $\begin{array}{l}\text { The choice of the physical arrangement of production facilities such as machines, } \\
\text { tools, and plant layout }\end{array}$ \\
\hline
\end{tabular}

Table 1.

The basic elements in design processes for RMS [25].

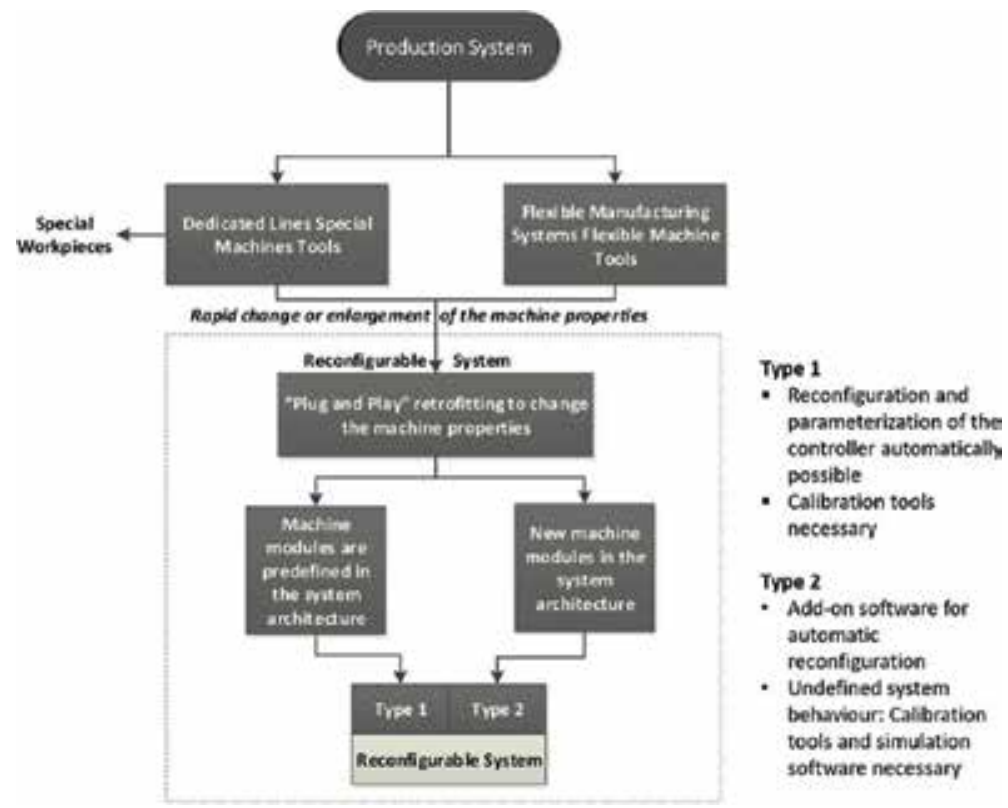

Figure 6.

The type of configuration and reconfiguration system [26].

\begin{tabular}{|c|c|}
\hline Elements & Details \\
\hline Convertibility & $\begin{array}{l}\text { The ability to transform the functionality from the existing system to new production } \\
\text { requirements easily }\end{array}$ \\
\hline Scalability & $\begin{array}{l}\text { The ability to modify production capacity by adding or subtracting component of the } \\
\text { system easily }\end{array}$ \\
\hline Modularity & $\begin{array}{l}\text { The ability to manipulate between alternate production scheme for the optimal } \\
\text { arrangement }\end{array}$ \\
\hline Integrability & $\begin{array}{l}\text { The ability to integrate module rapidly and precisely by a set of mechanical, } \\
\text { informational, and control interface }\end{array}$ \\
\hline Customization & The ability to produce a particular product based on the customer's requirement \\
\hline Diagnosability & $\begin{array}{l}\text { The ability to automatically read the current state of a system and quickly correct } \\
\text { operational defects }\end{array}$ \\
\hline
\end{tabular}

Table 2.

The characteristics of reconfigurability [27]. 


\section{Reconfigurable conveyor system}

A production system consists of material handling equipment, production machines and tooling, computer control system, and others that promote the efficient use of energy, material, resources, and equipment. As the main component of production systems, material-handling systems can be defined by the movement, storage, protection, and control of products and materials throughout the processes of manufacturing, disposal, distribution, and consumption of all related materials and goods [28]. In possessing a new production system, a new concept of material handling should be proposed. Since conveyor is the most commonly used material handling equipment in production industries, research was conducted in developing a concept of reconfigurable conveyor system that supports changeability in production.

\subsection{Reconfiguration in automated conveyor system life cycle}

The development of a conventional and centralized controlled conveyor system lies in a range of activities, which are different from technology and personnel requirements set by the system manufacturer. Current approaches for developing the system, while well-established and using well-proven methods, still follow a rigid sequential model and use an ad hoc collection of poorly integrated tools to translate requirements into the desired system (Figure 7) [29]. The planning and design of the system, fabrication of the mechanical structures, construction of electrical components, formation of control systems, and validation of the systems take place sequentially. In such an engineering process, the creation of the control system can only be carried out after all the electrical and mechanical units have been integrated.

In the operational phase, the conveyor system is utilized as it is intended. An operator of the system can monitor the operating status, identify malfunctions, and fix minor problems. In case of major problems, the help of the system provider is needed. Depending on the problem complexity, the system provider will help through a hotline, remote maintenance, or onsite maintenance.

After several years of operations or, in certain cases, changing of control strategies, restructuring or exchanging individual conveyor system units, expansion or modernization of an existing system are necessary. This is normally triggered by an increase in throughput demands, storage and buffer capacity, or a change in product variants. In principle, from the perspective of the system provider, the life cycle of the system will go through again for such cases (Figure 8). However, the key difference in these activities is the integration of new components with the existing systems either physical hardware (physical reconfiguration) or control software technology (logical reconfiguration) [26]. Specifically, the adaptation of existing conveyor system control software requires high efforts due to the engagement of all control logic levels. The largest effort lies in reconfiguring, reprogramming, and commissioning of an adapted material-flow control system [30].

\subsection{The conceptual framework}

A conceptual framework of a reconfigurable conveyor system can be classified into two categories, which are physical and logical. The physical aspect is the overall design of the conveyor including the shape, size, and material used. The conceptual design is drawn in computer-aided design software to visualize the suitability of the design with the reconfigurability criteria, before their construction. For 
Revolution of Production System for the Industry 4.0

DOI: $h t t p: / / d x$. doi.org/10.5772/intechopen.90772

Without utilising digital factory tools

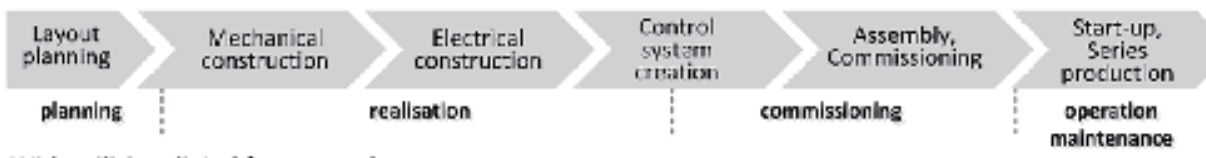

With utilising digital factory tools

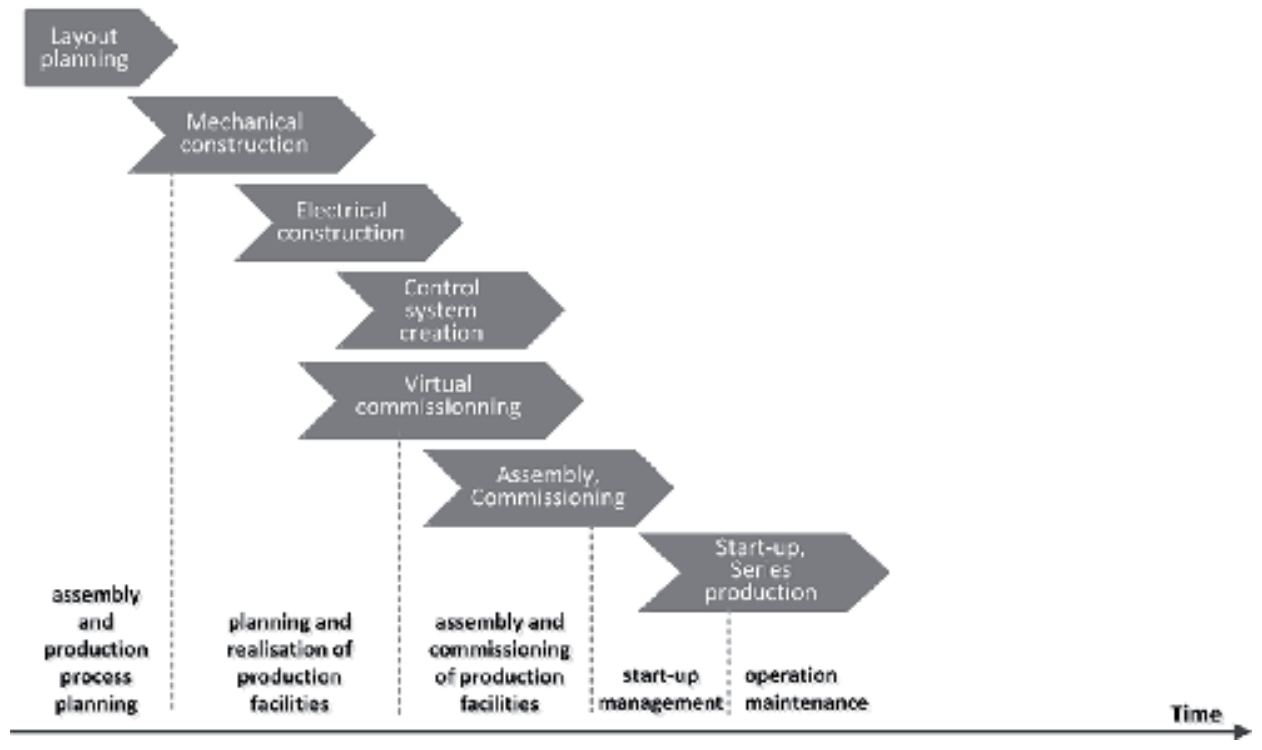

Figure 7.

The life cycle of an automated conveyor system [10].

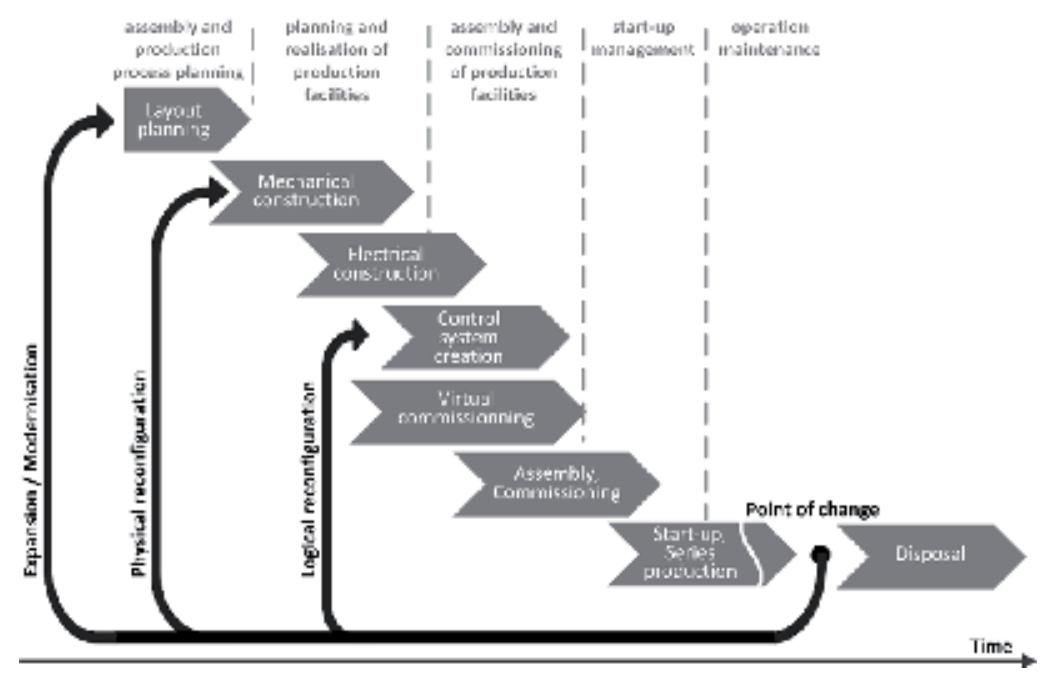

Figure 8.

Changes in the life cycle of an automated conveyor system [10].

the logical aspect, the programmable logic controller (PLC) is used as the control system since it is the most commonly used controller in production industries.

The physical reconfigurable conveyor system was designed in modules

(Figure 9), in which each module consists of few components such as adjustable steel combine stands, adjustable wheels, pneumatic cylinders with turntable, and belt conveyor. This modular concept makes the conveyor system easier to integrate, 
customize, and convert when all the modules are connected in order to form a system. Figure 9 shows the module of the reconfigurable conveyor system.

The concept for reconfigurable conveyor systems used adjustable magnetic locking systems to connect the modular components. It had replaced the fasteners with a better quick-change performance and fewer tools required. Based on its modularity, several possible layouts can be created by using the modules that had been designed. Some of the basic possible layout arrangements for the

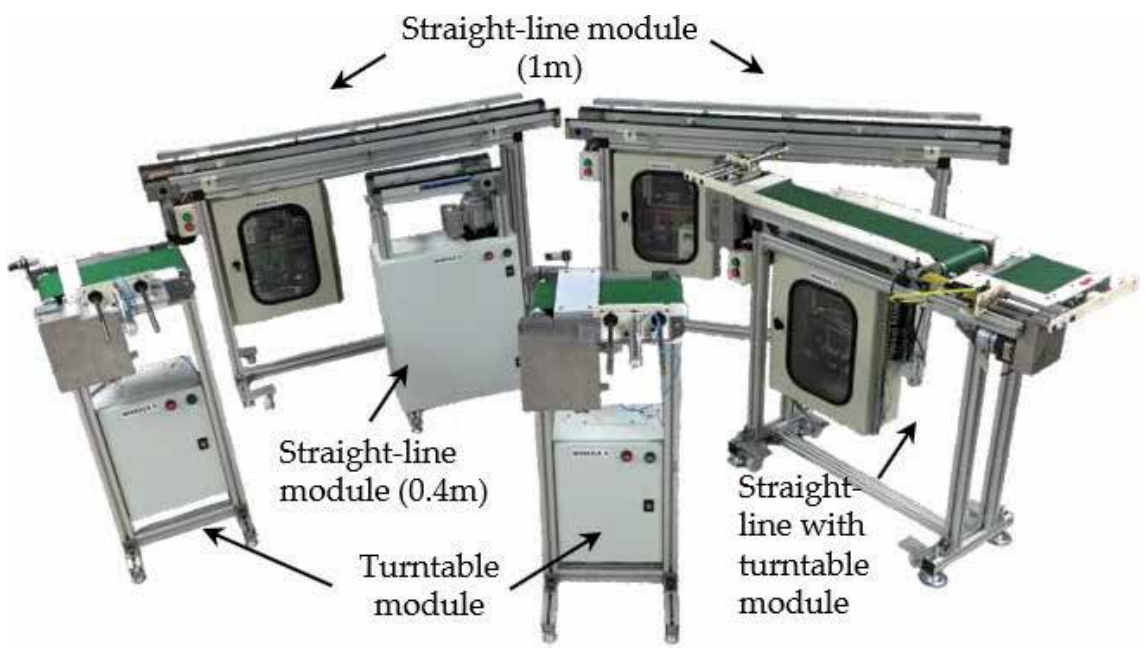

Figure 9.

Modules of the reconfigurable conveyor system.

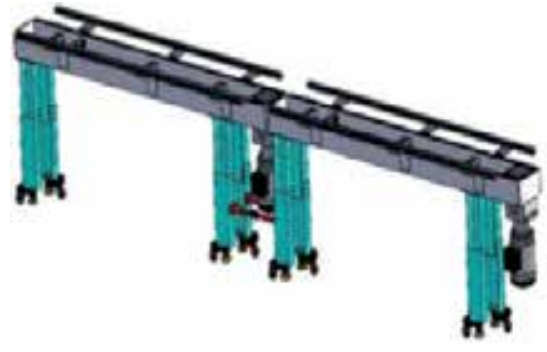

(i) Straight line layout arrangement

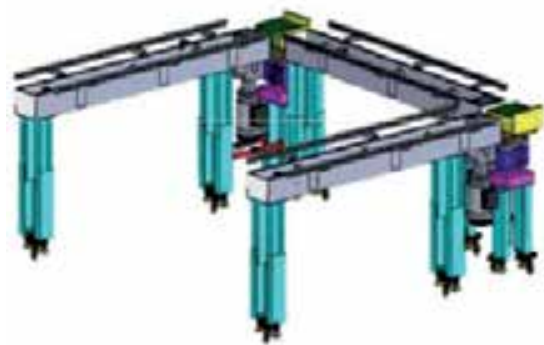

(iii) U-shaped layout arrangement

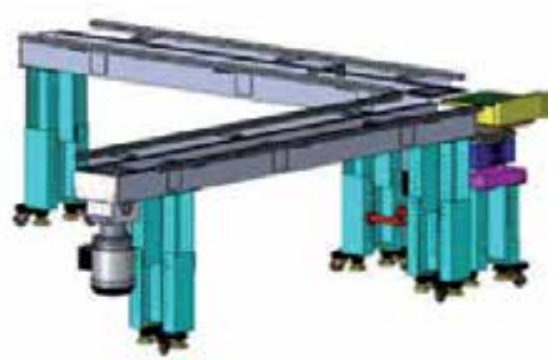

(ii) L-shape layout arrangement

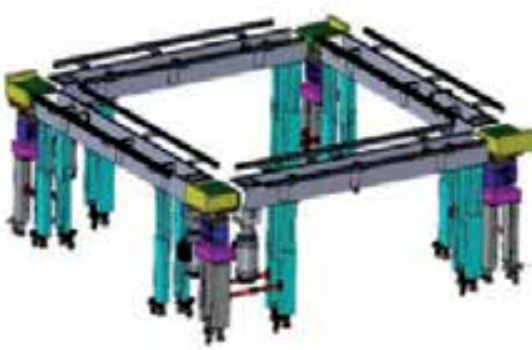

(iv) Closed-loop layout arrangement 
reconfigurable conveyor system are straight-line layout arrangement, L-shape layout arrangement, U-shape layout arrangement, and closed-loop layout arrangement (Figure 10).

The overall changeover operations have become less complex and faster. Maynard Operation Sequence Technique (MOST) analysis is used to conduct the predetermined time system of the conveyor system. The unit used for the MOST analysis is time measurement units (TMU) where 100,000 TMUs are equivalent to 1 hour. Two sequence models will be used to analyze the setup time of the existing conveyor system and conceptual reconfigurable conveyor system. A total of five operations are needed to carry out the dedicated conveyor system, whereas only three operations are carried out by a reconfigurable conveyor system.

Table 3 shows the comparison of the total time needed to assemble the L-shape layout between a dedicated conveyor system and a reconfigurable conveyor system. The reconfigurable conveyor system only needs 39.24 min to make the L-shaped configuration compare with a dedicated conveyor system, which takes $81.72 \mathrm{~min}$.

\begin{tabular}{lccc}
\hline Type of conveyor & Operation & Changeover time (min) & Total time (min) \\
\hline Dedicated conveyor & Fasten 14 steel bars & 33.6 & 81.72 \\
system & Fasten 8 support stands & 20.64 & \\
& Fasten 4 steel bars & 10.32 & \\
& Loosen 4 steel bars & 10.32 & \\
& Miscellaneous & 6.84 & 39.24 \\
Reconfigurable & Fasten 10 combine stand & 12.00 & \\
conveyor system & Fasten 10 bolts for 2 modules & 21.00 & \\
& Miscellaneous & 6.24 & \\
\hline
\end{tabular}

Table 3.

The MOST analysis of the reconfigurable conveyor system.

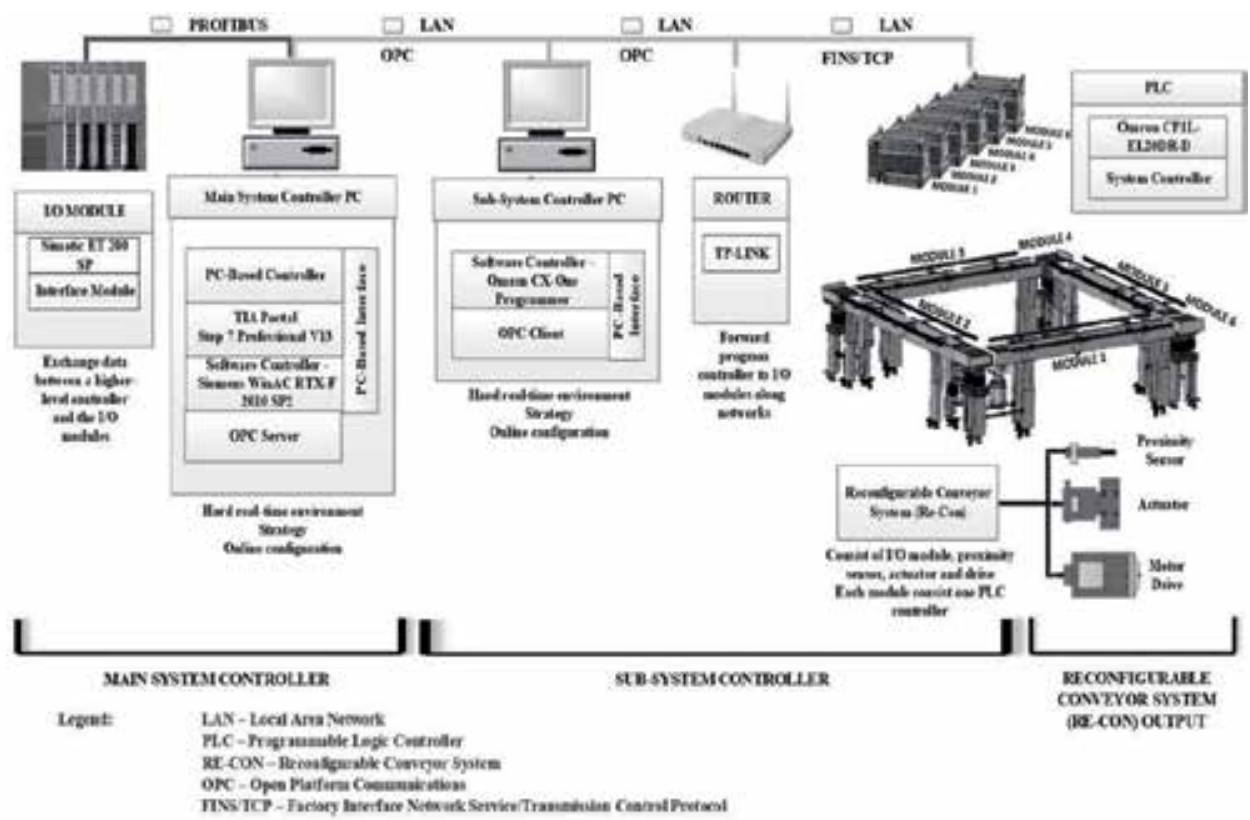

Figure 11.

The architecture of reconfigurable conveyor system. 
Almost $50 \%$ of the changeover time is reduced by using a reconfigurable conveyor system.

The architecture of the reconfigurable conveyor system concept consists of two controllers, which are the main system controller and a subsystem controller (Figure 11). The main system controller is using a Siemens controller as its main control. An application-oriented integration of three software programs is used in a realizing concept for reconfiguration. This software includes Siemens TIA Portal, Siemens Step 7 Professional V13, and Siemens Simatic WinAC RTX-F 2010 SP2. In this research, Siemens Simatic WinAC RTX-F is used as the software controller. A PC-based controller is used as the basis for the connection. All software used must support each other to make sure the connection and program control can be transferred without any error.

Furthermore, a Profibus card reader is installed at Siemens SIMATIC ET200SP to exchange data between high-level controllers to the Inputs/Outputs (I/Os) module. After that, the control program will be transferred to the I/Os module through a TP-Link router. The control program consists of logic control programs. All the relevant I/Os need to be considered based on the program that has been

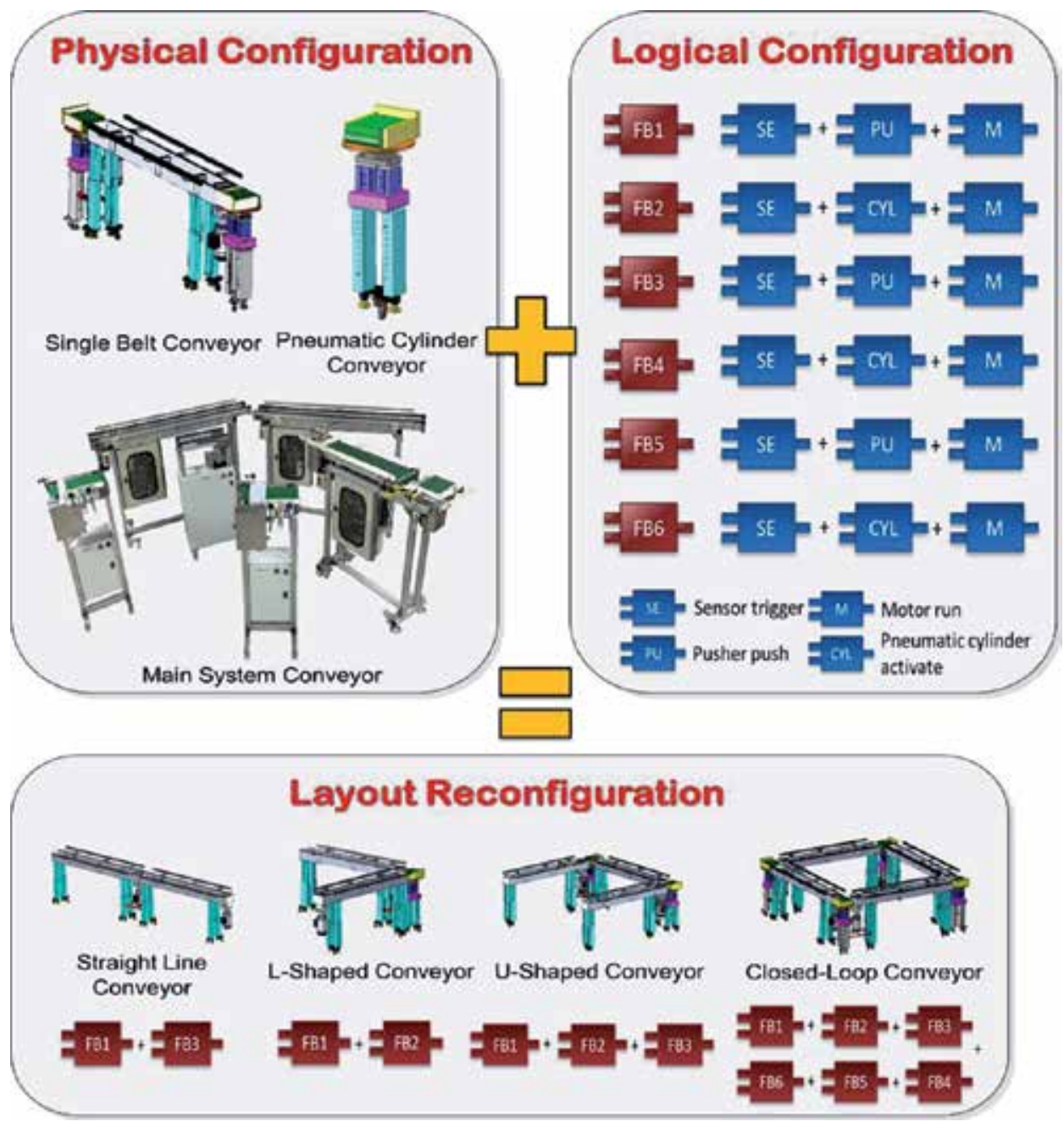

Figure 12.

The conceptual framework of the reconfigurable conveyor system. 
designed according to the mechanical structure. The control logic is drawn in a ladder diagram. The control program will be transferred to six modules of Omron CP1L-EL20DR-D through the Open Platform Communications (OPC) server and the Factory Interface Network Service (FINS)/Transmission Control Protocol (TCP) network by using local area network cables. OPC is used for communication of real-time implementation between controllers that have different manufactures. Meanwhile, the FINS/TCP Ethernet network is used to connect PLCs through multiple segments at the same network to obtain an IP address. Omron CP1L-EL20DR-D comes with an Ethernet function for communication. The Ethernet is used as a communication method between each controller in this system. IP and MAC address from each controller will be considered to transfer the control program to each sequence of operation. After all, the program is transferred successfully, and the reconfigurable conveyor system outputs including sensor, actuator, and motor drive will be functioning.

Lastly, the main system controller software connected to I/Os modules will receive the signal from the physical equipment. If the condition is satisfied, the conveyor will continue to move based on the control program. But, if there are any errors, the main system controller PC will show the errors and the user can change and modify the program online directly without stopping the conveyor.

The logical (re-)configuration of the reconfigurable conveyor system is designed by using function blocks. Each function of the physical components (sensors and actuators) has its own function block, which are stored in the function block library. The program of each module consists of combinations of function blocks from different numbers of sensors, pushers, pneumatic cylinders, and motors. Depending on the layout (re-)configurations, the main control program for the reconfigurable conveyor system can be designed by combining the module's function block. Figure 12 illustrates the overall reconfiguration concept of the system.

\section{Discussion: production system for the future}

The term Industry 4.0 and its reference architecture model are originated from Germany (Industry 4.0). It was first introduced in 2011. Now, the vision-and reality-of the Industry 4.0 has caught the attention of organizations across the globe. Moreover, even though Industry 4.0 originally was used only for production, it is de facto going further. We clearly see nowadays how the several parties that were involved in Industry 4.0 themselves move it to smart transportation and logistics, smart buildings, smart oil and gas plant, smart healthcare, and even smart cities.

In the fourth industrial revolution (Figure 13), the production industry is moving from 'just' the Internet and the client-server model to ubiquitous mobility, that integrates digital and physical environments referred to as Cyber-Physical Systems. This can be achieved through the integration of information and communication technologies (such as Internet of Things-IoT and Big Data) with operation technologies (such as collaborative robots and artificial intelligence/smart cognitive), which allows Industry 4.0 factories to automate and optimize in completely new ways and bring the smart factory up to the next level.

Research has been performed by Qin et al. [31] to analyze the current production system and comparing them with the concepts of the Industry 4.0 requirements. Based on their research outcome (Figure 14), it is obvious that the current implemented production system has not yet achieved the Industry 4.0 level comprehensively, although many researchers and companies are working on this topic. There is still a long way to go to improve production up to the required level to match all concepts with all dimensions. 

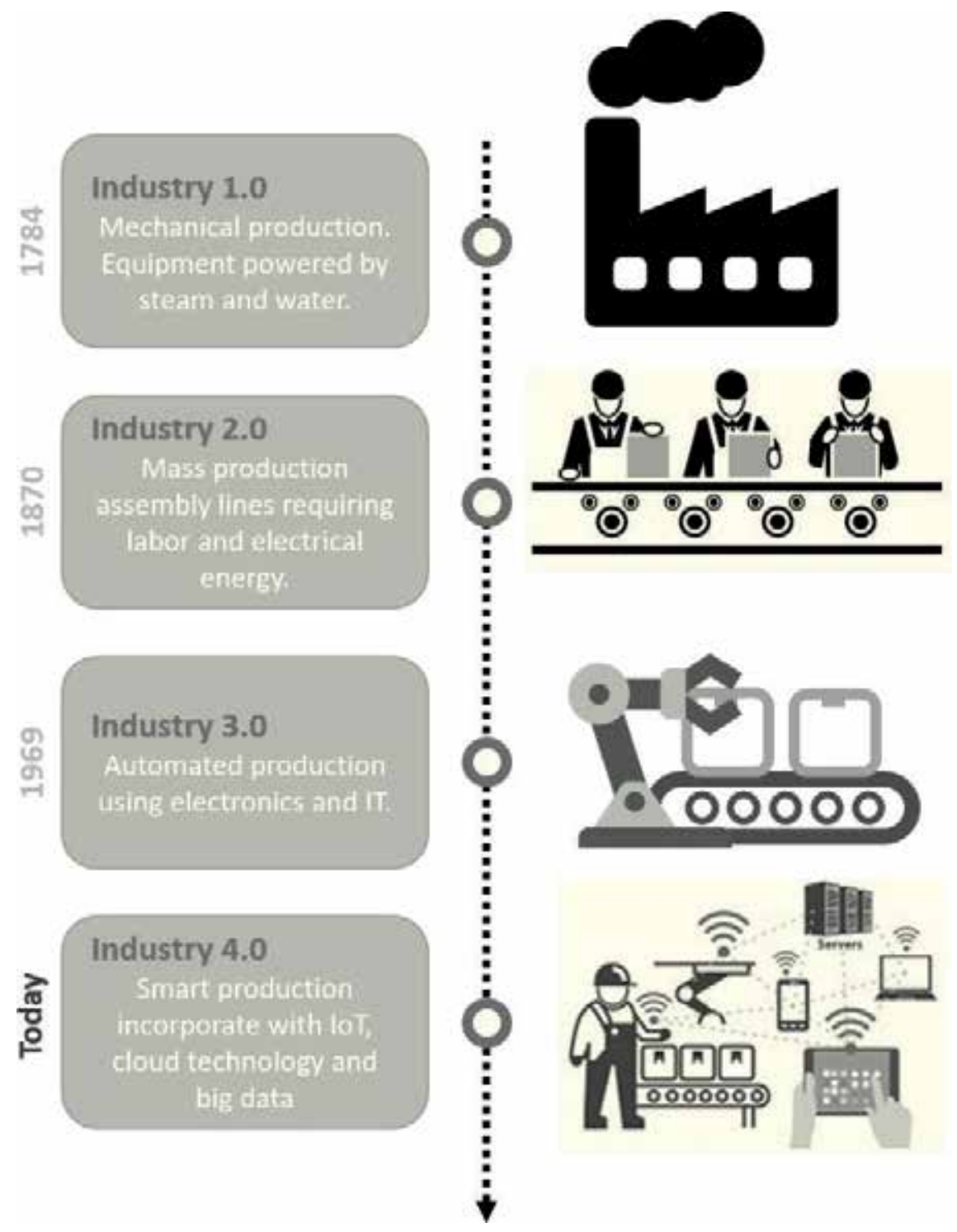

Figure 13.

The revolution of the production industry.

\section{Conclusion}

Production industries have shifted from one paradigm to another for the last couple of decades, starting from craft production, mass production, customization production, and personalized production. The growing later paradigm would cover the goals and strategies of a previous paradigm and will involve more reactive production systems. Fluctuating product demands and dynamic market environment in personalized production has resulted in the development of RMS, which are able to react and adapt to frequent changes while maintaining the flexibility of FMS.

The importance of changeability in production systems has been well recognized and applied for many years. Since then, several research activities have been conducted to fulfill the needs of changeability. At an operational level, a lot of activities are focused on physical and logical reconfiguration including reconfigurable 


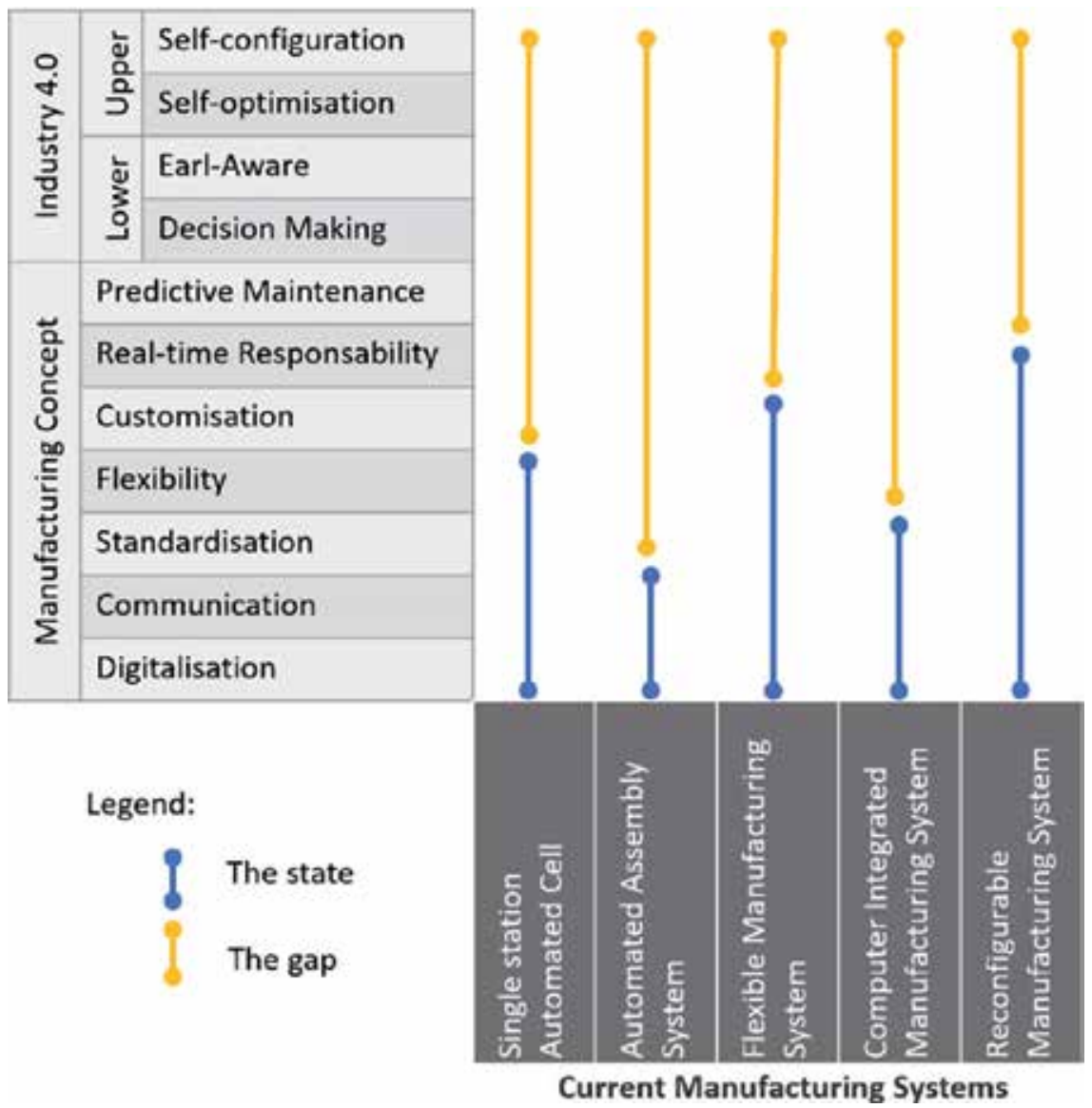

Figure 14.

The identified gap between current production systems and the Industry 4.0 concept.

material handling systems. Interfaces between mechanical structures have been studied for easy-to-use and plug-and-producible concept, and construction kits for modular material handling systems have been developed to realize the concept. A conceptual framework of reconfigurable conveyor system that supports physical and logical reconfiguration is introduced.

Future fields of research in production engineering will focus greatly on enhancing the autonomy and changeability of the production system. In line with the Industry 4.0, Artificial Intelligence and Cyber-Physical System technologies also need to be implemented for the enhancement of the conceptual framework. Strong interdisciplinary activities in this research field are, therefore, to be anticipated in the next few years.

\section{Acknowledgements}

The author are pleased to acknowledge the financial and administrative support from Universiti Teknikal Malaysia Melaka and the Minister of Education (MOE), Malaysia under the FRGS/1/2014/TK01/FKP/03/F00229 Research grant project entitles "A novel concept of reconfigurable material handling systems to support changeability in manufacturing". Special thanks also go to all the researchers who contributed to the research. 


\section{Author details}

Azrul Azwan Abdul Rahman

Advanced Manufacturing Centre (AMC), Universiti Teknikal Malaysia Melaka, Melaka, Malaysia

*Address all correspondence to: azrulazwan@utem.edu.my

\section{IntechOpen}

(C) 2020 The Author(s). Licensee IntechOpen. This chapter is distributed under the terms of the Creative Commons Attribution License (http://creativecommons.org/licenses/ by/3.0), which permits unrestricted use, distribution, and reproduction in any medium, provided the original work is properly cited. (cc) BY 


\section{References}

[1] United Nations Industrial Development Organization (UNIDO). International Yearbook of Industrial Statistics 2018. Cheltenham: Edward Elgar; 2018. p. 663. DOI: $10.4337 / 9781788116596$

[2] Abele E, Liebeck T, Wörn A. Measuring flexibility in investment decisions for manufacturing systems. CIRP Annals - Manufacturing Technology. 2006;55(1):433-440. DOI: 10.1016/S0007-8506(07)60452-1

[3] Schuh G, Harre J, Gottschalk S, Kampker A. Design for changeability (DFC) - Das richtige Maß an Wandlungsfähigkeit finden, Ergebnisse des EU-Verbundforschungsprojektes "modular plant architecture". wt Werkstattstechnik online. 2004;94:100-106

[4] Chryssolouris G. Manufacturing System: Theory and Practice. New York: Springer-Verlag; 2006. p. 606. DOI: 10.1007/0-387-28431-1

[5] Seliger G. Sustainable manufacturing for global value creation. In: Proceedings of the 9th Global Conference on Sustainable Manufacturing (GCSM); 22-24 November 2011. Abu Dhabi; 2012. pp. 3-8

[6] Arnold D, Furmans K. Materialfluss in Logistiksystemen. Berlin Heidelberg: Springer-Verlag; 2009. p. 396. DOI: 10.1007/978-3-642-01405-5

[7] VDI 2689. Leitfaden für Materialflussuntersuchungen. Beuth Verlag GmbH; 2010

[8] Hu SJ, Ko J, Weyland L, ElMaraghy HA, Lien TK, Koren Y, et al. Assembly system design and operations for product variety. CIRP Annals Manufacturing Technology. 2011;60(2):715-733. DOI: $10.1016 /$ j. cirp.2011.05.004
[9] Berthelot F, Nouvel F, Houzet D. A flexible system level design methodology targeting runtime reconfigurable FPGAs. EURASIP Journal on Embedded Systems. 2008;2008:1-18. DOI: $10.1155 / 2008 / 793919$

[10] Abdul Rahman AA. Approach for integrating predictive-reactive job shop scheduling with PLC-controlled material flow [thesis]. Berlin: Technischen Universitat; 2013

[11] Koren Y, Shpitalni M. Design of reconfigurable manufacturing systems. Journal of Manufacturing Systems. 2010;29(4):130-141. DOI: 10.1016/j. jmsy.2011.01.001

[12] Renna P. Capacity reconfiguration management in reconfigurable manufacturing systems. The International Journal of Advanced Manufacturing Technology. 2010;46(1-4):395-404. DOI: $10.1007 /$ s00170-009-2071-2

[13] Gupta D, Buzacott JA. A framework for understanding flexibility of manufacturing systems. Journal of Manufacturing Systems. 1989;8(2):89-97. DOI: 10.1016/0278-6125(89)90028-9

[14] Delorme X, Dolgui A, Dolgui, Essafi M, Linxe L, Poyard D. Machining Lines Automation. Springer Handbook of Automation. Berlin Heidelberg: Springer; 2009. p. 617. DOI: 10.1007/978-3-540-78831-7

[15] Pine II BJ. Mass Customization: The New Frontier in Business Competition. Boston: Harvard Business School Press; 1993. p. 333. DOI: 10.1177/031289629301700206

[16] Binder AK. Ward's Automotive Yearbook. Detroit: Prism Business Media Inc.; 2006 
[17] Liu ST. A fuzzy DEA/AR approach to the selection of flexible manufacturing systems. Computers \& Industrial Engineering. 2008;54(1): 66-76. DOI: 10.1016/j.cie.2007.06.035

[18] Spano MR Sr, O’Grady PJ, Young RE. The design of flexible manufacturing systems. Computers in Industry. 1993;21(2):185-198. DOI: 10.1016/0166-3615(93)90135

[19] Harrison R, Colombo AW, West AA, Lee SM. Reconfigurable modular automation systems for automotive power-train manufacture. International Journal of Flexible Manufacturing Systems. 2006;18(3):175-190. DOI: 10.1007/ s10696-006-9008-y

[20] Koren Y, Hu SJ, Gu P, Shpitalni M. Open architecture products. CIRP Annals - Manufacturing Technology. 2013;61(2):719-729. DOI: 10.1016/j. cirp.2013.06.001

[21] SFB 582. Marktnahe roduktion individualisierter Produkte. TU München. 2005. Available from: https:// www.sfb582.de

[22] Tseng MM, Jiao RJ, Wang C. Design for mass personalization. CIRP Annals - Manufacturing Technology. 2010;59(1):175-178. DOI: 10.1016/j. cirp.2010.03.097

[23] Koren Y, Heisel U, Jovane F, Moriwaki T, Pritschow G, Ulsoy G, et al. Reconfigurable manufacturing systems. CIRP Annals - Manufacturing Technology. 1999;48(2):527-540. DOI: 10.1016/S0007-8506(07)63232-6

[24] Abdi MR. Layout configuration selection for reconfigurable manufacturing systems using the fuzzy AHP. International Journal of Manufacturing Technology and Management. 2009;17(1/2):149-165. DOI: 10.1504/IJMTM.2009.023783
[25] Koren Y, Gu X, Guo W.

Reconfigurable manufacturing systems: Principles, design, and future trends. Frontiers of Mechanical Engineering. 2018;13(2):121-136. DOI: 10.1007/ s11465-018-0483-0

[26] Pritschow G, Wurst KH, Kircher C, Seyfarth M. Control of reconfigurable machine tools. In: ElMaraghy HA, editor. Changeable and Reconfigurable Manufacturing Systems. London: Springer-Verlag; 2012. pp. 71-100. DOI: 10.1007/978-1-84882-067-8

[27] Makinde OA, Mpofu K, Popoola API. Review of the status of reconfigurable manufacturing systems (RMS) application in South Africa mining machinery industries. Procedia CIRP. 2014;17:136-141. DOI: 10.1016/j.procir.2014.02.035

[28] Raymond AK. Materials Handling Handbook. 2nd ed. New York: Wiley; 1985. p. 1458. DOI: $10.1002 / 9780470172490$

[29] Harrison R, Colombo AW, West AA, Lee SM. Reconfigurable modular automation system for automotive power-train manufacture. International Journal of Flexible Manufacturing Systems. 2006;18(3):175-190. DOI: 10.1007/s10696-006-9008-y

[30] Günthner W, ten Hompel M.

Internet der Dinge in der Intralogistik.

Berlin Heidelberg: Springer-

Verlag; 2010. p. 329. DOI:

10.1007/978-3-642-04896-8

[31] Qin J, Liu Y, Grosvenor R.

A categorical framework of manufacturing for industry 4.0 and beyond. Procedia CIRP. 2016;52:173-178. DOI: 10.1016/j.procir.2016.08.005 


\title{
Innovate Manufacturing SMEs in the Context of Industry 4.0: A Formal Approach
}

\author{
Teresa Taurino and Agostino Villa
}

\begin{abstract}
A few years ago, the "Industry 4.0" programs have been launched in several European countries and USA to support the development and the innovation of SMEs. The common goal of these programs is to innovate SMEs in terms of automation (of machines), integration (of lines), and interconnection (of the production system with its management). For SMEs, it would be a great opportunity. However, SME managers (who usually are at the same time, owners, operations managers, and technicians) face great difficulties in accessing funding from an "Industry 4.0" plan, due to lack of information and limits on their knowledge of new information technologies. This chapter aims at guiding a manager/technician toward the opportunities offered by "Industry 4.0 " by presenting some formal models on which managers can base their decisions of innovating their SMEs.
\end{abstract}

Keywords: Industry 4.0, cyber physical systems, interconnection, small and medium enterprises, innovation

\section{Introduction}

After the great financial crisis started in 2007, plans have been launched in various countries to support the development and the innovation of SMEs: until now, there are 15 European programs for Industry 4.0 all over Europe (Germany, Italy, France, Austria, Belgium, Czech Republic, Denmark, Spain, Hungary, Lithuania, Luxembourg, Holland, Poland, Portugal, and Sweden). The common goal of these programs is to innovate SMEs in terms of automation (of machines), integration (of lines), and interconnection (of the production system with its management). However, in the practical application, this innovation plan encounters a problem common among several countries: managers of SMEs, generally owners with technical competencies, do not have the knowledge and skill necessary to define their innovation programs for their own SME, such to satisfy the constraints of the "Industry 4.0" plans [1].

Information technology (IT) is the heart of all the manufacturing systems with the presence of many technological innovations such as sensors, actuators, and computerized information that have been used by manufacturing companies for decades [2], but full potential of these technologies has not been realized [3] in the current advanced manufacturing processes. This is due to the fact that connectivity and integration of information systems is limited to a relatively homogeneous area, for example, part manufacturing, or assembling or quality testing $[4,5]$. 
Given the inadequate technical skill of typical SME managers, we need a new methodology and related formal models to guide them in identifying the most convenient innovation perspective for their company, to analyze how this innovation can be financed in the context of Industry 4.0, to evaluate costs and benefits to be developed in terms of:

a. What are the measures of Industry 4.0 that favor the connection and the integration of an SME;

b. How an Industry 4.0 measure can be applied to an SME with a certain impact.

Therefore, this chapter is organized as follows. Section 2 provides an outline of the mail existing literature. Then, a new logical scheme decision-making process to select one of the four alternative measures of the Industry 4.0 program is presented (Section 3). To describe in formal terms the main usable Industry 4.0 measures, the most utilized alternative measures of the aforementioned logical model are reformulated in terms of mathematical models, defined in a sufficiently simple form to be understood by SME managers and technicians (Sections 3.1 and 3.2). By analyzing a real applications of Industry 4.0 to an Italian SME (to be developed within the Italian PMInnova Program, that is, a program to promote innovation and development of SMEs under the official agreement of Politecnico di Torino and the Bank Group of Asti, Biella, Vercelli, North-East Italy), the difficulties and benefits of Industry 4.0 are discussed in a small mechanical production plant (Section 4). Section 5 contains a comparison among Industry 4.0 programs in some European countries. Then, some concluding remarks are reported in Section 7.

\section{Outline of main literature results}

The Industry 4.0 program, launched in similar forms in 15 European countries, was designed to involve SMEs in the "IV industrial revolution" [6] by pushing companies to apply the new enabling technologies that are developed in three main areas:

- the availability of digital data and analytics of Big Data, together with low-cost sensors and cloud computing;

- robotics and advanced automation, with new man-machine interactions; and

- pushed connectivity, using intelligent sensors (Internet of Things).

Digitization has given a further push to the processes of transformation of the company, along some precise guidelines $[1,7]$ :

a. interconnection: the machine's ability to exchange information with internal systems (management system, planning systems, and design systems) and external systems (customers, suppliers, and partners), through links based on documented, public, and internationally reconfigured specifications (guidelines);

b. virtualization: a "virtual pair" (digital twin) of the real system or its components is created and supplied with data to predict the evolution of the behavior of the system by means of simulations [8]; 
c. decentralization: the various cyber and physical components that make up the production system have appropriate strategies (e.g., to correct process drifts) in an autonomous manner;

d.remote interaction: the devices are remotely accessible so as to be able to detect operating data and introduce corrective measures;

e. real time processing and reactions: the presence of functions that allow to collect process data in real time and to adopt the necessary actions or corrections.

Based on the five guidelines that characterize the typical actions of Industry 4.0, a wide literature has been developed according to the following main lines:

- Schematic description of the Industry 4.0 program to highlight the main enablers $[1,9]$;

- Analysis of the development trajectory from lean manufacturing to Industry 4.0 to explain changes and their usefulness [10-13]; and

- Discussion of any critical issues in the application of Industry 4.0, especially in SMEs [14-16].

With reference to the analysis of the Sommer paper, it is necessary that the researchers make clear that in the practical application of the Industry 4.0 plans, the technology road-map is still not clear in industry and in academy [15]. Some literature reviews show that Industry 4.0 projects only is a cost-driven initiatives; however it is rare to find papers where precise indications on the convenience of using some actions of the Industry 4.0 program are given [17]. This is particularly evident in the case of micro, small and medium-sized enterprises. Usually, the SME manager is also the founder of the company and the holder of the knowledge and techniques on which the industrial process was built and developed. These figures of manager/ technician, and owner, are very tied to their original technical knowledge. Therefore, they resist to accept that their company becomes the object of innovation programs that meet the constraints of the "Industry 4.0 " plans $[1,17,18]$.

Consequently, it is understandable why small enterprises managers ask to have a "method" to guide them in selecting which innovation of their business could be better implemented by applying one of the Industry 4.0 measures.

\section{The logical decision-making model}

The logical model of the Industry 4.0 decision-making process can be interpreted as follows: known the current state of the production process, the manager decides to choose the measure of Industry 4.0 which he considers the most convenient according to the needs of innovation of his SME, by estimating which financing or which tax credit could get. The four main measures of Industry 4.0 corresponding to the following choices (see the following decisional scheme in Figure 1) are:

a. buy a new high-tech machine in case the manager wants to increase efficiency and productivity of his production process;

b. develop a research and development program (R\&D), if he wants to design new products or define a new work organization; 


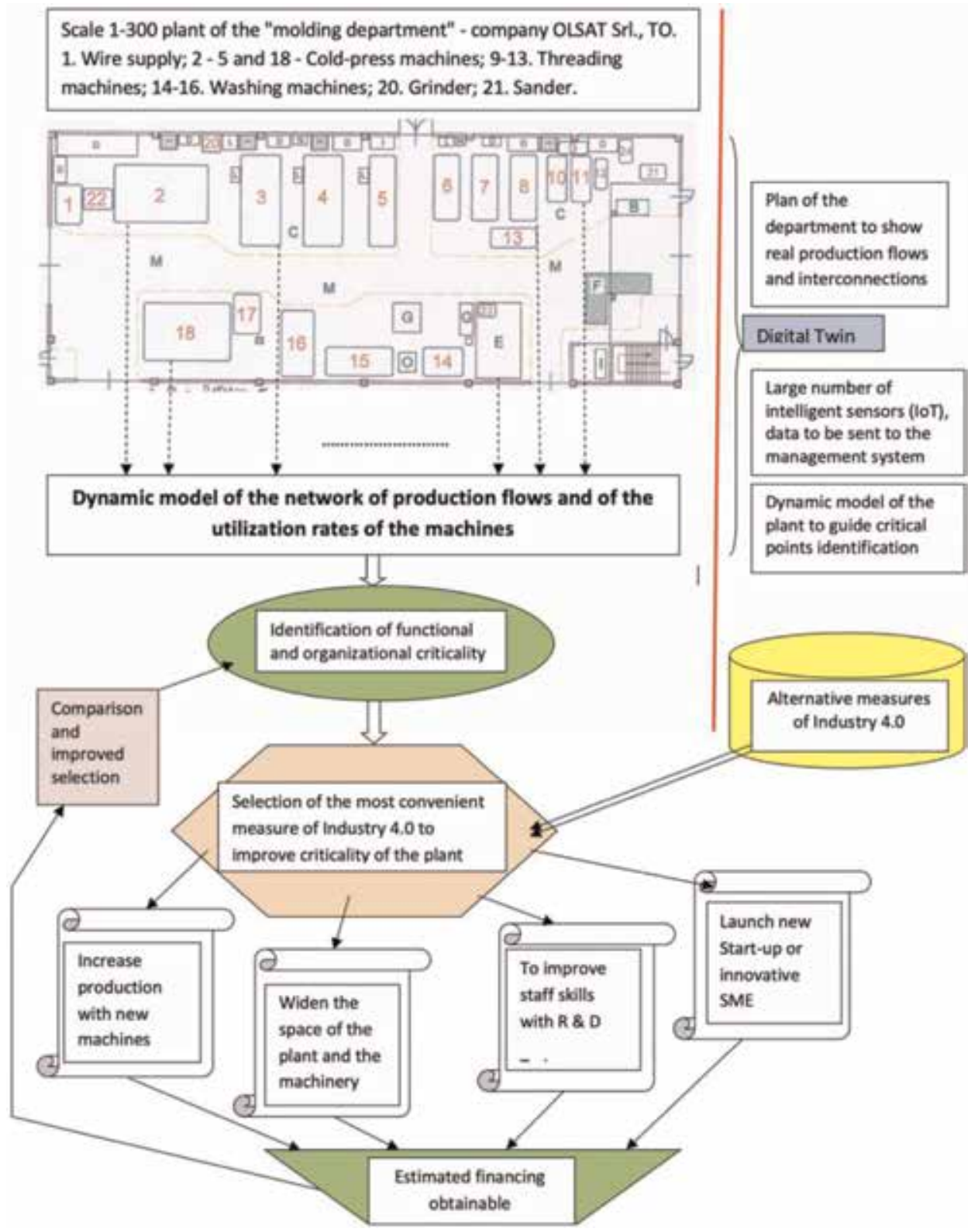

Figure 1.

Logical scheme of the Industry 4.0 decisional process.

c. expand the plant with other buildings and also insert operating machines already at disposal or purchased, if the space of the SME seems to become smaller for the increase of the customers' demand; and

d.found a start-up or an innovative SME, if one or more young people with good skills and good organizational training want to start a new high-tech activity.

For sake of simplicity, the approach to select and verify the convenience of asking support for a SME according to one of said four alternative measures of Industry 4.0, will be based by considering the SME production process as organized in terms of a supply chain, that is, a typical organization of the production flows in a 
small or micro-enterprise, where simplified interconnections of working machines are preferred (as the Authors have verified in about $80 \%$ of the 160 SMEs, that have been analyzed during the last 6 months of 2018 in the PMInnova Program).

In addition, in order to analyze approaches to existing SMEs' innovations, an effective evaluation can be only done among SME modifications obtained according to the first three alternatives (a)-(c) outlined above, the latter (d) being only related to the launch of a new company.

Figure 1 describes a logical scheme according to which the selection of the most convenient measure of the Industry 4.0 program (among the four alternatives above listed) can be done, with the goal of improving the efficiency, effectiveness, and convenience of a given SME.

\subsection{SME innovation through new high-tech machine inclusion in the process plant}

In case of a SME innovation through interconnection in the exiting process of a new high-tech manufacturing machine that will substitute an older one, the starting point will be the definition of a formal model, possibly simplified (to allow an easy understanding by the SME manager), of the process, by assuming that the new machine is included in a given point of the production line.

Owing to the higher production capacity of the new machine with respect to the others, the production line can be modeled by an equivalent production center. Then, the evaluation of the production capacity increase can be obtained by formulating and solving an Aggregate Production Planning (APP) Problem, as stated in $[19,20]$ :

$$
\min \left\{\sum_{t=1}^{T}\left[w \cdot W_{t}+o \cdot O_{t}+\sum_{i=1}^{N}\left(c_{i} \cdot I_{i, t}\right)\right]\right\}
$$

s.t.

$$
\begin{aligned}
& I_{i, t}=I_{i, t-1}+x_{i, t}-d_{i, t}, \forall i, t \\
& I_{i, 0}=I_{i}^{0}, \forall i \\
& \sum_{i=1}^{N} x_{i, t} \cdot a_{i} \leq W_{t}+O_{t}, \forall t \\
& W_{t} \leq W^{*}, \forall t \\
& O_{t} \leq O^{*}, \forall t \\
& x_{i, t}, I_{i, t}, W_{t}, O_{t} \geq 0, \forall i, t
\end{aligned}
$$

\subsubsection{Parameters}

$c_{i}$ unit inventory cost for product $i$;

$I_{i, t}$ inventory of product $i$ in period $t$;

$d_{i t}$ demand of product $i$ in period $t$;

$I_{i, 0}$ starting inventory level of product $i$;

$O_{t}$ straordinary work in period $t$;

$O^{*}$ maximum capacity of straordinary work;

$o$ straordinary cost;

$W_{t}$ ordinary work in period $t$; 
$W^{*}$ maximum capacity of ordinary work;

$w$ ordinary cost;

$a_{i}$ processing time of product $i$;

\subsubsection{Decision variable}

$x_{i, t}$ produced quantity of product $i$ in period $t$.

The above stated APP problem also includes the quantity of labor (and its bounds) because the inclusion of a new high-tech machine in a production process reflects either in a reduction of the workforce or in a modification of the employees' skills, effects that must be taken into account in the global evaluation of the costbenefits balance.

In case of constant demand, the above general APP problem can be approximated as:

$$
\begin{aligned}
& d_{i, t}=d_{i} \text { (domanda costante) } \\
& \text { costo prevalente }-c_{i} \\
& \widetilde{J}=\sum_{i=1}^{N} \sum_{t=1}^{T} c_{i} \cdot I_{i, t}
\end{aligned}
$$

With simple solution given by:

$$
\begin{aligned}
& x_{i, t}=\operatorname{costante}=d_{i}-\frac{I_{i}^{0}}{T} \\
& I_{i, t}=I_{i}^{0}-\frac{I_{i}^{0}}{T-t}, \quad t=1, \ldots, T-1 \\
& I_{i, T}=0 \\
& W_{t}=W^{*} \\
& O_{t}=O^{*}
\end{aligned}
$$

The resulting solution conditions allows to compare different alternatives of new different high-tech machines, depending on the production rates assured by each one of them and the necessary personnel.

\subsection{Plan of a research and development program to include a new product in the existing mix}

If the SME manager feels the need to expand his production mix to include a new product, the problems to be solved are mainly two: (a) designing the new product in order to use as many existing production operations, and related machines as possible and (b) estimate demand for the new product, rebalancing the production flows within the machine graph so as to avoid the creation of —or make less critical-bottlenecks. 
It is not discussed here, due to space requirements and because already analyzed by the authors in a previous paper [21], the first problem, whose solution is obtained by a "composition" of the operations of processing and assembly of the new product, trying to draw them from "Bills of Materials" of products already in the works.

About the second problem, this requires an analysis of the production flows with the presence of the increased mix: something that can be obtained from a Production Flow Analysis model [22].

The following data are necessary to analyze the production flows within the plant, for every manufactured product, $p$ : (a) sequence (ordered list) of the utilized resources, $L R_{p}$ and (b) the standard (average) volumes required by market, $V_{p}$.

These data summed up in the Map of Production Mix, defined by:

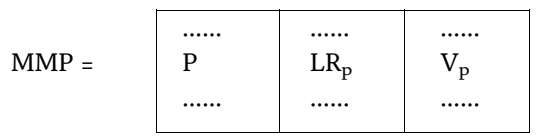

Based on such data, one can apply the PFA steps as follows:

a. From the List of Resources of the product $p, L R_{p}$, one has to fill the map product-resources, otherwise called Functional Map of Layout (since it shows as the available resources are used to work the mix of products under examination) is defined as follows:

$M F L_{p, r}=1$, if the product $p$ "uses" resource $r$, $=0$, otherwise.

b. To the Functional Map of Layout, the Map of Work Requests, $M R L_{p, r}$ corresponds, as defined by:

$M F L_{p, r}=1$, if the product $p$ "uses" resource $r$, $=0$, otherwise.

c. parallel, again from the List of Resources, the Structural Map of Layout, MSL $L_{r, s}$, that is the matrix of connections among the work centers included in the layout, is defined as follows:

$M S L_{r, s / p} \rightarrow$ contains the set of products $p$ which utilize the work center $r$ and then the work center $s$; $=0$, otherwise.

By using said maps, one can apply the following analysis considerations:

i. The Structural Map of Layout allows to recognize all work centers to which several production flows are directed; they could be potential bottlenecks or, at least, congested centers;

ii. The Functional Map of Layout is the basic matrix for the clustering procedure to identify product families and work cells;

iii. The Map of Work Requests is used in the procedure to identify bottlenecks, by estimating the requests for work at each work center. 
In this sufficiently simple way, the manager can verify the impact of the new product on the pattern of existing production flows, and estimate the cost of including said new product in its own production mix.

\subsection{Expanding the SME production space}

The typical application of this measure of Industry 4.0 is related to the expansion of the plant space of a small company whose demand for products has undergone a recent but steady growth. In this case, the main activities must be dedicated to the reorganization of the warehouse and internal logistics (see the first activity), which generally constitute the two main elements of the crisis of the SME. From this activity, the estimate of necessary space and extension of the plant will also be achieved. Subsequently, some machine operating in the production process should be moved to new space, allowing a reorganization of the logistics paths (i.e., production flows). As in the two previous cases, an evaluation of the aforementioned activities could be obtained by the same PFA model adopted in the second type of Industry 4.0 measure.

\section{A real application}

Started in February 2018, the PMInnova Program [18] has so far registered more than 160 SMEs in its archive, and for 60 of them Politecnico di Torino has analyzed the current technical-organizational-functional status and evaluated the feasibility of their innovation and development plans in an "Industry 4.0" perspective [23].

An interesting "success case" (i.e., an innovation project by inclusion of a new high-tech machine in the existing plant, that have been already approved by the "Industry 4.0" reviewers) is shown in detail, by only omitting the company name for confidentiality reasons, but by using real data and information.

The success case refers to an SME (which we will call SME//1) founded in 1989, located in the Turin area, with about 70 employees, dedicated to the production of components for automotive, made by steel, on the basis of a CAD drawings. The finished product is obtained from a steel wire with a cold molding process and, if required, a chip removal. Examples of products of SME//1 are: inflators for airbags, small components for assembling the interior of seats, small components for anti-vibration systems, and joining tools.

The innovation project of SME//1 was the purchase and introduction into the production process of a machine for printing reels, drilling, and internal threading. With eight programmable complementary units, loading and unloading stations, CNC control and mini PC for connection to the company's management system. The system of interconnection to the corporate network, to the CAD/CAM design center and, through rewalls, to outside, is represented by the diagram in Figure 2.

The model described in Section 3.1 has been used as "formal tools" to develop the evaluation of the impact of the new machine in the existing process. In practice, said model have been used to compute the innovated production capacity: to this aim, some software tools already at disposal of the SME have been applied for obtaining real internal order transmission to the machine, once the production plan computation has been done, the MRP application in order to translate the production plan into internal orders, and the CRP to verify the model-based estimation of the production capacity increase.

In this project, the most critical requirement-according to the "Industry 4.0" standards - to which the machine had to satisfy, was the "interconnection" to the factory computer systems, with remote loading of instructions and/or parts of programs. According to the system specifications required by "Industry 4.0", the characteristic of the interconnection of the machine with the factory information 


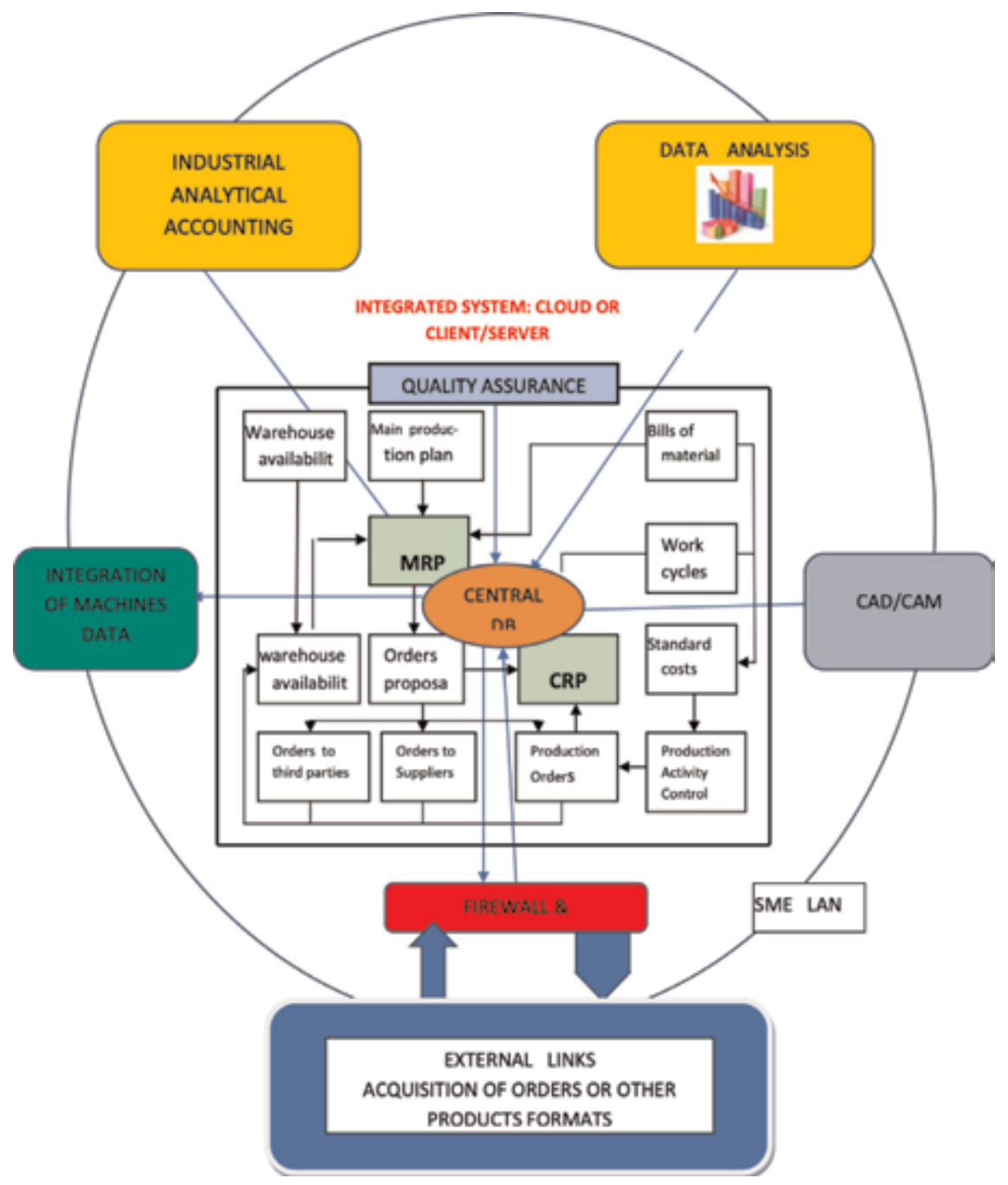

Figure 2.

Scheme showing the main interconnections to the corporate network, to the CAD/CAM.

system through remote loading of instructions and/or parts of programs, is satisfied if the machine exchanges information with internal systems (e.g., management system, planning systems, product design and development systems, monitoring, even remotely, and control, other plant machines, etc.). Moreover, to satisfy other Industry 4.0 requirement, both physical and informative integration has to be assured, such to guarantee the traceability of the products/batches made through dedicated automated tracking systems (e.g., bar-codes, RFID tags, etc.) [24, 25].

\begin{tabular}{lc}
\hline Cost of the purchased machine & $500.000 €$ \\
\hline Over evaluation of $150 \%$ from Ind. 4.0 & $750.000 €$ \\
\hline Virtual cost of the machine & $1.250 .000 €$ \\
\hline Tax saving of $24 \%$ & $-300.000 €$ \\
\hline Net investment & $+200.000 €$ \\
\hline
\end{tabular}

Table 1.

Tax credit "hyper-amortization" according computation done for the SME//1. 
On the financial point of view, obviously, the SME//1 manager will require higher tax credit possible under the plan "Industry 4.0": to this aim, a "hyperamortization" has been computed, based on the value of the purchased machine tool, according to the computation in Table $\mathbf{1}$ :

\section{Comparison of the funding measures of "Industry 4.0 " in the main European countries}

While in Section 4, the analysis of applications of the "Industry 4.0" plan has been referred to an Italian success case, now a picture of the industrial sectors and services that have used the Industry 4.0 funding opportunities in other industrialized European countries is outlined.

First comparative data are available from the various countries with reference to July 2017, in percentages of growth or less referred to the year 2016. From the first quarter of 2016, it is observed that the gross domestic product (GDP) is in constant growth in Germany, France, United Kingdom, United States, and Italy, with an average increase of around $0.3 \%$ in these countries, while the highest percentage of industrial growth is observed in Japan $(+0.6 \%)$ [26].

In terms of the effects of the different interventions of the "Industry 4.0" measures in the major European countries, a particularly interesting variety can be seen. Italy, with its plan strongly based on maximum savings and tax credit, appears among the leading countries for fiscal support to businesses. In its "Industry 4.0", Germany has not focused on tax credits to stimulate research, but above all on direct funds disbursed by tender and on the financing of KfW-Kreditanstalt für Wiederaufbau $[27,28]$ to businesses. The federal government has planned the construction of 16 competence centers ( 5 already active) linked to the production specialization of the Lander. But the Italian model looks more like another German network of excellence, the Research Campuses that develop public-private partnerships with universities. France with "Industrie du Future" represents a model closer to Italy for some incentive choices, starting from super-amortization and tax credit [29]. It does not have a platform specifically dedicated to Industry 4.0, but the United Kingdom has recently changed gear on industrial policy with the green book "Building our industrial strategy" (U.K. Government, Building our Industry Strategy, 2017). GBP 4.7 billion is planned for research by 2020-2021. Great Britain has also made extensive use of tax credits over the last few decades, but now, the new strategy's pillar is the support to commercialization of the results of the innovation of the companies, entrusted to the "Catapults Center" (HVM Catapult-High Value Manufacturing, see web site, 2018). Unlike Italy, the whole strategy of the Netherlands started from the identification of nine leading sectors. To develop them, 19 consortia were created in public-private partnerships that take care of the planning, under them the Field Labs operate, laboratories serving companies [30].

\section{Open research problems and perspectives}

The analysis of the real cases of two small companies of the Piedmont Region, presented in the previous section, and the illustration of the challenges to apply the four main measures of Industry 4.0 to SMEs suggest open problems for an industrial research that wants to expand and make the innovation and development policies of the SME more effective. Some recent data from the Italian Ministry for Economic Development give preliminary indications useful for identifying open problems and research developments. 
The first document is the survey carried out by the Italian Ministry of Economic Development on the use of the various measures of Industry 4.0. According to the report, almost half of the manufacturing companies with over 250 employees made use of Industry 4.0 , while only $6 \%$ of those with less than 10 employees and $18 \%$ of those with 10-50 employees did so. These data for the first time highlight the reduced propensity of micro and small businesses to invest in new technologies [https://www.met-economia.it/viavia-indagine-met-2017]. On this phenomenon, the report of the Supervisor of Micro and Small Medium Enterprises, appointed ad hoc by the Government, has been tried, with an intervention in which it proposes a revision of the amortization coefficients, modifying the hyper amortization, currently supporting main investments in machinery, providing a reward for datadriven innovation of production processes, and a renewed focus on issues of safety at work, ergonomics and collaborative automation.

These surveys confirm the opinion of the authors, concerning the ability of SMEs managers to access the measures of Industry 4.0. With reference to the "hyper-amortization" measure requested by the company SME//1, the objective to be achieved is the digitization of the entire production process, with the insertion of three machines for cold molding. Above all, it seemed difficult to interconnect the model and the process, in order to transmit real data to the model itself. This is because the company-like the majority of SMEs—has few data collection points.

With this in mind, the proposal of a line of research and industrial development based on the use of intelligent sensors like the Internet of Things (IoT) even in an SME is very promising.

The problem immediately following was the definition of a map of measurement points, with specification of the type of information obtainable and of the data format, quantitative or qualitative. This aspect is particularly important for the identification of the model, and therefore of its use. It follows the need to develop an industrial research on procedures for the identification of models of dynamic production processes.

Another problem was the management of a very large number of data, collected with small sampling step. For example, approximate data of the SME//1 company indicate about 30,000 small output products from each of the 5 lines per hour, measured from about 20 measurement points in 15 working hours (two shifts). Therefore about 2000 data/hours collected from each of the measurement points must be channeled, cataloged, and evaluated in order to guarantee the traceability of the products. The amount of data and the speed necessary to treat them opens another line of industrial research.

A common conclusion can be drawn from the above analysis: Industry 4.0 offers a really new opportunity for all companies that want to seize the opportunities connected to the fourth industrial revolution, where the key words of "digitalization of industrial processes" and "enhancement of skills in the development of new products and new technologies" are associated with operational project tools. However, researchers and managers have to find a common language, and analyze together tools for the project, for the evaluation, and for the possible application of new machines for very fast and very accurate processing, which can be easily interconnected with others in an existing plant, and are equipped with sensors that follow the movements of components and products, allowing complete traceability This aspect-search for a common language-is perhaps the problem that needs the fastest possible solution. 


\section{Author details}

Teresa Taurino and Agostino Villa*

The Polytechnic University of Turin (Italian: Politecnico di Torino), Italy

*Address all correspondence to: agostino.villa@polito.it

\section{IntechOpen}

(C) 2019 The Author(s). Licensee IntechOpen. This chapter is distributed under the terms of the Creative Commons Attribution License (http://creativecommons.org/licenses/ by/3.0), which permits unrestricted use, distribution, and reproduction in any medium, provided the original work is properly cited. (cc) BY 


\section{References}

[1] Fatorachian H, Kazemi H. A critical investigation of Industry 4.0 in manufacturing: Theoretical operationalisation framework. Production Planning and Control. 2018; 29(8):633-644. DOI: 10.1080/ 09537287.2018 .1424960

[2] Naqvi STH, Farooq S, Johansen J. Operational performance: The impact of automation and integrated development. In: Proceedings of the $22^{\text {nd }}$ EurOMA Conference-Operations Management for Sustainable Competitiveness; June 26-July 1, Neuchaatel, Switzerland; 2015

[3] Da Xu L. Enterprise systems: State of the art and future trends. IEEE Transactions on Industrial Informatics. 2011;7(4):630-640

[4] Panetto H, Molina A. Enterprise integration and interoperability in manufacturing systems: Trends and issues. Computers in Industry. 2008:59, 641-57, 646

[5] Veeramani D, Bernardo JJ, Chung $\mathrm{CH}$, Gupta YP. Computer-integrated manufacturing: A taxonomy of integration and research issues.

Production and Operations Management. 1995;4(4):360-380

[6] Xu LD, Xu EL, Li L. Industry 4.0: State of the art and future trends. International Journal of Production Research. 2018;56(8):2941-2962. DOI: 10.1080/00207543.2018.1444806

[7] MISE. Ministero dello Sviluppo Economico, Circ. N. 4/E, 30 March 2017 (in Italian); 2017

[8] Wang XV, Wang L. Digital twinbased WEEE recycling, recovery and remanufacturing in the background of Industry 4.0. International Journal of Production Research. 2018. DOI: 10.1080/00207543.2018.1497819
[9] Liao Y, Deschamps F, de Freitas Rocha Loures E, Luiz Felipe Pierin R. Past, present and future of Industry 4.0 -A systematic literature review and research agenda proposal. International Journal of Production Research. 2017; 55(12):3609-3629. DOI: 10.1080/ 00207543.2017 .1308576

[10] Brettel Malte, Friederichsen Niklas, Keller Michael, Rosenberg Marius. 2014. How virtualization, decentralization and network building change the manufacturing landscape: An Industry 4.0 perspective. International Journal of Mechanical, Aerospace, Industrial and Mechatronics Engineering V 8, N 1, pp 37-44. https://publications.rwth-aachen. $\mathrm{de} / \mathrm{record} / 465283$

[11] Kolberg D, Zühlke D. Lean automation enabled by Industry 4.0 technologies. IFAC-Papers OnLine. 2015;48(3):1870-1875, ISSN 2405-8963. DOI: 10.1016/j.ifacol.2015.06.359

[12] Sanders A, Elangeswaran C, Wulfsberg J. Industry 4.0 implies lean manufacturing: Research activities in Industry 4.0 function as enablers for lean manufacturing. Journal of Industrial Engineering and Management. 2016;9(3):811-833, ISSN 2013-0953. DOI: 10.3926/jiem.1940

[13] Schlechtendahl J, Keinert M, Kretschmer F, Lechler A, Alexander V. Making existing production systems Industry 4.0-ready. Production Engineering. 2015;9:143-148

[14] Hofmann E, Marco R. Industry 4.0 and the current status as well as future prospects on logistics. Computers in Industry. 2017;89:23-34. DOI: 10.1016/j. compind.2017.04.002

[15] Jian Q, Liu Y, Grosvenor R. A Categorical Framework of Manufacturing for Industry 4.0 and 
Beyond, Procedia CIRP. 2016;52:173178. ISSN 2212-8271. https://doi.org/ 10.1016/j.procir.2016.08.005

[16] Sommer L. Industrial revolutionIndustry 4.0: Are German

manufacturing SMEs the first victims of this revolution? Journal of Industrial Engineering and Management. 2015;8:5

[17] Moeuf A, Pellerin R, Lamouri S, Tamayo-Giraldo S, Barbaray R. The industrial management of SMEs in the era of Industry 4.0. International Journal of Production Research. 2018; 56(3):1118-1136. DOI: 10.1080/ 00207543.2017.1372647

[18] Taurino T, Villa A. Promoting SME innovation trough collaboration and collective-intelligence networks. In: PRO-VE $1819^{\text {th }}$ IFIP/SOCOLNET Working Conference on Virtual Enterprises; 17-19 September 2018; Cardiff, UK; 2018

[19] Brandimarte P, Villa A. Optimization Models and Concepts in Production Management. London: Gordon \& Breach Publishers; 1995a

[20] Brandimarte P, Villa A. Advanced Models for Manufacturing Systems Management. Boca Raton, CA: CRC Press; 1995b

[21] Bruno G, Taurino T, Villa A. An approach to support SMEs in manufacturing knowledge organization. Journal of Intelligent. 2018;29(6): 1379-1392

[22] Burbidhe John L. IFIP Glossary of Terms Used in Production Control. North-Holland: Elsevier; 1987

[23] Legge 232. Gazzetta Ufficiale (in Italian). 11 dicembre 2016; n. 232; 2016

[24] Modrak V, Moskvich V. Impacts of RFID implementation on cost structure in networked manufacturing.
International Journal of Production

Research. 2012;50(14):3847-3859

[25] Zhang Y, Qu T, Ho OK, Huang GQ. Agent-based smart gateway for RFID enabled real-time wireless

manufacturing. International Journal of Production Research. 2011;49(5):

1337-1352

[26] Techeconomy. 2017. Report: Industry 4.0 e smart factory: I trend italiani e europei. Available from: http:// www.techeconomy.it/2017/07/27/ industry-4-0-smart-factory-trenditaliani-europei/ [Accessed: 27 July 2017]

[27] Kohler D, Weisz J-D. Industry 4.0:

Les défis de la transformation numérique du modèle industriel allemand [Industry 4.0: The Challenges of the Digital Transformation of the German Industrial Model]. Paris: La Documentation française, 176; 2016. ISBN 978-2-11-010210-2

[28] Ohm C, Bürger M. Ausblicke auf Industrie 4.0 und ihrKybertariat. 2015. Retrieved from: http://www.s-gs.de/ wordpress/wpcontent/uploads/2015/ 06/OhmCh-u.-B\%C3\%BCrgerM2015-Ausblicke-auf-Industrie-4.0-undihr-Kybertariat.pdf

[29] Danjou C, Rivest L, Pellerin R. Industrie 4.0: Des pistes pour aborderl'ère du numérique et de la connectivité [Industry 4.0: Paths to the Era of Digital and Connectivity]. CEFRIO; 2016

[30] NLR. 2016. Netherlands Aerospace Centre. Dutch Smart Industry Field Lab; 2016 



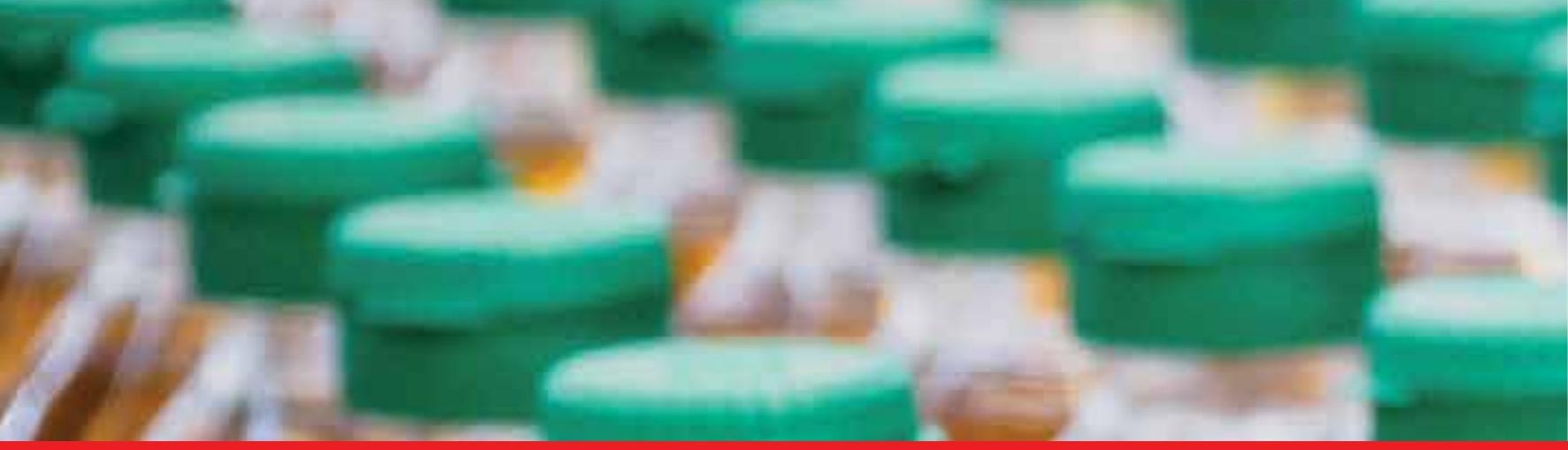

\section{Edited by Anil Akdogan and Ali Serdar Vanli}

It is always hard to set manufacturing systems to produce large quantities of standardized parts. Controlling these mass production lines needs deep knowledge, hard experience, and the required related tools as well. The use of modern methods and techniques to produce a large quantity of products within productive manufacturing processes provides improvements in manufacturing costs and product quality. In order

to serve these purposes, this book aims to reflect on the advanced manufacturing systems of different alloys in production with related components and automation technologies. Additionally, it focuses on mass production processes designed according to Industry 4.0 considering different kinds of quality and improvement works in mass production systems for high productive and sustainable manufacturing. This book may be interesting to researchers, industrial employees, or any other partners who work for better quality manufacturing at any stage of the mass production processes.

Published in London, UK

\section{IntechOpen}
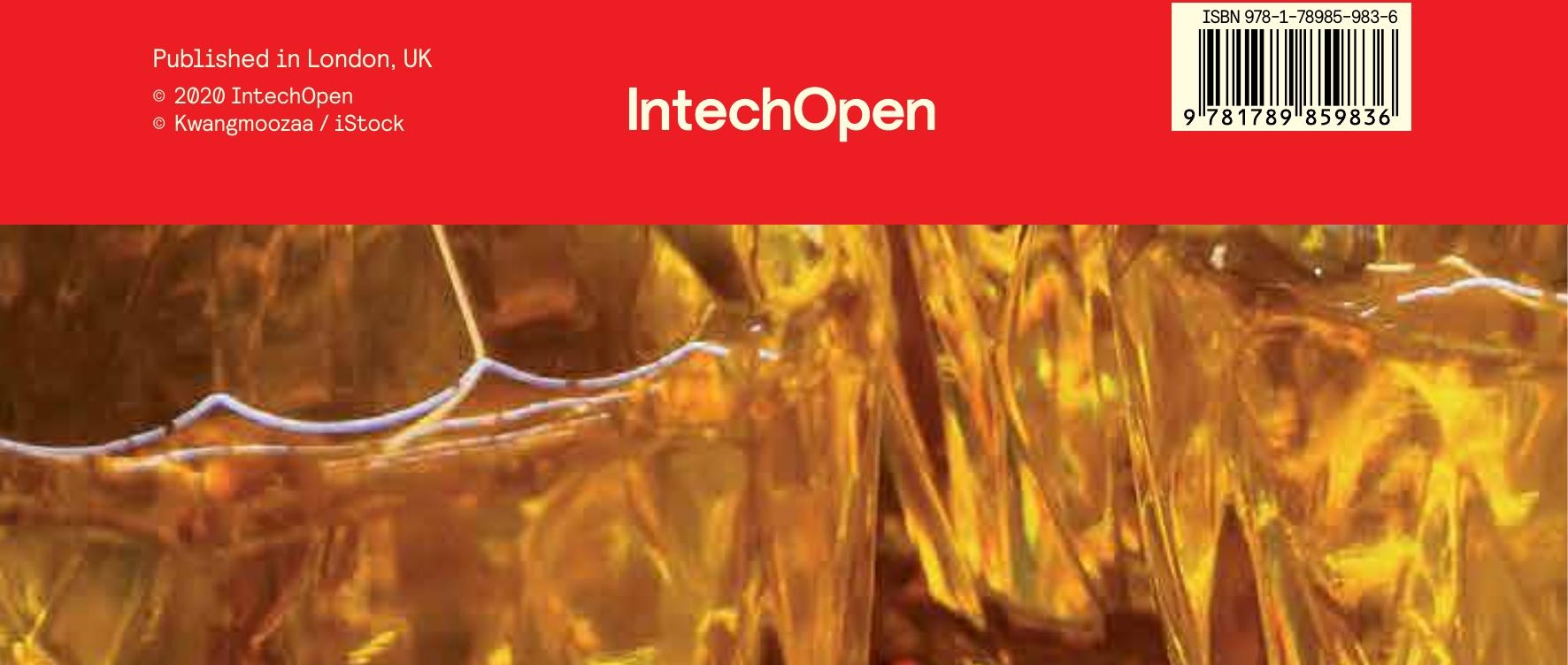